Portland State University

PDXScholar

Summer 1-10-2014

\title{
Detection of Homocysteine with Bridged Viologen Chemical Probes
}

Davin Rautiola

Portland State University

Follow this and additional works at: https://pdxscholar.library.pdx.edu/open_access_etds

Part of the Diagnosis Commons, and the Medical Biochemistry Commons Let us know how access to this document benefits you.

\section{Recommended Citation}

Rautiola, Davin, "Detection of Homocysteine with Bridged Viologen Chemical Probes" (2014).

Dissertations and Theses. Paper 1541.

https://doi.org/10.15760/etd.1540

This Thesis is brought to you for free and open access. It has been accepted for inclusion in Dissertations and Theses by an authorized administrator of PDXScholar. Please contact us if we can make this document more accessible: pdxscholar@pdx.edu. 
Detection of Homocysteine with Bridged Viologen Chemical Probes

by

Davin Rautiola

A thesis submitted in partial fulfillment of the requirements for the degree of

Master of Science

in

Chemistry

Thesis Committee:

Robert Strongin, Chair

David Stuart

Niles Lehman

Portland State University

2013 


\begin{abstract}
Increased blood plasma concentrations of the aminothiol homocysteine (Hcy) are associated with a variety of disease states including those which cause impaired renal function, many forms of cardiovascular disease, and neurodegenerative diseases such as Alzheimer's. Therefore, Hcy has the potential to be a significant diagnostic biomarker. Routine monitoring of Hcy plasma concentration is encumbered by the time and resources required to quantify Hcy using currently accepted instrumental analysis methods. As part of the continuing effort to develop a quick, reliable, inexpensive, and user-friendly test to quantify Hcy at the point of care, we have designed a series of novel colorimetric and fluorescent chemical probes based on bridged viologen structures. The absorbance at $540 \mathrm{~nm}$ for the para-bridged bis-nitrile viologen probe $(\mathrm{pCN})$ was found to be proportional to the concentration of Hcy analyte, with $\mathrm{LOD}=2.17 \mu \mathrm{M}$ and LOQ $=$ $6.10 \mu \mathrm{M}$ where unhealthy Hcy plasma concentrations are $>15 \mu \mathrm{M}$. The mechanism of reactivity between $\mathrm{pCN}$ and Hcy encompasses a dynamic set of reactions which involve pimerization of radical probe species and thioether adduct formation of $\mathrm{pCN}$ with Hcy. Preliminary results with fluorometric analogs of the bridged viologen probes are also presented.
\end{abstract}




\section{Dedication}

To my departed mother, who laid down for her final rest this year: I'm sorry I was away so much and I hope you know how much I love you. 


\section{Acknowledgements}

I would like to express my deepest appreciation and warmest sentiments for the entire Strongin research group: most notably to Dr. Robert Strongin for his boundless patience and kindness; Dr. Martha Sibrian-Vazquez for sharing her incredibly vast knowledge of chemistry with me; Dr. Jorge Escobedo for keeping a calm, positive atmosphere alive in the lab and for always being willing to help me out; Dr. Mark Lowry for teaching me spectroscopy; Aabha Barve for her assistance with optimizing probe reaction conditions; as well as Lovemore Hakuna, Shelly Chu, Jialu Wang, Lei Wang, and Thomas Seidl for their kind support.

I also owe a debt of gratitude to non-group members: Dr. Wilbes Mbiya for showing me how to collect EPR spectra; Dr. Siming Wang for MALDI services; Boulder Diagnostics for providing funding; and the indispensable, darling Jackie Slack for sharing her sweet smile even on the gloomiest of days.

Finally, a special thanks to my committee members, Dr. Niles Lehman and Dr. David Stuart, for setting aside time in their busy schedules to review this thesis. 


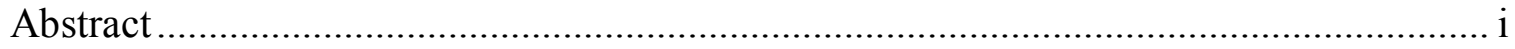

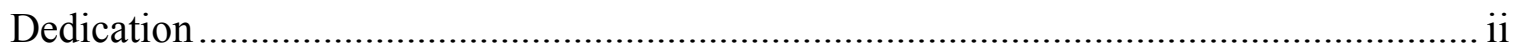

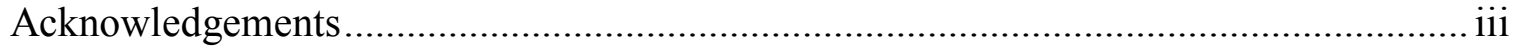

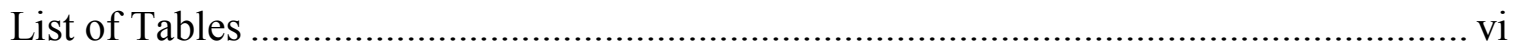

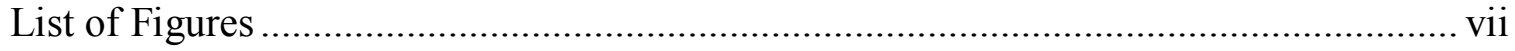

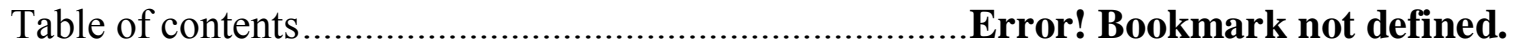

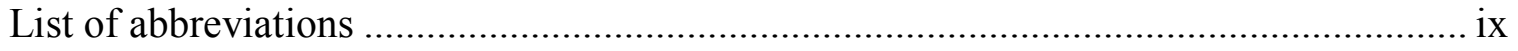

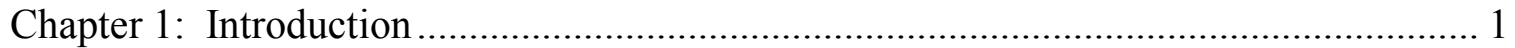

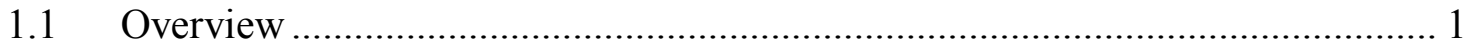

1.2 Relevance of the biological analyte homocysteine ............................................ 1

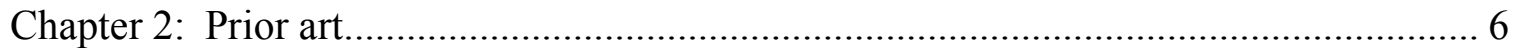

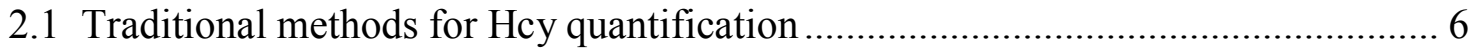

2.2 Selective Hcy detection without chromatography or biomolecule reagents ............ 7

2.3 Selective detection of Hcy by the $\alpha$-amino carbon-centered radical..................... 11

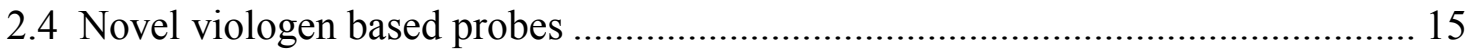

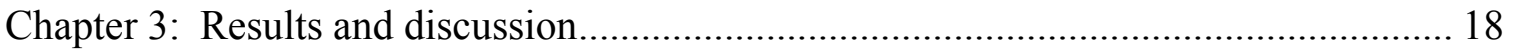

3.1 Detection of Hcy with the para-bridged bis-CN viologen probe........................... 18

3.2 Ortho and meta isomers of the bridged bis-nitrile viologen ................................. 21

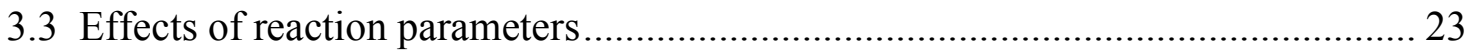

Chapter 4: Mechanism of the bridged bis-nitrile viologens.......................................... 30

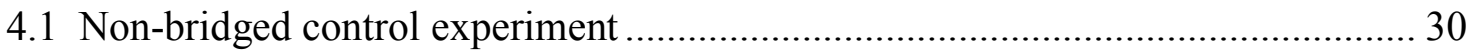

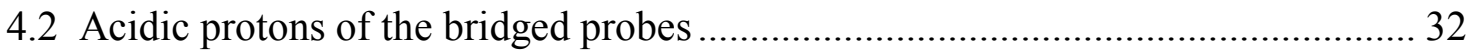

4.3 Electron paramagnetic resonance spectroscopy ………….................................. 35

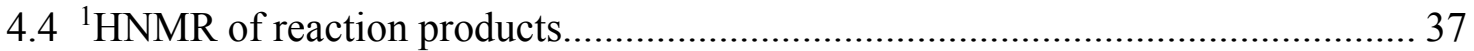

4.5 Mechanism of the bridged bis-nitrile viologen probes....................................... 40

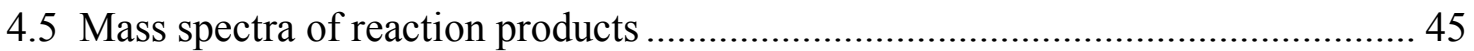

Chapter 5: Preliminary survey of bridged bis-coumarin viologens ................................. 50

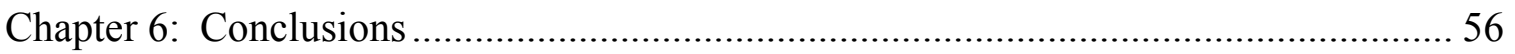

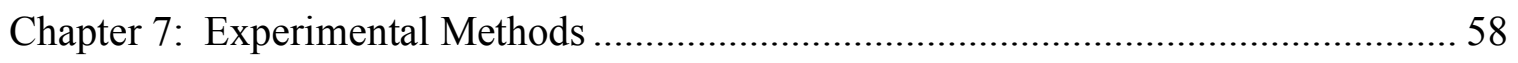

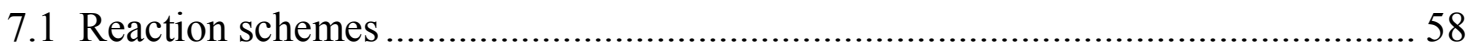

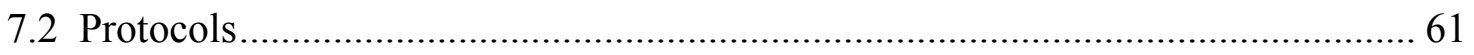

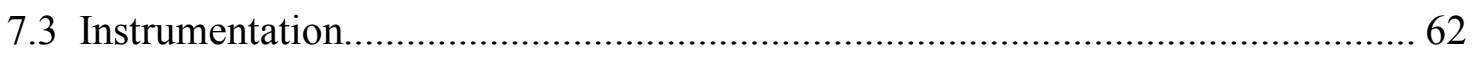




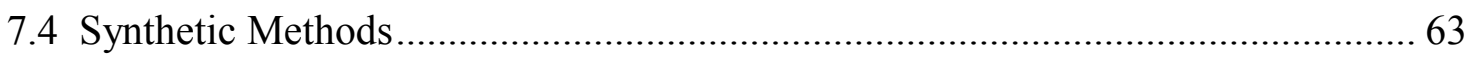

Chapter 8: Notes for continued investigations of these probes....................................... 70

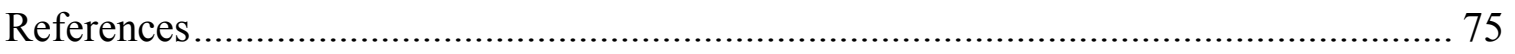

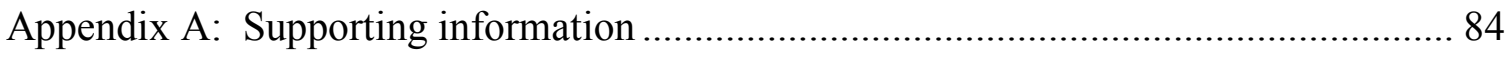

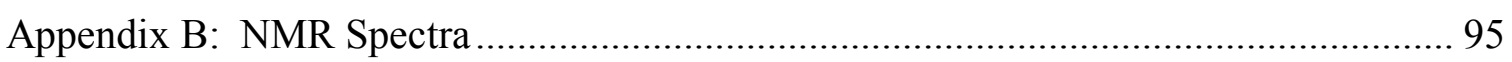

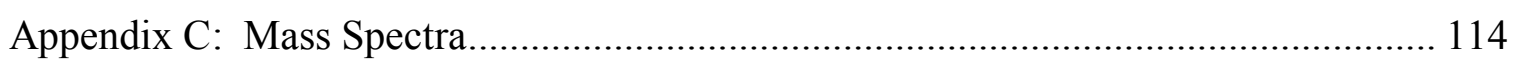




\section{List of Tables}

Table 1. Ions of Hcy oxidation products with $\mathrm{m} / \mathrm{z}$ similar to signals in the mass spec.....46

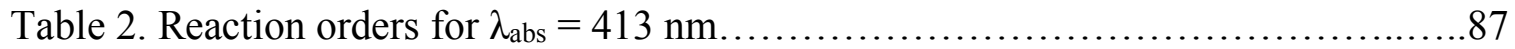

Table 3. Ions of $\mathrm{pCN}$ probe fragments identified in the reaction mixture ass spectra......89 


\section{List of Figures}

Figure 1. Structures of homocysteine (Hcy), cysteine (Cys), and glutathione (GSH)...... 2

Figure 2. Homocysteine metabolism ........................................................................ 3

Figure 3. Iridium (III) based chemical probe............................................................ 8

Figure 4. Nanoparticles and nanocluster probes ..................................................... 9

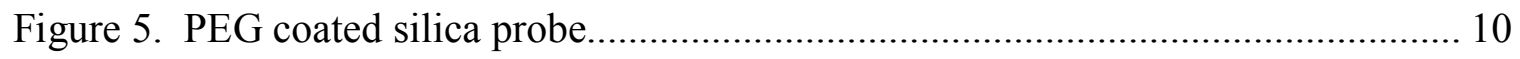

Figure 6. Carbon nanotube paste electrodes. ......................................................... 10

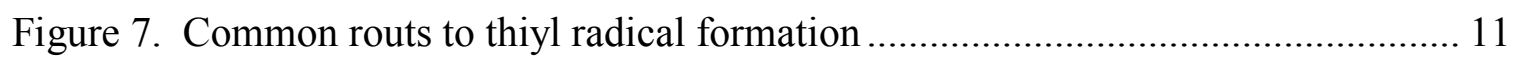

Figure 8. Formation of the $\alpha$-amino carbon centered radical of Hcy. ............................ 12

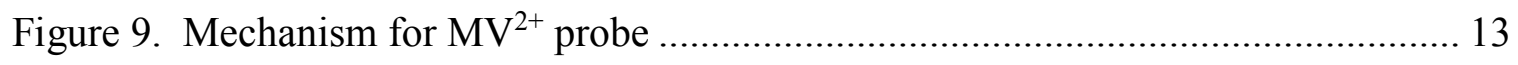

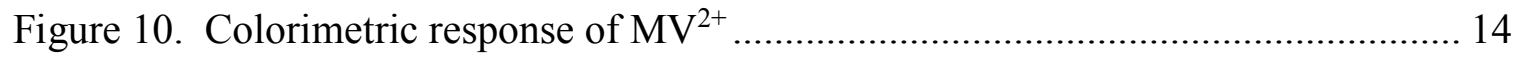

Figure 11. pH cutoff points for viologen probes.................................................. 14

Figure 12. Structures of bridged viologen based probes.......................................... 17

Figure 13. Colorimetric selectivity for Hcy with $\mathrm{pCN}$............................................ 18

Figure 14. Colorimetric selectivity for Hcy with $\mathrm{pCN}$ in deproteinized plasma matrix.. 19

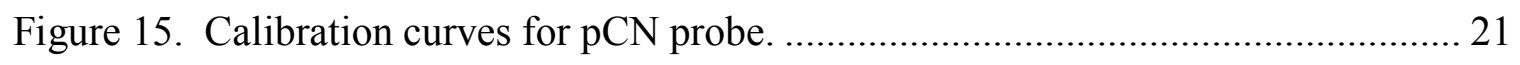

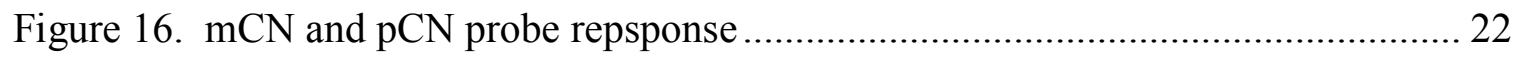

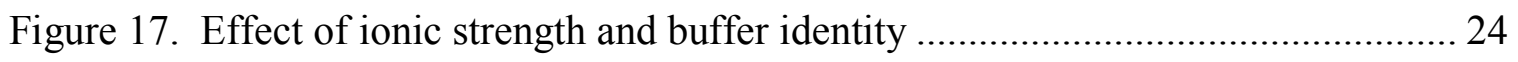

Figure 18. Response with organic solvent added................................................... 26

Figure 19. Absorbance spectrum comparison with added organic solvent ................... 28

Figure 20. Effect of varying Cys and GSH concentrations ........................................ 29

Figure 21. Structure of bridged pCN compared with non-bridged BNV . ...................... 30

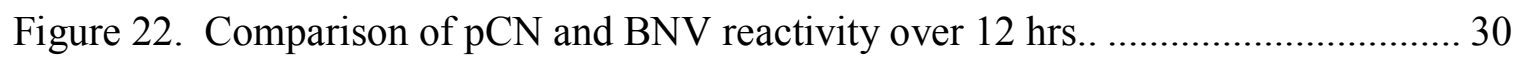

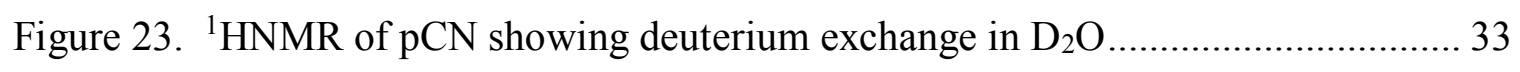

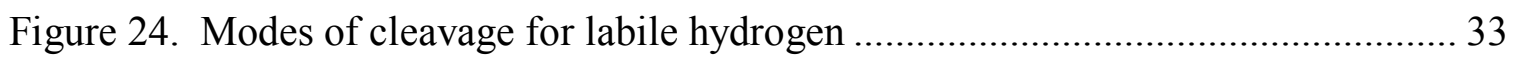

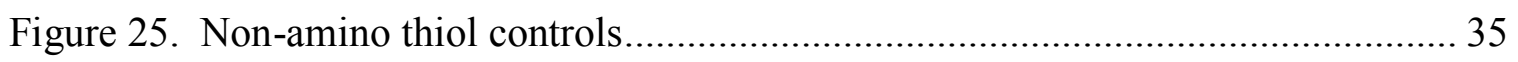

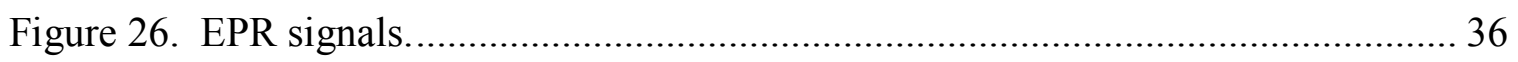

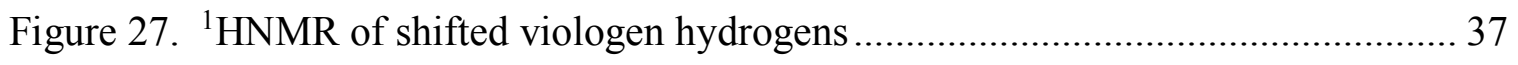

Figure 28. ${ }^{1} \mathrm{HNMR}$ of potential Hcy oxidation products ............................................. 38

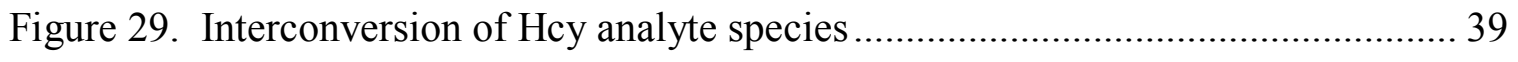

Figure 30. Reactive site of substituted viologen probes ........................................... 43

Figure 31. Dynamic evolution of probe-analyte adducts ......................................... 44 


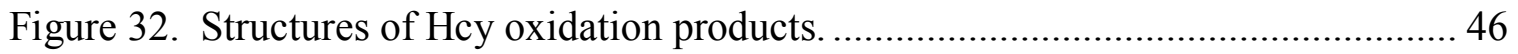

Figure 33. Structures of ions identified in the mass spectra the reaction mixture ........... 49

Figure 34. Structures of the bridged bis-coumarin viologen probes............................... 50

Figure 35. Fluorescence of the acetylcoumarin substituent....................................... 51

Figure 36. $\mathrm{pH}$ dependent selectivity of oAC for Cys.................................................. 52

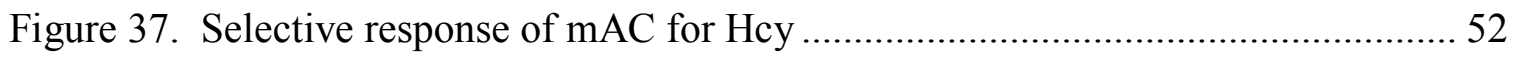

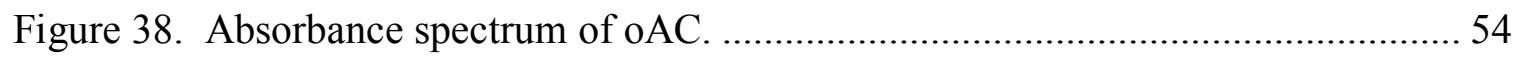

Figure 39. PEG and dialysis as potential methods to remove protein interference ........ 59

Figure 40. Reaction scheme for synthesis of bridged viologen bis-nitrile compounds ... 60

Figure 41. Reaction scheme for meta- and para- bridged viologen bis-coumarin .......... 60

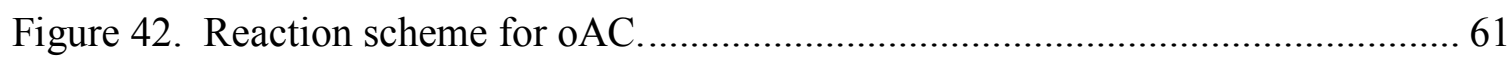

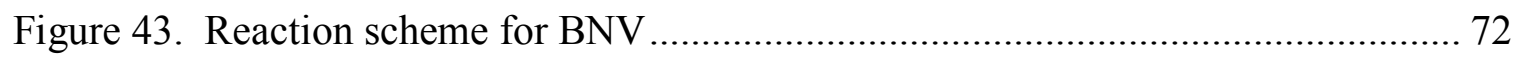

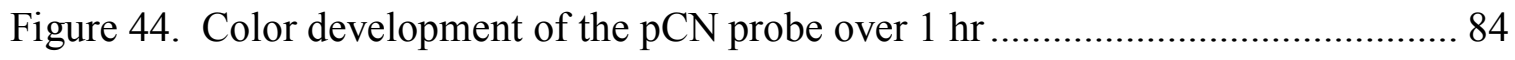

Figure 45. Linearity and time point analysis for $\mathrm{pCN}$ calibration curve in Figure 15-A. 84

Figure 46. Linearity and time point analysis for $\mathrm{pCN}$ calibration curve in Figure 15-B. 85

Figure 47. Calibration curve for Hcy using the initial rates of $\lambda_{\text {abs }}$ increase.................... 86

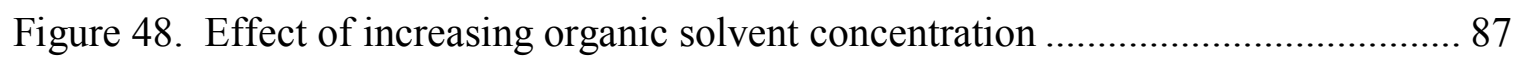

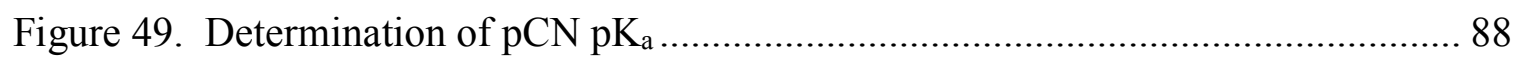

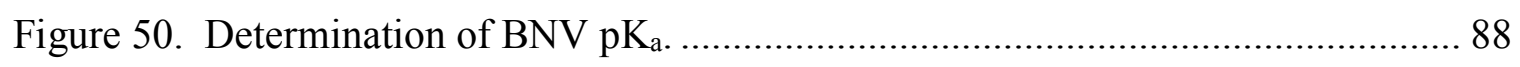

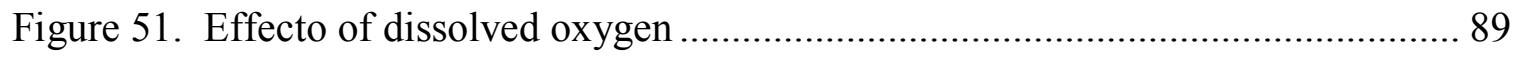

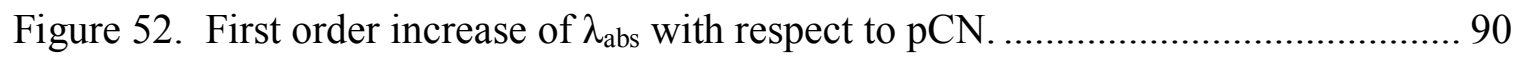

Figure 53. Structures of ions $\mathbf{3 0}-\mathbf{5 0}$ identified in the mass spectra of the reaction ....... 91

Figure 54. Structures of ions $\mathbf{5 1 - 6 0}$ identified in the mass spectra of the reaction ....... 92

Figure 55. Fluorescence selectivity for Hcy with mAC. .......................................... 93

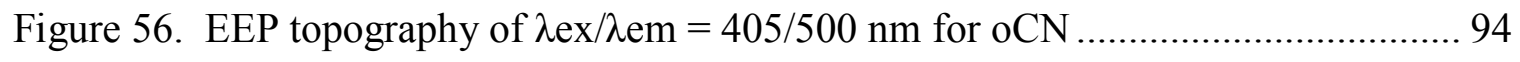

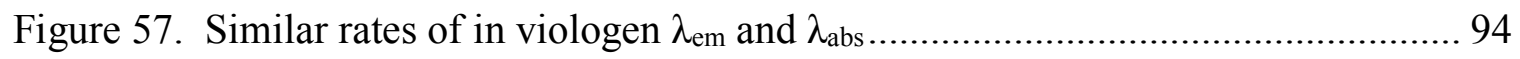


List of abbreviations

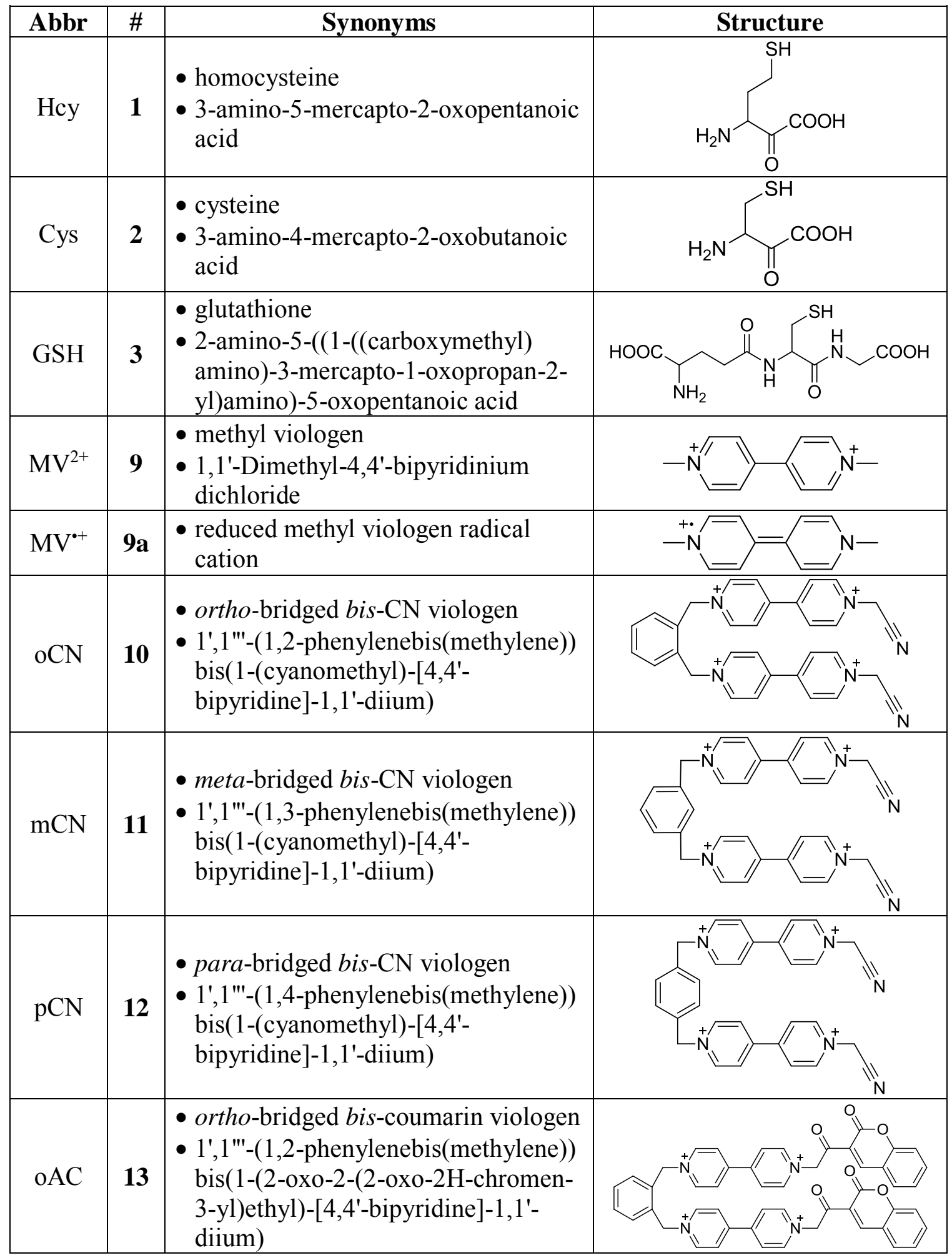




\begin{tabular}{|c|c|c|c|}
\hline Abbr & $\#$ & Synonyms & Structure \\
\hline $\mathrm{mAC}$ & 14 & $\begin{array}{l}\text { - meta-bridged bis-coumarin viologen } \\
\text { 1',1"'-(1,3-phenylenebis(methylene)) } \\
\text { bis(1-(2-oxo-2-(2-oxo-2H-chromen- } \\
\text { 3-yl)ethyl)-[4,4'-bipyridine]-1,1'- } \\
\text { diium) }\end{array}$ & \\
\hline $\mathrm{pAC}$ & 15 & $\begin{array}{l}\text { - para-bridged bis-coumarin viologen } \\
\text { 1',1"'-(1,4-phenylenebis(methylene)) } \\
\text { bis (1-(2-oxo-2-(2-oxo-2H-chromen- } \\
\text { 3-yl)ethyl)-[4,4'-bipyridine]-1,1'- } \\
\text { diium) }\end{array}$ & \\
\hline BNV & 16 & $\begin{array}{l}\text { - benzyl-nitrile-viologen } \\
\text { - non-bridged probe control } \\
\text { - 1-benzyl-1'-(cyanomethyl)-[4,4'- } \\
\text { bipyridine]-1,1'-diium }\end{array}$ & \\
\hline BME & 17 & $\begin{array}{l}\text { - } \beta \text {-mercaptoethanol } \\
\text { - reducing agent } \\
\text { - non-amino analyte control }\end{array}$ & \\
\hline MPA & 18 & $\begin{array}{l}\text { - 3-mercaptopropionic acid } \\
\text { - reducing agent } \\
\text { - non-amino analyte control }\end{array}$ & \\
\hline TCEP & & $\begin{array}{l}\text { - } \operatorname{tris}(2 \text {-carboxyethyl)phosphine } \\
\text { - reducing agent }\end{array}$ & \\
\hline HEPES & & $\begin{array}{l}\text { - zwitterionic buffer } \\
\text { 2-[4-(2-hydroxyethyl)piperazin-1- } \\
\text { yl]ethanesulfonic acid }\end{array}$ & \\
\hline Tris & & $\begin{array}{l}\text { - cationic buffer } \\
\text { - 2-Amino-2-hydroxymethyl-propane- } \\
\text { 1,3-diol }\end{array}$ & $\mathrm{NH}_{2}$ \\
\hline СТАВ & & $\begin{array}{l}\text { - cationic surfactant } \\
\text { - hexadecyl-trimethyl-ammonium } \\
\text { bromide }\end{array}$ & \\
\hline
\end{tabular}




\begin{tabular}{|c|c|c|c|}
\hline Abbr & \# & Synonyms & Structure \\
\hline $\begin{array}{l}\text { Tween } \\
80\end{array}$ & & $\begin{array}{l}\text { - non-ionic surfactant } \\
\text { - Polysorbate } 80 \\
\text { - polyoxyethylene (20) sorbitan } \\
\text { monooleate }\end{array}$ & $\begin{array}{c}\left(x_{7}\right)_{7} \\
+x+y+z=20\end{array}$ \\
\hline SDS & & $\begin{array}{l}\text { - anionic surfactant } \\
\text { - sodium lauryl sulfate }\end{array}$ & $a^{+}$ \\
\hline IPA & & - isopropyl alcohol & \\
\hline DSS & & $\begin{array}{l}\text { - NMR standard } \\
\text { - 4,4-Dimethyl-4-silapentane-1- } \\
\text { sulfonic acid }\end{array}$ & \\
\hline $\mathrm{P}_{2}$ & & - diradical pimer & 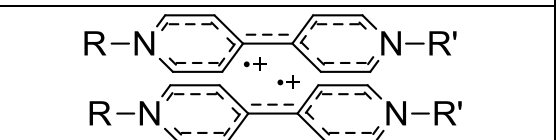 \\
\hline $\mathrm{P}_{2}^{\cdot+}$ & & - radical pimer & $\mathrm{R}-\mathrm{N}^{+}$ \\
\hline HAT & & - homolytic Hydrogen Atom Transfer & \\
\hline$\cdot \mathrm{X}$ & & - any radical species & \\
\hline ROS & & $\begin{array}{l}\text { - reactive oxygen species, including } \\
\text { radicals and not limited to oxygen }\end{array}$ & \\
\hline$: \mathrm{Nu}^{-}$ & & $\begin{array}{l}\text { - generic reactant acting as } \\
\text { nucleophile }\end{array}$ & \\
\hline$: \mathrm{B}^{-}$ & & - generic reactant acting as a base & \\
\hline [o] & & - generic reactant causing oxidation & \\
\hline EPR & & $\begin{array}{l}\text { - Electron Paramagnetic Resonance } \\
\text { spectroscopy } \\
\text { - aka Electron Spin Resonance (ESR) }\end{array}$ & \\
\hline$g_{e}$ & & $\begin{array}{l}\text { - magnetic moment of a free electron } \\
\text { - accepted spin g-factor }\end{array}$ & \\
\hline$g$ & & $\begin{array}{l}\text { - measured magnetic moment of } \\
\text { paramagnetic electron } \\
\text { - calculated spin g-factor }\end{array}$ & \\
\hline$\Delta \beta$ & & $\begin{array}{l}\text { - peak-to-peak linewidth of EPR } \\
\text { signal }\end{array}$ & \\
\hline$\beta_{0}$ & & $\begin{array}{l}\text { - Hall field } \\
\text { - externally applied magnetic field } \\
\text { strength in units of Gauss }(\mathrm{G})\end{array}$ & \\
\hline
\end{tabular}




\begin{tabular}{|c|c|l|l|}
\hline Abbr & $\#$ & \multicolumn{1}{|c|}{ Synonyms } & Structure \\
\hline$\Delta \mathrm{E}$ & & $\bullet$ energy difference between two states & \\
\hline MTHFR & $\begin{array}{l}\bullet \text { methylenetetrahydrofolate reductase } \\
\bullet \text { enzyme of Hcy metabolism }\end{array}$ & \\
\hline UPW & $\bullet$ ultra-pure water & \\
\hline LOD & $\bullet$ limit of detection & \\
\hline LOQ & $\bullet$ limit of quantitation & \\
\hline$\lambda_{\text {abs }}$ & & $\bullet$ absorbance wavelength & \\
\hline$\lambda_{\text {ex }}$ & & $\bullet$ excitation wavelength & \\
\hline$\lambda_{\text {em }}$ & & $\bullet$ emission wavelength & \\
\hline
\end{tabular}




\subsection{Overview}

\section{Chapter 1: Introduction}

The biological analyte homocysteine (Hcy) is an important biomarker and independent predictor for a variety of disease states. The first section of this document discusses the role of Hcy in the body and the difficulties associated with designing a chemical probe to easily quantify Hcy in plasma at the point-of-care. This is followed by a review of established detection techniques as well as novel methodology found in recent literature. Sections 2.3 and 2.4 conclude the background material with a discussion of our research group's previous approach to Hcy detection using viologen based chemical probes and the theory that led us to investigate the probes used in this study. Results from our investigation are divided amongst three chapters, the bulk of which address performance characteristics of colorimetric bridged bis-nitrile viologen probes (Chapter 3) and examine mechanistic aspects of their unique reactivity (Chapter 4). Chapter 5 briefly summarizes preliminary work with fluorometric bridged biscoumarin viologen probes. A chapter dedicated to concluding remarks precedes sections detailing experimental methods, notes for future work, and supporting data.

\subsection{Relevance of the biological analyte homocysteine}

Biological aminothiols maintain intracellular and extracellular redox homeostasis. Aminothiols such as the amino acid cysteine (Cys) and tripeptide glutathione (GSH) are considered beneficial and essential to physiological function because they protect cells from oxidative stress, preventing damage caused by reactive oxygen species (ROS) such as free radicals and peroxides. GSH can be thought of as a reserve form of Cys since its 
thiol group comes from a Cys residue. Cys and GSH not only act as antioxidants, they participate in many metabolic processes as well. ${ }^{1}$ The thiol group of Cys acts as a nucleophile in enzymatic reactions and plays an important structural role in protein folding by forming covalent disulfide bridges between Cys residues. ${ }^{2}$

In recent years there has been increased interest in a related aminothiol, homocysteine (Hcy), as a biological analyte and a potential risk factor for a variety of disease states. ${ }^{3}$ It is a homologue of Cys and an intermediate in the biosynthesis of Cys from methionine. ${ }^{4}$ Hcy and Cys differ only by a single methylene group (Figure 1); however, Hcy is rarely incorporated in proteins by translation, only occasionally replacing methionine residues. ${ }^{5}$<smiles>N[C@@H](CCS)C(=O)O</smiles>

Hcy<smiles>NC(CS)C(=O)O</smiles>

Cys<smiles>N[C@@H](CCC(=O)NC(CS)C(=O)NCC(=O)O)C(=O)O</smiles>

GSH

Figure 1. Structures of biological aminothiols homocysteine (Hcy), cysteine (Cys), and glutathione (GSH).

Normal plasma concentrations of Hcy in healthy adults can range from 5-15

$\mu \mathrm{M}$. An elevated level of Hcy in plasma $(>15 \mu \mathrm{M})$ is a condition known as hyperhomocysteinemia and is considered detrimental to physiology. ${ }^{6-10}$

Hyperhomocysteinemia can be caused by environmental factors, disease, poor nutrition, or genetic disorders. For example, certain endocrine diseases such as hypothyroidism or diabetes mellitus can cause elevated levels of Hcy by modulating Hcy metabolism. ${ }^{11-13}$ 
Kidney disease can lead to poor renal clearance of Hcy from circulation. ${ }^{14}$ Chronic consumption of alcohol has also been observed to increase levels of Hcy. ${ }^{15-16}$

Homocytinuria is a genetic disorder which leads to the abnormal accumulation of Hcy in blood and urine. Homocytinuria type I is a recessively inherited autosomal defect in the transulfuration pathway which catabolizes excess Hcy into Cys. ${ }^{4}$ Types II and III are recessively inherited defects in the remethylation pathway which convert the thiol group of Hcy into a thioether to form methionine (Figure 2). Methylenetetrahydrofolate reductase (MTHFR) synthesizes 5-methyltetrahydrofolate, the major carbon donor for remethylation. Reduced function polymorphisms in MTHFR occur in about $10 \%$ of the world's population. ${ }^{17-19}$

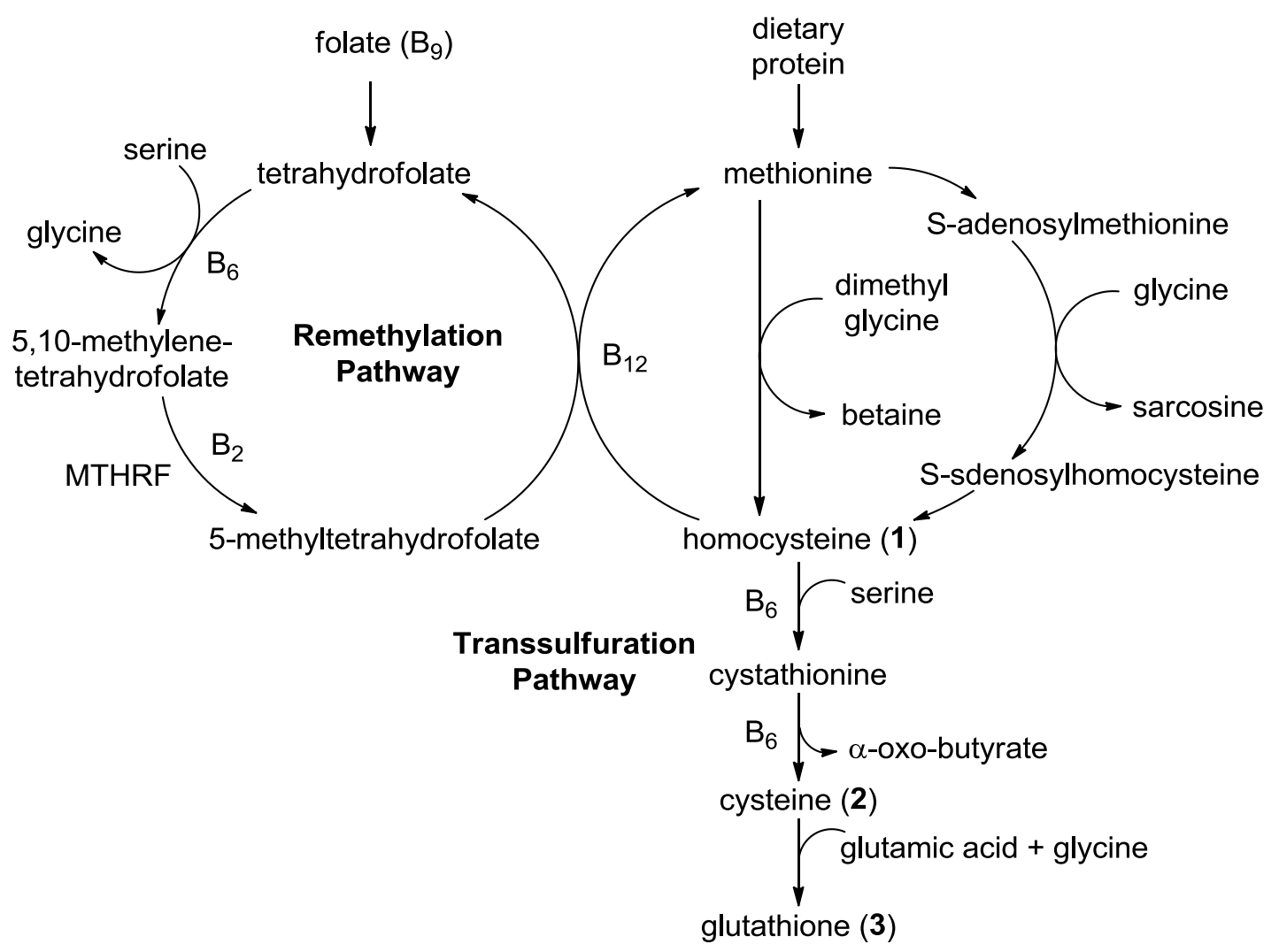

Figure 2. Homocysteine metabolism. ${ }^{20-21}$ 
Excess Hcy disrupts the structure and function of proteins by degrading cysteine disulfide bridges (S-homocysteinylation) and forming an amide bond with the $\varepsilon$-amine of lysine residues (homocystamides). ${ }^{22-24}$ This affects extracellular matrix components such as collagen, elastin, and proteoglycans causing damage to endothelial tissue. ${ }^{25-27} \mathrm{Hcy}$ is also implicated in the peroxidation of low density lipids. ${ }^{28}$ Both, damaged endothelia tissue and oxidized low density lipids, activate platelets and increase platelet aggregation which leads to thrombogenicity. ${ }^{29}$

Since Hcy is toxic to endothelial tissue and can induce clotting, Hcy could be a causal risk factor for cardiovascular disease. Many clinical studies have demonstrated significantly increased concentrations of Hcy at each stage of ischemic heart disease, from the onset of atherosclerosis to eventual myocardial infarction or stroke. ${ }^{30-34}$ Monitoring Hcy levels in blood plasma can help predict and possibly prevent these health issues. $^{35}$

Hcy has also been proposed as a novel early warning biomarker for neurodegenerative diseases. ${ }^{36}$ Accumulation of Hcy in circulation corresponds to an increased concentration of Hcy in the interstitial fluid of the central nervous system. This is associated with decreased plasticity in hippocampal neuronal cells,${ }^{37}$ reduced cerebral white matter volume, larger ventricles, and ultimately lower cognitive functioning. ${ }^{38}$ Abnormally high levels of Hcy have been found in patients who suffer from various forms of dementia such as schizophrenia and Alzheimer's disease. ${ }^{39-41}$ Furthermore, hyperhomocysteinemia is known to cause neural tube defects in embryos and other complications during pregnancy. ${ }^{42}$ 
Although high plasma concentrations of Hcy have been firmly established to independently predict cardiovascular disease and modes of Hcy toxicity have been demonstrated in several ex vivo studies, a controversy has developed over the causal relationship of between Hcy and disease. Researchers Smulders and Blom reviewed the literature and concluded the reluctance to formally implicate Hcy as a true 'risk factor' was primarily based on results from two types of clinical experiments: intervention studies and Mendelian genetic studies. ${ }^{43}$ Intervention studies that treated patients who initially presented with high levels of Hcy did not result in a lower instance of cardiovascular disease. Problems with Hcy metabolism due to reduced function phenotypes or environmental factors such as poor diet can be corrected by treatment with vitamin B supplements. Since the buildup and degradation of atherosclerotic plaques are extremely slow processes, the duration of intervention studies may have been too short to observe a statistical improvement. Excessive vitamin B intake might have been counterproductive, causing inflammation and spreading of existing atherosclerotic lesions. Mendelian randomized genetic studies of MTHFR polymorphisms have reported conflicting results. Population variance in Hcy concentration does not arise exclusively from a single polymorphism. Without controlling the influence of confounding factors and other risk factors the results of these genetic studies are inconclusive. Regardless of culpability, measurements of plasma Hcy concentration remain valid for the prediction and diagnosis of many diseases. 


\subsection{Traditional methods for Hcy quantification}

As an important biological analyte, the direct detection of Hcy in plasma is hindered by the presence of structurally related matrix components such as Cys and GSH. The interference can be significant since normal plasma concentrations of reduced free Cys and GHS are approximately $200-300 \mu \mathrm{M}$ and $3-7 \mu \mathrm{M}$ respectively, compared to a normal Hcy plasma concentration of $5-15 \mu \mathrm{M}^{8-9,44-46}$ Additionally, Hcy is largely invisible to most spectroscopic detectors because it is not a strong chromophore in either the UV or visible regions. ${ }^{47}$ Therefore, quantification techniques typically employ chromatographic separations followed by electrochemical detection, derivatization for spectrophotometric detection, or mass spectrometry. ${ }^{48-49}$

While these techniques generally produce excellent sensitivity and selectivity, they are not without disadvantages: Peak overlap from coelution of cysteinyl-glycine, normally present at $35.0 \pm 5.8 \mu \mathrm{M}$ in plasma, ${ }^{44-45}$ and insufficient column regeneration contribute to poor specificity with many chromatographic protocols. ${ }^{50}$ The electrodes used in postcolumn electrochemical detection tend to leach redox mediators, deteriorating the measurement cell over time and leading to poor reproducibility. ${ }^{48}$ Post- or precolumn derivatization introduces additional sample processing steps and additional reagents such as the chromophore and internal standard. Furthermore, the instrumentation used for these techniques is prohibitively expensive for point of care testing and requires skilled personnel to operate. Sample processing is often labor intensive and time consuming. Such low throughput protocols are unsuitable for routine diagnostic applications. ${ }^{51}$ 
Enzymatic and immunoassays are also available for Hcy determination. Although these assays are less labor intensive, they utilize fragile biomolecules which tend to be expensive and problematic to store. ${ }^{49}$ High concentrations of hemoglobin from hemolysis, bilirubin from icterus, or triglycerides from lipemia are known interferences. ${ }^{52}$ Inter- and intralaboratory variation has also been reported with these assays. ${ }^{51-55}$ Ideally, inaccuracy from systematic error inherent in a particular assay should be $<10 \%$ and imprecision for replicate measurements of the sample should be $<5 \% .{ }^{51}$ However, a 2008 study comparing six different commercially available biomolecule based assays confirmed inaccuracies which ranged from $-29.3 \%$ to $7.2 \%$ and imprecisions from 1.7 to 9.4\%. Five of the six assays determined Hcy concentrations in standardized samples that were outside of the NIST-certified range. ${ }^{52}$

\subsection{Selective Hcy detection without chromatography or biomolecule reagents}

There are many chemical probes available for the direct detection of total thiols in biological fluids. Since thiol groups are nucleophilic, the mechanism often involves substitution or addition to a chromophore. Some probes have been reported to react selectively with Cys in the presence of other aminothiols. Cys selectivity is primarily attributed to its smaller size for accessing hindered reactive sites, the lower $\mathrm{pK}_{\mathrm{a}}$ of its thiol group ( $\mathrm{pK}_{\mathrm{a}} \mathrm{SH}: \mathrm{Hcy}^{22}=10.0, \mathrm{Cys}^{22,56}=8.33, \mathrm{GSH}^{56-57}=9.12$ ), or its ability to form kinetically favored five membered heterocycles. ${ }^{58-63}$ However, very few probes have been shown to detect Hcy selectively in the presence of Cys because their chemical structures are so similar. 
Chen et al. reported an iridium based phosphorescent probe which responded selectively for Hcy when compared with analytes Cys, GSH, and other amino acids (Figure 3). ${ }^{64}$ While both, Hcy and Cys, formed adducts with the probe, the proposed mechanism for selectivity implicated a photoinduced electron-transfer process which caused emission quenching for the Cys adduct. However, the reaction was performed with a high ratio of organic solvent (9:1 v/v DMSO:HEPES buffer) which is generally not useful for biological samples. The minor response observed for Cys and use of 200 equivalents of Hcy to probe would also have a significant impact on accuracy and sensitivity when realistic biological concentrations of the analytes are measured.
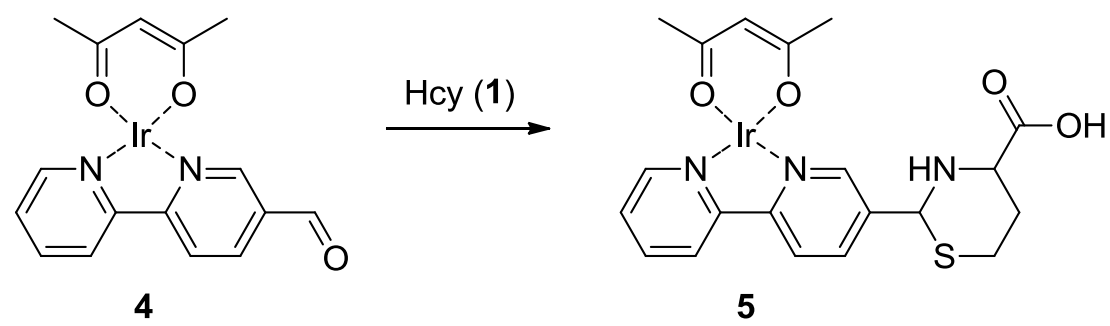

Figure 3. Iridium (III) based chemical probe.

Recently, resonance light scattering (RLS) from metal nanoparticles has been employed to determine Hcy in biological fluids (Figure 4). Xiao et al. reported the kinetics of Cys induced aggregation of fluorosurfactant-capped gold nanoparticles to be rapid at $\mathrm{pH} 12$ while nearly identical for Hcy and Cys at $\mathrm{pH} 6.5{ }^{65}$ Thus, by changing the $\mathrm{pH}$ and measuring RLS, Hcy and Cys could be quantified. The technique was demonstrated in urine with good recoveries. However, the ionic strength of the samples can have a dramatic effect on selectivity and gold tends to be an expensive reagent. Sun et al. reported an enhanced RLS signal from Hcy induced assembly of polyaziridine silver nanoclusters. ${ }^{66}$ Ultrafiltration was necessary to eliminate RLS interferences from 
serum samples. Optimal reaction conditions also required heating to $70{ }^{\circ} \mathrm{C}$ and the unstable silver nanoclusters cannot be stored longer than two weeks.
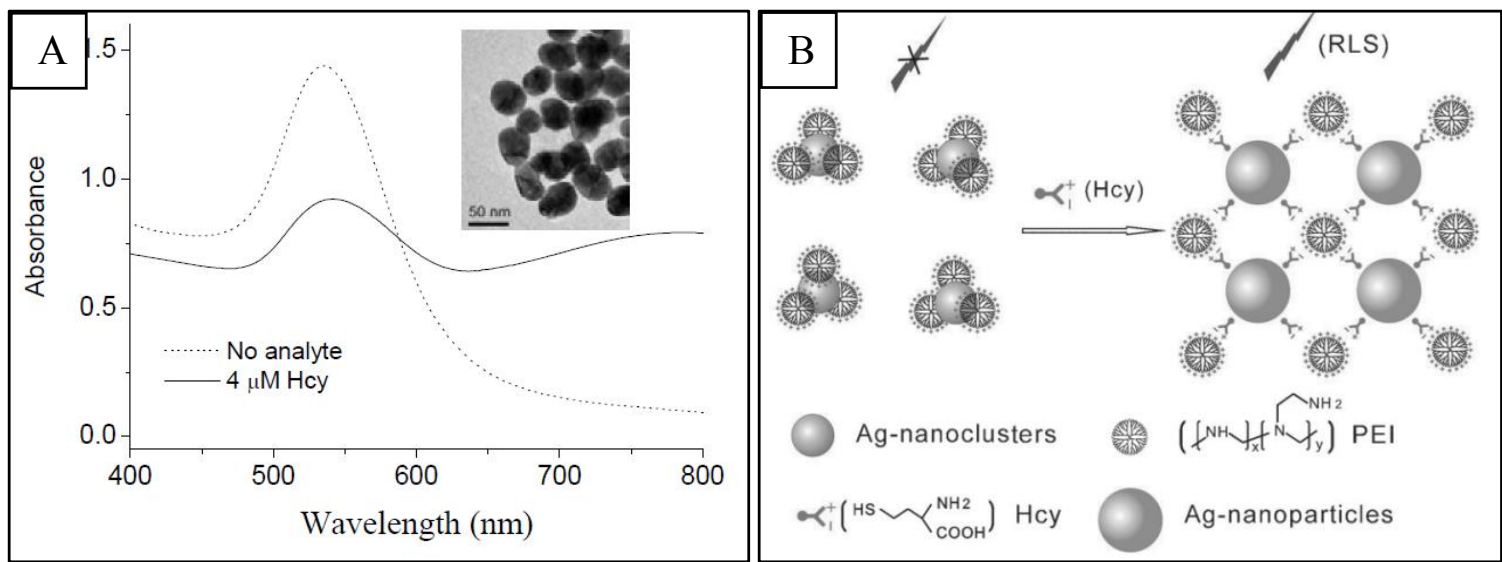

Figure 4. (A) Aggregation of fluorosurfactant-capped gold nanoparticles. ${ }^{67}$ (B) Assembly of polyaziridine silver nanoclusters. ${ }^{66}$

Yu et al. designed a nanoparticle probe using mesoporous silica with polyethylene glycol (PEG) covalently bound to the outer surface. ${ }^{68}$ The silica pores were loaded with an anthracene nitroolefin fluorophore (6). Nirtoolefins undergo Michael addition with thiols unselecively, however the PEG acted as a selective barrier which prevented other aminothiols from entering the nanoparticle to react with the fluorophore (Figure 5). The probe was demonstrated to be Hcy selective by comparing the fluorescence increase of Hcy, Cys, and GSH at $50 \mu \mathrm{M}$ each. Some fluorescence increase was observed with Cys and GSH. Since biological concentrations of Cys are $\sim 20$ time higher than Hcy, the response due to Cys would become significant. Furthermore, the complexity of the probe introduces multiple variables such as particle size and fluorophore loading which would need to be controlled in order to achieve good reproducibility. 

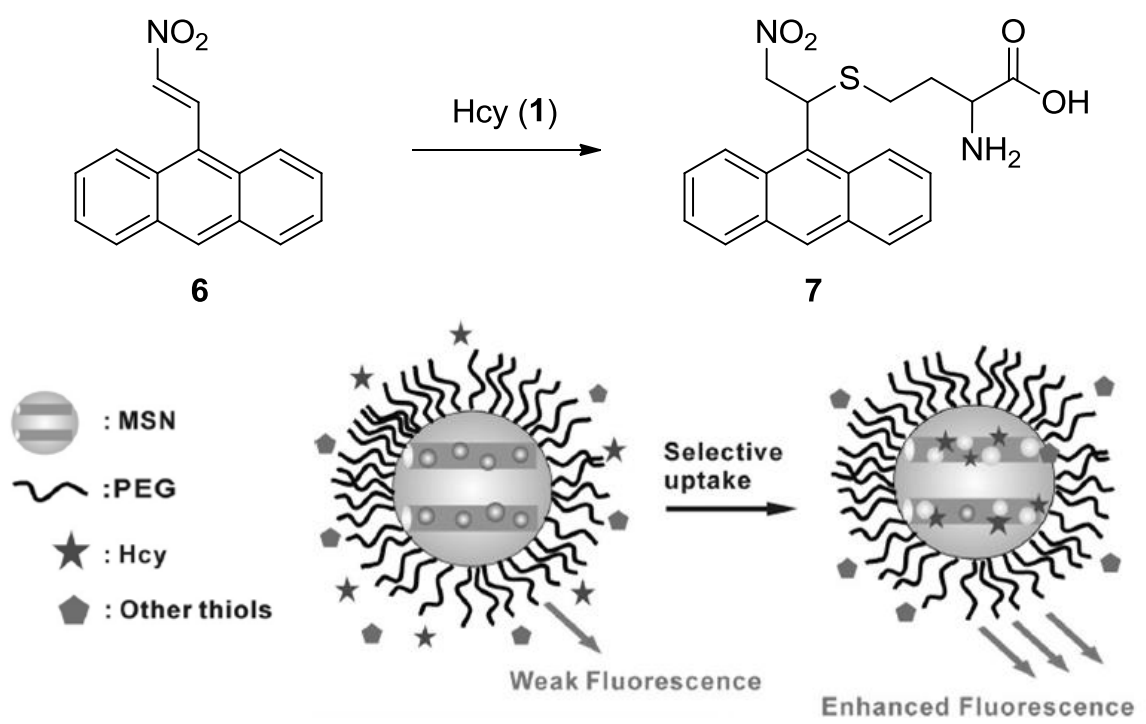

Figure 5. Mesoporous silica nanoparticle (MSN) loaded with fluorophore 6 and coated with PEG. ${ }^{68}$

Gholami-Orimi et al. have reported the voltammetric determination of Hcy in directly in urine and serum using carbon nanotube paste electrodes with chlorpromazine as a mediator (Figure 6). ${ }^{69}$ However, the endogenous Hcy concentrations in the biological fluids were below the detection limit. The serum samples required $50 \mu \mathrm{M}$ of additional Hcy to be added before it could be detected. The method relied on square wave voltammetry, which detects the oxidation or reduction of a species. Though the authors studied interferences from some common sugars and amino acids, they did not address possible interference from $\mathrm{Cys}, \mathrm{GSH}$, or foreign reducing agents commonly used to free Hcy bound by disulfide linkage.<smiles>CN(C)CCCN1c2ccccc2Sc2ccc(Cl)cc21</smiles>

Figure 6. Chlorpromazine mediator for voltammetric detection of Hcy with carbon nanotube paste electrodes. 
2.3 Selective detection of Hcy by the $\alpha$-amino carbon-centered radical

Thiol groups are easily oxidized to form thiyl radicals. In biological systems, thiyl radicals are generated a variety of ways (Figure 7): ${ }^{70}$ Thiyls are most commonly formed by radical propagation such as in the hydrogen atom transfer (HAT) from the thiol group of GSH to the $\mathrm{C4}$ '-centered sugar radical of damaged DNA during the "repair reaction." Thiyls can also be formed during oxidative stress by ROS such as $\mathrm{H}_{2} \mathrm{O}_{2}$, by homolytic cleavage of disulfides to produce two thiyl species, or though enzymatic oxidation of thiols by some peroxidases. In turn, the thiyl radicals of aminothiols like Hcy, Cys, and GSH can undergo intramolecular HAT reactions to generate an $\alpha$-amino carbon-centered radical. ${ }^{71}$

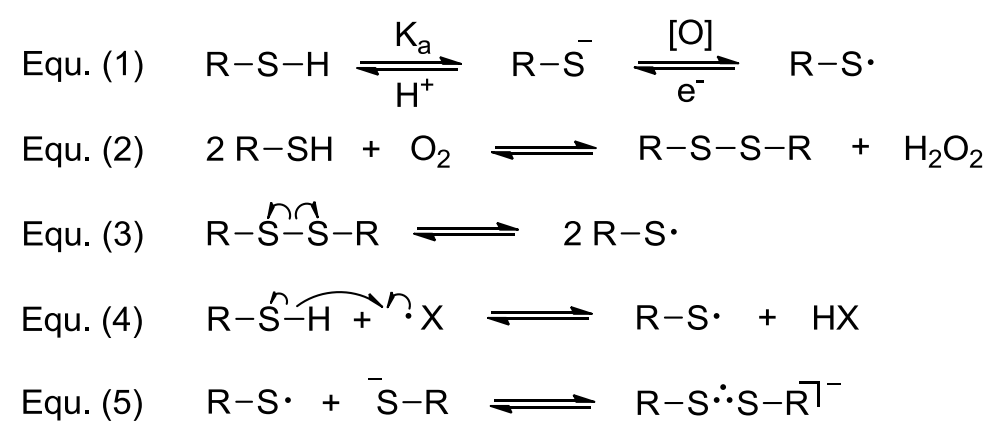

Figure 7. Some common routs to thiyl radical formation: (1) $\mathrm{pH}$ dependent formation of thiolate and subsequent oxidation to thiyl. (2) Oxidation to symmetric or mixed disulfides followed by (3) Homolytic cleavage of disulfide. (4) Reaction with generic radical species, $\bullet X$, or other ROS. (5) Formation of disulfide radical anion.

The rate of interconversion from the thiyl radical to the $\alpha$-amino carbon-centered radical by intramolecular HAT is influenced by the geometry of the transition state. Hcy forms a kinetically favored 5-membered ring transition state while Cys and GSH form 4 and 9 membered rings in their respective transition states (Figure 8). The carbon radical 
is captodatively stabilized by the geminal amine and carboxylate. ${ }^{71}$ With a weakly acidic $\mathrm{pK}_{\mathrm{a}}$ of $\sim 8-10$, thiols and their conjugate thiolate anions are relatively stable species. Therefore, the electron deficient thiyl radical is an oxidizing species with standard potential $\mathrm{E}_{\text {red }}^{\circ}=1.35 \pm 0.04 \mathrm{~V}^{72}$ However, the $\alpha$-amino carbon-centered radical is known to be a reducing species $\left(\mathrm{E}_{\text {red }}^{\circ} \approx-0.55 \pm 0.10 \mathrm{~V}\right)^{73}$ due to iminium ion stabilization of the carbocation resulting from the loss of an additional electron from the carbon-centered radical. ${ }^{74}$
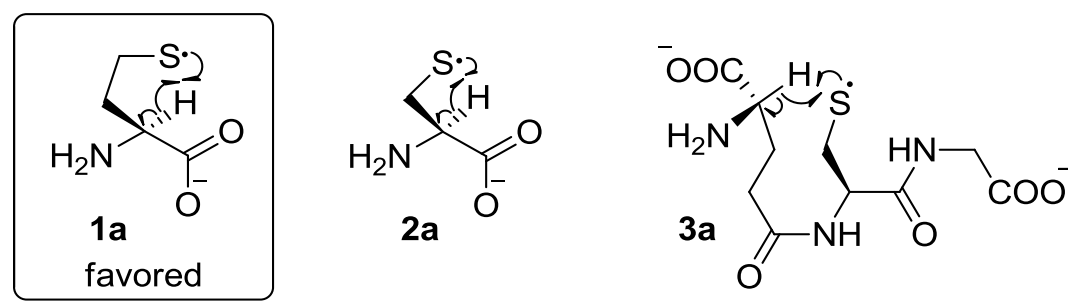

Figure 8. Formation of $\alpha$-amino carbon centered radical from thiyl radical by intramolecular HAT. Five membered ring transition state of Hcy (1a) is favored as compared to the four membered ring of Cys (2a) or nine membered ring of GSH (3a).

In addition to transition state geometry, intramolecular HAT for aminothiols is also influenced by $\mathrm{pH}$. At high $\mathrm{pH}$ the amine group is predominately neutral and can donate electron density to the $\alpha$-carbon. This causes the $\alpha-\mathrm{C}-\mathrm{H}$ bond to be substantially weaker than expected for a tertiary carbon and several $\mathrm{kJ} / \mathrm{mol}$ lower than the $\mathrm{S}-\mathrm{H}$ bond. ${ }^{75}$ Since the equilibrium of amine to ammonium cation is $\mathrm{pH}$ dependent, the activation energy barrier for HAT and subsequent concentration of $\alpha$-amino carbon centered radicals is also $\mathrm{pH}$ dependent. Thus the effective reduction potential of the aminothiols varies with $\mathrm{pH}^{73}$

In 1994, Zhao et al. utilized the moderate electron acceptor methyl viologen $\left(\mathrm{MV}^{2+}\right)\left(\mathrm{E}_{\text {red }}^{\circ}=-0.448 \mathrm{~V}\right)$ as a probe to study the carbon-centered radicals of Hcy, Cys, 
and GSH. ${ }^{71}$ Originally colorless, $\mathrm{MV}^{2+}(\mathbf{9})$ turns blue from increased absorptions at 398 and $605 \mathrm{~nm}$ produced by the reduced radical cation species, $\mathrm{MV}^{\circ+}(9 \mathrm{a})$ (Figure 9). The authors observed reduction of $\mathrm{MV}^{2+}$ to colored $\mathrm{MV}^{*+}$ by each of the aminothiols without apparent selectivity for Hcy. Under the experimental conditions, $\mathrm{pH} 10.5$, thiolate and thiyl species are abundant and readily form reducing disulfide radical anions $\left(\mathrm{E}^{\circ}\right.$ red $\approx-1.7$ V) irrespective of aminothiol identity (Figure 7, Equ. 5). ${ }^{73}$ At this $\mathrm{pH}$, facile intramolecular HAT and the presence of disulfide radical anions account for the nonselective reduction of $\mathrm{MV}^{2+}$.

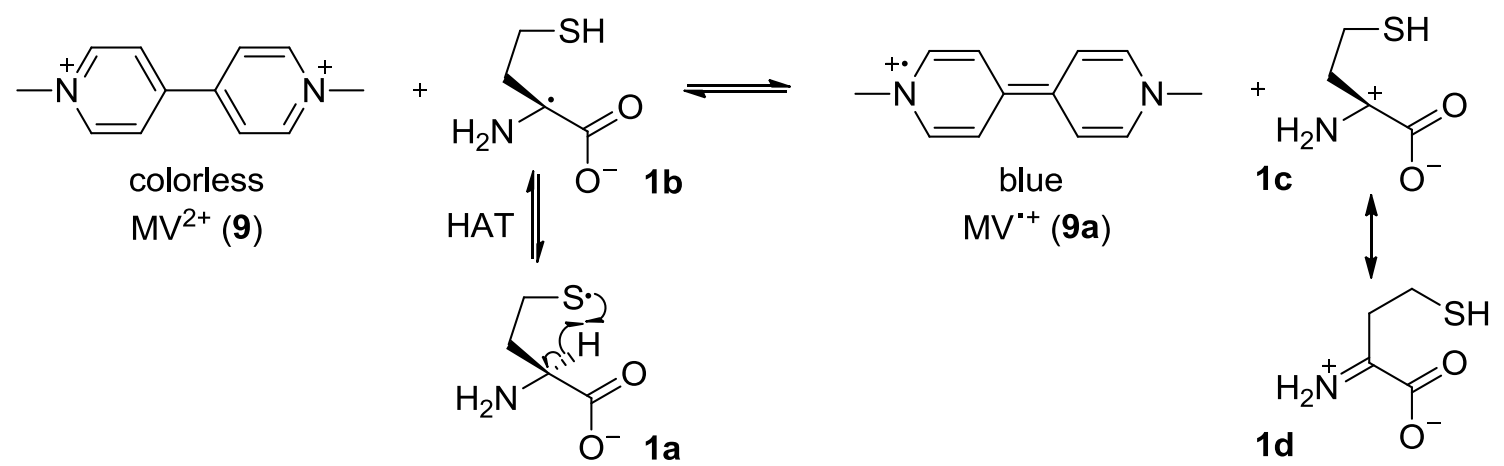

Figure 9. Mechanism for $\mathrm{MV}^{2+}$ probe: Oxidative thiyl radical of homocysteine (1a) undergoes HAT to form the reducing $\alpha$-amino carbon-centered radical (1b). $\mathrm{MV}^{2+}(\mathbf{9})$ is then reduced by $1 \mathrm{~b}$ to produce blue $\mathrm{MV}^{*+}(\mathbf{9 a})$ and the $\alpha$-amino carbocation (1c) which is stabilized by iminium formation (1d).

In 2004, the Strongin research group pioneered the direct detection of Hcy in plasma using chemical probes by showing a selective color change can be achieved with the $\mathrm{MV}^{2+}$ probe at neutral $\mathrm{pH}$ under refluxing conditions (Figure 10$){ }^{76}$ Selectivity relied on the diminished presence of disulfide radical anions and attenuated ability for Cys and GSH to undergo intramolecular HAT at lower $\mathrm{pH}$. A follow-up study was done in which a series of bis-substituted viologen probes were refluxed in the presence of Hcy or Cys. ${ }^{73}$ As expected, color formation was observed to be $\mathrm{pH}$ dependent, corresponding to the 
reduction potential of the probe. In general, probes with a less negative reduction potential were able to be reduced by the aminothiols at lower $\mathrm{pH}$. Additionally, Hcy was able to reduce the probes at a lower $\mathrm{pH}$ than Cys due to the kinetically favored formation of the $\alpha$-amino carbon-centered radical (Figure 11).

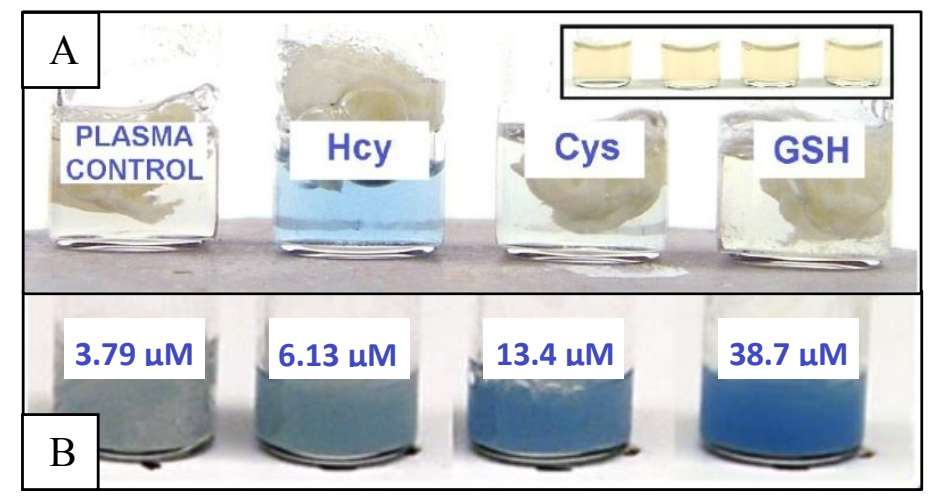

Figure 10. (A) Selective color change, $\mathrm{MV}^{2+} \rightarrow \mathrm{MV}^{\bullet+}$. Human plasma spiked with 4.0 $\mathrm{mM}$ of each aminothiol, $8.0 \mathrm{mM} \mathrm{MV}^{2+}$, buffered to $\mathrm{pH} 7.5$ with $0.5 \mathrm{mM}$ Tris, and refluxed for $5 \mathrm{~min}$. Inset shows samples before heating. ${ }^{61}$ (B) Proportional probe response to endogenous Hcy concentrations in human serum calibration standards in the presence of disulfide reducing agent, tris(2-carboxyethyl)phosphine (TCEP). ${ }^{62}$

\begin{tabular}{|c|c|c|c|c|}
\hline Entry & R (viologen) & $E^{0} / \mathrm{mV}$ & $\begin{array}{l}\mathrm{pH} \\
\text { endpoint } \\
\text { of Hcy }\end{array}$ & $\begin{array}{l}\mathrm{pH} \\
\text { endpoint } \\
\text { of Cys }\end{array}$ \\
\hline 1 & 2,4-Dinitrophenyl & ND & None & $\leq 0$ \\
\hline 2 & $-\mathrm{CH}_{2} \mathrm{CN}$ & -150 & ND & $\leq 0$ \\
\hline 3 & $-\mathrm{CH}_{2} \mathrm{CO}_{2} \mathrm{Et}$ & -267 & 3.8 & 5.8 \\
\hline 4 & $-\mathrm{Ph}$ & -288 & 2.5 & 3.8 \\
\hline 5 & $-\mathrm{CH}_{2} \mathrm{Ph}$ & -370 & 3.6 & 4.8 \\
\hline 6 & $-\mathrm{CH}_{2} \mathrm{CH}=\mathrm{CH}_{2}$ & -408 & 4.2 & 4.7 \\
\hline 7 & $-\mathrm{CH}_{2}\left(\mathrm{CH}_{2}\right)_{5} \mathrm{CH}_{3}$ & -415 & 4.3 & $5.8-7.0,8.8$ \\
\hline 8 & $-\mathrm{CH}_{3}$ & -446 & 5.0 & $6.0-7.0,8.2$ \\
\hline
\end{tabular}

Figure 11. Minimum $\mathrm{pH}$ at which Hcy or Cys $(17 \mathrm{mM})$ produced colorimetric response with various symmetric viologen probes $(4.0 \mathrm{mM}){ }^{73}$ 


\subsection{Novel viologen based probes}

While the selective detection of Hcy directly in human plasma was an impressive achievement by our research group, the use of heat to promote the reaction was not ideal for simple, high-throughput testing or an at-home testing kit. During our investigation of symmetric viologen probes, the probes with less negative reduction potentials were observed to have a persistence of color when removed from the heat, a more intense color change, and a faster onset of color when the $\mathrm{pH}$ of the solution was increased beyond the colorimetric endpoint. ${ }^{73}$ Therefore, it was thought that tuning the redox properties of the viologen probe would allow for the selective detection of Hcy without the need for reflux.

At high concentrations, the radical cation species of viologens have been shown to associate by cofacial $\pi$-stacking to form intermolecular pimers. ${ }^{77}$ These pimers are stabilized by spin paring of the free radicals to a diamagnetic state. ${ }^{78}$ In addition to radical stabilization, cofacial proximity of a radical cation species to a fully oxidized dictation species causes the dictation to be more easily reduced. ${ }^{79}$ By tethering two viologen molecules together with a xylene linker, the proximity of the viologens subunits can be adjusted via ortho, meta, or para isomers of the linker. The termini of the bridged viologens could then be further functionalized, providing a tuned reduction potential amenable to room temperature reduction and the formation of stable radical species.

The use of a bridged viologen probe was also seen as an opportunity to explore possible supramolecular sensing mechanisms. Since the rotatable bonds of the bridge allows for a range of open and closed conformations, there is likely to be conformational 
rearrangement upon reduction. ${ }^{79}$ Binding of an analyte may also cause a conformational change whereby selectivity for a particular analyte would be delimited according to the size of the closed conformation cavity. These conformational changes could be monitored by functionalizing the termini of the probe with fluorophores, since short range interactions of the fluorophore moieties would result in enhanced florescence or quenching.

Initial screening of bis- benzyl, allyl, propargyl, acetal, carboxylate, and nitrile analogs of the bridged viologen probe revealed the nitrile analog to be the most promising candidate for the selective room temperature detection of Hcy near physiological $\mathrm{pH}^{80}$ The work herein details the characterization of ortho, meta, and para isomers of the bis-nitrile bridged viologen probe, addresses issues with optimization of this probe for use with biological samples, and proposes a mechanism for the observed reactivity. Additionally, coumarin was chosen as a convenient fluorophore for preliminary studies of supramolecular interactions (Figure 12). 

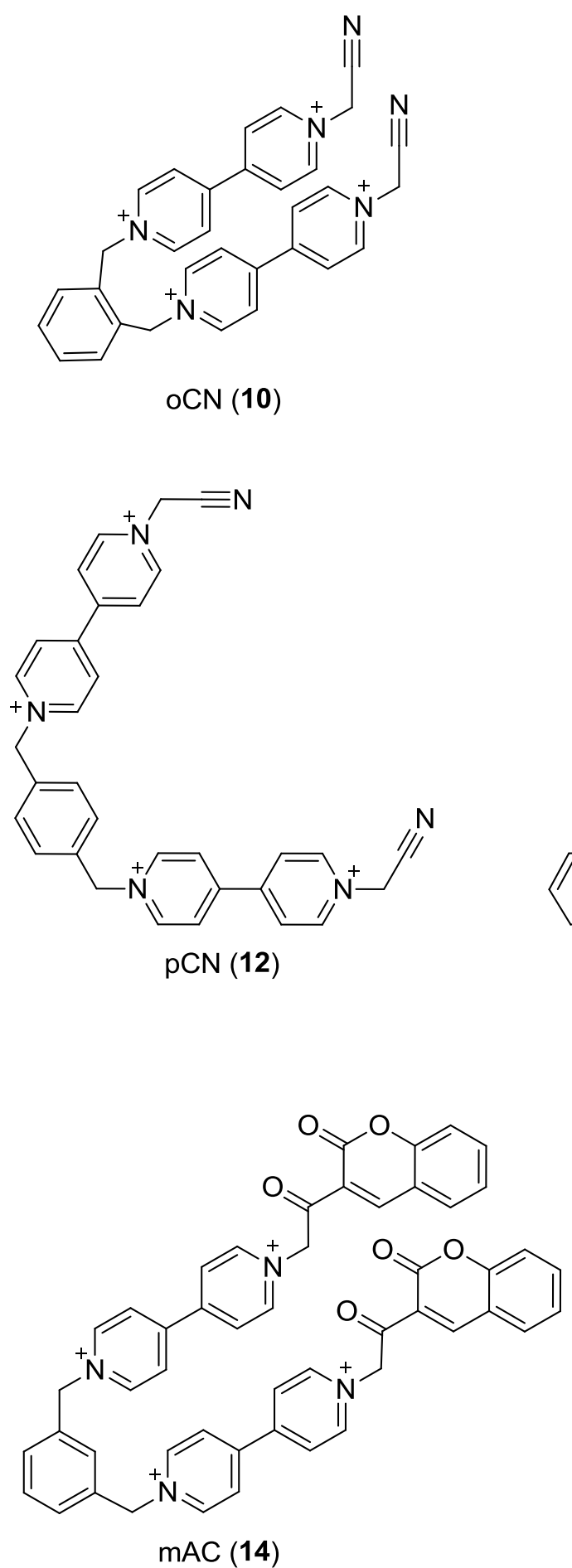
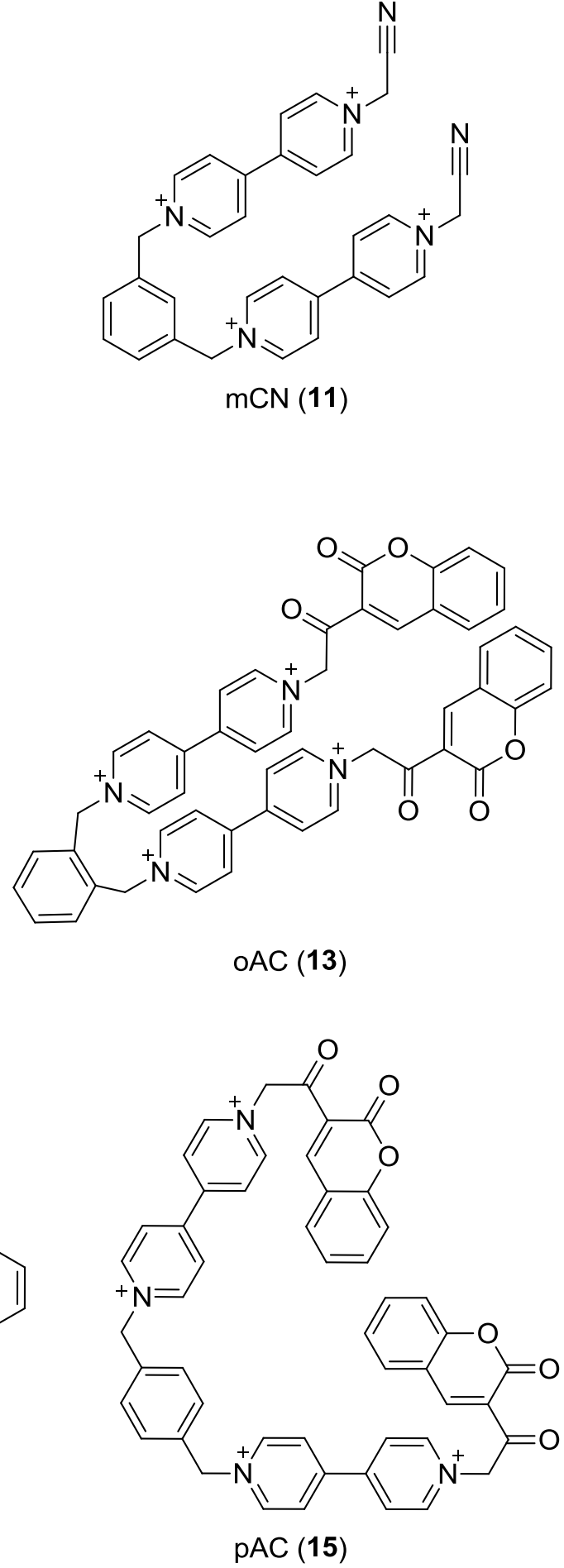

Figure 12. Structures of bridged viologen based probes. 


\section{Chapter 3: Results and discussion}

3.1 Detection of Hcy with the para-bridged bis-CN viologen probe

Selective detection of Hcy at room temperature was achieved using para-bridged

bis- $\mathrm{CN}$ viologen $(\mathrm{pCN}, 12)$. At $\mathrm{pH} 8$, the probe developed a red color in solution with

Hcy while solutions containing Cys or GSH remained a similar color to the blank. In

Figure 13, the concentrations used for the Cys and GSH controls reflect their normal biological concentration in human plasma, while $15 \mu \mathrm{M}$ of Hcy was used to represent mild homocysteinemia.

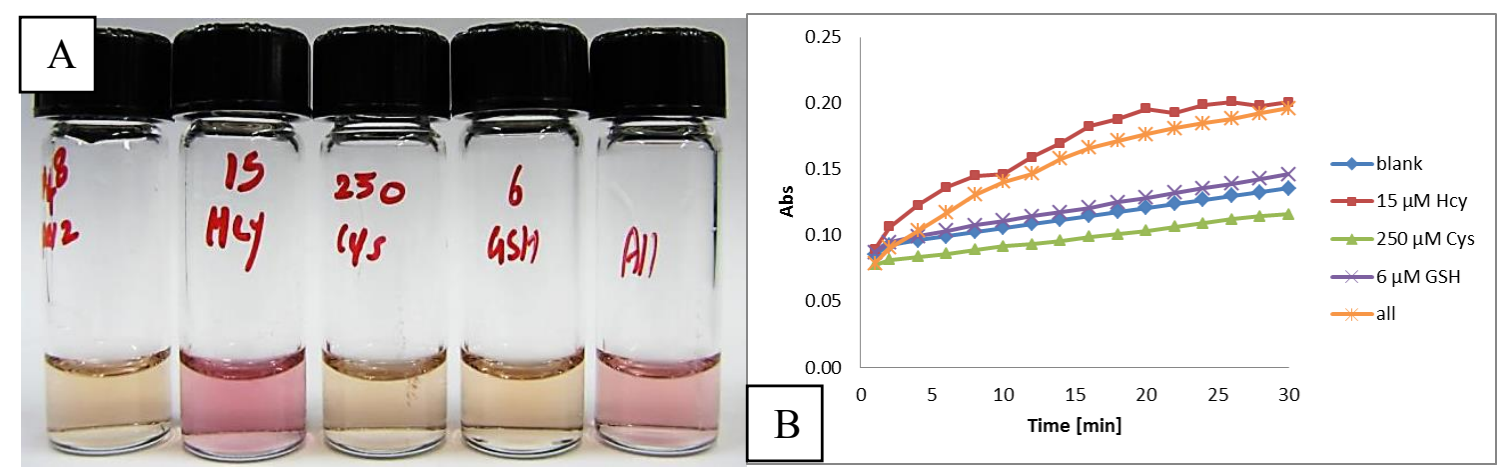

Figure 13. Colorimetric selectivity for Hcy in $80.0 \mathrm{mM}$ phosphate buffer $\mathrm{pH} 8.0$ with $2.00 \mathrm{mM}$ pCN probe. (A) Photo after $20 \mathrm{~min}$ at room temperature. From left: blank, $15.0 \mu \mathrm{M}$ Hcy, $250 \mu \mathrm{M}$ Cys, $6.00 \mu \mathrm{M}$ GSH, all thiols combined. (B) Measured $\lambda_{\text {abs }}=540$ $\mathrm{nm}$ increased over time.

There were two absorbance peaks observed in the visible region, $\lambda_{\mathrm{abs}}=413$ and $540 \mathrm{~nm}$ (for behavior at $413 \mathrm{~nm}$ see Section 3.3). Both of the peaks increased with time; however, the peak at $540 \mathrm{~nm}$ increased at a faster rate in the presence of Hcy (Figure 13B). After several hours, the absorbance increase due to Hcy plateaus and converges with the level of absorbance produced by Cys or GSH, making solutions of the aminothiols indistinguishable. Interestingly, probe response at $540 \mathrm{~nm}$ in the presence of Cys was slightly lower than the response of the blank; though the rate of increase was similar. 
The presence of Cys may be responsible for the attenuated response observed for Hcy when all of the aminothiols are combined.

Plasma proteins were also found to interfere with the probe response, causing the probe to become intensely colored. Deproteinization was necessary to distinguish samples spiked with Hcy from blank samples. After deproteinization the probe behaved similarly to the non-plasma buffer controls (Figure 14). There was, however, a slight decrease in overall absorbance. This was attributed primarily to the high salt content of plasma (see Section 3.3).

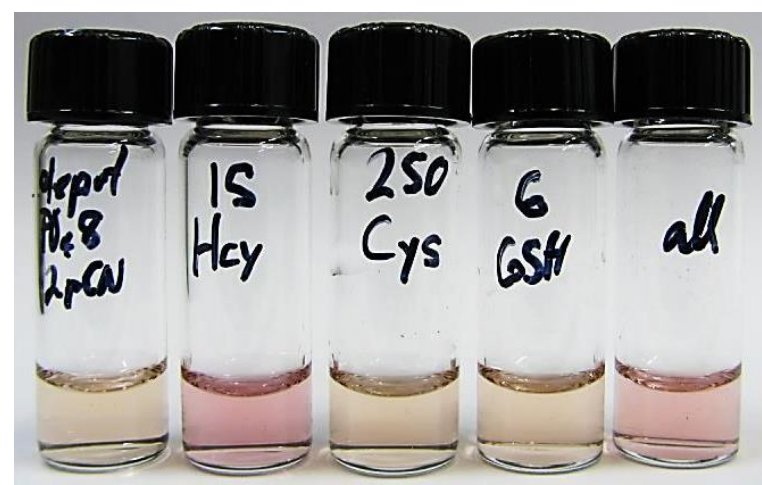

Figure 14. Selective color change in presence of $25 \% \mathrm{v} / \mathrm{v}$ deproteinized bovine plasma. Photo after $20 \mathrm{~min}$ at room temperature in $80.0 \mathrm{mM}$ phosphate buffer $\mathrm{pH} 8.0$ with 2.00 $\mathrm{mM}$ pCN probe. Aminothiols were spiked according to: blank, $15.0 \mu \mathrm{M} \mathrm{Hcy}, 250 \mu \mathrm{M}$ Cys, $6.00 \mu \mathrm{M} \mathrm{GSH}$, all thiols combined.

Calibration curves for Hcy were constructed with Hcy spiked to deproteinized plasma. Accounting for the plasma dilution, the curve in Figure 15-A was spiked with normal biological concentrations of Cys and GSH. This curve appeared linear, though the deviation of the replicates was not ideal. Since the blank was only measured once, the limit of detection (LOD) was calculated by regression statistics according to the formula LOD $=3 \times$ [standard error of y values] / [slope]. The limit of quantification (LOQ) was calculated according to $L O Q=10 \times$ [standard error of y values] / [slope]. For 
the diluted sample solutions: $\mathrm{LOD}=3.40 \mu \mathrm{M}$ and $\mathrm{LOQ}=11.3 \mu \mathrm{M}$. These values correspond to $\mathrm{LOD}=13.6 \mu \mathrm{M}$ and $\mathrm{LOQ}=45.3 \mu \mathrm{M}$ in the plasma after accounting for the dilution. When higher concentrations of deproteinized plasma were used, the absorbance measurements were not significantly different. However, a modest dilution is anticipated from sample processing steps needed to remove erythrocytes and proteins if this probe is to be used for a point-of-care test kit (see Chapter 8).

The calibration curve in Figure 15-B was constructed using a slightly higher $\mathrm{pH}$ buffer, $\mathrm{pH} 8.3$ instead of $\mathrm{pH}$ 8.0. At higher $\mathrm{pH}$, the sensitivity of the probe increases; however, the increase in reactivity also leads to an increase in response to reductants other than Hcy. Although the response from Cys and GSH at pH 8.3 is negligible, the data for this calibration curve was collected without spiking Cys or GSH in an effort to identify the variable most responsible for replicate deviations. The precision of the replicates improved though the data points appear to be slightly non-linear (concave down). Since replicates of the blank were performed, LOD and LOQ were calculated by $3 \times$ [standard deviation of the blank] and $10 \times$ [standard deviation of the blank]. It should be noted that the blank had the largest deviation in the data set, thus the limits may be artificially inflated by a potential outlier. For the diluted sample solutions: $L O D=2.17$ $\mu \mathrm{M}$ and $\mathrm{LOQ}=6.10 \mu \mathrm{M}$. These values correspond to $\mathrm{LOD}=8.67 \mu \mathrm{M}$ and $\mathrm{LOQ}=24.4$ $\mu \mathrm{M}$ in the plasma after accounting for the dilution. Even though the slope of the curve was increased by increasing the $\mathrm{pH}$, the sensitivity was not improved enough for the LOQ to fall within the range of the curve (for an alternative curve based on initial rates see Appendix A, Figure 47). 


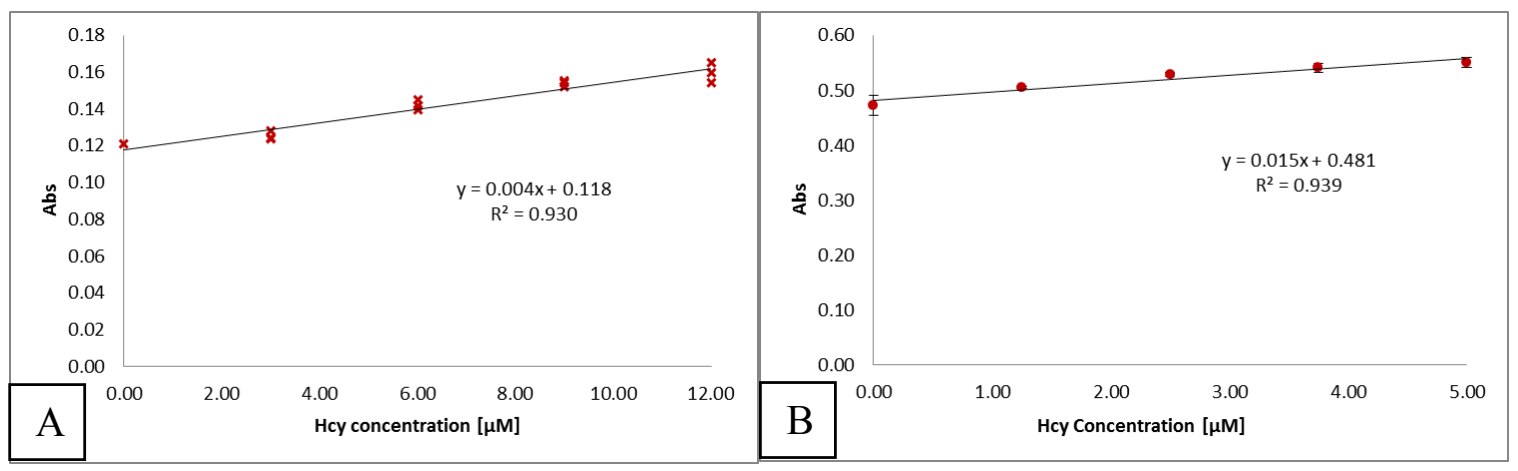

Figure 15. Calibration curves for $\mathrm{pCN}$ probe. All samples contained $25 \% \mathrm{v} / \mathrm{v}$ deproteinized bovine plasma, $2.00 \mathrm{mM}$ pCN probe, and $80.0 \mathrm{mM}$ phosphate buffer. Absorbances measured at $540 \mathrm{~nm}$ after $30 \mathrm{~min}$. (for $\lambda_{\text {abs }}$ and time point selection see Appendix A, Figure 45 and Figure 46) (A) pH 8.0 with $62.5 \mu \mathrm{M}$ Cys and $1.50 \mu \mathrm{M}$ GSH spiked to each sample. $\mathrm{LOD}=3.40 \mu \mathrm{M}$ and $\mathrm{LOQ}=11.3 \mu \mathrm{M}$. (B) $\mathrm{pH} 8.3$ without Cys and $\mathrm{GSH}$. $\mathrm{LOD}=2.17 \mu \mathrm{M}$ and $\mathrm{LOQ}=6.10 \mu \mathrm{M}$.

\subsection{Ortho and meta isomers of the bridged bis-nitrile viologen}

The ortho-bridged bis-nitrile viologen (oCN) and meta-bridged bis-nitrile viologen $(\mathrm{mCN})$ were also found to respond selectively to Hcy under certain conditions (Figure 16). The local maximum $\lambda_{\text {abs }}$ for oCN was determined to be $550 \mathrm{~nm}$, while $\mathrm{mCN}$ and $\mathrm{pCN}$ had maximums at $540 \mathrm{~nm}$. The $10 \mathrm{~nm}$ redshift and broader peak gives the reduced $\mathrm{oCN}$ probe a purple appearance that is unique among the positional isomers. The purple color was attributed to skewed intramolecular pimerization of the viologen moieties. Pimerization or ' $\pi$-dimerization' is the cofacial stacking and interaction of $\pi$ systems. When two viologen radical cations pimerize $\left(\mathrm{P}_{2}\right)$, the spins of the SOMO electrons pair to form a diamagnetic closed shell without actually forming a bond. This localizes the stabilizes the radicals, resulting in a larger ground state to excited state energy gap $(\Delta \mathrm{E})$ and $\lambda_{\mathrm{abs}}$ blueshift compared to the monomeric radical. The magnitude of $\Delta \mathrm{E}$ is partially dependent the extent of $\pi$-orbital overlap allowed with bridged or sterically hindered pimer subunits. Increasing the distance between viologen moieties or 
skewing orbital alignment by reducing the degrees of freedom gives a $\lambda_{\text {abs }}$ redshift relative to the ideal $\mathrm{P}_{2}$ geometry. When the $\pi$-stacking occurs between an unreduced dication and a radical cation viologen $\left(\mathrm{P}_{2}{ }^{++}\right)$, the electrostatic interaction causes delocalization of the free electron and a redshift results. ${ }^{77,81-83}$

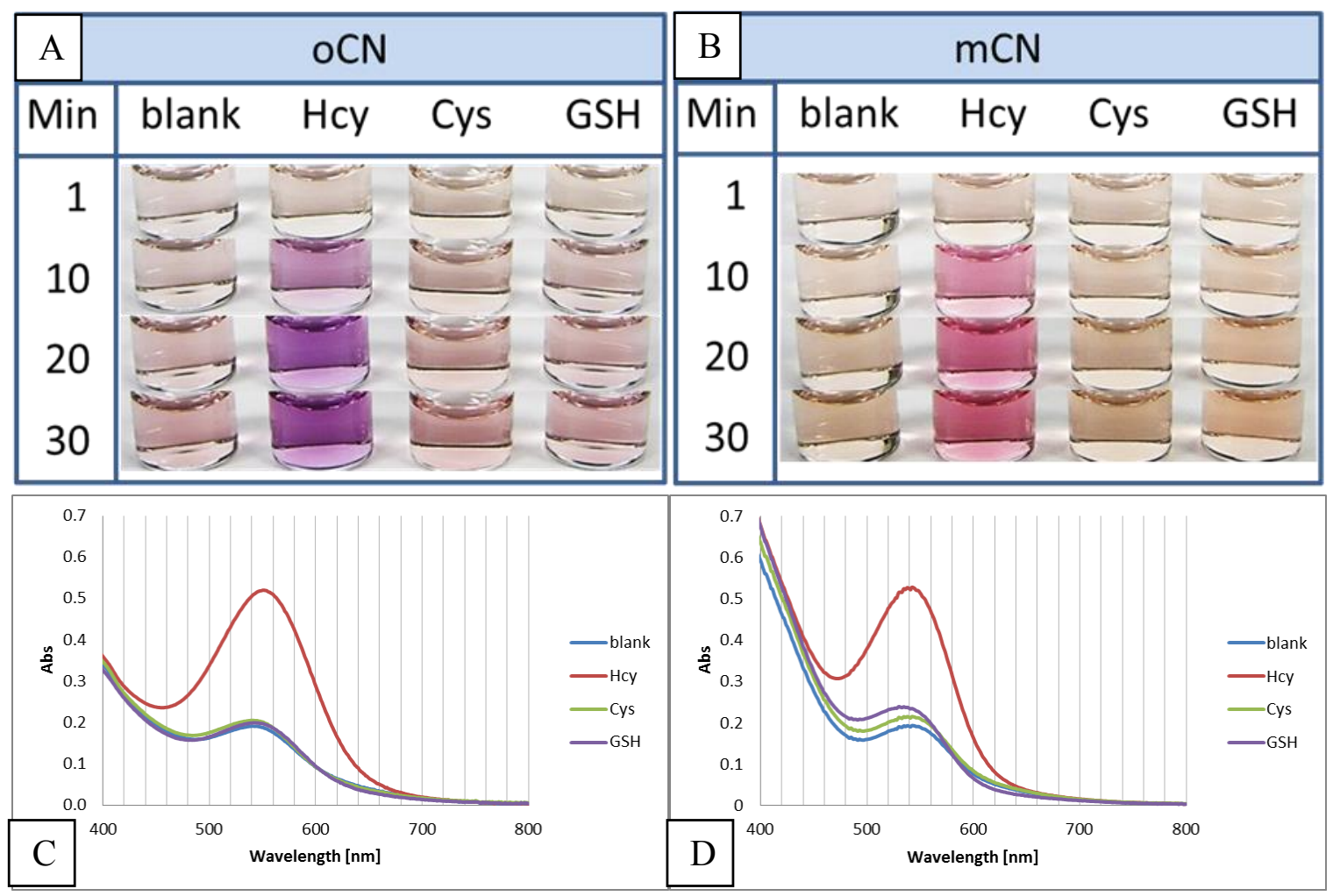

Figure 16. All panels show $200 \mu \mathrm{M}$ of each aminothiol at $\mathrm{pH} 7.0$ (A) $4.00 \mathrm{mM}$ oCN, $80.0 \mathrm{mM}$ phosphate buffer, $200 \mathrm{mM} \mathrm{NaCl}$. (B) $8.00 \mathrm{mM} \mathrm{mCN}, 80.0 \mathrm{mM}$ HEPES buffer. (C) oCN absorbance spectrum at conditions from panel A measured at $22 \mathrm{~min}$. (D) $\mathrm{mCN}$ absorbance spectrum at conditions from panel B measured at $30 \mathrm{~min}$.

Ortho xylene bridged viologens form mostly intramolecular pimers whereas meta and para isomers tend to form intermolecular pimers. ${ }^{77}$ Additionally, pimerization occurs preferentially with oCN because the tethered viologen moieties are already positioned in close proximity, minimizing translational and rotational components of the activation energy barrier. The acceptor/donor interaction of the oCN pimer is a charge 
transfer complex which stabilizes the radical cation. Therefore, the pimer is formed more easily than an unassociated radical cation. ${ }^{82}$ This means the first reduction potential of tetracationic $\mathrm{oCN}$ is less negative than the $\mathrm{mCN}$ and $\mathrm{pCN}$ isomers. For a given $\mathrm{pH}, \mathrm{oCN}$ was observed to be more reactive than $\mathrm{mCN}$ and $\mathrm{pCN}$. Figure 16-CD shows similar absorbance intensities for oCN and $\mathrm{mCN}$; however, the spectrum for oCN corresponds to an earlier time point and half the probe concentration. Although oCN possessed increased reactivity and both isomers appeared to have an intense, selective response to Hcy, the optimization of these probes did not reveal reaction conditions at which a useful LOD could be obtained.

\subsection{Effects of reaction parameters}

There was a decrease in reactivity of the bridged bis-nitrile viologen probes as ionic strength was increased by the addition of $\mathrm{NaCl}$ (Figure 17-A). Similarly, Kertesz et al. observed a decrease in Cys thiyl radical when ionic strength was increased. ${ }^{84}$ The authors rationalized this observation by invoking counter ion clusters which surround charged molecules in solution, thereby retarding their interaction and ability to generate radicals. This diffusion limiting explanation is only partially satisfying for the bridged viologens since the response of the probe in solution without aminothiols (designated as 'blank') also decreased. Other considerations may include increased radical quenching and geminal recombination with the increased dielectric nature of the solution and an increase in the dissociation constant of viologen pimers by counter ion stabilization of the monomers. ${ }^{85}$ Interestingly, the probe response due to GSH was more affected by ionic strength than the other aminothiols. It appeared that controlling the ionic strength would 
be useful to block interference from GSH and promote selectivity towards Hcy; however, the response due to $\mathrm{GSH}$ at biological concentrations (3 - $7 \mu \mathrm{M}$ in plasma) was minimal with the $\mathrm{pCN}$ probe under optimal conditions.

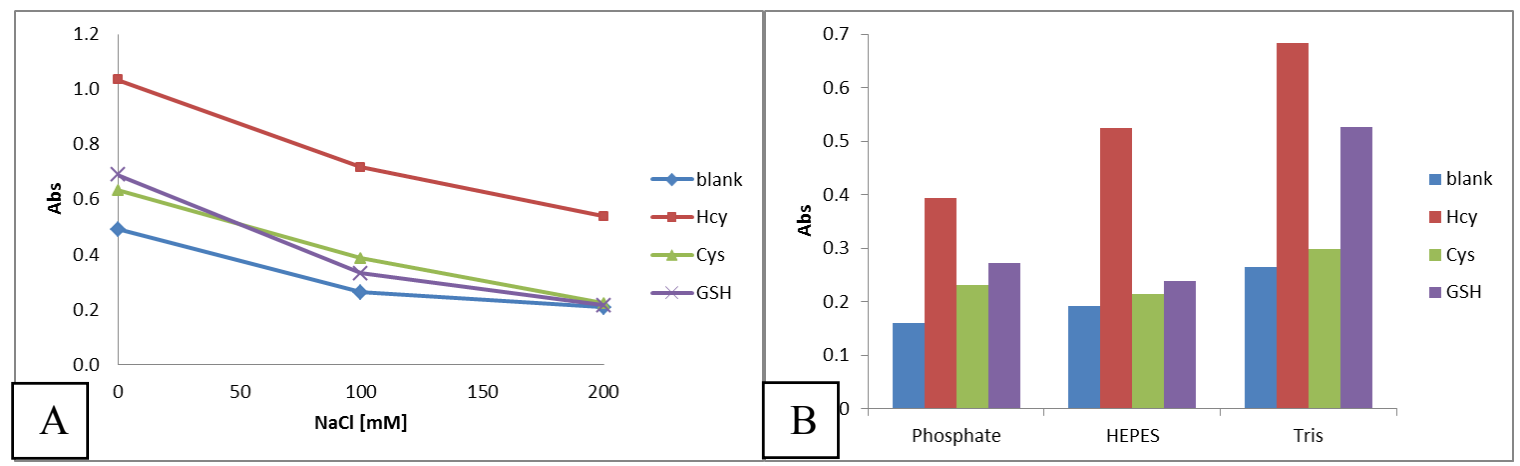

Figure 17. Effect of ionic strength and buffer identity. (A) $4.00 \mathrm{mM} \mathrm{oCN}, 200 \mu \mathrm{M}$ of each aminothiol, $80.0 \mathrm{mM}$ phosphate buffer $\mathrm{pH} 7.0, \lambda_{\mathrm{abs}}=550 \mathrm{~nm}$, after $30 \mathrm{~min}$. (B) 8.00 $\mathrm{mM} \mathrm{mCN}, 200 \mu \mathrm{M}$ of each aminothiol, $80.0 \mathrm{mM}$ buffer $\mathrm{pH} 7.0, \lambda_{\mathrm{abs}}=540 \mathrm{~nm}$, after 30 $\min$.

The bridged bis-nitrile viologen probes also behaved differently in different buffers. Three types of buffers were examined: anionic phosphate, zwitterionic HEPES, and cationic Tris. For $\mathrm{mCN}$, it was found that HEPES buffer provided the best selectivity towards Hcy (Figure 17-B), while oCN and $\mathrm{pCN}$ produced better results in phosphate buffer. For all three isomers, a dampening of probe response was observed with increasing concentration of phosphate buffer, presumably due to the accompanied increase in ionic strength. Higher concentrations of Tris buffer had the opposite effect, causing an increase in the probe response. However, consistently poor selectivity for Hcy was observed when Tris was used.

Surfactants were also investigated as a way to remove protein interference by denaturing them or by sequestering the probe from interferences. The observations attributed to the formal charge of the buffers, did not hold with surfactants. The anionic 
surfactant, SDS, caused the probe to turn purple and precipitate from solution. Neutral surfactant, Tween 80 , caused an increase in probe response and loss of selectivity. Cationic surfactant, CTAB, did not appear to affect the probe up to the highest concentration tested, $10 \mathrm{mM}$. The addition of CTAB to plasma samples did not block interferences.

One possible explanation for the variability observed with these additives is the extent to which they solvate the probe along its reaction coordinates. As a tetra-cationic species, the unreduced probe is soluble in an aqueous medium. Upon reduction, the charge decreases and the probe becomes increasingly less soluble. Fully reduced, neutral bridged viologens precipitate completely from aqueous solutions. ${ }^{77}$ A reduction in solubility due to the loss of charge is enthalpically and entropically disfavored, causing an increase in the energy of the activation complex. ${ }^{86}$ By increasing the organic character of the medium, the activation complex is stabilized and reduction of the probe occurs more readily. This difference in solvation energy of the activation complex has been attributed to the increasingly less negative reduction potential observed for $\mathrm{MV}^{2+}$ when the dielectric constant of the solvent was decreased by adding ethanol. ${ }^{87}$

The effect of adding water miscible organic solvents was investigated using acetone, methanol, ethanol, isopropanol (IPA), dimethyl sulfoxide, dimethylformamide, tetrahydrofuran, dioxane, and acetonitrile. As expected, the probe response increased proportionally to the ratio of organic solvent used, with only subtle differences in intensity and selectivity. In strictly aqueous solutions buffered at $\mathrm{pH} \leq 6.0$, none of the bridged bis-nitrile viologen probes produced notable increases of absorbance in the 
visible region. However, with the addition of organic solvent, the probes would respond below $\mathrm{pH}$ 6. At low $\mathrm{pH}$ and with added organic solvent, Cys became a prominent interference. There was no discernible difference between protic and non-protic solvents; though probe reactivity was observed to increased according to the trend methanol $>$ ethanol > IPA.

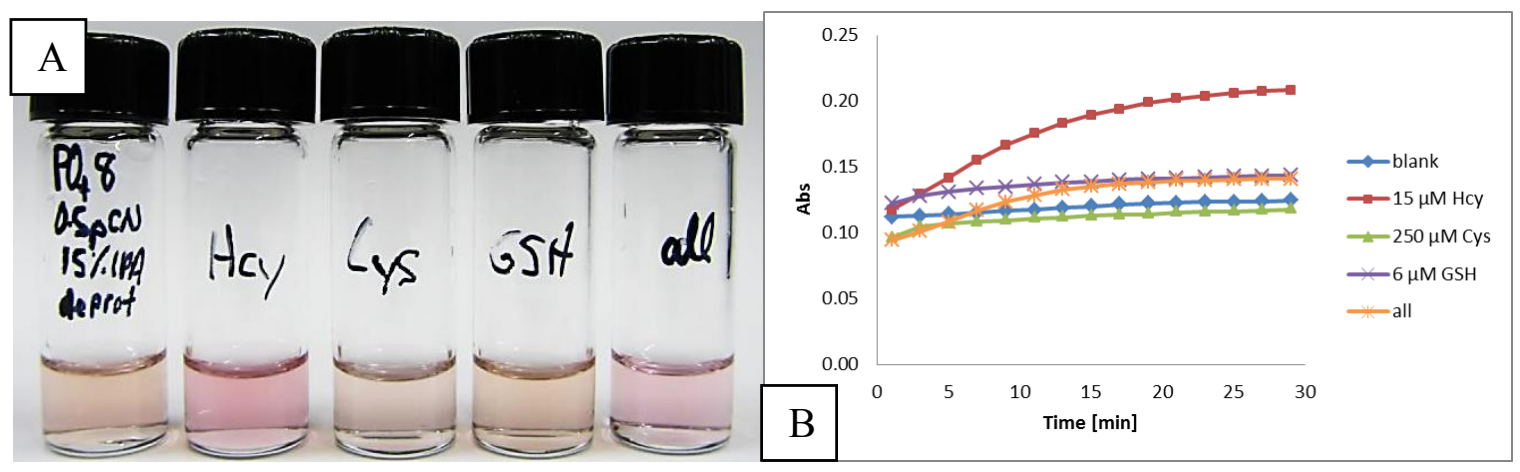

Figure 18. Samples with organic solvent. (A) Selective color change for Hcy after 20 min in $80.0 \mathrm{mM}$ phosphate buffer $\mathrm{pH} 8.0$ with $25 \% \mathrm{v} / \mathrm{v}$ deproteinized plasma, $15 \% \mathrm{v} / \mathrm{v}$ IPA, $0.500 \mathrm{mM}$ pCN probe. From left: blank, $15.0 \mu \mathrm{M}$ Hcy, $250 \mu \mathrm{M}$ Cys, $6.00 \mu \mathrm{M}$ GSH, all thiols combined. (B) $\lambda_{\text {abs }}=540 \mathrm{~nm}$ in $80.0 \mathrm{mM}$ phosphate buffer $\mathrm{pH} 8.0$ with $15 \%$ IPA and $0.500 \mathrm{mM} \mathrm{pCN}$ probe.

When high concentrations of organic solvent were used the samples would become completely opaque with color, obscuring any potential selectivity. Visual selectivity for Hcy in 15\% IPA became discernible again when the $\mathrm{pCN}$ probe concentration was decreased by a factor of four (Figure 18-A). Although the colors of the vials appear similar to those in Figure 14, there were some distinct differences in the absorbance spectra. The sample designated by 'all' contained a mixture of Hcy, Cys, and GSH at concentrations respective of those used for the individual analyte samples. According to measurements of the diagnostic peak at $30 \mathrm{~min}$, the species responsible for absorbtion of yellow-green light at $\lambda_{\mathrm{abs}}=540 \mathrm{~nm}$ and the appearance of red colored solutions was present at the same concentration in the sample with $6 \mu \mathrm{M} \mathrm{GSH}$ as 
compared to the sample that contained 'all' the aminothiols together (Figure 18-B). This discrepancy between the observed color and measured absorbance has to do with a decrease in the rate of absorbance increase at $413 \mathrm{~nm}$ relative to $540 \mathrm{~nm}$ (Figure 19). An equilibrium shift away from species responsible for the peak at $413 \mathrm{~nm}$ was attributed, in part, to increased $\mathrm{pK}_{\mathrm{a}}$ values associated with the use of less polar solvents $\left(\mathrm{K}_{\mathrm{a}}\right.$ of probes discussed in Section 4.2). ${ }^{88}$ The peak at $413 \mathrm{~nm}$ was absorbing violet light and contributed to the appearance of yellow colored solutions. The GSH samples in IPA appeared visibly yellow after $30 \mathrm{~min}$ because the peak at $413 \mathrm{~nm}$ dominated, while this peak was less prominent for the 'all' sample. Increased interference at $\lambda_{\mathrm{abs}}=540 \mathrm{~nm}$ from Cys and GSH in the presence of organic solvent was also observed (Figure 20). This is most likely due to the decreased probe to analyte ratio and increased radical disproportionation of the analytes prior to interaction with the probe. 


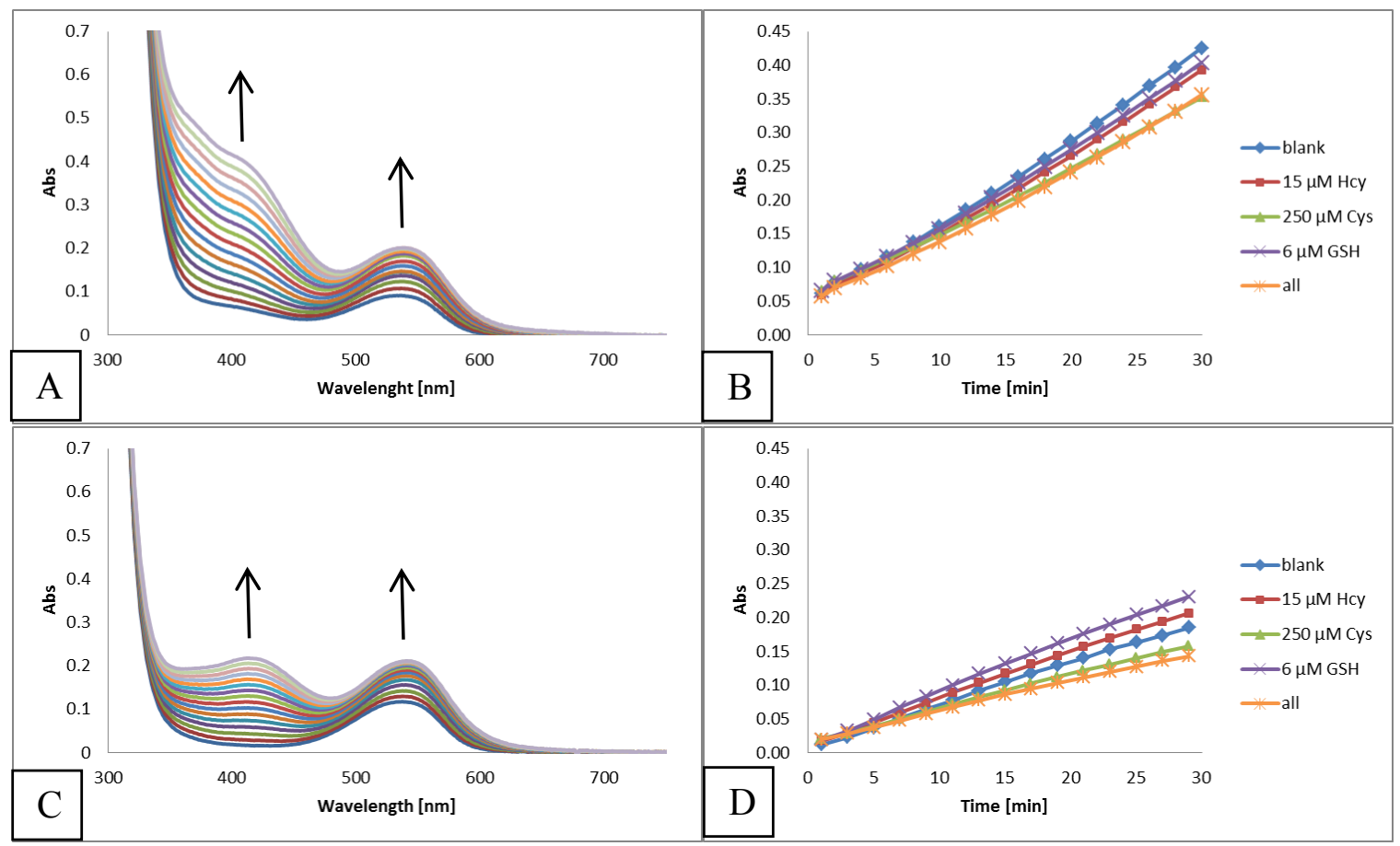

Figure 19. Effect of adding organic solvent. (A) Spectrum of $2.00 \mathrm{mM} \mathrm{pCN}$ in $80.0 \mathrm{mM}$ phosphate buffer $\mathrm{pH} 8.0$ with $15.0 \mu \mathrm{M}$ Hcy. Time frame: 0 - $30 \mathrm{~min}$ with a scan every 2 min. (B) $\lambda_{\text {abs }}=413 \mathrm{~nm}$ corresponding conditions from panel A. (C) Spectrum of 0.500 $\mathrm{mM}$ pCN in $80.0 \mathrm{mM}$ phosphate buffer $\mathrm{pH} 8.0$ with $15.0 \mu \mathrm{M}$ Hcy and $15 \% \mathrm{v} / \mathrm{v}$ IPA. Time frame: 0 - $30 \mathrm{~min}$ with a scan every $2 \mathrm{~min}$. (D) $\lambda_{\mathrm{abs}}=413 \mathrm{~nm}$ corresponding to conditions from panel $\mathrm{C}$. 


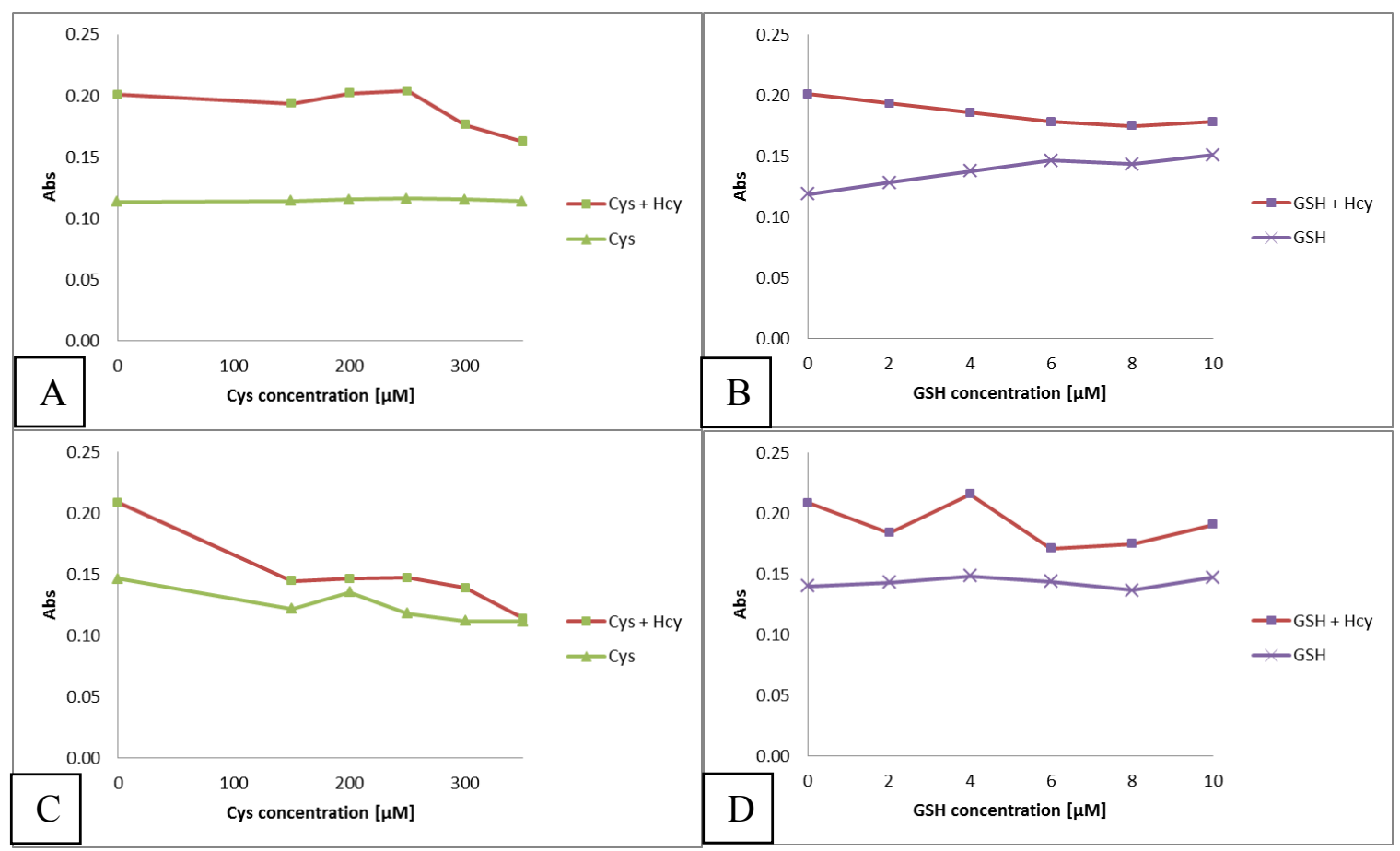

Figure 20. Effect of Cys and GSH concentrations, with and without organic solvent. All panels: $\lambda_{\text {abs }}=540 \mathrm{~nm}$ at $30 \mathrm{~min}$ in $80.0 \mathrm{mM}$ phosphate buffer $\mathrm{pH} 8.0$ with $15 \mu \mathrm{M}$ Hcy constant where indicated. (A) $2.00 \mathrm{mM}$ pCN probe with Cys concentration varied. (B) $2.00 \mathrm{mM}$ pCN probe with GSH concentration varied. (C) $0.500 \mathrm{mM}$ pCN probe in $15 \%$ IPA with Cys concentration varied. (D) $0.500 \mathrm{mM} \mathrm{pCN}$ probe in $15 \%$ IPA with GSH concentration varied. 
Chapter 4: Mechanism of the bridged bis-nitrile viologens

\subsection{Non-bridged control experiment}

To assess the way bridging the viologens effected reactivity, a non-bridged asymmetric viologen was synthesized with methylene nitrile and benzyl substituents (Figure 21). The non-bridged, benzyl-nitrile-viologen (BNV, 16), showed similar reactivity as pCN in regards to producing absorbance peaks at $413 \mathrm{~nm}$ and $540 \mathrm{~nm}$. BNV also produced the familiar red color in the presence of Hcy under the same conditions as $\mathrm{pCN}$, though twice the concentration of $\mathrm{BNV}$ was necessary to produce comparable color intensity.

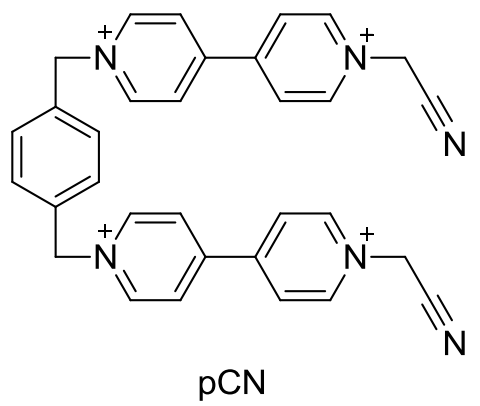

12

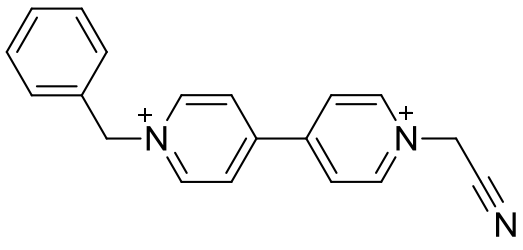

BNV

Figure 21. Structure of bridged pCN compared with non-bridged BNV.

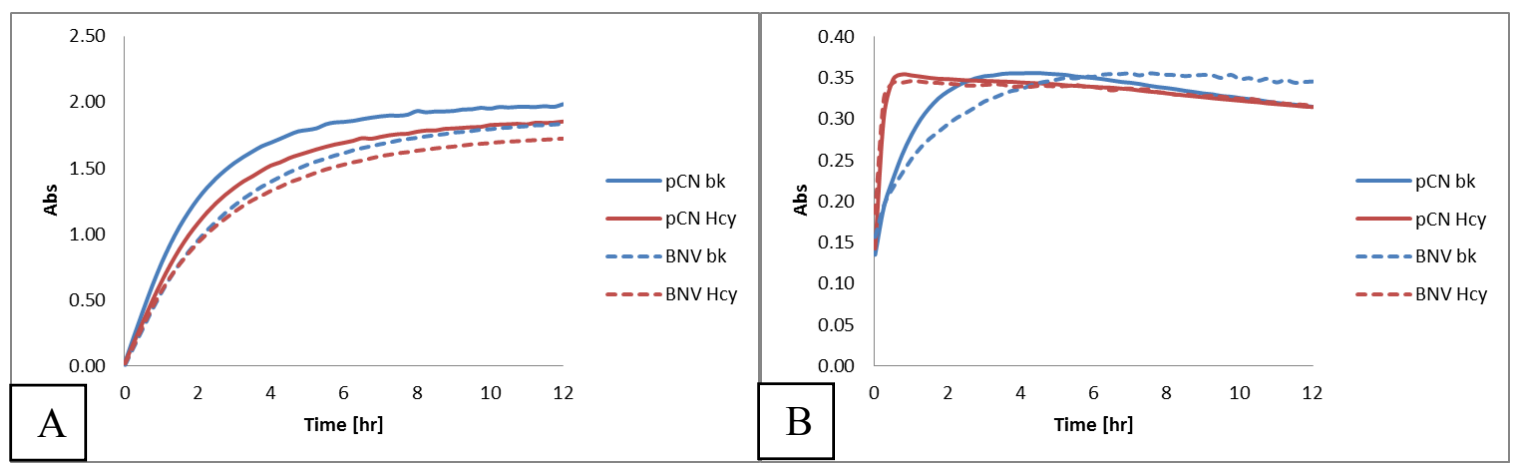

Figure 22. Comparison of $\mathrm{pCN}$ and BNV reactivity over $12 \mathrm{hrs}$. Measurements made every 15 min. Samples in $80.0 \mathrm{mM}$ phosphate buffer $\mathrm{pH} 8.0$ with $15 \% \mathrm{v} / \mathrm{v}$ IPA. Probe concentrations: $1.00 \mathrm{mM}$ pCN or $2.00 \mathrm{mM} \mathrm{BNV}$. $15.0 \mu \mathrm{M}$ Hcy and bk = blank where indicated. (A) $\lambda_{\mathrm{abs}}=413 \mathrm{~nm}$. (B) $\lambda_{\mathrm{abs}}=540 \mathrm{~nm}$. 
When absorbances were measured over 12 hours, BNV revealed a slightly different reaction profile than $\mathrm{pCN}$ (Figure 22). The rate of absorbance increase at 413 $\mathrm{nm}$ was slower for BNV compared to a stoichiometric equivalent of $\mathrm{pCN}$. BNV also had a slower rate of absorbance increase at $540 \mathrm{~nm}$ when no Hcy was present while samples with Hcy had nearly identical absorbance rates at $540 \mathrm{~nm}$. Interestingly, both probes show a decline in absorbance at $540 \mathrm{~nm}$ after reaching a maximum. At $413 \mathrm{~nm}$, the absorbance reaches a maximum, but does not decline. Samples left on the lab bench longer than $36 \mathrm{hrs}$ appeared uniformly yellow/brown from the diminished absorbance at $540 \mathrm{~nm}$ and persistence of the absorbance at $413 \mathrm{~nm}$.

Another difference between $\mathrm{pCN}$ and $\mathrm{BNV}$ was the measured $\mathrm{pK}_{\mathrm{a}}$ values. When a solution of $\mathrm{BNV}$ was titrated with dilute $\mathrm{NaOH}$, a buffering region was observed which corresponded to a $\mathrm{pK}_{\mathrm{a}}$ of 8.38 . When $\mathrm{pCN}$ was titrated there were two regions where the $\mathrm{pH}$ remained constant with the addition of base, $\mathrm{pK}_{\mathrm{a} 1}=6.83$ and $\mathrm{pK}_{\mathrm{a} 2}=7.92$ ( see Appendix A, Figure 49 and Figure 50). Increasing cofacial interaction between viologen moieties by holding them in close proximity to each other with a xylene bridge is known to enhance pimerization. ${ }^{89}$ Tethering increases the local positive charge density and facilitates charge distribution through pimerization. Therefore, the electron withdrawing property of the pyridine rings was increased for the bridged probe, substantially weakening the methylene $\mathrm{C}-\mathrm{H}$ bond relative to the non-bridged probe. 


\subsection{Acidic protons of the bridged probes}

The $\mathrm{pH}$ dependent reactivity and selectivity of non-bridged N-methylene functionalized viologens was originally attributed to the reduction potential of the probe and $\mathrm{pH}$ dependent formation of reductive analyte radical species. ${ }^{73}$ However, the reactivity of these types of probes may be due, in part, to labile hydrogens vicinal to electron withdrawing groups. Figure 23 shows gradual deuterium exchange of hydrogens at peak ' $b$ ' when samples of the pCN probe were left in $\mathrm{D}_{2} \mathrm{O}$. This indicated the presence of acidic hydrogens on the probe and a potential site of reactivity. Radicals may be generated by oxidation, reduction, or homolytic cleavage. If the probe undergoes a typical acid/base proton transfer, then a conjugated non-radical species would result. This species may be responsible for the absorbance at $413 \mathrm{~nm}$ which makes the solution appear yellow. If the labile hydrogen is removed by intermolecular HAT, a radical species is produced which absorbs $540 \mathrm{~nm}$ and causes the solutions to appear red (Figure 24). ${ }^{83}$ 


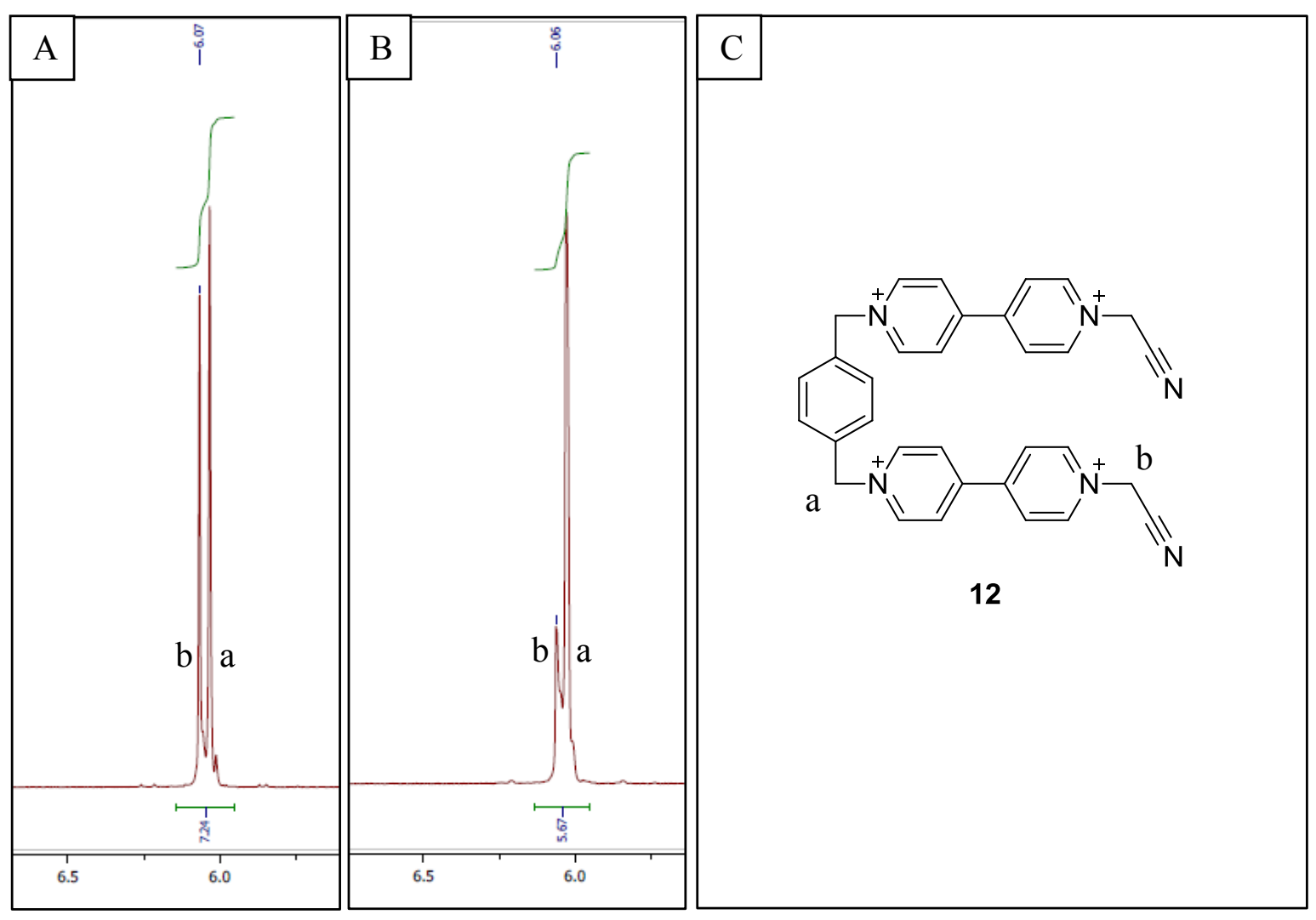

Figure 23. ${ }^{1} \mathrm{HNMR}$ of $\mathrm{pCN}$ showing deuterium exchange in $\mathrm{D}_{2} \mathrm{O}$. (A) Methylene hydrogens immediately after preparing NMR sample. (B) Methylene hydrogens after 1 hr. (C) Structure of pCN showing peak assignments.
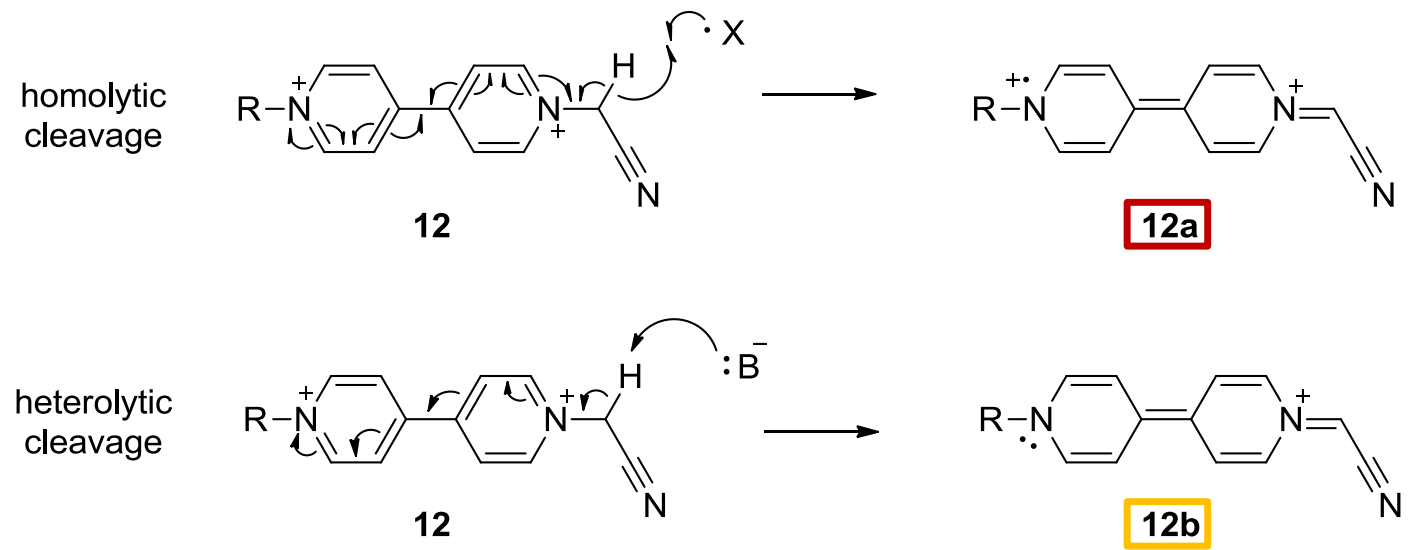

Figure 24 . Modes of cleavage for labile hydrogen. Here ' $\bullet X$ ' is any radical species.

In the case of $\mathrm{MV}^{2+}(\mathbf{9})$, solutions were heated to reflux in order to transfer and sustain a radical on the viologen probe. Oxygen is known to compete with $\mathrm{MV}^{2+}$ in 
radical reactions and quench $\mathrm{MV}^{\cdot+}$, so it was thought that reflux was required to drive dissolved oxygen from solution. ${ }^{90-91}$ For the bridged bis-nitrile viologen radical species, such as 12a, there is increased stabilization of the radical by delocalization in the extended conjugation of the $\pi$-system. This resonance stabilization contributes to reactivity at room temperature and persistence of the radical species. Furthermore, when the sample solutions were enriched with oxygen, $\mathrm{pCN}$ reacted at a faster rate with Hcy. Conversely, when argon was aspirated through the solutions to purge oxygen, pCN reacted at a slower rate with Hcy (see Appendix A, Figure 51). This indicated oxygen was acting as a reactant or a radical mediator rather than an inhibitor, suggesting a more complex mechanism than direct reduction of the probe by the $\alpha$-amino carbon centered radical.

To assess the involvement of the $\alpha$-amino carbon centered radical, other thiol reducing agents were tested as controls (Figure 25). 2-Mercaptoethanol (BME, 17) and 3-Mercaptopropionic acid (MPA, 18) were chosen because their $\mathrm{pK}_{\mathrm{a}}$ values for the thiol group are similar to $\mathrm{Hcy}\left(\mathrm{pK}_{\mathrm{a}} \mathrm{SH}: \mathrm{Hcy}^{22}=10.0, \mathrm{BME}^{92}=9.7, \mathrm{MPA}^{92}=10.3\right)$ and they are not able to produce a captodatively stabilized carbon centered radical. The strong probe response produced by Hcy in comparison to BME and MPA implicated the $\alpha$ amino carbon centered radical of Hcy as an augmenting factor. However, the response observed with BME and MPA in comparison to the blank suggested radical species generated by the thiol group, such as thiyl radicals and radical disulfide anions, were propagated to produce the red colored radical species of the probe. 


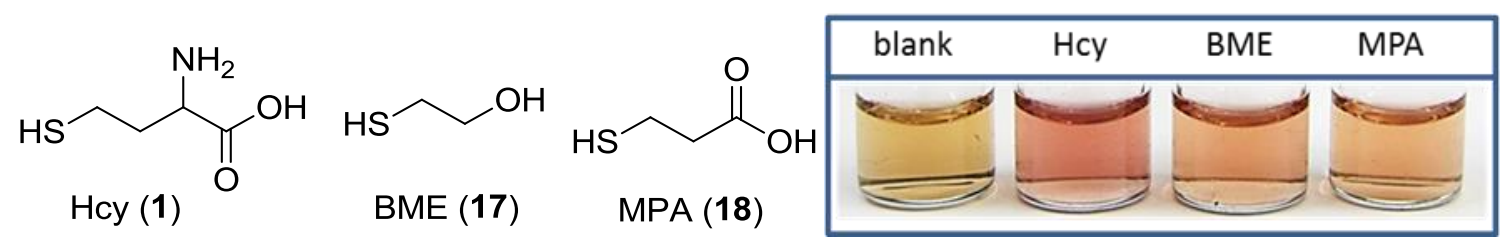

Figure 25. Non-amino thiol controls. Structures from left: $\mathrm{Hcy}_{\mathrm{pK}}=10.0 ; 2-$ Mercaptoethanol (BME) $\mathrm{pK}_{\mathrm{a}}=9.7$; 3-Mercaptopropionic acid (MPA) $\mathrm{pK}_{\mathrm{a}}=10.3$. Photo: $2.00 \mathrm{mM}$ pCN probe in $80.0 \mathrm{mM}$ phosphate buffer $\mathrm{pH} 8.0$ with $50.0 \mu \mathrm{M}$ of the indicated thiol after $20 \mathrm{~min}$.

\subsection{Electron paramagnetic resonance spectroscopy}

Electron paramagnetic resonance (EPR) spectroscopy was used to confirm radical propagation from Hcy to the $\mathrm{pCN}$ probe. The magnetic moment of a free electron is called the spin g-factor $(g)$. If paramagnetic electrons are present, the value of $g$ calculated from EPR spectral measurements should be near the accepted magnetic moment of a free electron $\left(g_{e}\right)$. The current value is $g_{e}=2.0023193043617 \pm 1.52$ ppt. $^{93}$ The EPR spectra for the reaction of $\mathrm{pCN}$ with Hcy was measured and an unpaired electron was found as expected, with $g=2.002301$ (Figure 26-B). A single isotropic signal was measured, denoting symmetry in the electron wave function. ${ }^{94}$ The signal had a broad peak to peak linewidth $(\Delta \beta)$ of $\sim 10 \mathrm{G}$.

More interestingly, $\mathrm{pCN}$ without Hcy produced the same EPR signal, but with greater amplitude. The amplitude is proportional to the concentration of resonating paramagnetic species in the sample. ${ }^{94}$ Therefore, the $\mathrm{pCN}$ probe was able to generate radicals in the absence of a reducing agent such as Hcy. Furthermore, the concentration of radical species represented by the EPR spectra was apparently diminished by the presence of Hcy. Sun and Yang observed a similar broad, single isotropic signal and attributed it to the localization of electrons in $\mathrm{P}_{2}$ type pimerization while assigning 
spectra with hyperfine coupling to $\mathrm{P}_{2}{ }^{\cdot+}$ and monomeric radical species. ${ }^{82}$ However, $\mathrm{P}_{2}$ type pimerization is largely undetectable with standard EPR spectroscopy methods because the spins of the two interacting electrons pair to become diamagnetic. ${ }^{81,83}$ Single isotropic signals with large $\Delta \beta$ and unresolved hyperfine interactions can result from signal averaging of multiple paramagnetic species interacting with multiple nuclei. ${ }^{94}$ The diminished signal amplitude of $\mathrm{pCN}$ radicals in the presence of Hcy actually corresponded to an increase in radical species and subsequent formation of EPR silent $\mathrm{P}_{2}$ type pimers. Radicals were not observed at $\mathrm{pH} 6.0$, providing further evidence that cleavage of the probes' labile hydrogens may play a role in the reaction mechanism (Figure 26-C).

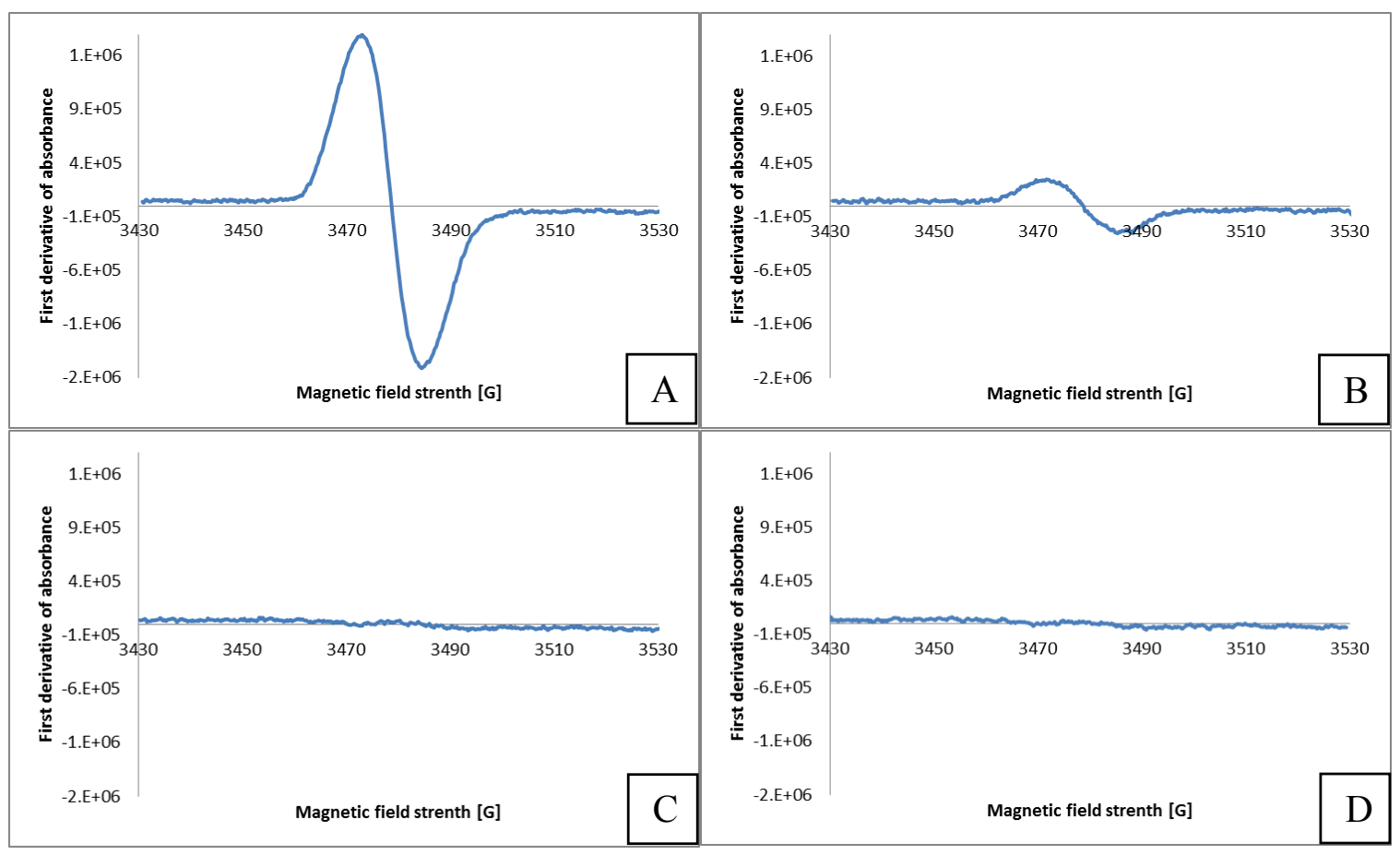

Figure 26. EPR signals. 120 scans $(\sim 20 \mathrm{~min})$ using $\mathrm{x}$-band frequency $v=9.754434 \mathrm{GHz}$ and Hall Field $\beta_{0}=3480.651 \mathrm{G}$, in $100 \mathrm{mM}$ phosphate buffer. (A) $20.0 \mathrm{mM} \mathrm{pCN}$ at $\mathrm{pH}$ $8.0, g=2.002312, \Delta \beta=\sim 10 \mathrm{G}$. (B) $20.0 \mathrm{mM} \mathrm{pCN}$ with $20 \mathrm{mM}$ Hcy at $\mathrm{pH} 8.0, g=$ 2.002301, $\Delta \beta=\sim 10 \mathrm{G}$. (C) $20.0 \mathrm{mM} \mathrm{pCN}$ at pH 6.0. (D) $20.0 \mathrm{mM}$ Hcy at $\mathrm{pH} 8.0$. 


\section{$4.4{ }^{1} \mathrm{HNMR}$ of reaction products}

${ }^{1} \mathrm{HNMR}$ of the reaction between $\mathrm{pCN}$ and Hcy revealed shifting of the viologen hydrogens upfield (Figure 27). This was consistent with reduction of the viologen subunits since the addition of electron density would lead to greater shielding and a diamagnetic shift. Convergence of the interior hydrogens ' $b$ ' and ' $c$ ' indicated delocalization of the $\pi$-system across the originally isolated pyridine rings. Hydrogens at positions ' $a$ ' and 'd' did not fully converge due to asymmetry of the substituents.

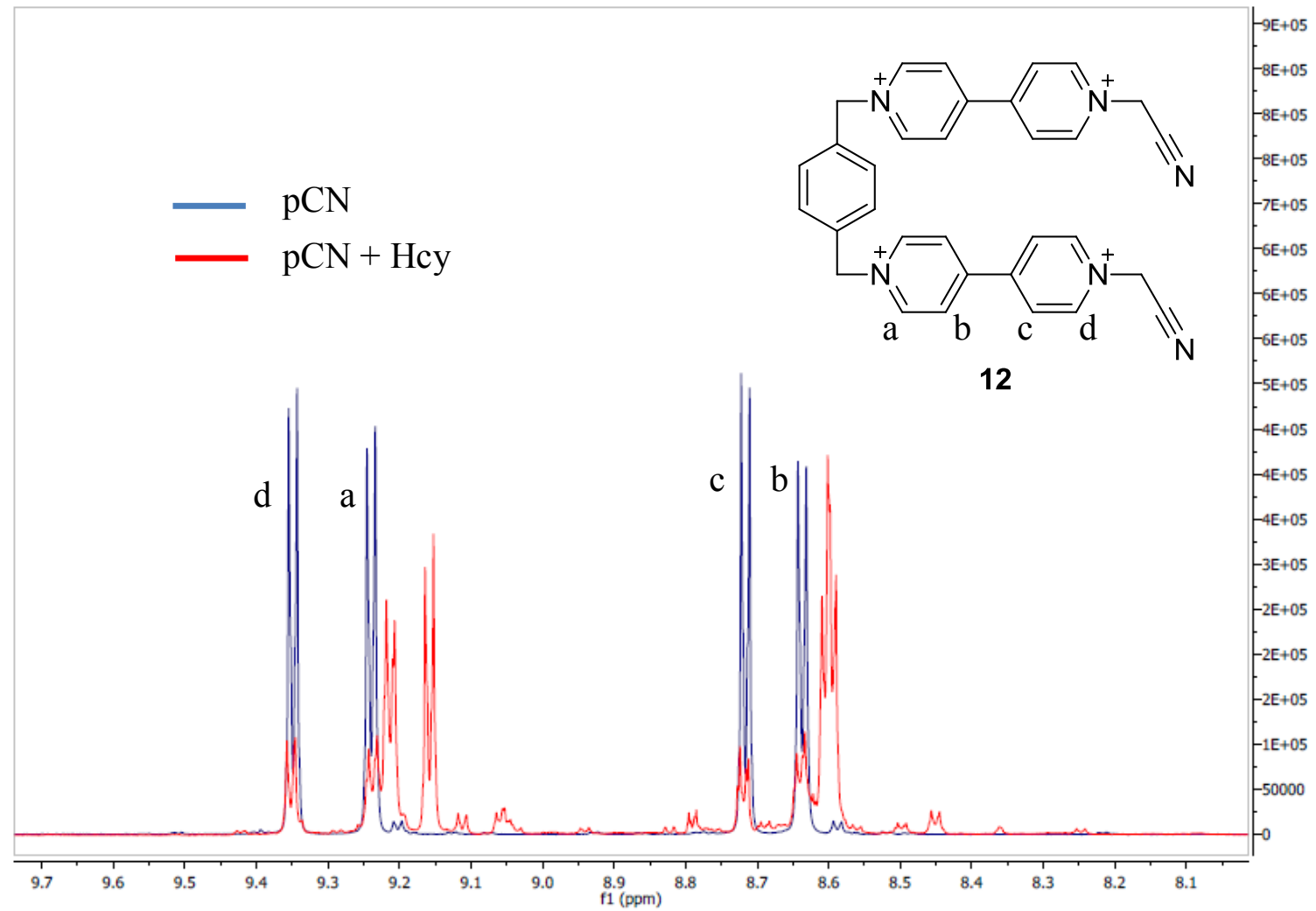

Figure 27. ${ }^{1} \mathrm{HNMR}$ of viologen hydrogens shifting. 80:20 $\mathrm{D}_{2} \mathrm{O}: \mathrm{H}_{2} \mathrm{O}$ with $100 \mathrm{mM}$ phosphate buffer $\mathrm{pH} 8.0$ and DSS standard. Blue line: $\mathrm{pCN}$ probe only. Red line: reaction of $20.0 \mathrm{mM}$ pCN with $20.0 \mathrm{mM}$ Hcy after $4 \mathrm{hr}$. 


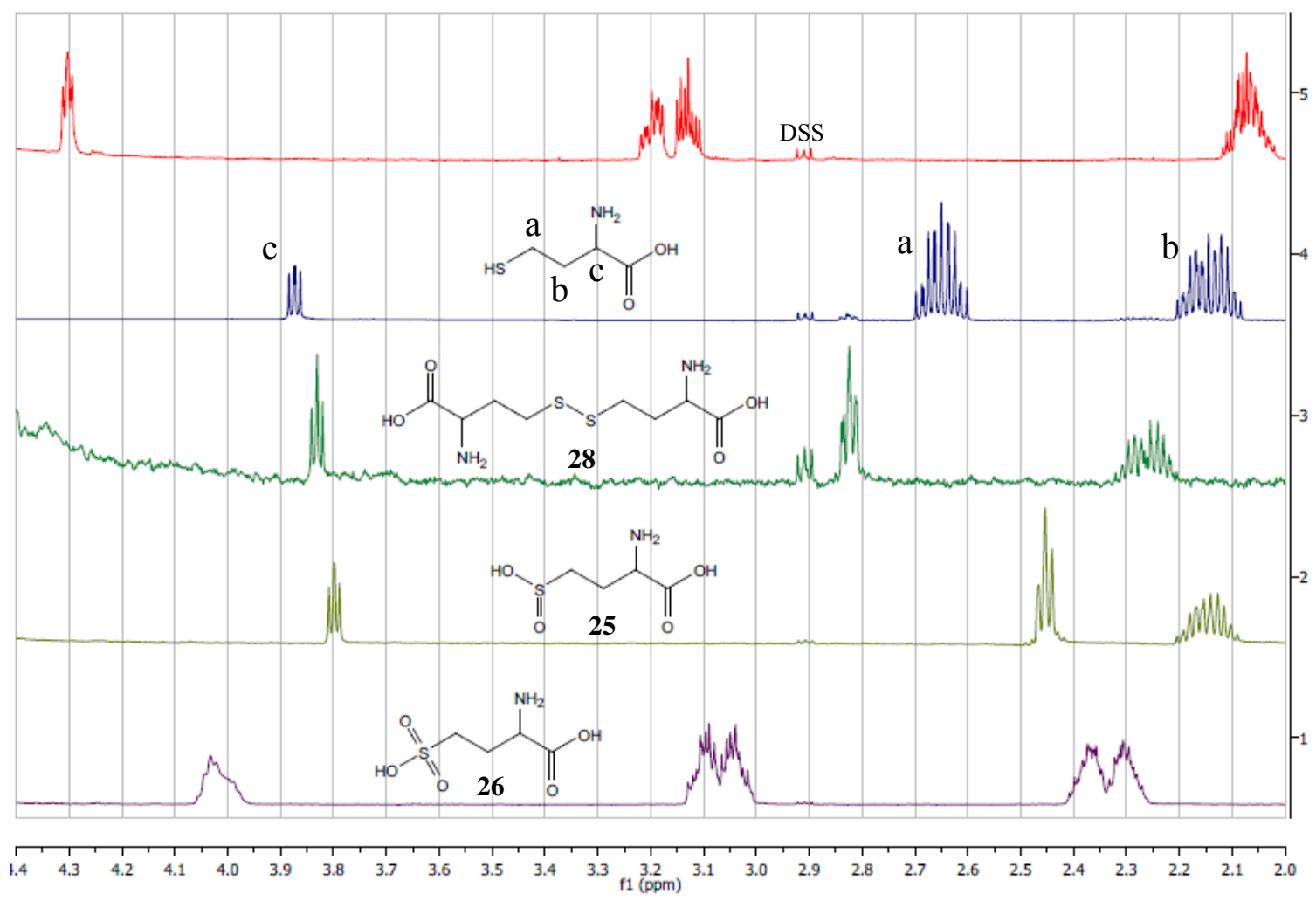

Figure 28. ${ }^{1} \mathrm{HNMR}$ of potential Hcy oxidation products. 80:20 $\mathrm{D}_{2} \mathrm{O}: \mathrm{H}_{2} \mathrm{O}$ with $100 \mathrm{mM}$ phosphate buffer pH 8.0 and DSS standard. From bottom: (lane 1) homocysteic acid, (lane 2) homocysteinesulfinic acid, (lane 3) homocystine, (lane 4) Hcy control, (lane 5) reaction of $20.0 \mathrm{mM} \mathrm{pCN}$ with $20.0 \mathrm{mM}$ Hcy after $4 \mathrm{hr}$.

${ }^{1} \mathrm{HNMR}$ spectra of the available Hcy oxidation products were compared with the Hcy peaks of the reaction mixture (Figure 28). Homocystine (28), homocysteinesulfinic acid (25), and homocysteic acid (26) were ruled out as potential reaction products since they did not produce the same shifts. Homocysteine thiolactone (29) (not shown) was also rule out by comparison of the ${ }^{1} \mathrm{HNMR}$ peaks. A notable feature in the ${ }^{1} \mathrm{HNMR}$ spectrum of the pCN and Hcy reaction mixture is the presence of the $\alpha$-amino carbon hydrogen at $4.3 \mathrm{ppm}$. The peak for the $\alpha$-amino carbon hydrogen in the reaction mixture integrated for a full hydrogen relative to the $\beta$ and $\gamma$ positions which integrated for two hydrogens each. If the probe was being reduced by the $\alpha$-amino carbon centered radical 
of Hcy, the resulting $\alpha$-amino carbocation of Hcy (1c) would be stabilized by resonance to form the Hcy iminium species (1d) and a hydrogen would not be present at the $\alpha$ position. Since this is not the case, it seems unlikely that $\mathrm{pCN}$ was reduced by electron transfer directly from the $\alpha$-amino carbon centered radical.

Instead, Hcy may facilitate radical propagation in general by interconversion of the of thiyl radical (1a) with the $\alpha$-amino carbon centered radical (1) $)$. Sterics and resonance stabilization deter geminate recombination and radical disproportionation, leading to an increase in the residence time of the carbon centered radical. The uniquely facile intramolecular HAT of Hcy provides a convenient rout to "store" and "regenerate" the thiyl radical (Figure 29). This allows greater diffusion and accumulation of radical species in solutions that contain Hcy.
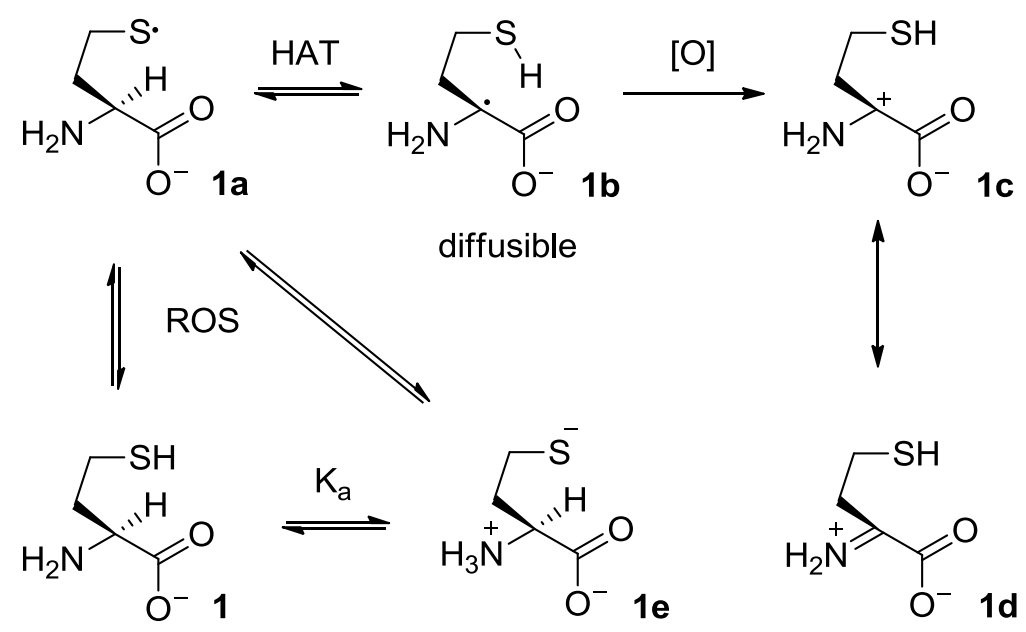

Figure 29. Interconversion of Hcy analyte species to reactive thiyl radical (1a) and thiolate anion (1e). 
4.5 Mechanism of the bridged bis-nitrile viologen probes

Electron deficient viologen dication moieties will readily accept an electron by reduction. The mechanism of Hcy detection based strictly on reduction of the probe is represented by the probe species sequence $12 \rightarrow \mathbf{1 2 c} \rightarrow \mathbf{1 2 d}$ where $12 \mathrm{c}$ is the diagnostic species with $\lambda_{\mathrm{abs}}=540 \mathrm{~nm}$ (Figure 30). If 12c is a required intermediate en route to the fully oxidized yellow species, $\mathbf{1 2 d}$; then the prevalence of $\mathbf{1 2 d}$ should also correspond to the reduction potential of analytes. However, the faster rate of increase at $\lambda_{\mathrm{abs}}=413 \mathrm{~nm}$ observed with blank solutions of probe compared to solutions with aminothiol present contradicted this mechanism (Figure 19-B).

The viologen dication moieties will also accept electrons from neighboring atoms provided they can be delocalized from the donor. Heterolytic cleavage of the methylene $\mathrm{C}-\mathrm{H}$ bond by anions in solution produces an iminium intermediate that conjugates the viologen with the nitrile substituent. The new $\mathrm{sp}^{2}$ center, positioned between two electron withdrawing groups, is electrophilic and susceptible to nucleophilic addition. A variety of transient anions in solution can interact with the probe as a base $\left(: \mathrm{B}^{-}\right)$or as a nucleophile $\left(: \mathrm{Nu}^{-}\right)$. Since the $\mathrm{pK}_{\mathrm{a}}$ of the Hcy thiol group is just $2 \mathrm{pH}$ units greater than the buffered reaction solution $\left(\mathrm{Hcy} \mathrm{S}-\mathrm{H} \mathrm{pK} \mathrm{a}_{\mathrm{a}}=10.0\right)$, the Hcy thiolate anion (1e) is an ideal candidate to drive the equilibrium of these reactions towards products. However, anion interactions with the probe following the sequence $\mathbf{1 2} \rightarrow \mathbf{1 2 b} \rightarrow \mathbf{1 2 f}$ do not produce a radical species with $\lambda_{\mathrm{abs}}=540 \mathrm{~nm}$. Products $\mathbf{1 2 b}$ and $\mathbf{1 2 f}$ are expected to appear yellow from absorptions near $400 \mathrm{~nm}$ due to the $\pi$-system conjugation. Under certain reaction conditions, peak overlap in this region of the spectrum could be discerned 
and an additional absorbtion peak was found with $\max \lambda_{\mathrm{abs}}=370 \mathrm{~nm}$ (see Appendix A, Figure 48).

Homolytic cleavage of the probe $\mathrm{C}-\mathrm{H}$ bond has the potential to result in the red radical probe species $(\mathbf{1 2} \rightarrow \mathbf{1 2 a})$ or disproportion the probe radical to the yellow species $(\mathbf{1 2 c} \rightarrow \mathbf{1 2 b})$. Similar to reactivity with anions, a variety of transient ROS in solution can propagate a radical to the probe by HAT. However, the propensity for thiols to form relatively stable thiyl radicals makes the thiyl radical a convenient agent for HAT from the probe. Thiol $\mathrm{pK}_{\mathrm{a}}$ values for Hcy, Cys, and $\mathrm{GSH}\left(\mathrm{pK}_{\mathrm{a}}=10.0,8.33\right.$, and 9.12 respectively $)^{22,56-57}$ give the order of thiolate anion/thiol ratio for theses analytes in solutions buffered at $\mathrm{pH} 8.0$ as $\mathrm{Cys}>\mathrm{GSH}>\mathrm{Hcy}$ by the Henderson-Hasselbalch equation. This relationship, interpreted as order of thiolate anion stability, insinuates a slower rate of thiyl radical formation for Cys because the sulfur atom of Cys is more effective at withdrawing electrons than GSH or Hcy. ${ }^{95}$ The comparatively higher rate of thiyl radical (1a) formation for Hcy follows the same argument. Facile intramolecular HAT for Hcy provides additional pseudo-stability for Hcy radical species by partitioning the residence time of the analyte radical between the thiyl radical (1a) and resonance stabilized $\alpha$-amino carbon radical (1b). The relative stability of $\mathbf{1 b}$ increases analyte radical half-life and the ability to regenerate the 1a radical from ancillary 'storage' results in a greater concentration of reactive thiyl species for Hcy.

Besides disproportionation of the probe, contributions to the decline of $\lambda_{\mathrm{abs}}=540$ nm observed over extended periods of time can come from the addition of a radical species, such as the Hcy thiyl radical (1a), which results in radical termination $(\mathbf{1 2 a} \rightarrow$ 
12g). Conversely, adduct formation by radical addition can result in an increase of $\lambda_{\mathrm{abs}}=$ $540 \mathrm{~nm}$ by reactions of the form $(\mathbf{1 2 b} \rightarrow \mathbf{1 2 e})$. Various combinations of radical addition, nucleophilic addition, redox interactions, and proton transfers are feasible which would account for the observed absorbance changes as the reaction progresses. A singular reaction pathway is unlikely as speciation would be governed by equilibria and highly dependent on the reaction conditions. The relationship between mixed competitiveconsecutive and parallel reactions depicted in the flow diagram of Figure 31 summarizes the dynamic evolution of probe products; however, only one arm of the bridged probe is represented. As one side of the molecule reacts, the chemistry of the local environment changes and effects reactivity on the opposing side. 

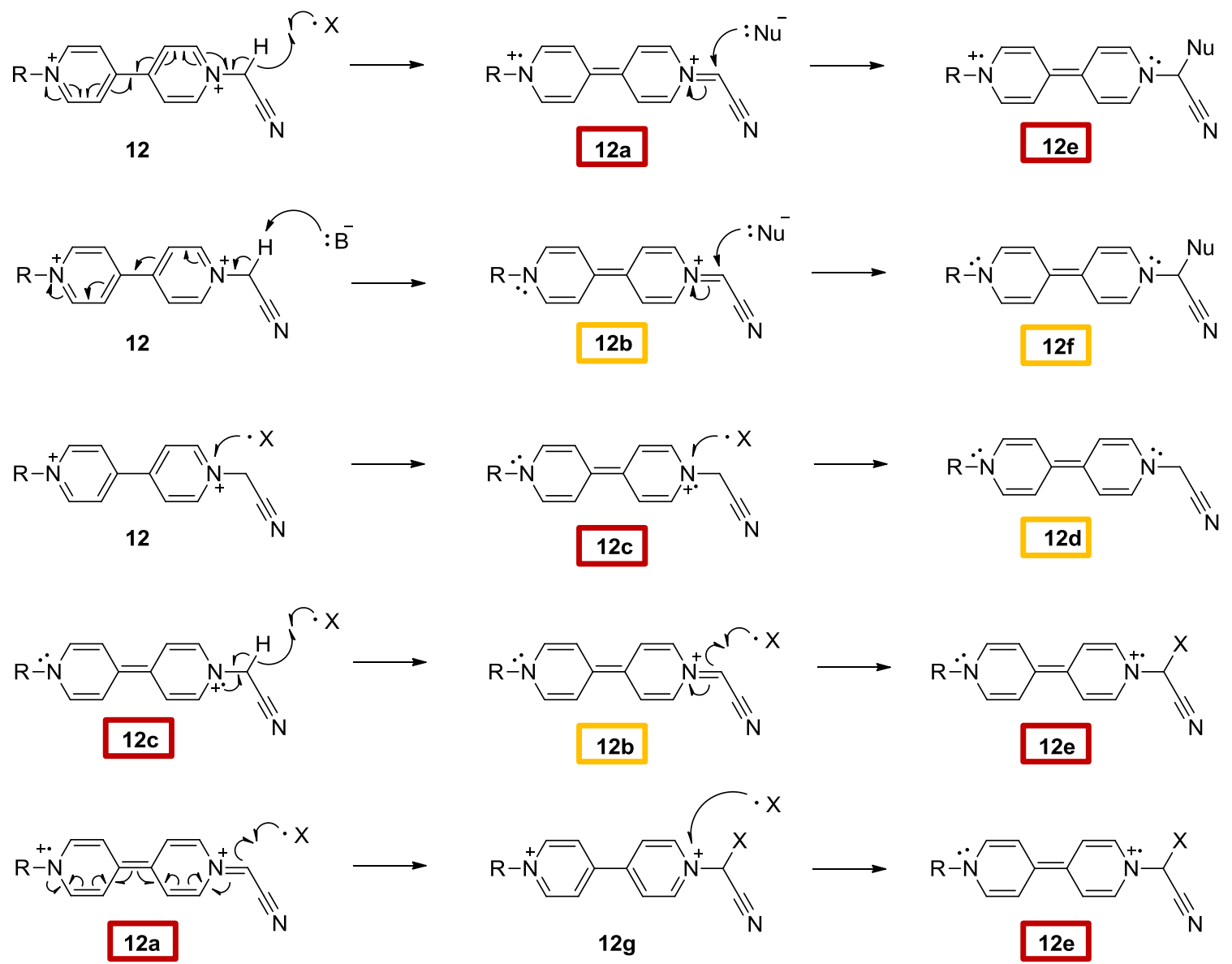

Figure 30. Reactive site of N-substituted-N'-(cyanomethyl)viologen probes.

The reaction mechanisms in Figure 30 are represented with forward reaction arrows and insinuate bimolecular transitions states. However, equilibrium and the possibility of unimolecular transitions states such as those of E1 and Sn1 type reactions are also implied. Since the $\mathrm{pK}_{\mathrm{a}}$ of the probe is lower than the $\mathrm{pH}$ of the buffered reaction, some uncoordinated proton dissociation would be expected. See Appendix A, Figure 52 for data indicating the rate of increase at $\lambda_{\mathrm{abs}}=413 \mathrm{~nm}$ is approximately first order with respect to $\mathrm{pCN}$. This reinforces the likelihood of a unimolecular transition state en route to the product(s) responsible for $\lambda_{\mathrm{abs}}=413 \mathrm{~nm}$. 


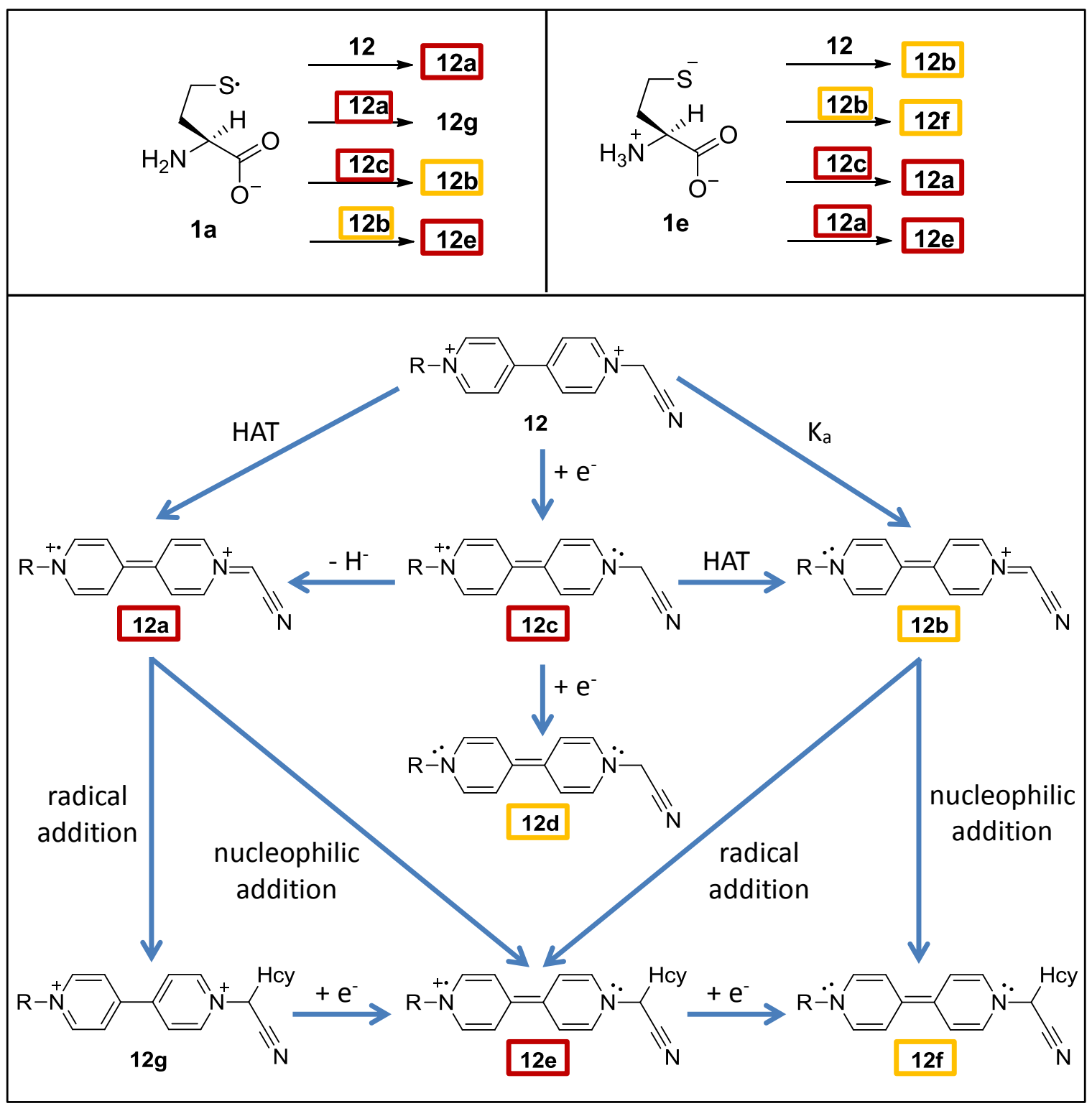

Figure 31. Dynamic evolution of probe-analyte adducts. Colored boxes assign the predicted contribution of that compound to the perceived solution color and measured $\lambda_{\text {abs. }}$ Red box: $\lambda_{\text {abs }} \approx 540 \mathrm{~nm}$. Yellow box: $\lambda_{\text {abs }} \approx 400 \mathrm{~nm}$. 


\subsection{Mass spectra of reaction products}

${ }^{1} \mathrm{HNMR}$ data discussed in Section 4.4 indicated the reaction between $\mathrm{pCN}$ and Hcy had gone to completion after 4 hours, resulting in a conspicuous major product for the $\mathrm{pCN}$ probe and a lone product for the fully converted Hcy analyte. It was thought that the large downfield shift of the hydrogen $\alpha$ to the amine of Hcy could have been caused by oxidation of the amine to an electron withdrawing nitrosamine (18) or nitro group (22). However, ions of these Hcy products as well as the other potential oxidation products shown in Figure 32 were not found in the mass specta of the reaction mixture.

Mass spectra of the reaction were obtained by two different ionization methods, electrospray ionization (ESI) and matrix-assisted laser desorption/ionization (MALDI). Refer to Section 8.3 for method details. Peaks in the spectra that were close to potential products are listed in Table 1. A peak found in the ESI spectrum at 196.08 Da was close to the $[\mathrm{M}-\mathrm{H}+2 \mathrm{Na}]^{+}$ions of oxidation products $\mathbf{2 1}, \mathbf{2 2}$, or $\mathbf{2 3}$ which were calculated to be 196.01 Da. However, better mass accuracy is obtained from probe fragment ions $\mathbf{3 8}, \mathbf{3 9}$, and 40 with $m / z=196.08,196.09$, and 196.09 Da respectively (Figure 33). There were also several peaks with masses close to various ions of oxidation product 27: $[\mathrm{M}+\mathrm{H}+\mathrm{K}]^{2+}$ 138.02 Da calculated, 138.08 Da by ESI; $[\mathrm{M}+2 \mathrm{~K}]^{2+} 156.50$ Da calculated, $157.06 \mathrm{Da}$ by ESI; [M+Na] ${ }^{+} 259.07$ Da calculated, 259.10 Da by ESI, 259.14 Da by MALDI. However, these peaks also had better mass accuracy with probe fragments $32,33, \mathbf{3 4}, \mathbf{4 4}$, and 45 with $m / z=138.06,157.06,157.08,259.11$, and 259.12 Da respectively.

Compound 29 had an ion mass similar to a peak found in the spectra: $[\mathrm{M}+2 \mathrm{Na}]^{2+} 172.51$ Da calculated, 172.07 or 172.93 Da by MALDI. Probe fragments $\mathbf{3 6}$ and $\mathbf{3 7}$ with 
calculated $m / z=172.06$ and $173.07 \mathrm{Da}$ would more accurately account for these peaks. Peaks found which were similar to those expected for ions of oxidation products $\mathbf{2 6}$ and 28 were also listed in Table 1, though neither was considered to represent the Hcy reaction product based on previous elimination by ${ }^{1} \mathrm{HNMR}$ comparisons (Figure 28).<smiles>NC1CCSC1=O</smiles>

19<smiles>NC(CC[SH]=O)C(=O)O</smiles>

22<smiles>O=NC(CCS)C(=O)O</smiles>

20<smiles>O=C(O)C(CCS)NO</smiles>

23<smiles>NC(CCSO)C(=O)O</smiles>

21<smiles>O=C(O)C(CCS)[N+](=O)[O-]</smiles>

24<smiles>NC(CCS(=O)O)C(=O)O</smiles>

25<smiles>NC(CCSSCCC(N)C(=O)O)C(=O)O</smiles>

28<smiles>NC(CCS(=O)(=O)O)C(=O)O</smiles>

26<smiles>NC(CCSCCC(N)C(=O)O)C(=O)O</smiles>

27

Figure 32. Structures of Hcy oxidation products.<smiles>NC(CCS(=O)S(=O)CCC(N)C(=O)O)C(=O)O</smiles> 
Table 1. Various salts and ionization states of Hcy oxidation products with potential mass spec signal. Calculated $\mathrm{m} / \mathrm{z}$ for ionic species indicated by parenthesis. NF $=$ not found; $\mathrm{E}=$ peak found in MS obtained by electrospray ionization; $\mathrm{D}=$ peak found in MS obtained by Matrix-assisted laser desorption/ionization. Rows that are shaded correspond to compounds which have been ruled out as reaction products based ${ }^{1} \mathrm{HNMR}$.

\begin{tabular}{|c|c|c|c|c|c|c|c|}
\hline \# & Mass & {$[\mathbf{M}+\mathbf{H}]^{+}$} & {$[\mathbf{M}+\mathbf{K}]^{+}$} & {$[\mathrm{M}-\mathrm{H}+\mathbf{2 K}]^{+}$} & {$[\mathbf{M}+\mathbf{N a}]^{+}$} & ${ }_{[\mathrm{M}-\mathrm{H}+2 \mathrm{Na}]^{+}}$ & {$[\mathrm{M}-\mathrm{H}+\mathrm{K}+\mathrm{Na}]^{+}$} \\
\hline 1 & 135.04 & NF & $\begin{array}{l}(174.00) \\
173.98 \mathrm{E}\end{array}$ & NF & NF & NF & NF \\
\hline 19 & 117.03 & $\mathrm{NF}$ & & & & & \\
\hline 20 & 149.01 & $\mathrm{NF}$ & $\mathrm{NF}$ & $\mathrm{NF}$ & $\mathrm{NF}$ & $\mathrm{NF}$ & $\mathrm{NF}$ \\
\hline 21 & 151.03 & NF & $\mathrm{NF}$ & NF & NF & $\begin{array}{l}(196.01) \\
196.08 \mathrm{E}\end{array}$ & NF \\
\hline 22 & 151.03 & $\mathrm{NF}$ & NF & NF & NF & $\begin{array}{l}(196.01) \\
196.08 \mathrm{E}\end{array}$ & $\mathrm{NF}$ \\
\hline 23 & 151.03 & NF & NF & $\mathrm{NF}$ & $\mathrm{NF}$ & $\begin{array}{l}(196.01) \\
196.08 \mathrm{E}\end{array}$ & NF \\
\hline 24 & 165.01 & $\mathrm{NF}$ & $\mathrm{NF}$ & $\mathrm{NF}$ & $\mathrm{NF}$ & NF & NF \\
\hline 25 & 167.03 & NF & $\mathrm{NF}$ & $\mathrm{NF}$ & $\mathrm{NF}$ & NF & NF \\
\hline 26 & 183.02 & NF & NF & $\begin{array}{l}(259.95) \\
260.15 \mathrm{D}\end{array}$ & $\mathrm{NF}$ & NF & NF \\
\hline 27 & 236.08 & NF & $\mathrm{NF}$ & $\mathrm{NF}$ & $\begin{array}{l}(259.07) \\
259.14 \mathrm{D} \\
259.10 \mathrm{E}\end{array}$ & $\mathrm{NF}$ & $\mathrm{NF}$ \\
\hline 28 & 268.06 & $\mathrm{NF}$ & NF & $\mathrm{NF}$ & $\begin{array}{l}(291.04) \\
291.15 \mathrm{E}\end{array}$ & NF & $\mathrm{NF}$ \\
\hline 29 & 300.05 & $\mathrm{NF}$ & $\mathrm{NF}$ & $\mathrm{NF}$ & $\mathrm{NF}$ & $\mathrm{NF}$ & $\mathrm{NF}$ \\
\hline
\end{tabular}

\begin{tabular}{|c|c|c|c|c|c|c|}
\hline$\#$ & {$[\mathrm{M}+2 \mathrm{H}]^{2+}$} & {$[\mathrm{M}+\mathrm{H}+\mathrm{K}]^{2+}$} & {$[\mathrm{M}+2 \mathrm{~K}]^{2+}$} & {$[\mathrm{M}+\mathrm{H}+\mathrm{Na}]^{2+}$} & {$[\mathrm{M}+2 \mathrm{Na}]^{2+}$} & {$[\mathrm{M}+\mathrm{K}+\mathrm{Na}]^{2+}$} \\
\hline \multirow[t]{2}{*}{27} & & (138.02) & $(156.50)$ & & & \\
\hline & NF & $138.08 \mathrm{E}$ & $157.06 \mathrm{E}$ & $\mathrm{NF}$ & $\mathrm{NF}$ & NF \\
\hline \multirow[t]{2}{*}{28} & & & $(172.49)$ & & $(156.52)$ & \\
\hline & NF & $\mathrm{NF}$ & $172.93 \mathrm{D}$ & $\mathrm{NF}$ & $157.06 \mathrm{E}$ & $\mathrm{NF}$ \\
\hline 29 & $\mathrm{NF}$ & NF & $\mathrm{NF}$ & NF & $\begin{array}{l}(172.51) \\
172.07 \mathrm{D} \\
172.93 \mathrm{D}\end{array}$ & NF \\
\hline
\end{tabular}

The only ion peak in Table 1 that did not have a corresponding probe fragment with better mass accuracy belonged to non-oxidized Hcy (1) $[\mathrm{M}+\mathrm{K}]^{+} 174.00 \mathrm{Da}$ calculated, $173.98 \mathrm{Da}$ by ESI. This signal had low relative abundance and could have been produced by fragmentation during analysis. Most importantly, the ions responsible for the base peaks of both spectra (314.09 Da by ESI and 314.12 by MALDI) was determined to arise from the parent ion 49 and related isoelectric tautomers such as ion 
48, each with $m / z=314.12 \mathrm{Da}$. A comprehensive list of ions identified in the mass spectra can be found in Appendix A, Table 3 with associated structures in Figure 53 and Figure 54. These ions confirm the identity of the Hcy reaction product shown in Lane 5 of Figure 28 as a thioether adduct with the $\mathrm{pCN}$ probe. The ${ }^{1} \mathrm{HNMR}$ peak shifts for the Hcy adduct, particularly the downfield shift observed with the $\alpha$-amino proton, was attributed primarily to the extreme chemical environment localized to the probe with some inductive contributions through the thioether linkage. Ions with distinct $\mathrm{m} / \mathrm{z}$ corresponding to Hcy adducts bonded by a secondary amine, ether, ester, or at the carbonyl carbon were not found in the mass spectra. 


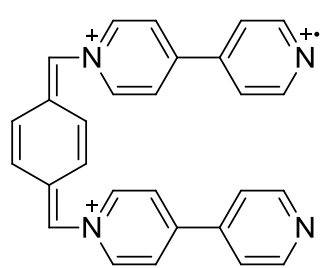

32
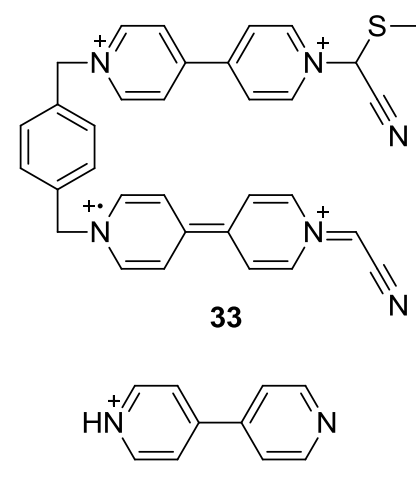

34

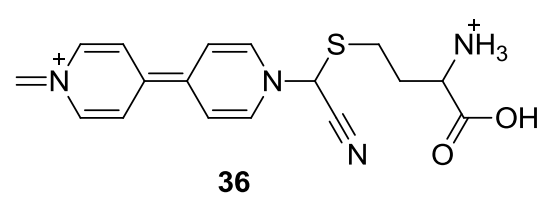

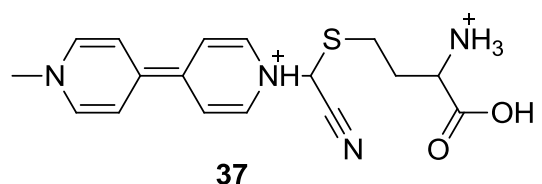
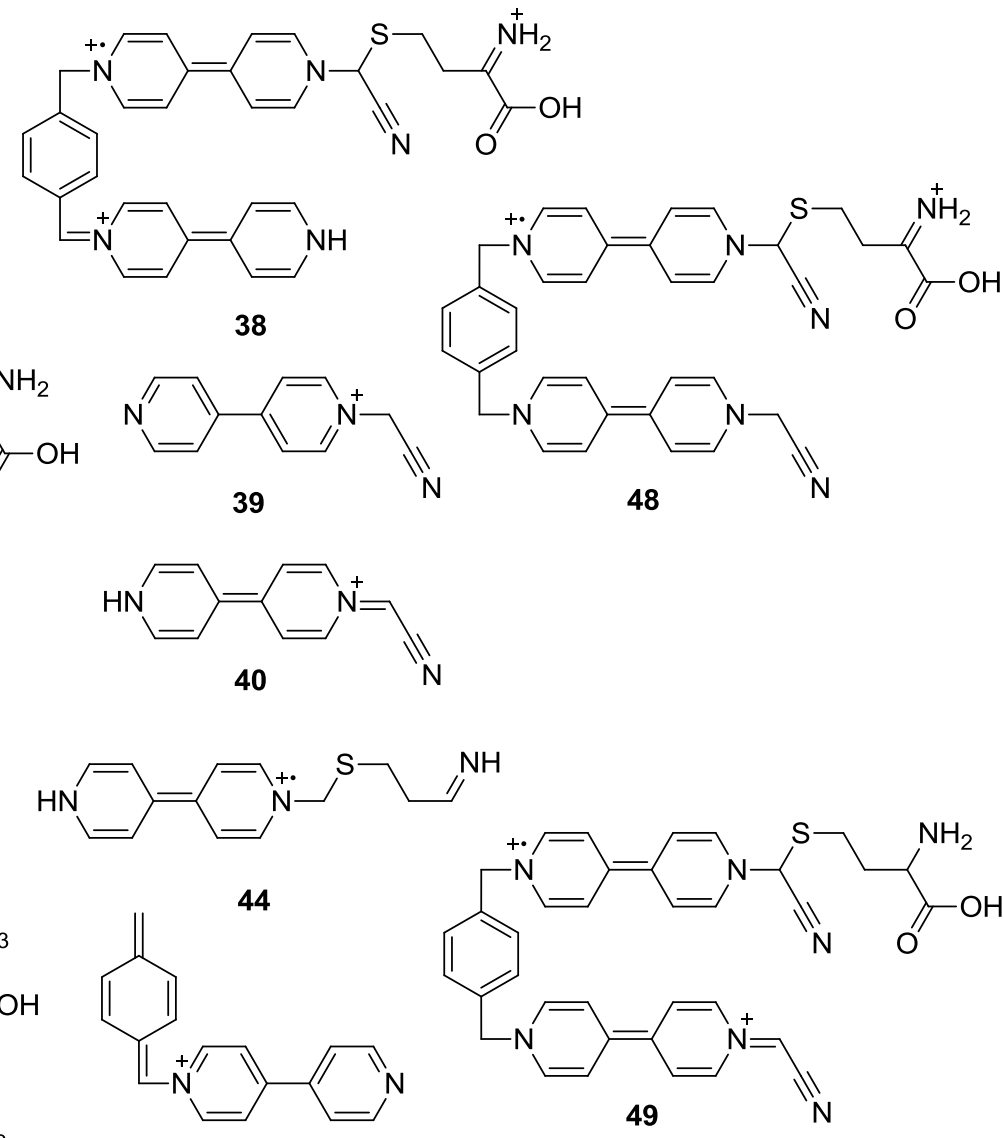

Figure 33. Structures of selected ions identified in the mass spectra of the $\mathrm{pCN}$ and Hcy reaction mixture (for additional structures see Appendix A, Figure 53, Figure 54, and Table 3). 
Chapter 5: Preliminary survey of bridged bis-coumarin viologens Analogs of the bridged viologen probe were synthesized by replacing the methylene-nitrile substituent with 3-acetylcoumarin (Figure 34). Coumarin is a common chromophore scaffold used in fluorescent brighteners and laser dyes due to its tunable absorbance and fluorescence properties. ${ }^{96}$ Molecular modeling showed ordered stacking of the two fluorescent acetylcoumarin moieties for the para-bridged bis-coumarin viologen $(\mathrm{pAC}, \mathbf{1 5})$ in its lowest energy conformation. The stacked fluorophore were predicted to quench each other in this conformation due to the small separation, $\sim 3.3 \AA$. Analyte interactions with the probes would increase the distance between the fluorophores and lead to changes in the fluorescence spectrum. These conformational changes could be induced by supramolecular interactions, such as the binding of GSH within the cavity of $\mathrm{pAC}$, or by reactions with the probe, such as the straightening and rotation of pyridine rings upon reduction of the viologens.
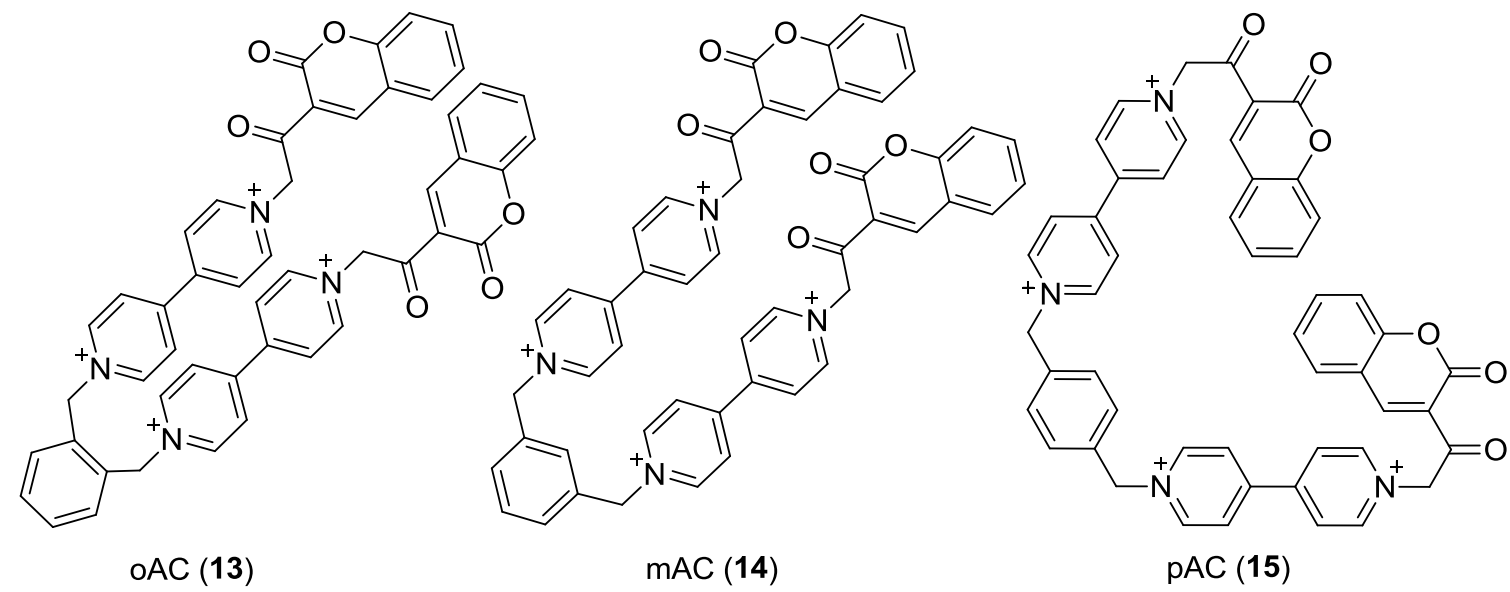

Figure 34. Structures of the bridged bis-coumarin viologen probes. Positional isomers: $\mathrm{oAC}(\mathbf{1 3})=$ ortho, $\mathrm{mAC}(\mathbf{1 4})=$ meta, and $\mathrm{pAC}(\mathbf{1 5})=$ para . 
Fluorescence excitation $\left(\lambda_{\mathrm{ex}}\right)$ and emission $\left(\lambda_{\mathrm{em}}\right)$ wavelengths for coumarins similar in structure to the acetylcoumarin substituent used here have been reported near $\lambda_{\mathrm{ex}} / \lambda_{\mathrm{em}}=320 / 440 \mathrm{~nm} .{ }^{97}$ Each of the bridged bis-coumarin viologen probes were found to fluoresce at $\lambda_{\mathrm{ex}} / \lambda_{\mathrm{em}}=345 / 460 \mathrm{~nm}$ in the absence of aminothiol analyte. This blueshifted $\lambda_{\text {ex }} / \lambda_{\text {em }}$ was assigned to the acetylcoumarin substituents and monitored for spectral changes with the addition of aminothiol analytes. Preliminary trials using mAC or pAC in phosphate buffer with analytes Hcy, Cys, and GSH did not result in a selective change in intensity at $\lambda_{\mathrm{em}}=460 \mathrm{~nm}$ for any particular analyte.

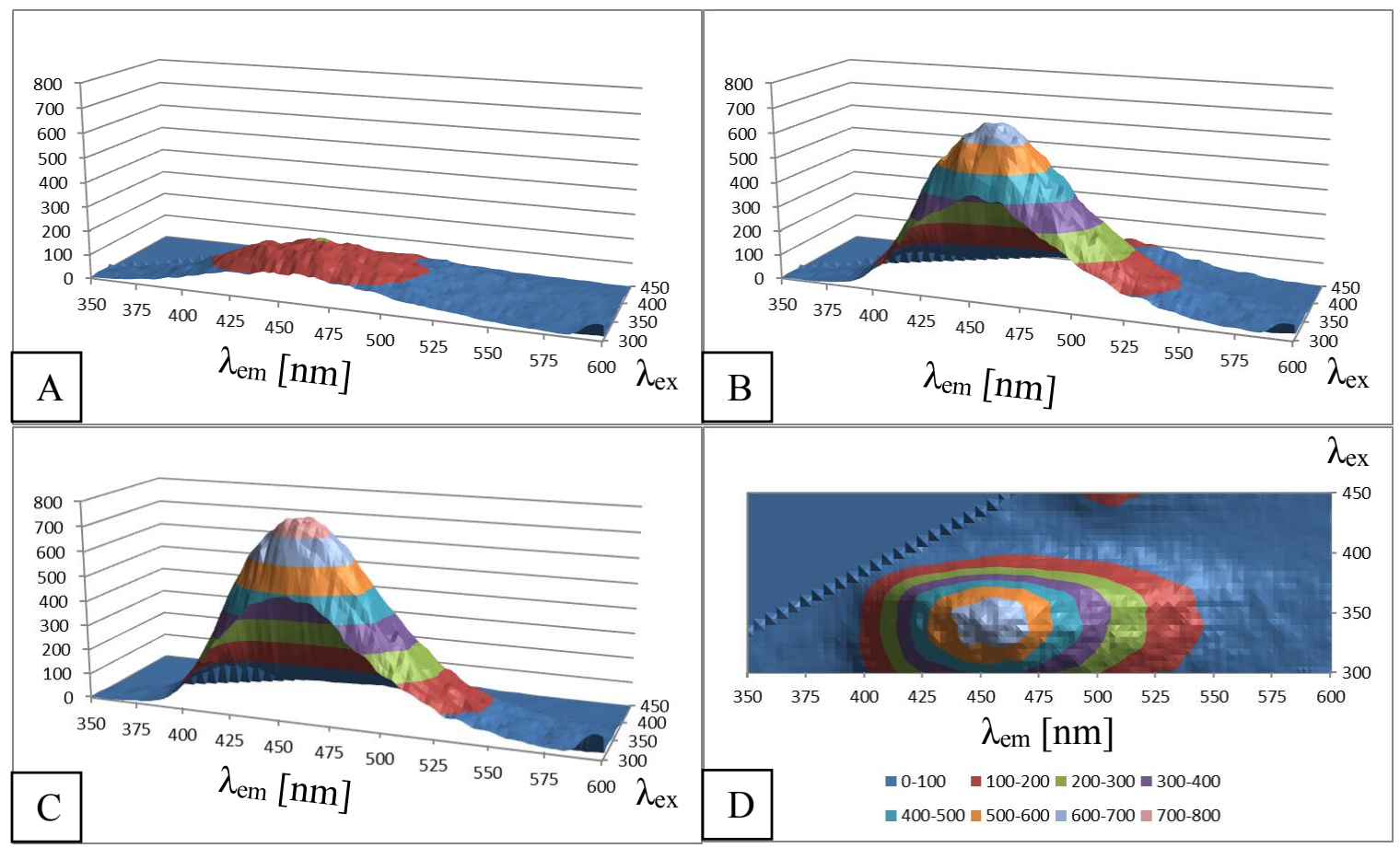

Figure 35. Fluorescence of the acetylcoumarin was quenched with isomer oAC. EEM spectra of $50.0 \mu \mathrm{M}$ probe after $1 \mathrm{hr}$ in $80.0 \mathrm{mM}$ phosphate buffer at $\mathrm{pH} 6.0$ without analyte. $\lambda_{\mathrm{em}}$ intensity did not change significantly over time. $\operatorname{Max} \lambda_{\mathrm{ex}} / \lambda_{\mathrm{em}}=345 / 460 \mathrm{~nm}$. (A) oAC. (B) mAC. (C) pAC. (D) 2D view of mAC topology.

For the oAC probe fluorescence at $\lambda_{\mathrm{ex}} / \lambda_{\mathrm{em}}=345 / 460 \mathrm{~nm}$ was significantly quenched, regardless of the presence of aminothiols (Figure 35). A survey of $\lambda_{\text {ex }}$ revealed 
fluorescence at $\lambda_{\mathrm{ex}} / \lambda_{\mathrm{em}}=405 / 500 \mathrm{~nm}$ that was found to have $\mathrm{pH}$ dependent selectivity for Cys (Figure 36). Probes $\mathrm{mAC}$ and $\mathrm{pAC}$ did not fluoresce at these wavelengths under the same conditions. However, a selective fluorescence response in the presence of Hcy was found for $\mathrm{mAC}$ at $\lambda_{\mathrm{ex}} / \lambda_{\mathrm{em}}=485 / 510 \mathrm{~nm}$. With $\mathrm{mAC}$, the rate of increase at $\lambda_{\mathrm{em}}=510 \mathrm{~nm}$ in the presence of Hcy did not abate during the first hour of data collection, requiring more than 12 hrs to level-off (Figure 37).

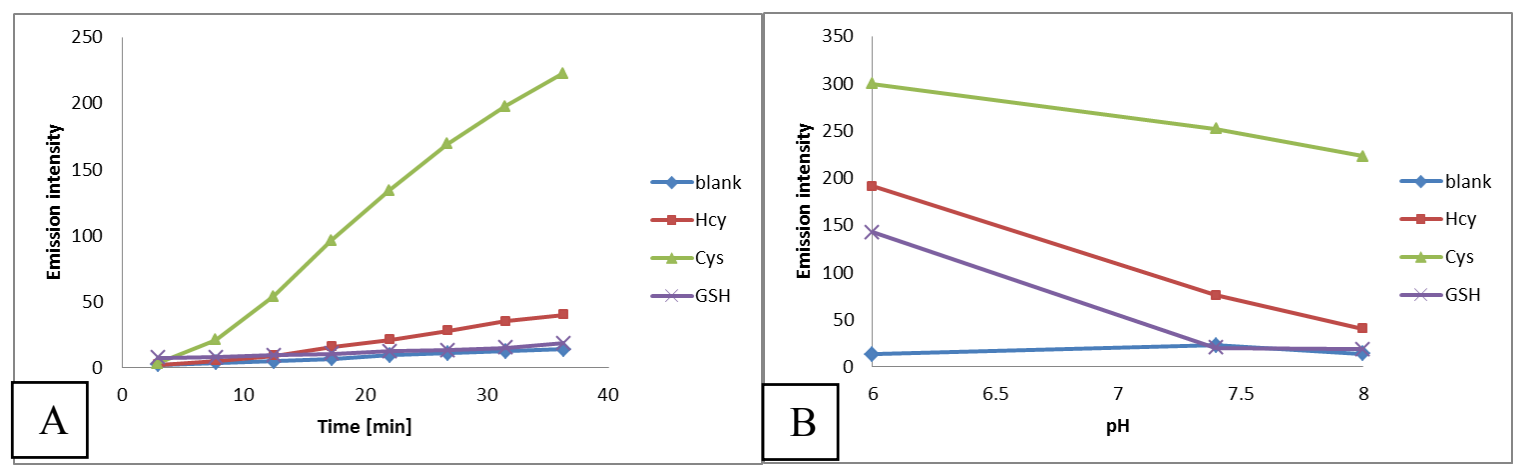

Figure 36. $\lambda_{\text {ex }} / \lambda_{\mathrm{em}}=405 / 500 \mathrm{~nm}$. $50.0 \mu \mathrm{M}$ oAC in $80.0 \mathrm{mM}$ phosphate buffer with 200 $\mu \mathrm{M}$ of the indicated thiol. (A) $\lambda_{\mathrm{em}}=500 \mathrm{~nm}$ at $\mathrm{pH} 8.0$ over $35 \mathrm{~min}$. (B) $\mathrm{pH}$ dependent response to analytes at 35 min time point. Figure 56 in Appendix A provides an example of the topography for this peak.

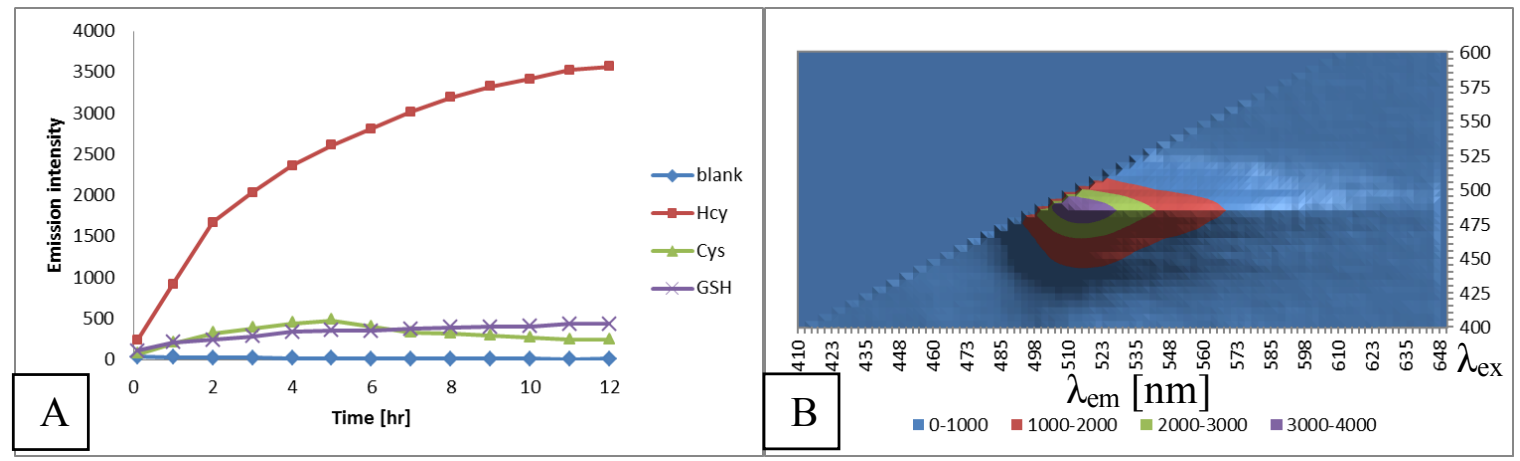

Figure 37. $\lambda_{\mathrm{ex}} / \lambda_{\mathrm{em}}=485 / 510 \mathrm{~nm}$. $50.0 \mu \mathrm{M} \mathrm{mAC}$ in $80.0 \mathrm{mM}$ phosphate buffer $\mathrm{pH} 6.0$ with $200 \mu \mathrm{M}$ of the indicated thiol. (A) $\lambda_{\mathrm{em}}=510 \mathrm{~nm}$ over $12 \mathrm{hrs}$. (B) Surface plot of Hcy at $12 \mathrm{hr}$ point. See Appendix A, Figure for surface plots of the blank, Cys, and GSH.

Curiously, similar UV/Vis absorbance spectra were observed for all three positional isomers of the probe. In phosphate buffer at $\mathrm{pH} 8.0$ the absorbances were 
essentially stable over the course of an hour; only negligible deviations were measured. The strongest absorbance was increasing over time with a $\max \lambda_{\text {abs }}=260 \mathrm{~nm}$. There was an isobestic point at $300 \mathrm{~nm}$ which enunciated a shoulder vanishing from side the main peak. Isobestic points at 405 and $452 \mathrm{~nm}$ marked the inflections of a small increase at $\lambda_{\mathrm{abs}}=420 \mathrm{~nm}$ and another decrease at $\lambda_{\mathrm{abs}}=540 \mathrm{~nm}$. Figure 38 illustrates the minor changes in absorbance observed for oAC (with and without Cys analyte) under the same reaction conditions that produced a fluorescence response for Cys at $\lambda_{\mathrm{ex}} / \lambda_{\mathrm{em}}=405 / 500$ $\mathrm{nm}$ nearly 50 times greater than the probe without analyte. Contrary to what would be expected, $\lambda_{\mathrm{ex}}=405 \mathrm{~nm}$ for $\mathrm{oAC}$ is at a low absorbance isobestic point in the UV/Vis spectra. Although, absorbance in this area was observed to increase rapidly with the bridged nitrile analogs (Figure 19). 


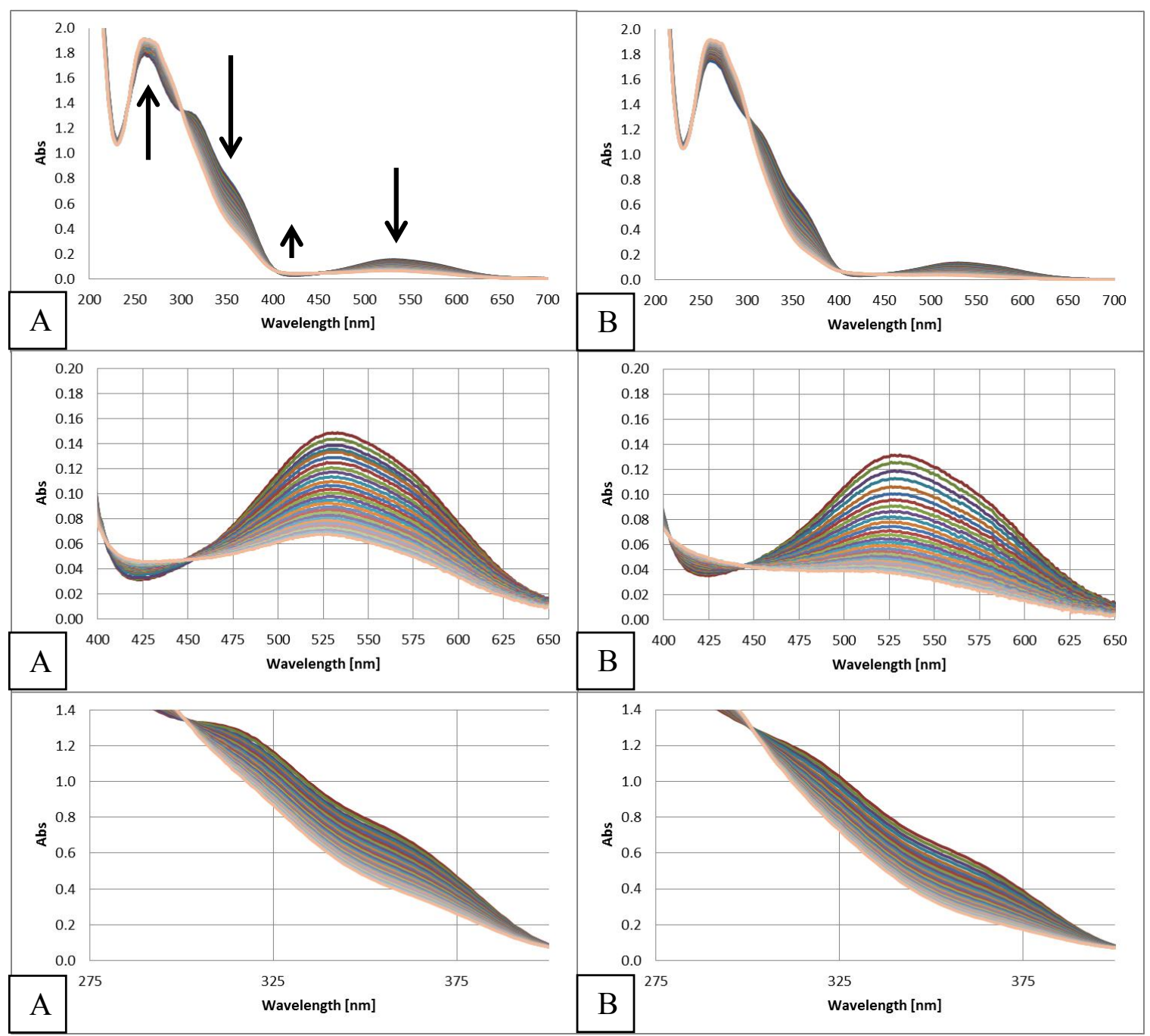

Figure 38. Absorbance spectrum of $50.0 \mu \mathrm{M}$ oAC in $80.0 \mathrm{mM}$ phosphate buffer $\mathrm{pH} 6.0$ over $1 \mathrm{hr}$ with a scan every $2 \mathrm{~min}$. Expanded views retain the same label: (A) without analyte. (B) with $200 \mu \mathrm{M}$ Cys.

Another interesting aspect of the absorbance spectra of the bridged bis-coumarin viologens was the decrease at $\lambda_{\mathrm{abs}}=540 \mathrm{~nm}$ that corresponded to $\lambda_{\mathrm{abs}}$ of the diagnostic peak for the bridged bis-nitrile viologen probes. Furthermore, the bridged bis-nitrile viologen probes were found to fluoresce at $\lambda_{\mathrm{ex}} / \lambda_{\mathrm{em}}=480 / 510 \mathrm{~nm}$. This fluorescence corresponded to $\lambda_{\mathrm{ex}} / \lambda_{\mathrm{em}}$ of the $\mathrm{mAC}$ probe, implicating the viologen moieties as the 
fluorophore in $\mathrm{mAC}$ and providing a possible explanation for the selective response observed with Hcy (Figure 57).

Coumarin chromophores are known to act as radical initiators and photosensitizers. ${ }^{96,98-100}$ Since $\lambda_{\mathrm{em}} \approx 510 \mathrm{~nm}$ for the bridged bis-nitrile viologens, $\mathrm{mAC}$, and $\mathrm{oAC}$; the fluorescence of oAC might be explained by photosensitization of the viologen by acetylcoumarin. A charge transfer mechanism of fluorescence from the acetylcoumarin chromophores to the viologen of oAC before emission of a photon is supported by the quenching of acetylcoumarin fluorescence at $\lambda_{\mathrm{em}}=460 \mathrm{~nm}$, just $20 \mathrm{~nm}$ away from $\lambda_{\text {ex }}$ observed for the viologens. Close spatial arrangement of the oAC probe arms might allow this energy gap to be overcome. 


\section{Chapter 6: Conclusions}

Fluorometric and colorimetric responses of the bridged viologen probes to aminothiol analytes are dependent on reaction conditions such as $\mathrm{pH}$, buffer identity, ratio of solvent, ionic strength of the solution, and reaction time. Compared to the other aminiothiols, Cys and GSH, facile interconversion of Hcy between its thiyl radical and $\alpha$ amino carbon centered radical species allows greater accumulation of analyte radical species and subsequent propagation to the probe. The resulting radical cations of the bridged bis-nitrile probes are stabilized by pimerization with $\lambda_{\text {abs }} \approx 540 \mathrm{~nm}$ attributed to $\mathrm{P}_{2}$ type pimers. Biological concentrations of Hcy can be detected selectively in deproteinized plasma buffered with phosphate to $\mathrm{pH} 8.0$ by measuring the increase in $\lambda_{\mathrm{abs}}$ $=540 \mathrm{~nm}$ of the $\mathrm{pCN}$ probe $(\mathrm{LOD}=2.17 \mu \mathrm{M}$ and $\mathrm{LOQ}=6.10 \mu \mathrm{M})$. The mechanism of reactivity between $\mathrm{pCN}$ and Hcy also involves cleavage of the probe's labile $\mathrm{C}-\mathrm{H}$ bond vicinal to the nitrile group, followed by either radical or nucleophilic addition of Hcy to form the thioether adduct.

Differences in colorimetric response of for positional isomers of the xylene bridge were subtle with the bridged bis-nitrile viologen probes. The short ortho linkage of oCN led to a slight increase in reactivity and broadening of the diagnostic $\lambda_{\text {abs }}$ accompanied by a $10 \mathrm{~nm}$ redshift. Preliminary fluorometric results with the bridged bis-coumarin analogs revealed different $\lambda_{\text {ex }} / \lambda_{\text {em }}$ profiles for each positional isomer and $\mathrm{pH}$ dependent responses to analytes. Selective increases in $\lambda_{\mathrm{em}}$ were observed for Hcy using $\mathrm{mCN}$ at $\mathrm{pH} 6.0$ with $\lambda_{\mathrm{ex}} / \lambda_{\mathrm{em}}=485 / 510 \mathrm{~nm}$ and for Cys using oCN at pH 8.0 with $\lambda_{\mathrm{ex}} / \lambda_{\mathrm{em}}=405 / 500 \mathrm{~nm}$. These responses did not correspond to the expected $\lambda_{\mathrm{ex}} / \lambda_{\mathrm{em}}$ for acetylcoumarin, suggesting 
involvement of the viologen moieties in the fluorescence mechanism. Thorough studies of the bridged bis-coumarin viologen probes concerning optimization of the reaction conditions, elucidation of the mechanism, and assessment of tolerance to interferences will provide crucial information for the next generation of fluorophore-viologen probes. 


\section{Chapter 7: Experimental Methods}

7.1 Reaction schemes

The synthetic strategy for target compounds oCN (10), mCN (11), pCN (12), mAC (14), and pAC (15) was adapted from the method used by Geuder et al. to synthesize bridged viologen compounds (Figure 39 and Figure 40). ${ }^{77}$ This method was low yielding in the final alkylation step. Attempts to optimize reactant ratios and reflux time gave similar results. The final alkylation failed repeatedly for the target compound oAC (13). An unidentified product was consistently isolated from the reaction mixture in high purity and yield. The total ${ }^{1} \mathrm{HNMR}$ integration did not agree with the target compound but did indicate a possible coumarin dimer. ${ }^{96}$ Presumably, sterics would not allow the attachment of a second large acetylcoumarin moiety to a viologen bridge constrained in the ortho position. By reversing the order of the reaction scheme, the synthesis of oAC was achieved more efficiently and with a higher yield than the other isomers (Figure 41). BNV (16) was synthesized expediently and with high yield using microwave irradiation by adapting the method used by Lamberto et al. to synthesize asymmetrically substituted viologens (Figure 42). ${ }^{101}$ A mixture of $\mathrm{Br}^{-}$and $\mathrm{PF}_{6}{ }^{-}$salts precipitated from the reaction solvent. The first crop of BNV filtered from the solvent was water soluble. After reducing the solvent volume under vacuum, a second crop of BNV was obtained that had the same ${ }^{1} \mathrm{HNMR}$ spectra and reactivity as the first batch, yet was only slightly soluble in water. It was thought that the first crop had a higher ratio of $\mathrm{PF}_{6}{ }^{-}$counterions which made it less soluble in the reaction solvent and more soluble in water. 


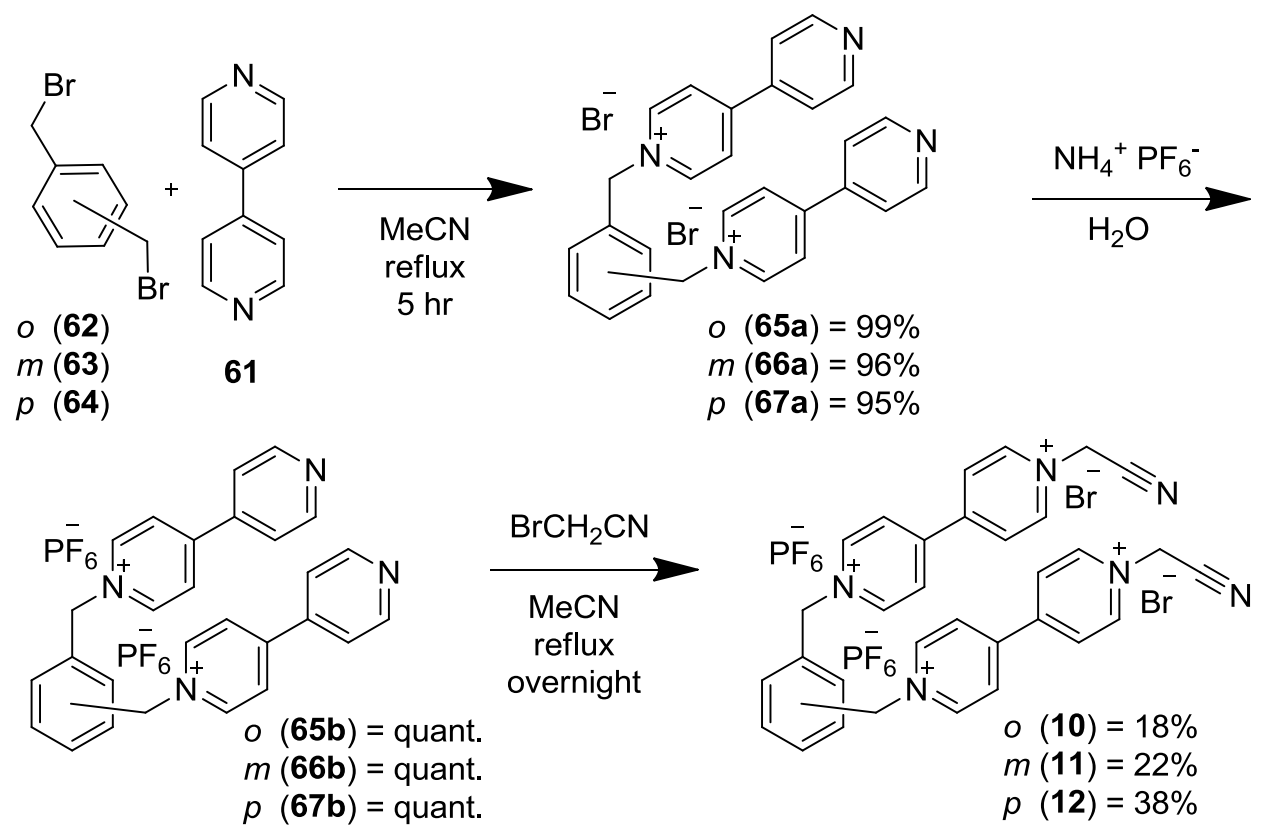

Figure 39. Reaction scheme for bridged viologen bis-nitrile compounds. Using isomerically pure starting material give an isomerically pure product. Overall yields: $18 \%$ oCN (10), $21 \%$ mCN (11), and 36\% pCN (12). 


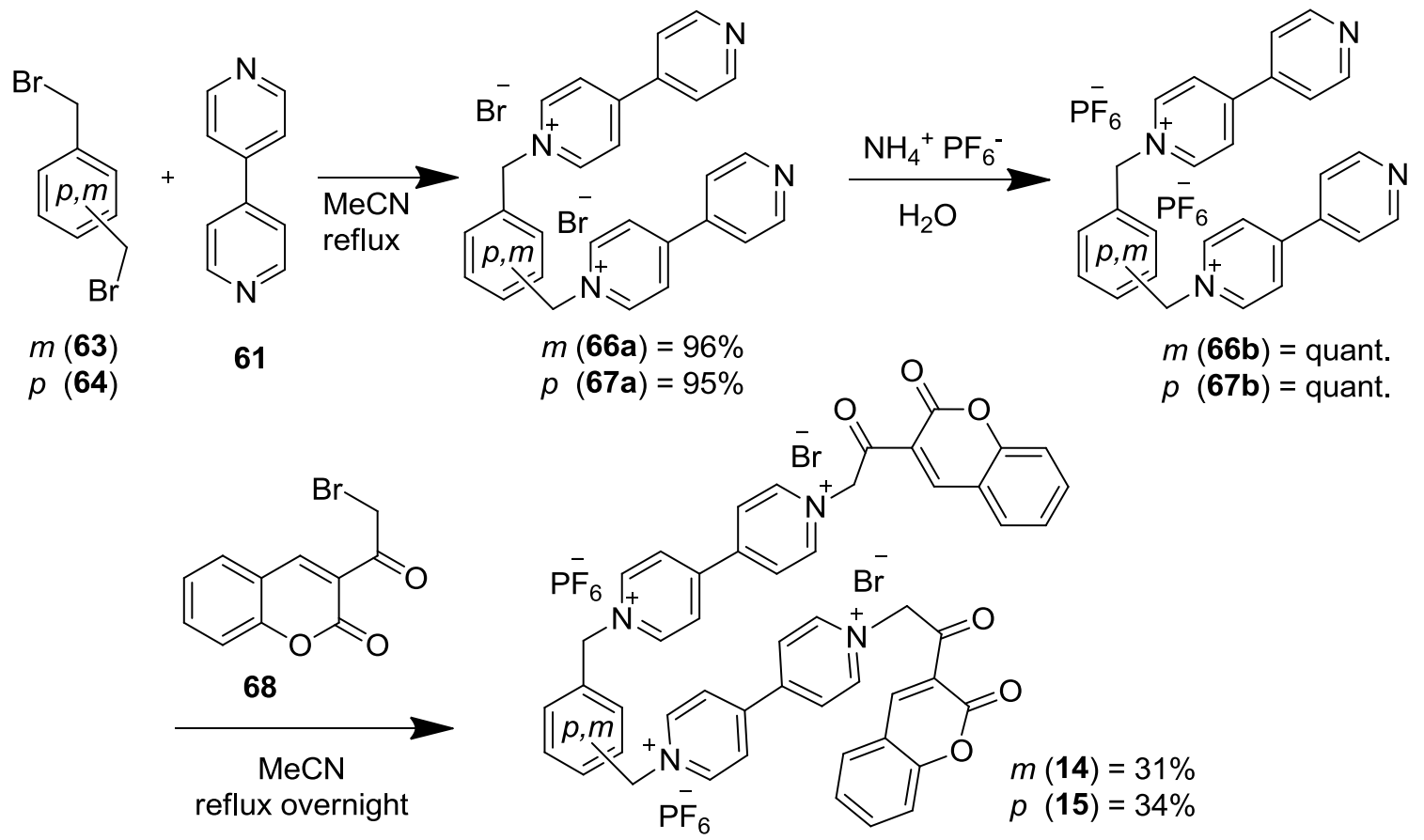

Figure 40. Reaction scheme for meta- and para- bridged viologen bis-coumarin. This scheme failed repeatedly with for the ortho isomer, target compound oAC. Overall yields: 30\% $\mathrm{mAC}(\mathbf{1 4})$ and $32 \% \mathrm{pAC}$ (15).

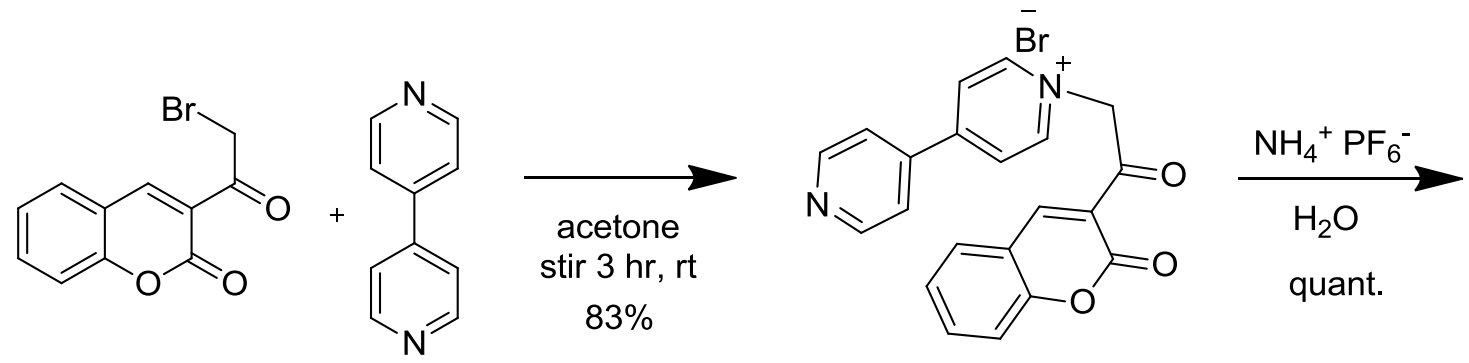

68

61

$69 a$<smiles>O=C(C[n+]1ccc(-c2ccncc2)cc1)c1cc2ccccc2oc1=O</smiles>

$69 \mathrm{~b}$

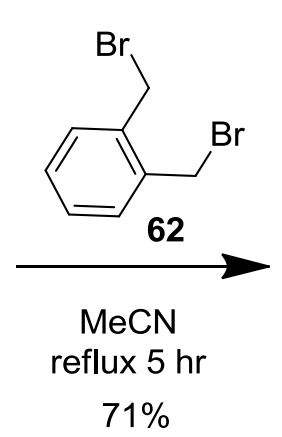

$71 \%$<smiles>CC(=O)OC[n+]1ccc(-c2cc[n+](Cc3ccccc3C[n+]3ccc(-c4cc[n+](CC(=O)c5cc6ccccc6oc5=O)cc4)cc3)cc2)cc1</smiles>

Figure 41. Reaction scheme for oAC (13). 59\% overall yield. 


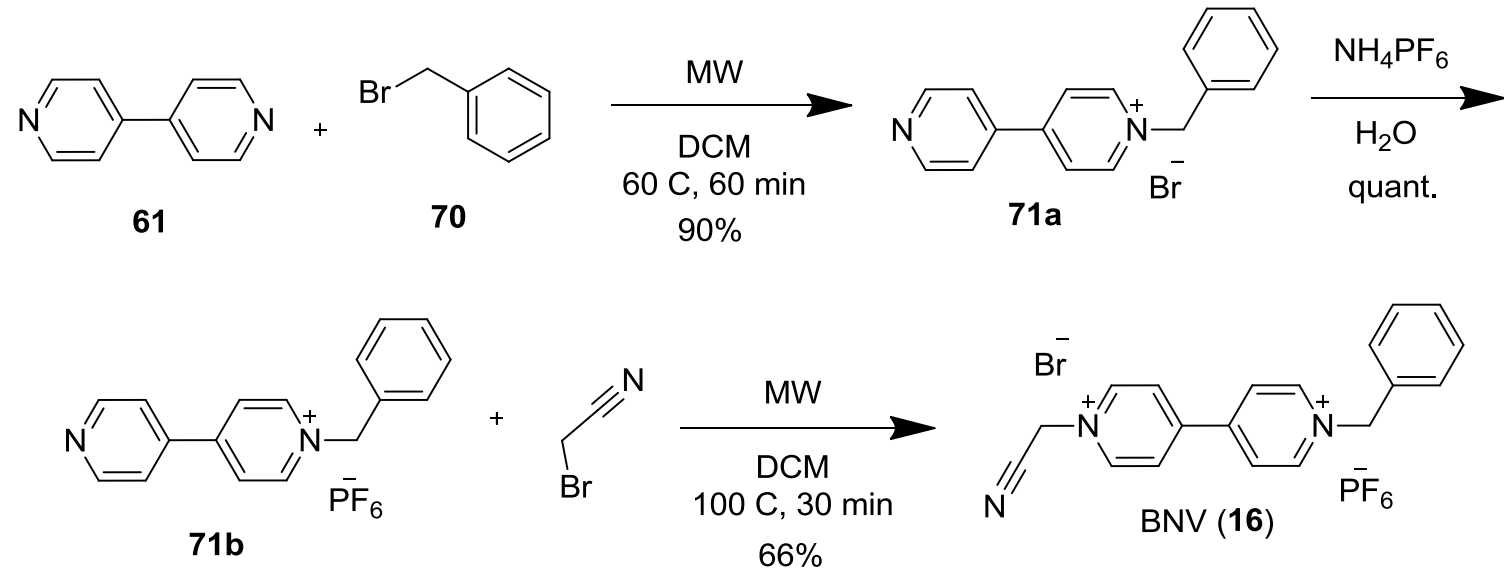

Figure 42. Reaction scheme for BNV (16). 59\% overall yield.

\subsection{Protocols}

The procedure for screening in buffer was performed as follows:

Reduced Hcy, Cys, and GSH with purities $\geq 98.0 \%$ were purchased from Sigma-

Aldrich. Stock solutions of the probe, homocysteine, cysteine, glutathione were prepared fresh using ultra-pure water (UPW). Buffer solutions were prepared with UPW and were kept no longer than a month. Mixing of the solutions was carried out in $4 \mathrm{~mL}$ sample vials. The volumes of each stock solution needed to achieve the appropriate concentrations in $1.00 \mathrm{~mL}$ of total volume were calculated. The volume of UPW necessary to fill the remainder of the total sample volume was also calculated. Then the initial order of addition of to an empty sample vial was: UPW, stock buffer, and stock aminothiol solution respectively. Without delay, the vial was immediately vortexed for $\sim 3 \mathrm{sec}$ to mix the buffer and aminothiol; the probe solution was added to initiate the reaction; and the vial vortexed a second time for $\sim 5 \mathrm{sec}$ to ensure a homogeneous 
solution. The solution was either immediately pipetted into a cuvette for spectrophotometry or left in the vial to observe color changes visually.

Samples which contained deproteinized plasma were prepared by the same procedure for screening in buffer vide supra, except the $4 \mathrm{~mL}$ sample vial initially contained lyophilized deproteinized plasma. To obtain deproteinized plasma, lyophilized bovine plasma purchased from Sigma-Aldrich was reconstituted with UPW to $1 / 3$ of the reconstitution volume. Two equivalents of acetonitrile ( $2 / 3$ of the reconstitution volume) were added and the solution was vortexed for $10 \mathrm{~min}$. The solution was allowed to stand for an additional $10 \mathrm{~min}$ before centrifuging at $4000 \mathrm{rpm}$ for $30 \mathrm{~min}$ to pellet the proteins. The decanted supernatant was aliquoted into sample vials and re-lyophilized. The vials were then sealed and stored in a refrigerator.

\subsection{Instrumentation}

Absorbance measurements were performed using a Cary $50 \mathrm{UV} / \mathrm{Vis}$ Spectrophotometer with Scan Software Version: 3.00(303). The automated speed was set to normal. Fluorescence measurements were performed with Cary Eclipse Fluorometer using Scan Software Version: 1.1(132). Typical settings were Ex. slit: 5 nm, Em. slit: 5 $\mathrm{nm}$, scan rate: $857.14 \mathrm{~nm} / \mathrm{min}$, data interval: $2.5000 \mathrm{~nm}$, averaging time: $0.1750 \mathrm{sec}$, PMT voltage: high (900W), Ex. increment: $5 \mathrm{~nm}$, filters: 0.1 and 0.5 OD. EPR spectra were obtained using a Bruker e-scan instrument with WinEPR Acquisition Software version 4.40 rev. 05. 1994-2007 Bruker BioSpin GmbH; X band frequency: 9.754229 GHz; Hall Field $\beta_{0}=3480.651247 \mathrm{G}$; attenuation: $2 \mathrm{~dB}$; and power: $31.55 \mathrm{~mW}$. Microwave reactions were irradiated while stirring in air cooled sealed vials stirring using 
a Biotage Initiator with absorption level set to normal. ESI-FTMS $+\mathrm{p}$ for the identification of synthetic products was done in $50 \% \mathrm{MeOH}$ on a ThermoElectron LTQOrbitrap Discovery high resolution mass spectrometer with Accela HPLC. Reaction products of $20.0 \mathrm{mM}$ pCN with $20.0 \mathrm{mM}$ Hcy in $100 \mathrm{mM}$ phosphate buffer $\mathrm{pH} 8.0$ were analyzed by ESI-TOF-MS and MALDI-TOF-MS, both in positive ion mode. The ESI method was performed by diluting the sample in $\mathrm{MeOH}$ with $0.1 \%$ formic acid before injecting into a Waters Micromass Q-TOF micro instrument. The MALDI method R+ of reaction solution was performed using an $\alpha$-Cyano-4-hydroxycinnamic acid matrix on an ABI 4800 MALDI TOF-TOF analyzer.

\subsection{Synthetic Methods}

1,4-bis(N-methylene-4,4'-bipyridinium)benzene (67a): 4,4'-Bipyridine 61 (3.33 g, $21.3 \mathrm{mmol}$ ) was brought to refux in $25 \mathrm{~mL}$ of MeCN. 1,4-bis(bromomethyl)benzene 64 (1.00 g, $3.79 \mathrm{mmol})$ dissolved in $70 \mathrm{~mL}$ of MeCN was added dropwise over $1 \mathrm{hr}$. Reflux was maintained for an additional $5 \mathrm{hr}$, after which the precipitate was hot filtered and the filter cake washed with $\mathrm{MeCN}$. The yellow solid was dried under vacuum overnight to give $2.08 \mathrm{~g}$ (3.61 mmol, 95\% yield) of compound $67 \mathrm{a}$ as the bromide salt. ${ }^{1} \mathrm{H}$ NMR (400 MHz, $\left.\mathrm{D}_{2} \mathrm{O}\right) \delta 9.09$ (4 H, d), 8.81 (4 H, d), 8.47 (4 H, d), 7.95 (4 H, d), 7.67 (4 H, s), 5.98 (4 H, s). $\left.{ }^{13} \mathrm{C} \mathrm{NMR} \mathrm{(101} \mathrm{MHz,} \mathrm{D} 2 \mathrm{O}\right) \delta 157.16$, $152.76,147.71,145.17,137.16,132.84,129.03,125.24,66.39$.

\section{Anionic exchange of bromide salt (67a) to hexafluorophosphate salt (67b):}

Compound 67a (2.00 g, $3.47 \mathrm{mmol})$ was dissolved in $20 \mathrm{~mL}$ of water with stirring. Some isomers required gentle heating $<60{ }^{\circ} \mathrm{C}$. Stirring was continued as $15 \mathrm{~mL}$ of a 
1.00 $\mathrm{M}$ aqueous $\mathrm{NH}_{4} \mathrm{PF}_{6}$ was dipped in. The precipitated solid was filtered, washed with water, and air dried. The yield of $67 \mathbf{b}$ was quantitative $(2.45 \mathrm{~g}, 3.47 \mathrm{mmol})$.

Para-bridged bis-CN viologen (pCN) (12): Bromoacetonitrile (2.00 mL, $28.71 \mathrm{mmol}$ ) was brought to reflux in $20 \mathrm{~mL}$ of $\mathrm{MeCN}$. Compound 67b (2.00 g, $2.83 \mathrm{mmol})$ dissolved in $100 \mathrm{~mL}$ of $\mathrm{MeCN}$ was added dropwise in over $1 \mathrm{hr}$. Reflux was maintained for an additional $12 \mathrm{hr}$. The precipitate was filtered and washed thoroughly with $\mathrm{MeCN}$. The corresponding meta and ortho isomers were found to be increasingly hydroscopic and had a tendency to become gooey if air was pulled through the filter cake too long. The resulting yellow solid was dried under vacuum overnight to give $1.01 \mathrm{~g}$ of compound $\mathbf{1 2}$ as the mixed salt $(1.07 \mathrm{mmol}, 38 \%$ reaction yield, $36 \%$ overall yeild), which was stored under argon, in an amber vial, and in a desiccator at $-80{ }^{\circ} \mathrm{C} .{ }^{1} \mathrm{H}$ NMR $\left(400 \mathrm{MHz}, \mathrm{D}_{2} \mathrm{O}\right) \delta 9.34(4 \mathrm{H}, \mathrm{d}), 9.23(4 \mathrm{H}, \mathrm{d}), 8.71(4$ H, d), $8.63(4 \mathrm{H}, \mathrm{d}), 7.67(4 \mathrm{H}, \mathrm{s}), 6.07(4 \mathrm{H}, \mathrm{s}), 6.03(4 \mathrm{H}, \mathrm{s}) .{ }^{13} \mathrm{C} \mathrm{NMR}(101 \mathrm{MHz}$, $\left.\mathrm{D}_{2} \mathrm{O}\right) \delta 154.76,152.73,148.91,148.50,136.78,133.13,130.38,130.18,115.42$, 66.96, 50.82. FTMS +p ESI: $m / z$, calculated: 247.1104 , found: $247.1102[\mathrm{M}-2 \mathrm{H}]^{2+}$; calculated: 263.1235 , found: $263.1232[\mathrm{M}+\mathrm{MeO}]^{2+}$.

1,3-bis(N-methylene-4,4'-bipyridinium)benzene (66a): 4,4'-Bipyridine 61 (1.68 g, $10.76 \mathrm{mmol}$ ) was brought to reflux in $20 \mathrm{~mL}$ of $\mathrm{MeCN} .1,3-$ bis(bromomethyl)benzene $\mathbf{6 3}(1.00 \mathrm{~g}, 3.79 \mathrm{mmol})$ dissolved in $20 \mathrm{~mL}$ of MeCN was added dropwise in over $1 \mathrm{hr}$. Reflux was maintained for an additional $5 \mathrm{hr}$, after which the precipitate was hot filtered and the filter cake washed with MeCN. The yellow solid was dried under vacuum overnight to give $2.10 \mathrm{~g}(3.64 \mathrm{mmol}, 96 \%$ 
yield) of compound 66a as the bromide salt. ${ }^{1} \mathrm{H}$ NMR $\left(400 \mathrm{MHz}, \mathrm{D}_{2} \mathrm{O}\right) \delta 9.00(4 \mathrm{H}$, d), $8.73(4 \mathrm{H}, \mathrm{d}), 8.40(4 \mathrm{H}, \mathrm{d}), 7.85(4 \mathrm{H}, \mathrm{d}), 7.64(3 \mathrm{H}, \mathrm{s}), 7.31(1 \mathrm{H}, \mathrm{s}), 5.94(4 \mathrm{H}$, s). ${ }^{13} \mathrm{C}$ NMR $\left(101 \mathrm{MHz}, \mathrm{D}_{2} \mathrm{O}\right) \delta 152.77,147.88,144.90,137.15,133.50,132.94$, $130.95,128.86,125.11,66.41$.

Meta-bridged bis-CN viologen (mCN) (11): Anionic exchange of bromide salt (66a) to hexafluorophosphate salt (66b) and subsequent transformation to the mixed salt of compound 11 was done by the same procedure given for compound 67. Overall yield for the reaction scheme of compound $\mathbf{1 1}$ was $21 \% .{ }^{1} \mathrm{H}$ NMR $\left(400 \mathrm{MHz}, \mathrm{D}_{2} \mathrm{O}\right) \delta 9.35$ (4 H, d), $9.24(4 \mathrm{H}, \mathrm{d}), 8.72(4 \mathrm{H}, \mathrm{d}), 8.64(4 \mathrm{H}, \mathrm{d}), 7.78(1 \mathrm{H}, \mathrm{s}), 7.68(3 \mathrm{H}, \mathrm{s}), 6.08(4$ $\mathrm{H}, \mathrm{s}), 6.04(4 \mathrm{H}, \mathrm{s}) .{ }^{13} \mathrm{C}$ NMR $\left(101 \mathrm{MHz}, \mathrm{D}_{2} \mathrm{O}\right) \delta 154.77,152.69,148.87,148.46$, 136.26, 133.71, 133.67, 132.92, 130.40, 130.21, 115.41, 66.99. FTMS +p ESI: $m / z$, calculated: 262.1157 , found: $262.1157[\mathrm{M}-2 \mathrm{H}+\mathrm{MeO}]^{2+}$.

1,2-bis(N-methylene-4,4'-bipyridinium)benzene (65a): 4,4'-Bipyridine 61 (1.50 g, $9.58 \mathrm{mmol}$ ) was brought to refux in $10 \mathrm{~mL}$ of $\mathrm{MeCN}$. 1,2-bis(bromomethyl)benzene 62 $(1.00 \mathrm{~g}, 3.79 \mathrm{mmol})$ dissolved in $10 \mathrm{~mL}$ of $\mathrm{MeCN}$ was added dropwise in over 1 hr. Reflux was maintained for an additional $3 \mathrm{hr}$, after which the precipitate was hot filtered and the filter cake washed with $\mathrm{MeCN}$. The yellow solid was dried under vacuum overnight to give $2.17 \mathrm{~g}$ ( $3.77 \mathrm{mmol}, 99 \%$ yield) of compound $\mathbf{6 5 a}$ as the bromide salt. ${ }^{1} \mathrm{H}$ NMR $\left(400 \mathrm{MHz}, \mathrm{D}_{2} \mathrm{O}\right) \delta 8.79(4 \mathrm{H}, \mathrm{d}), 8.57$ (4 H, d), $8.24(4 \mathrm{H}, \mathrm{d})$, 7.85-7.82 (2 H, m), 7.80-7.77 (2 H, m), $7.66(4 \mathrm{H}, \mathrm{d}), 6.13(4 \mathrm{H}, \mathrm{s}) .{ }^{13} \mathrm{C}$ NMR (101 $\left.\mathrm{MHz}, \mathrm{D}_{2} \mathrm{O}\right) \delta 156.81,152.75,147.26,143.76,136.93,134.95,133.44,128.70$, $124.78,64.21$. 
Ortho-bridged bis-CN viologen (oCN) (10): Anionic exchange of bromide salt (65a) to hexafluorophosphate salt $(\mathbf{6 5 b})$ and subsequent transformation to the mixed salt of compound 10 was done by the same procedure given for compound 67 . Overall yield for the reaction scheme of compound 10 was $18 \%$. ${ }^{1} \mathrm{H}$ NMR $\left(400 \mathrm{MHz}, \mathrm{D}_{2} \mathrm{O}\right) \delta 9.36$ (4 H, d), 9.20 (4 H, d), 8.74 (4 H, d), 8.69 (4 H, d), 7.68-7.66 (2 H, m), 7.41-7.39 (2 $\mathrm{H}, \mathrm{m}), 6.23(4 \mathrm{H}, \mathrm{s}), 6.08(4 \mathrm{H}, \mathrm{s}) .{ }^{13} \mathrm{C} \mathrm{NMR}\left(101 \mathrm{MHz}, \mathrm{D}_{2} \mathrm{O}\right) \delta 154.67,153.13$, $148.94,148.71,134.14,133.61,133.39,130.45,130.39,130.32,115.41,64.02$. FTMS +p ESI: $m / z$, calculated: 262.1157, found: $262.1158[\mathrm{M}-2 \mathrm{H}+\mathrm{MeO}]^{2+}$.

Para-bridged bis-coumarin viologen (pAC) (15): 3-(bromoacetyl)coumarin 68 (2.00 g, $7.49 \mathrm{mmol})$ was brought to reflux in $20 \mathrm{~mL}$ of $\mathrm{MeCN}$. Compound 67b $(0.500 \mathrm{~g}$, $0.708 \mathrm{mmol}$ ) dissolved in $100 \mathrm{~mL}$ of $\mathrm{MeCN}$ was added dropwise in over $1 \mathrm{hr}$. Reflux was maintained for an additional $12 \mathrm{hr}$. The precipitate was filtered warm and washed thoroughly with MeCN. The resulting green solid was dried under vacuum overnight to give $0.301 \mathrm{~g}$ of the target compound as the mixed salt $(0.242 \mathrm{mmol}, 34 \%$ reaction yield, 32\% overall yield). ${ }^{1} \mathrm{H}$ NMR (400 MHz, DMSO) $\delta 9.65(4 \mathrm{H}, \mathrm{d}), 9.27$ (4 H, d), $9.02(2 \mathrm{H}, \mathrm{s}), 8.91(4 \mathrm{H}, \mathrm{d}), 8.89$ (4 H, d), $8.13(2 \mathrm{H}, \mathrm{d}), 7.89(2 \mathrm{H}, \mathrm{t}), 7.79(4$ H, d), 7.62 (2 H, d), 7.53 (2 H, t), 6.45 (4 H, s), 6.06 (4 H, s). ${ }^{13} \mathrm{C}$ NMR (101 MHz, DMSO) $\delta 187.75,158.66,154.85,149.79,149.27,149.18,147.12,145.93,135.99$, $135.36,131.58,129.80,127.27,126.36,125.56,121.08,117.93,116.47,68.94,62.62$.

Meta-bridged bis-coumarin viologen (mAC) (14): Attachment of the acetylcoumarin 68 moiety to the meta isomer of the viologen bridge $66 \mathrm{~b}$ was accomplished by the same procedure given for compound 15. The target compound was isolated as a 
yellow solid which was stored at $\mathrm{rt}$ for an extended period of time without any apparent degradation in its optical properties. Overall yield: $30 \%$. ${ }^{1} \mathrm{H}$ NMR (400 MHz, DMSO) $\delta 9.67$ (4 H, d), 9.28 (4 H, d), 9.02 (2 H, s), 8.95 (4 H, d), 8.92 (4 H, d), $8.13(2 \mathrm{H}, \mathrm{d}), 8.05(1 \mathrm{H}, \mathrm{s}), 7.89(2 \mathrm{H}, \mathrm{t}), 7.70(2 \mathrm{H}, \mathrm{d}), 7.60(3 \mathrm{H}, \mathrm{m}), 7.53(2 \mathrm{H}$, t), $6.46(4 \mathrm{H}, \mathrm{s}), 6.08(4 \mathrm{H}, \mathrm{s}) .{ }^{13} \mathrm{C}$ NMR $(101 \mathrm{MHz}, \mathrm{DMSO}) \delta 187.77,158.67$, $154.85,149.81,149.28,149.16,147.13,145.95,136.00,135.06,131.58,130.13$, $129.81,129.66,127.26,126.40,125.57,121.08,117.93,116.48,68.96,62.74$.

\section{1-(2-oxo-2-(2-oxo-2H-chromen-3-yl)ethyl)-[4,4'-bipyridin]-1-ium (69a): 4,4'-}

Bipyridine 61 (0.750 g, $4.80 \mathrm{mmol})$ and 3-(bromoacetyl)coumarin 68 (0.500 g, 1.87 mmol) were dissolved in $40 \mathrm{~mL}$ of acetone and stirred at rt for $3 \mathrm{hrs}$. The precipitate was filtered and washed with acetone ( $0.658 \mathrm{~g}, 1.55 \mathrm{mmol}, 83 \%$ yield). ${ }^{1} \mathrm{H}$ NMR (400 MHz, DMSO) $\delta 9.11(2 \mathrm{H}, \mathrm{d}), 9.02(1 \mathrm{H}, \mathrm{s}), 8.91(2 \mathrm{H}, \mathrm{d}), 8.76(2 \mathrm{H}, \mathrm{d}), 8.12(1$ H, d), $8.09(2 \mathrm{H}, \mathrm{d}), 7.89(1 \mathrm{H}, \mathrm{t}), 7.61(1 \mathrm{H}, \mathrm{d}), 7.52(1 \mathrm{H}, \mathrm{t}), 6.36(2 \mathrm{H}, \mathrm{s})$.

Ortho-bridged bis-coumarin viologen (oAC) (13): Anionic exchange of bromide salt (69a) to hexafluorophosphate salt (69b) and subsequent transformation to the mixed salt of compound $\mathbf{1 3}$ was performed with quantitative yield by the same procedure given for compound 67. After thorough drying, $0.500 \mathrm{~g}(1.02 \mathrm{mmol})$ of the hexafluorophosphate salt (69) was brought to reflux in $20 \mathrm{~mL}$ of $\mathrm{MeCN}$. A solution of 1,2-bis(bromomethyl)benzene $(0.135 \mathrm{~g}, 0.512 \mathrm{mmol})$ in $20 \mathrm{~mL}$ of $\mathrm{MeCN}$ was added over $1 \mathrm{hr}$ and reflux was maintained for an additional $3 \mathrm{hrs}$. The precipitate was filtered and washed with $\mathrm{MeCN}$ to provide $0.451 \mathrm{~g}(0.364 \mathrm{mmol}, 71 \%$ reaction yield, 59\% overall yield) of the target compound (13) as a green solid. ${ }^{1} \mathrm{H}$ NMR (400 
MHz, DMSO) $\delta 9.57$ (4 H, d), 9.29 (4 H, d), 9.04 ( 2 H, s), 8.95 (4 H, d), 8.93 (4 H, d), $8.13(2 \mathrm{H}, \mathrm{d}), 7.89(2 \mathrm{H}, \mathrm{t}), 7.60(2 \mathrm{H} \mathrm{d}), 7.57(2 \mathrm{H}, \mathrm{m}), 7.53(2 \mathrm{H}, \mathrm{t}), 7.35(2 \mathrm{H}$, m), 6.47 (4 H, m), 6.42 (4 H, m). ${ }^{13} \mathrm{C}$ NMR (101 MHz, DMSO) $\delta$ 187.78, 158.65, $154.84,149.86,149.37,149.17,147.17,146.27,136.01,132.73,131.57,130.19$, $129.69,127.23,126.39,125.56,121.04,117.92,116.46,68.99,60.29$.

1-benzyl-[4,4'-bipyridin]-1-ium (71a): Benzyl bromide 70 (0.500 g, $2.92 \mathrm{mmol})$ and 4,4'-bipyridine 61 (0.913 g, $5.85 \mathrm{mmol})$ were dissolved in $10.0 \mathrm{~mL}$ of DCM and irradiated in a Biotage Initiator on normal power for $60 \mathrm{~min}$ at $60{ }^{\circ} \mathrm{C}$. The pale yellow bromide salt precipitate $(0.862 \mathrm{~g}, 2.64 \mathrm{mmol}, 90 \%$ yield $)$ was filtered and washed with acetone. ${ }^{1} \mathrm{H}$ NMR (600 MHz, DMSO) $\delta 9.42(2 \mathrm{H}, \mathrm{d}), 8.87(2 \mathrm{H}, \mathrm{d})$, $8.67(2 \mathrm{H}, \mathrm{d}), 8.04(2 \mathrm{H}, \mathrm{d}), 7.62(2 \mathrm{H}, \mathrm{d}), 7.48(3 \mathrm{H}, \mathrm{m}), 5.94(2 \mathrm{H}, \mathrm{s})$.

\section{Anionic exchange of bromide salt (71a) to hexafluorophosphate salt (71b):}

Compound 71a (0.862 g, $2.64 \mathrm{mmol})$ was dissolved in $10 \mathrm{~mL}$ of water. The solution was stirred as $10 \mathrm{~mL}$ of a $0.500 \mathrm{M}$ aqueous $\mathrm{NH}_{4} \mathrm{PF}_{6}$ was dipped in over $10 \mathrm{~min}$. The solution was allowed to stir for an additional $10 \mathrm{~min}$ before the precipitated white hexafluorophosphate salt was filtered, washed with water, and air dried. The yield of 71b was quantitative (1.03 g, $2.64 \mathrm{mmol})$.

Benzyl-nitrile viologen (BNV) (16): Compound 71b (0.500 g, $1.27 \mathrm{mmol})$ and bromoacetonitrile $(0.266 \mathrm{~mL}, 3.82 \mathrm{mmol})$ were dissolved in $4.00 \mathrm{~mL}$ of DCM and irradiated in a sealed vial using a Biotage Initiator on normal power for $30 \mathrm{~min}$ at 100 ${ }^{\circ} \mathrm{C}$. The off white mixed salt precipitate $(0.433 \mathrm{~g}, 8.45 \mathrm{mmol}, 66 \%$ reaction yield, $59 \%$ overall yeild) was filtered, washed carefully with acetone, and dried by drawing 
air through the filter cake. The product appeared to be slightly soluble in acetone. ${ }^{1} \mathrm{H}$ NMR (600 MHz, DMSO) $\delta 9.55$ (4 H, d), 8.85 (4 H, d), 7.65 (2 H, d), 7.49 (3 H, m), $6.12(2 \mathrm{H}, \mathrm{s}), 6.00(2 \mathrm{H}, \mathrm{s}) .{ }^{13} \mathrm{C}$ NMR $(151 \mathrm{MHz}, \mathrm{DMSO}) \delta 150.50,148.86,146.45$, $145.77,134.06,129.54,129.28,128.89,127.31,127.09,114.13,63.55,47.80$. FTMS +p ESI: $m / z$, calculated: 286.1339 , found: $286.1338[\mathrm{M}-\mathrm{H}]^{+}$; calculated: 318.1601 , found: $318.1600[\mathrm{M}+\mathrm{MeOH}]^{+}$. 
Chapter 8: Notes for continued investigations of these probes

The ultimate goal for Hcy detection is to design a chemical probe that can be used in an at-home testing kit by people with no background in science. To this end the probe should be inexpensive, non-toxic, stable upon storage at room temperature, amenable to as few processing steps as possible, react within a reasonable timeframe without the use of excessive heat, sensitive enough to allow for sample dilution, selective for Hcy in the presence of other thiols and other interferences, and able to maintain an accurate quantification of Hcy with variations in matrix compositions.

Currently the known interferences for bridged bis-nitrile viologen probes are plasma proteins, variations in Cys and GSH concentration, and reducing agents. Larger plasma proteins cause a curiously intense color change with these probes. Presumably, the proteins initiate or propagate a radical to the probe. However, high $\mathrm{pH}$ and high concentrations of solvent can produce an equally intense response. To address the interference by plasma proteins, the mechanism of protein interference should be identified. Assays done with high concentrations of the plasma protein, albumin, did not cause significant interference, so a particular protein may be responsible for the probe response. Identifying the protein could be useful for devising a strategy for removing it or rendering it inert.

If the dielectric constant of plasma is much lower than the buffer controls, this may account for the increased reactivity of the probe. Dramatically increasing the ionic strength of plasma samples could correct this issue or might lead to a method for removing the proteins via precipitation from 'salting out. Decreasing the $\mathrm{pH}$ would also 
reign in the probe reactivity. Although the few trials that were performed at lower $\mathrm{pH}$ in whole plasma were not successful, the buffer concentration may not have been high enough to overcome the natural buffering capacity of biological fluids. Some initial experiments with these probes showed a 'no response' selectively for GSH, responding even less response than blank solutions. This was eventually identified as a $\mathrm{pH}$ effect from exceeding the buffer capacity. Buffers which are compatible with the probe at high concentrations should be identified and tested with plasma samples at a concentration that will confidently buffer the solution at the intended $\mathrm{pH}$. Another strategy would be to dampen the reactivity tuning the redox potential of the probe further by choosing substituents for the viologen, mindful of the mechanism described here, though any structure that decreases the reactivity of the probe is accompanied by the risk of decreased sensitivity as well.

The majority of Hcy is bound to plasma proteins by disulfide linkages. Normally, free Hcy in plasma is only $1-2 \%$ of the total Hcy present. ${ }^{102}$ To quantify Hcy, the disulfide bonds must be cleaved with a reducing agent prior to protein removal. If reaction conditions are found which prevent interference from protein, then the probe must be compatible with the reducing agent if all the components are to be combined in the directly in the sample solution. So far the reducing agents TCEP, BME, MPA, dithiothreitol, and tris(2-carboxyethyl)phosphine reducing agents were found to interfere with the probe response. It is likely that removal of the reducing agent will be necessary prior to probe addition. TCEP immobilized on cross-linked beaded agarose (bead size $45-165 \mu \mathrm{m}$ ) was 
found to be conveniently removed from plasma samples with mini-prep filter vials (filter pores 0.20 and $0.45 \mu \mathrm{m})$.

These filter vials would simultaneously remove precipitated proteins from plasma samples. Currently, the sensitivity of the probe does not allow excessive sample dilution with precipitating agents. Additionally, some precipitating techniques, such as the addition of excessive organic solvent, affect the probe response. Isoelectric point precipitation with an acid might work provided the $\mathrm{pH}$ could be readjusted for the probe. Polyethylene glycol (PEG) was found to be compatible with the probe (Figure 43), so PEG protein precipitation was attempted. However, the proteins were only partially precipitated at $10 \% \mathrm{w} / \mathrm{v}$ PEG concentration in the sample. Although the protein interference had diminished substantially after filtering, the remaining interference still obscured detection of Hcy at biological concentrations.
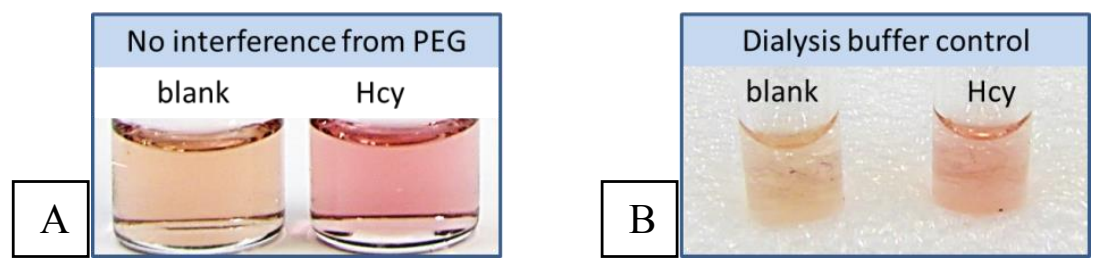

Figure 43. Polyethylene glycol (PEG) and dialysis as potential methods to remove protein interference. Common conditions: $2.00 \mathrm{mM} \mathrm{pCN}$ in $80.0 \mathrm{mM}$ phosphate buffer pH 8.0 after 20 min. (A) $15 \mu \mathrm{M}$ Hcy where indicated, both vials contain $10 \% \mathrm{w} / \mathrm{v}$ PEG (B) Dialysate: $15 \mu \mathrm{M}$ Hcy expected from $30 \mu \mathrm{M}$ Hcy equilibriated with an equal volume dialysate across a $3.5 \mathrm{kDa}$ cuttoff membrane for $90 \mathrm{~min}$.

Dialysis membranes may separate immobilized TCEP and precipitated proteins from samples more effectively than filter vials. Preliminary experiments showed $3.2 \mathrm{kDa}$ cutoff dialysis membranes were permeable to Hcy (Figure 43) and retained proteins precipitated by PEG better than micro filtration. There is analyte dilution associated diffusion across a membrane into the dialysate and the time allowed for equilibration of 
the dialysate is important. Incubation less than $30 \mathrm{~min}$ did not allow Hcy to fully equilibrate and the entire volume of dialysate was osmoticly drawn across the membrane with times $>4 \mathrm{hr}$. The appeal of using membrane diffusion for a disposable device to be used at the point-of-care is the potential to simultaneously remove erythrocytes and process blood directly from a finger prick. Hcy leaches from erythrocytes over time, which may be advantageous if the increase in Hcy concentration is predictable and/or proportional to exogenous Hcy concentrations in the plasma

Once a suitable probe and reaction conditions are identified, probe stability studies should be performed. The bridged bis-nitrile viologen probes were found to be hydroscopic, accumulating mass from moisture in the air and degrading over time. Even when stored under argon in a desiccator at $-80^{\circ} \mathrm{C}$, one month of periodic but repeated opening of stock vials and freeze thaw cycles rendered the bridged bis-nitrile probe response unreliable. The coumarin analogs did not suffer this issue with stability and were able to be stored on a dark shelf, at room temperature, for months with no detectable changes in the ${ }^{1}$ HNMR spectrum or noticeable differences in reactivity. However, it should be noted that the mAC coumarin analog did suddenly and completely lose its ability to fluoresce at certain wavelengths. A static gun was used to calm the uncooperative material when it was transferred from a stock container. Bombarding the compound with electrons from the static gun may have caused the abrupt change in optical properties.

The bridged bis-coumarin viologen probe studies are currently in their infancy. The Cys selective response observed with oAC was reproducible, consistent, and 
developed quickly in buffer. Perhaps the most informative experiment to be done would assess potential interferences in biological fluids by reproducing Cys selectivity using oAC with plasma added to the sample matrix. While the original hypothesis concerning quenching of the stacked fluorophores remains a valid avenue for investigation, a charge transfer mechanism of fluorescence appears to be more promising in regards to selective analyte response. The emission increases that took $12 \mathrm{hr}$ to develop could be indicative of probe degradation or covalent dimerization of the coumarins. ${ }^{96}$ Mild heating should be examined as a method of speeding up the kinetics of responses that develop slowly. Although reaction conditions that lead to a selective response for Hcy have not been exhausted for the coumarin analogs, the next generation of fluorophore bridged viologens designs should encompass fluorophores likely to participate in charge transfer. Photosensitization of the viologen probe would not be limited to bridged structures. 


\section{References}

1. Lushchak, V. I., Glutathione homeostasis and functions: potential targets for medical interventions. Journal of amino acids 2012, 2012.

2. Betts, M. J.; Russell, R. B., Amino acid properties and consequences of substitutions. Bioinformatics for geneticists 2003, 317, 289.

3. Schalinske, K. L.; Smazal, A. L., Homocysteine Imbalance: a Pathological Metabolic Marker. Advances in Nutrition: An International Review Journal 2012, 3 (6), 755-762.

4. Selhub, J., Homocysteine metabolism. Annu. Rev. Nutr. 1999, 19 (1), 217-246.

5. Jakubowski, H., Homocysteine is a protein amino acid in humans Implications for homocysteine-linked disease. J. Biol. Chem. 2002, 277 (34), 30425-30428.

6. Guttormsen, A. B.; Schneede, J.; Fiskerstrand, T.; Ueland, P. M.; Refsum, H. M., Plasma concentrations of homocysteine and other aminothiol compounds are related to food intake in healthy human subjects. The Journal of nutrition 1994, 124 (10), 1934.

7. Refsum, M., H.; Ueland, M., PM; Nygård, M., O.; Vollset, M., Dr. PH, SE, Homocysteine and cardiovascular disease. Annu. Rev. Med. 1998, 49 (1), 31-62.

8. Hortin, G. L.; Sullivan, P.; Csako, G., Relationships among plasma homocysteine, cysteine, and albumin concentrations: potential utility of assessing the cysteine/homocysteine ratio. Clin. Chem. 2001, 47 (6), 1121-1124.

9. Valente, A.; Bronze, M. R.; Bicho, M.; Duarte, R.; Costa, H. S., Validation and clinical application of an UHPLC method for simultaneous analysis of total homocysteine and cysteine in human plasma. J. Sep. Sci. 2012, 35 (24), 3427-3433.

10. Refsum, H.; Nurk, E.; Smith, A. D.; Ueland, P. M.; Gjesdal, C. G.; Bjelland, I.; Tverdal, A.; Tell, G. S.; Nygård, O.; Vollset, S. E., The Hordaland Homocysteine Study: a community-based study of homocysteine, its determinants, and associations with disease. The Journal of nutrition 2006, 136 (6), 1731S-1740S.

11. Nedrebø, B.; Ericsson, U. B.; Nygård, O.; Refsum, H.; Ueland, P.; Aakvaag, A.; Aanderud, S.; Lien, E., Plasma total homocysteine levels in hyperthyroid and hypothyroid patients. Metabolism. 1998, 47 (1), 89-93.

12. Purice, M.; Ursu, I.; Baicus, C.; Goldstein, A.; Niculescu, D., Hyperhomocysteinemia in moderate and severe hypothyroidism. Acta Endocrinologica (Buc) 2010, 6 (4), 431-442. 
13. Shaikh, M. K.; Devrajani, B. R.; Shaikh, A.; Shah, S. Z. A.; Shaikh, S.; Singh, D., Plasma Homocysteine Level in Patients with Diabetes mellitus. World Applied Sciences Journal 2012, 16 (9), 1269-1273.

14. Jardine, M. J.; Kang, A.; Zoungas, S.; Navaneethan, S. D.; Ninomiya, T.; Nigwekar, S. U.; Gallagher, M. P.; Cass, A.; Strippoli, G.; Perkovic, V., The effect of folic acid based homocysteine lowering on cardiovascular events in people with kidney disease: systematic review and meta-analysis. BMJ 2012, 344.

15. Bleich, S.; Bleich, K.; Kropp, S.; Bittermann, H. J.; Degner, D.; Sperling, W.; Rüther, E.; Kornhuber, J., Moderate alcohol consumption in social drinkers raises plasma homocysteine levels: a contradiction to the 'French Paradox'? Alcohol Alcohol 2001, 36 (3), 189-192.

16. Bleich, S.; Carl, M.; Bayerlein, K.; Reulbach, U.; Biermann, T.; Hillemacher, T.; Bönsch, D.; Kornhuber, J., Evidence of increased homocysteine levels in alcoholism: the Franconian alcoholism research studies (FARS). Alcoholism: clinical and experimental research 2005, 29 (3), 334-336.

17. Jacques, P. F.; Bostom, A. G.; Williams, R. R.; Ellison, R. C.; Eckfeldt, J. H.; Rosenberg, I. H.; Selhub, J.; Rozen, R., Relation between folate status, a common mutation in methylenetetrahydrofolate reductase, and plasma homocysteine concentrations. Circulation 1996, 93 (1), 7-9.

18. Schneider, J. A.; Rees, D. C.; Liu, Y. T.; Clegg, J. B., Worldwide distribution of a common methylenetetrahydrofolate reductase mutation. Am. J. Hum. Genet. 1998, $62(5), 1258$.

19. Xu, H.; Liu, C.; Wang, Q., Plaque Image Characteristics, Hyperhomocysteinemia, and Gene Polymorphism of Homocysteine Metabolism-Related Enzyme (MTHFR C677T) in Acute Coronary Syndrome. Cell Biochem. Biophys. 2013, 1-5.

20. Fowler, B., Disorders of homocysteine metabolism. J. Inherit. Metab. Dis. 1997, 20 (2), 270-285.

21. Massy, Z. A., Potential strategies to normalize the levels of homocysteine in chronic renal failure patients. Kidney Int. 2003, 63, S134-S136.

22. Glushchenko, A. V.; Jacobsen, D. W., Molecular targeting of proteins by Lhomocysteine: mechanistic implications for vascular disease. Antioxid. Redox Signaling 2007, 9 (11), 1883-1898.

23. Jakubowski, H., Pathophysiological consequences of homocysteine excess. The Journal of nutrition 2006, 136 (6), 1741S-1749S. 
24. Sibrian-Vazquez, M.; Escobedo, J. O.; Lim, S.; Samoei, G. K.; Strongin, R. M., Homocystamides promote free-radical and oxidative damage to proteins.

Proceedings of the National Academy of Sciences 2010, 107 (2), 551-554.

25. Demuth, K.; Moatti, N.; Hanon, O.; Benoit, M. O.; Safar, M.; Girerd, X., Opposite effects of plasma homocysteine and the methylenetetrahydrofolate reductase C677T mutation on carotid artery geometry in asymptomatic adults. Arterioscler. Thromb. Vasc. Biol. 1998, 18 (12), 1838-1843.

26. McLean, R. R.; Jacques, P. F.; Selhub, J.; Tucker, K. L.; Samelson, E. J.; Broe, K. E.; Hannan, M. T.; Cupples, L. A.; Kiel, D. P., Homocysteine as a predictive factor for hip fracture in older persons. N. Engl. J. Med. 2004, 350 (20), 2042-2049.

27. van Meurs, J. B. J.; Dhonukshe-Rutten, R. A. M.; Pluijm, S. M. F.; van der Klift, M.; de Jonge, R.; Lindemans, J.; de Groot, L. C.; Hofman, A.; Witteman, J. C. M.; van Leeuwen, J. P. T. M., Homocysteine levels and the risk of osteoporotic fracture. $N$. Engl. J. Med. 2004, 350 (20), 2033-2041.

28. Seo, H.; Oh, H.; Park, H.; Park, M.; Jang, Y.; Lee, M., Contribution of dietary intakes of antioxidants to homocysteine-induced low density lipoprotein (LDL) oxidation in atherosclerotic patients. Yonsei Med. J. 2010, 51 (4), 526-533.

29. Dardik, R.; Varon, D.; Tamarin, I.; Zivelin, A.; Salomon, O.; Shenkman, B.; Savion, N., Homocysteine and oxidized low density lipoprotein enhance platelet adhesion to endothelial cells under flow conditions: distinct mechanisms of thrombogenic modulation. Thromb. Haemostasis 2000, 83 (2), 338-344.

30. Stauffenberg, M. T.; Lange, R. A.; David Hillis, L.; Cigarroa, J.; Hsu, R. M.; Devaraj, S.; Jialal, I., Hyperhomocysteinemia measured by immunoassay: a valid measure of coronary artery atherosclerosis. Arch. Pathol. Lab. Med. 2004, 128 (11), 1263-1266.

31. Wali, V.; Bijapur, S. Y. D., Serum Homocysteine Levels As a Novel Biomarker in Patients with Acute Myocardial Infarction. Inetrnational Journal of Medical and Health Sciences, 1 (4), 39-46. 2012.

32. Alam, N.; Chowdhury, A.; Hossain, M.; Khondoker, M.; Mallik, M.; Amin, M.; Hasan, G., Serum homocysteine levels in patients with acute myocardial infarction. Journal of Dhaka Medical College 2013, 21 (1), 23-27.

33. Clarke, R., Homocysteine and risk of ischemic heart disease and stroke. JAMA: the journal of the American Medical Association 2002, 288 (16), 2015-2022.

34. Unal, E.; Mungan, S.; Bilen, S.; Karadag, Y.; Oztekin, N.; Bakir, F.; Ak, F., The effects of lipoprotein (a) and homocysteine on prognosis and risk factors in acute ischemic stroke. Int. J. Neurosci. 2013, (0), 1-18. 
35. Ueland, P. M.; Loscalzo, J., Homocysteine and cardiovascular risk: the perils of reductionism in a complex system. Clin. Chem. 2012, 58 (12), 1623-1625.

36. Herrmann, W.; Obeid, R., Homocysteine: a biomarker in neurodegenerative diseases. Clin. Chem. Lab. Med. 2011, 49 (3), 435-441.

37. Akchiche, N.; Bossenmeyer-Pourié, C.; Kerek, R.; Martin, N.; Pourié, G.; Koziel, V.; Helle, D.; Alberto, J. M.; Ortiou, S.; Camadro, J. M., Homocysteinylation of neuronal proteins contributes to folate deficiency-associated alterations of differentiation, vesicular transport, and plasticity in hippocampal neuronal cells. The FASEB Journal 2012.

38. Feng, L.; Isaac, V.; Sim, S.; Ng, T.-P.; Krishnan, K. R. R.; Chee, M. W., Associations between elevated homocysteine, cognitive impairment, and reduced white matter volume in healthy old adults. The American Journal of Geriatric Psychiatry 2013, 21 (2), 164-172.

39. Dietrich-Muszalska, A.; Malinowska, J.; Olas, B.; Głowacki, R.; Bald, E.; Wachowicz, B.; Rabe-Jabłońska, J., The oxidative stress may be induced by the elevated homocysteine in schizophrenic patients. Neurochem. Res. 2012, 1-6.

40. Chai, G. S.; Jiang, X.; Ni, Z. F.; Ma, Z. W.; Xie, A. J.; Cheng, X. S.; Wang, Q.; Wang, J. Z.; Liu, G. P., Betaine attenuates Alzheimer-like pathological changes and memory deficits induced by homocysteine. J. Neurochem. 2013, 124 (3), 388-396.

41. Sachdev, P. S., Alzheimer disease: homocysteine and alzheimer disease: an intervention study. Nature Reviews Neurology 2011, 7 (1), 9-10.

42. Blom, H. J.; Smulders, Y., Overview of homocysteine and folate metabolism. With special references to cardiovascular disease and neural tube defects. J. Inherit. Metab. Dis. 2011, 34 (1), 75-81.

43. Smulders, Y. M.; Blom, H. J., The homocysteine controversy. J. Inherit. Metab. Dis. 2011, 34 (1), 93-99.

44. Ferin, R.; Pavão, M. L.; Baptista, J., Methodology for a rapid and simultaneous determination of total cysteine, homocysteine, cysteinylglycine and glutathione in plasma by isocratic RP-HPLC. Journal of Chromatography B 2012, 911, 5-20.

45. Zinellu, A.; Sotgia, S.; Scanu, B.; Deiana, L.; Talanas, G.; Terrosu, P.; Carru, C., Low density lipoprotein S-homocysteinylation is increased in acute myocardial infarction patients. Clin. Biochem. 2012, 45 (4), 359-362.

46. Melnyk, S.; Pogribna, M.; Pogribny, I.; Hine, R. J.; James, S. J., A new HPLC method for the simultaneous determination of oxidized and reduced plasma 
aminothiols using coulometric electrochemical detection. The Journal of nutritional biochemistry 1999, 10 (8), 490-497.

47. Głowacki, R.; Bald, E., Fully automated method for simultaneous determination of total cysteine, cysteinylglycine, glutathione and homocysteine in plasma by HPLC with UV absorbance detection. Journal of Chromatography B 2009, 877 (28), 34003404 .

48. Nekrassova, O.; Lawrence, N. S.; Compton, R. G., Analytical determination of homocysteine: a review. Talanta 2003, 60 (6), 1085-1095.

49. Newton, L. A.; Sandhu, K.; Livingstone, C.; Leslie, R.; Davis, J., Clinical diagnostics for homocysteine: a rogue amino acid? Expert Rev. Mol. Diagn. 2010, 10 (4), 489-500.

50. Sawuła, W.; Banecka-Majkutewicz, Z.; Kadziński, L.; Jakóbkiewicz-Banecka, J.; Węgrzyn, G.; Nyka, W.; Banecki, B., Improved HPLC method for total plasma homocysteine detection and quantification. Acta Biochim. Pol. 2008, 55, 119-125.

51. Refsum, H.; Smith, A. D.; Ueland, P. M.; Nexo, E.; Clarke, R.; McPartlin, J.; Johnston, C.; Engbaek, F.; Schneede, J.; McPartlin, C., Facts and recommendations about total homocysteine determinations: an expert opinion. Clin. Chem. 2004, 50 (1), 3-32.

52. La'ulu, S. L.; Rawlins, M. L.; Pfeiffer, C. M.; Zhang, M.; Roberts, W. L., Performance characteristics of six homocysteine assays. Am. J. Clin. Pathol. 2008, $130(6), 969-975$.

53. Tripodi, A.; Chantarangkul, V.; Lombardi, R.; Lecchi, A.; Mannucci, P. M.; Cattaneo, M., Multicenter study of homocysteine measurement--performance characteristics of different methods, influence of standards on interlaboratory agreement of results. Thromb. Haemostasis 2001, 85 (2), 291.

54. Hanson, N. Q.; Eckfeldt, J. H.; Schwichtenberg, K.; Aras, Ö.; Tsai, M. Y., Interlaboratory variation of plasma total homocysteine measurements: results of three successive homocysteine proficiency testing surveys. Clin. Chem. 2002, 48 (9), $1539-1545$.

55. Haltmayer, M.; Mueller, T.; Gegenhuber, A.; Poelz, W., Comparison of the automated AxSYM and ADVIA centaur immunoassays for homocysteine determination. Clin. Lab. 2004, 50 (3-4), 175.

56. Neil, O., The Merck Index: An Encyclopedia of Chemicals, Drug, Biologicals, 14 th Edn., Merck \& Co. 14 ed.; 2006. 
57. Dean, J., Data for biochemical research. 15 ed.; McGraw-Hill, Inc.: New York, 1999.

58. Li, H.; Fan, J.; Wang, J.; Tian, M.; Du, J.; Sun, S.; Sun, P.; Peng, X., A fluorescent chemodosimeter specific for cysteine: effective discrimination of cysteine from homocysteine. Chem. Commun. (Camb.) 2009, (39), 5904-5906.

59. Wei, M.; Yin, P.; Shen, Y.; Zhang, L.; Xue, S.; Li, H.; Guo, B.; Zhang, Y.; Yao, S., A New Turn-On Fluorescent Probe for Selective Detection of Glutathione and Cysteine in Living Cells. Chem. Commun. (Camb.) 2013.

60. Jung, H. S.; Han, J. H.; Pradhan, T.; Kim, S.; Lee, S. W.; Sessler, J. L.; Kim, T. W.; Kang, C.; Kim, J. S., A cysteine-selective fluorescent probe for the cellular detection of cysteine. Biomaterials 2012, 33 (3), 945-953.

61. Wang, W.; Rusin, O.; Xu, X.; Kim, K. K.; Escobedo, J. O.; Fakayode, S. O.; Fletcher, K. A.; Lowry, M.; Schowalter, C. M.; Lawrence, C. M., Detection of homocysteine and cysteine. J. Am. Chem. Soc. 2005, 127 (45), 15949-15958.

62. Peng, H.; Chen, W.; Cheng, Y.; Hakuna, L.; Strongin, R.; Wang, B., Thiol Reactive Probes and Chemosensors. Sensors 2012, 12 (11), 15907-15946.

63. Chen, X.; Zhou, Y.; Peng, X.; Yoon, J., Fluorescent and colorimetric probes for detection of thiols. Chem. Soc. Rev. 2010, 39 (6), 2120-2135.

64. Chen, H.; Zhao, Q.; Wu, Y.; Li, F.; Yang, H.; Yi, T.; Huang, C., Selective phosphorescence chemosensor for homocysteine based on an iridium (III) complex. Inorg. Chem. 2007, 46 (26), 11075-11081.

65. Xiao, Q.; Zhang, L.; Lu, C., Resonance light scattering technique for simultaneous determination of cysteine and homocysteine using fluorosurfactant-capped gold nanoparticles. Sensors and Actuators B: Chemical 2012, 166-167, 650-657.

66. Sun, S.-K.; Wang, H.-F.; Yan, X.-P., A sensitive and selective resonance light scattering bioassay for homocysteine in biological fluids based on target-involved assembly of polyethyleneimine-capped Ag-nanoclusters. Chem. Commun. (Camb.) 2011, 47 (13), 3817-3819.

67. Lu, C.; Zu, Y., Specific detection of cysteine and homocysteine: recognizing onemethylene difference using fluorosurfactant-capped gold nanoparticles. Chem. Commun. (Camb.) 2007, (37), 3871-3873.

68. Yu, C.; Zeng, F.; Luo, M.; Wu, S., A silica nanoparticle-based sensor for selective fluorescent detection of homocysteine via interaction differences between thiols and particle-surface-bound polymers. Nanotechnology 2012, 23 (30), 305503. 
69. Gholami-Orimi, F.; Taleshi, F.; Biparva, P.; Karimi-Maleh, H.; Beitollahi, H.; Ebrahimi, H. R.; Shamshiri, M.; Bagheri, H.; Fouladgar, M.; Taherkhani, A., Voltammetric Determination of Homocysteine Using Multiwall Carbon Nanotube Paste Electrode in the Presence of Chlorpromazine as a Mediator. Journal of Analytical Methods in Chemistry 2012, 2012.

70. Abedinzadeh, Z., Sulfur-centered reactive intermediates derived from the oxidation of sulfur compounds of biological interest. Can. J. Physiol. Pharmacol. 2001, 79 (2), 166-170.

71. Zhao, R.; Lind, J.; Merenyi, G.; Eriksen, T. E., Kinetics of One-Electron Oxidation of Thiols and Hydrogen Abstraction by Thiyl Radicals from. alpha.-Amino $\mathrm{CH}$ Bonds. J. Am. Chem. Soc. 1994, 116 (26), 12010-12015.

72. Armstrong, D., Thermochemistry of sulfur radicals. S-centered radicals. Wiley, New York 1999, 27-61.

73. Wang, D.; Crowe, W. E.; Strongin, R. M.; Sibrian-Vazquez, M., Exploring the pH dependence of viologen reduction by $\alpha$-carbon radicals derived from Hcy and Cys. Chem. Commun. (Camb.) 2009, (14), 1876-1878.

74. Armstrong, D. A.; Rauk, A.; Yu, D., Aminoalkyl and alkylaminium free radicals and related species: structures, thermodynamic properties, reduction potentials, and aqueous free energies. J. Am. Chem. Soc. 1993, 115 (2), 666-673.

75. Armstrong, D.; Yu, D.; Rauk, A., Oxidative damage to the glycyl $\alpha$-carbon site in proteins: an ab initio study of the $\mathrm{CH}$ bond dissociation energy and the reduction potential of the C-centered radical. Can. J. Chem. 1996, 74 (6), 1192-1199.

76. Wang, W.; Escobedo, J. O.; Lawrence, C. M.; Strongin, R. M., Direct detection of homocysteine. J. Am. Chem. Soc. 2004, 126 (11), 3400-3401.

77. Geuder, W.; Hünig, S.; Suchy, A., Single and double bridged viologenes and intramolecular pimerization of their cation radicals. Tetrahedron 1986, 42 (6), 1665 1677.

78. Fahrenbach, A. C.; Sampath, S.; Late, D. J.; Barnes, J. C.; Kleinman, S. L.; Valley, N.; Hartlieb, K. J.; Liu, Z.; Dravid, V. P.; Schatz, G. C., A Semiconducting Organic Radical Cationic Host-Guest Complex. ACS Nano 2012, 6 (11), 9964-9971.

79. Neta, P.; Richoux, M.-C.; Harriman, A., Intramolecular association of covalently linked viologen radicals. J. Chem. Soc., Faraday Trans. 2 1985, 81 (9), 1427-1443.

80. Strongin, R. M.; Sibrian-vazquez, M., Thiol Detection. US Patent 20,120,276,649: 2012. 
81. Small, D.; Zaitsev, V.; Jung, Y.; Rosokha, S. V.; Head-Gordon, M.; Kochi, J. K., Intermolecular $\pi$-to- $\pi$ bonding between stacked aromatic dyads. Experimental and theoretical binding energies and near-IR optical transitions for phenalenyl radical/radical versus radical/cation dimerizations. J. Am. Chem. Soc. 2004, 126 (42), 13850-13858.

82. Sun, X.; Yang, Y.-K., Photochromism of double-bridged viologens in a polar polymer matrix. Journal of the Chemical Society, Perkin Transactions 2 1996, (2), 225-228.

83. Iyoda, T.; Matsushita, M. M.; Kawai, T., Redox-tunable pyridinium assemblies and their interactive spin-based functions. Pure Appl. Chem. 1999, 71 (11), 2079-2084.

84. Kertesz, J. C.; Wolf, M. B.; Wolf, W.; Chen, L. Y. A., Electron spin resonance studies of free radicals in solution III: $\mathrm{pH}$ dependence of thiyl free radical of cysteine. J. Pharm. Sci. 1974, 63 (6), 880-883.

85. Wardman, P., Reduction potentials of one-electron couples involving free radicals in aqueous solution. American Chemical Society and the American Institute of Physics for the National Institute of Standards and Technology: 1989.

86. Reichardt, C.; Welton, T., Solvents and solvent effects in organic chemistry. wileyVCH: 2011.

87. Wardman, P.; Clarke, E., Redox properties and rate constants in free-radical mediated damage. The British journal of cancer. Supplement 1987, 8, 172.

88. Anslyn, E. V.; Dougherty, D. A., Modern physical organic chemistry. University Science Books: 2006.

89. Iehl, J.; Frasconi, M.; de Rouville, H.-P. J.; Renaud, N.; Dyar, S. M.; Strutt, N. L.; Carmieli, R.; Wasielewski, M. R.; Ratner, M. A.; Nierengarten, J.-F., $\pi$-Dimerization of viologen subunits around the core of $\mathrm{C} 60$ from twelve to six directions. Chem. Sci. 2013, 4 (4), 1462-1469.

90. Dabestani, R.; Reszka, K. J.; Sigman, M. E., Surface catalyzed electron transfer from polycyclic aromatic hydrocarbons (PAH) to methyl viologen dication: evidence for ground-state charge transfer complex formation on silica gel. Journal of Photochemistry and Photobiology A: Chemistry 1998, 117 (3), 223-233.

91. Escobedo, J. O.; Wang, W.; Strongin, R. M., Use of a commercially available reagent for the selective detection of homocysteine in plasma. Nat. Protoc. 2007, 1 (6), 2759-2762.

92. Su, Y. T.; Lan, G. Y.; Chen, W. Y.; Chang, H. T., Detection of copper ions through recovery of the fluorescence of DNA-templated copper/silver nanoclusters in the 
presence of mercaptopropionic acid. Analytical Chemistry-Columbus 2010, 82 (20), 8566.

93. Odom, B.; Hanneke, D.; D'urso, B.; Gabrielse, G., New measurement of the electron magnetic moment using a one-electron quantum cyclotron. Phys. Rev. Lett. 2006, 97 (3), 030801 .

94. Rieger, P. H., Electron spin resonance: analysis and interpretation. Royal Society of Chemistry: 2007.

95. Hiller, K.; Asmus, K., Formation and reduction reactions of. alpha.-amino radicals derived from methionine and its derivatives in aqueous solutions. The Journal of Physical Chemistry 1983, 87 (19), 3682-3688.

96. Trenor, S. R.; Shultz, A. R.; Love, B. J.; Long, T. E., Coumarins in polymers: from light harvesting to photo-cross-linkable tissue scaffolds. Chem. Rev. 2004, 104 (6), 3059-3077.

97. Jing, L.; Xiang-Gao, L.; Shi-Rong, W., Crystal Structure, Photoluminescent, and Theoretical Studies of 3-Acetyl-8-methoxy-coumarin. J. Struct. Chem. 2012, 31 (7).

98. Allonas, X.; Fouassier, J.; Kaji, M.; Miyasaka, M.; Hidaka, T., Two and three component photoinitiating systems based on coumarin derivatives. Polymer 2001, 42 (18), 7627-7634.

99. Zhang, J.; Wu, S.; Wang, E., The Photopolymerization of MMA Initiated by 3Aryloylcoumarin Compounds. Chin. J. Polym. Sci. 1988, 6 (3), 282-284.

100. Lalevée, J.; Morlet-Savary, F.; Roz, M. E.; Allonas, X.; Fouassier, J. P., Thiyl Radical Generation in Thiol or Disulfide Containing Photosensitive Systems. Macromol. Chem. Phys. 2009, 210 (5), 311-319.

101. Lamberto, M.; Rastede, E. E.; Decker, J.; Raymo, F. M., Microwave-assisted synthesis of symmetric and asymmetric viologens. Tetrahedron Lett. 2010, 51 (42), 5618-5620.

102. Carmel, R.; Jacobsen, D. W., Homocysteine in health and disease. Cambridge University Press: 2001. 
Appendix A: Supporting information

\begin{tabular}{|c|c|c|c|c|c|c|c|c|c|c|c|}
\hline \multicolumn{6}{|c|}{$2.00 \mathrm{mM}$ pCN probe without IPA } & \multicolumn{6}{|c|}{$0.500 \mathrm{pCN}$ probe with $15 \%$ IPA } \\
\hline Min & blank & Hcy & Cys & GSH & all & Min & blank & Hcy & Cys & GSH & all \\
\hline 1 & & & & & & 1 & & & & & \\
\hline 10 & & - & + & 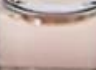 & $=$ & 10 & & & & & $=$ \\
\hline 20 & & $=$ & $\Rightarrow$ & $=$ & $=$ & 20 & & & & & הוד \\
\hline 30 & & - & - & - & $=$ & 30 & $\leqslant$ & & & - & 3 \\
\hline 40 & 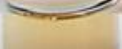 & - & 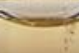 & $=$ & 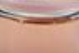 & 10 & 5 & & & & 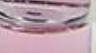 \\
\hline & 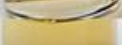 & 5 & 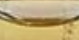 & 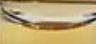 & $=$ & & & & & & 5 \\
\hline 50 & & & & & $\pi$ & 50 & & & & & \\
\hline 60 & & & & & 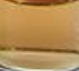 & 60 & & & & & \\
\hline
\end{tabular}

Figure 44. Color development of the $\mathrm{pCN}$ probe over $1 \mathrm{hr}$. $80.0 \mathrm{mM}$ phosphate buffer at $\mathrm{pH}$ 8.0, From left in each panel: blank, $15.0 \mu \mathrm{M}$ Hcy, $250 \mu \mathrm{M}$ Cys, $6.00 \mu \mathrm{M}$ GSH, all thiols combined.

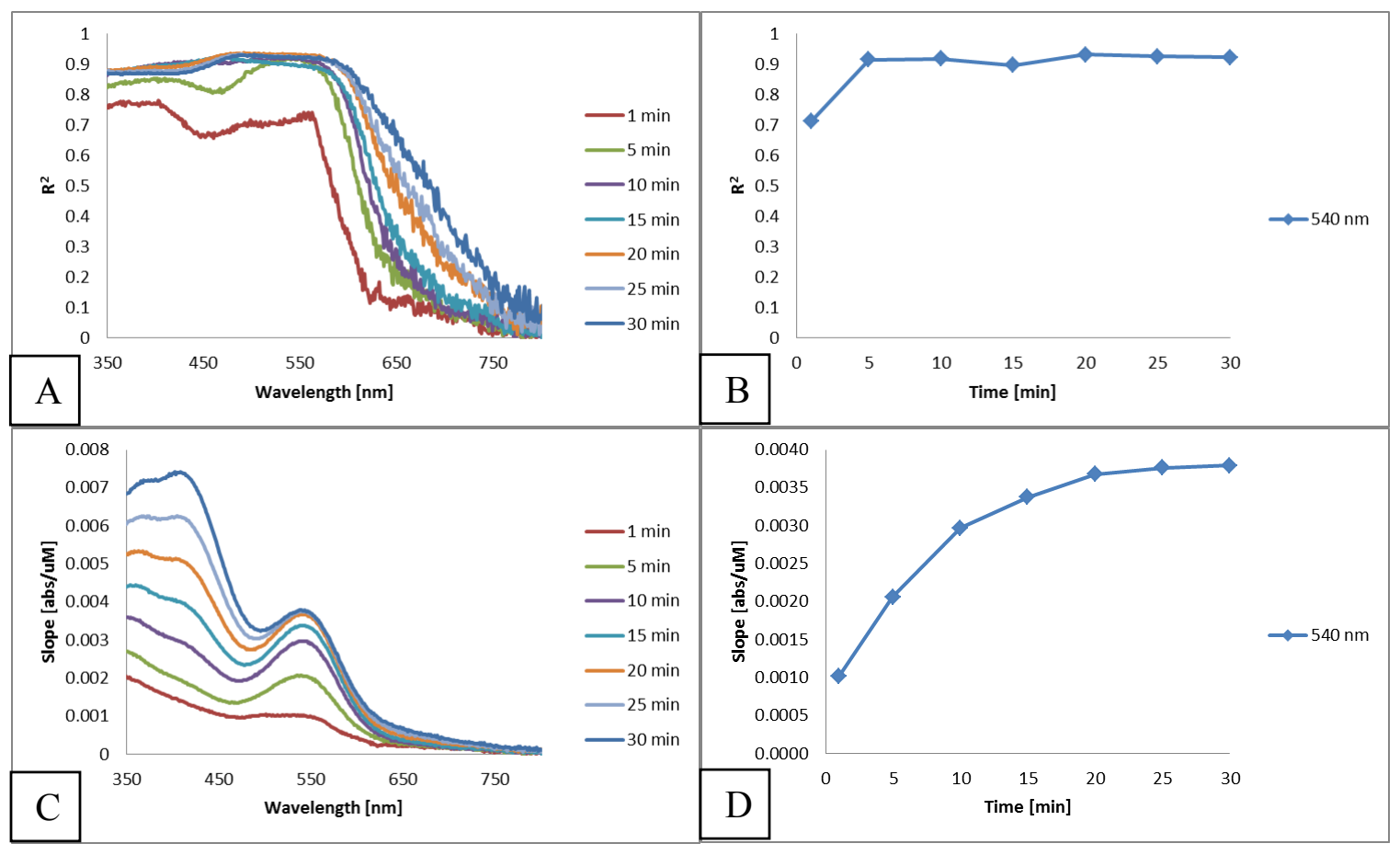

Figure 45. Linearity and time point analysis for $\mathrm{pCN}$ calibration curve in Figure 15-A. 


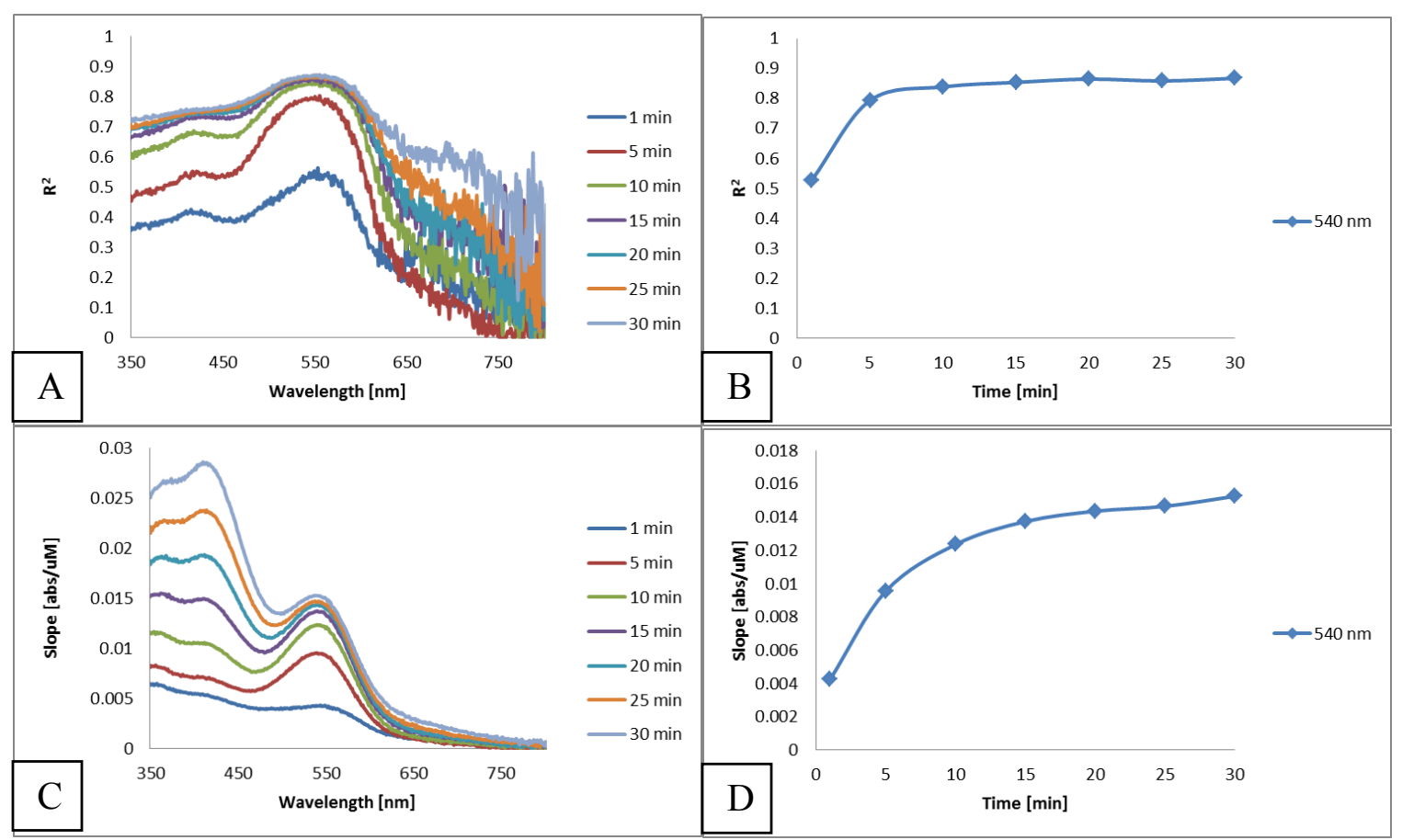

Figure 46. Linearity and time point analysis for $\mathrm{pCN}$ calibration curve in Figure 15-B.

The time point and $\lambda_{\text {abs }}$ of the most linear and sensitive data set for construction of the calibration curves was determined by plotting the square correlation coefficient $\left(\mathrm{R}^{2}\right)$ (Figure 45-A, Figure 46-B) and the slope (Figure 45-C, Figure 46-C) of regression lines for the entire range of $\lambda_{\text {abs }}$ measured. The local maximum for $\mathrm{R}^{2}$ and slope in the region of the diagnostic peak was found to be $540 \mathrm{~nm}$. This $\lambda_{\text {abs }}$ plotted over time provided the optimum time point, 30 min (Figure 45-BD, Figure 46-BD). Incidentally, the maximum of the diagnostic peak is also $540 \mathrm{~nm}$. 


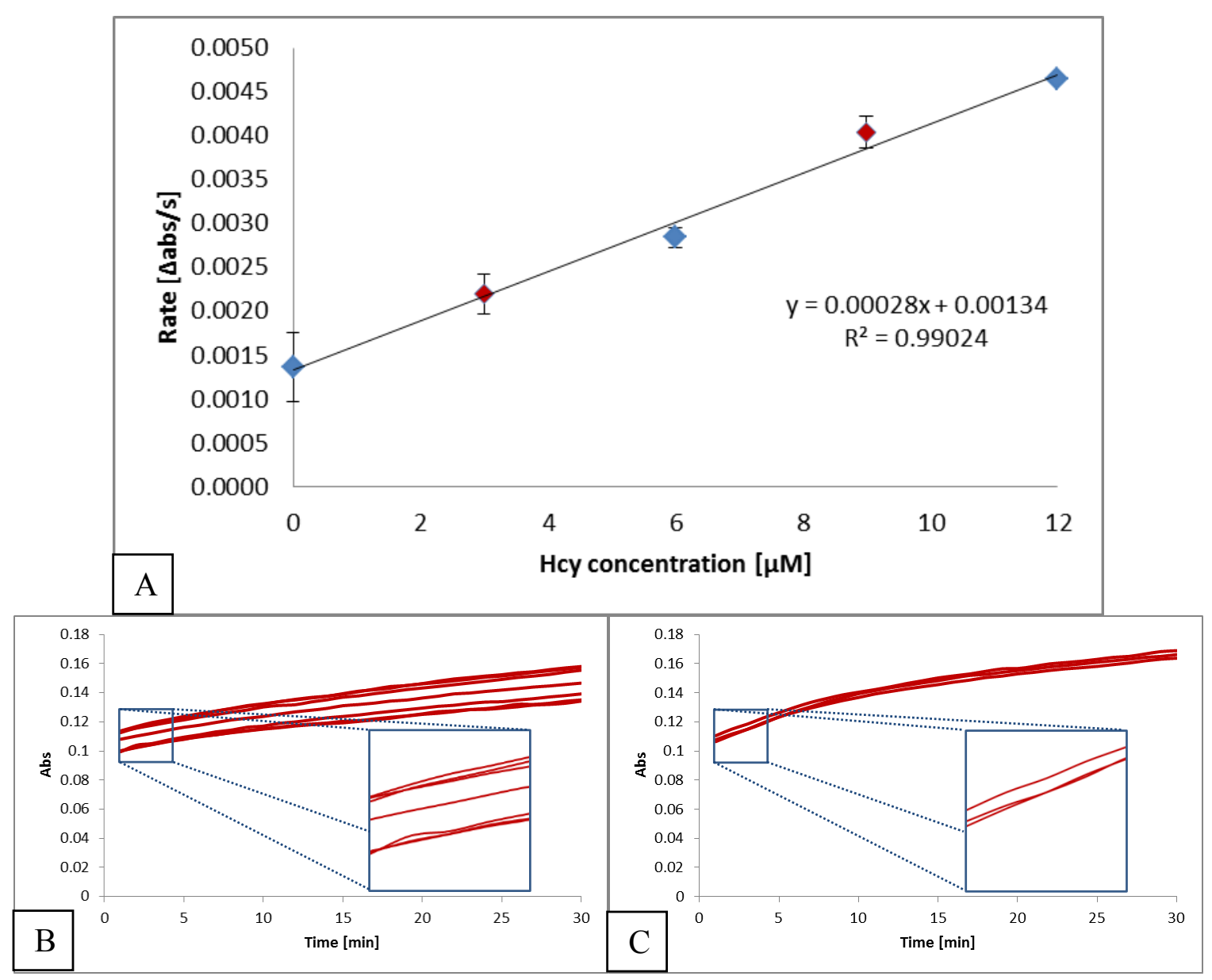

Figure 47. Calibration curve for Hcy using the initial rates of increase. $\lambda_{\text {abs }}=540 \mathrm{~nm}$ (A) Each sample contained 25\% v/v deproteinized bovine plasma, $2.00 \mathrm{mM} \mathrm{pCN}$ probe, $80.0 \mathrm{mM}$ phosphate buffer, $62.5 \mu \mathrm{M}$ Cys, and $1.50 \mu \mathrm{M}$ GSH. Slopes of the first $5 \mathrm{~min}$ of each run were used for the $y$-values. $\mathrm{LOD}=2.40 \mu \mathrm{M}$ and $\mathrm{LOQ}=8.00 \mu \mathrm{M}$. (B) Replicates for $3.00 \mu \mathrm{M}$ Hcy data point. (C) Replicates for $9.00 \mu \mathrm{M}$ Hcy data point.

A major source of imprecision for the replicates was variability introduced by plasma deproteinizion. The aliquots of deproteinized plasma did not appear to be perfectly homogenous, as was evident by the baseline shifting of the spectra from light scattering off suspended particles (Figure 47-BC). Although baseline shifting was significant, the initial rates of $\mathrm{pCN}$ reacting with Hcy were consistent. Therefore, measuring the initial rates for quantification eliminates the interference due to scattering. 
This approach also dramatically reduces the time needed to measure each sample. By the initial rates method, analytical limits were improved from Figure 15-A. The diluted sample solutions were found to have $\mathrm{LOD}=2.40 \mu \mathrm{M}$ and $\mathrm{LOQ}=8.00 \mu \mathrm{M}$. These values correspond to $\mathrm{LOD}=9.60 \mu \mathrm{M}$ and $\mathrm{LOQ}=32.0 \mu \mathrm{M}$ in the plasma after accounting for the dilution.

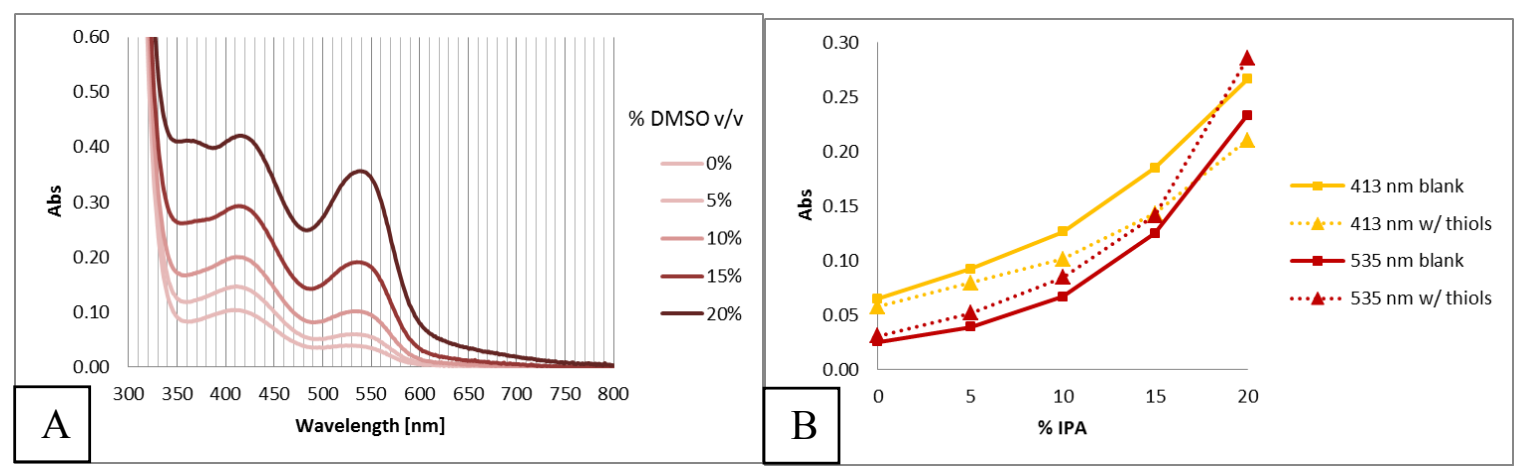

Figure 48. Effect of increasing organic solvent concentration. Data sets corresponding to each graph were collected using $0.500 \mathrm{mM}$ pCN probe in $80.0 \mathrm{mM}$ phosphate buffer at $\mathrm{pH} 8.0$ with absorbances at $30 \mathrm{~min}$ shown. (A) Increasing the ratio of DMSO in the reaction medium of non-analyte blanks revealed another peak which would appear yellow with $\lambda_{\text {abs }}=370 \mathrm{~nm}$. (B) $\lambda_{\text {abs }}$ at 413 and $540 \mathrm{~nm}$ measured for blank solutions and solutions which contained the combined aminothiols: $15.0 \mu \mathrm{M} \mathrm{Hcy,} 250 \mu \mathrm{M}$ Cys, and $6.00 \mu \mathrm{M}$ GSH. 


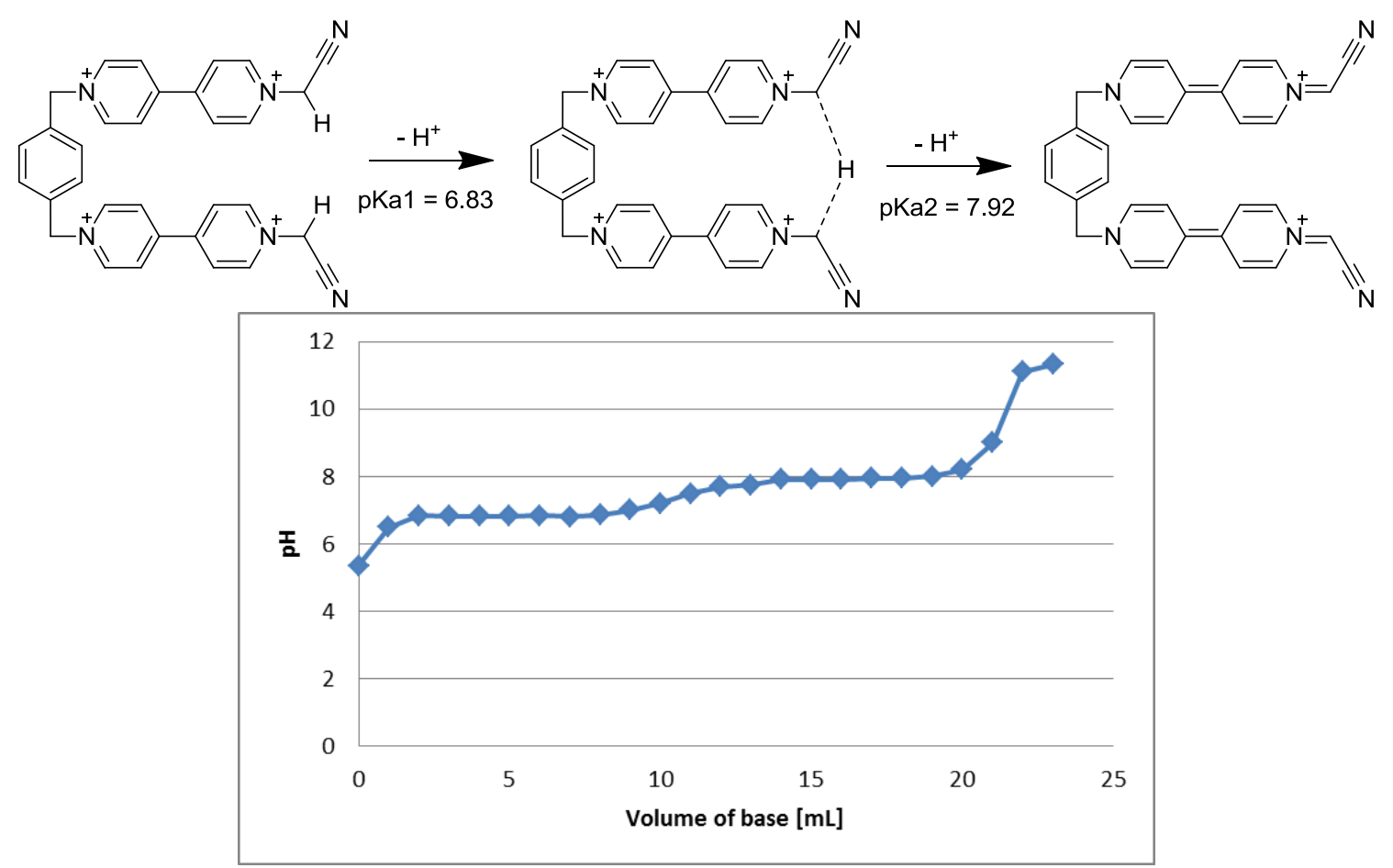

Figure 49. Determination of $\mathrm{pCN}_{\mathrm{pK}}$ values by titration with $\mathrm{NaOH}$. Plateaus at $\mathrm{pH}$ 6.83 and 7.92 indicated two buffer regions corresponding to $\mathrm{pK}_{\mathrm{a} 1}$ and $\mathrm{pK}_{\mathrm{a} 2}$ respectively.
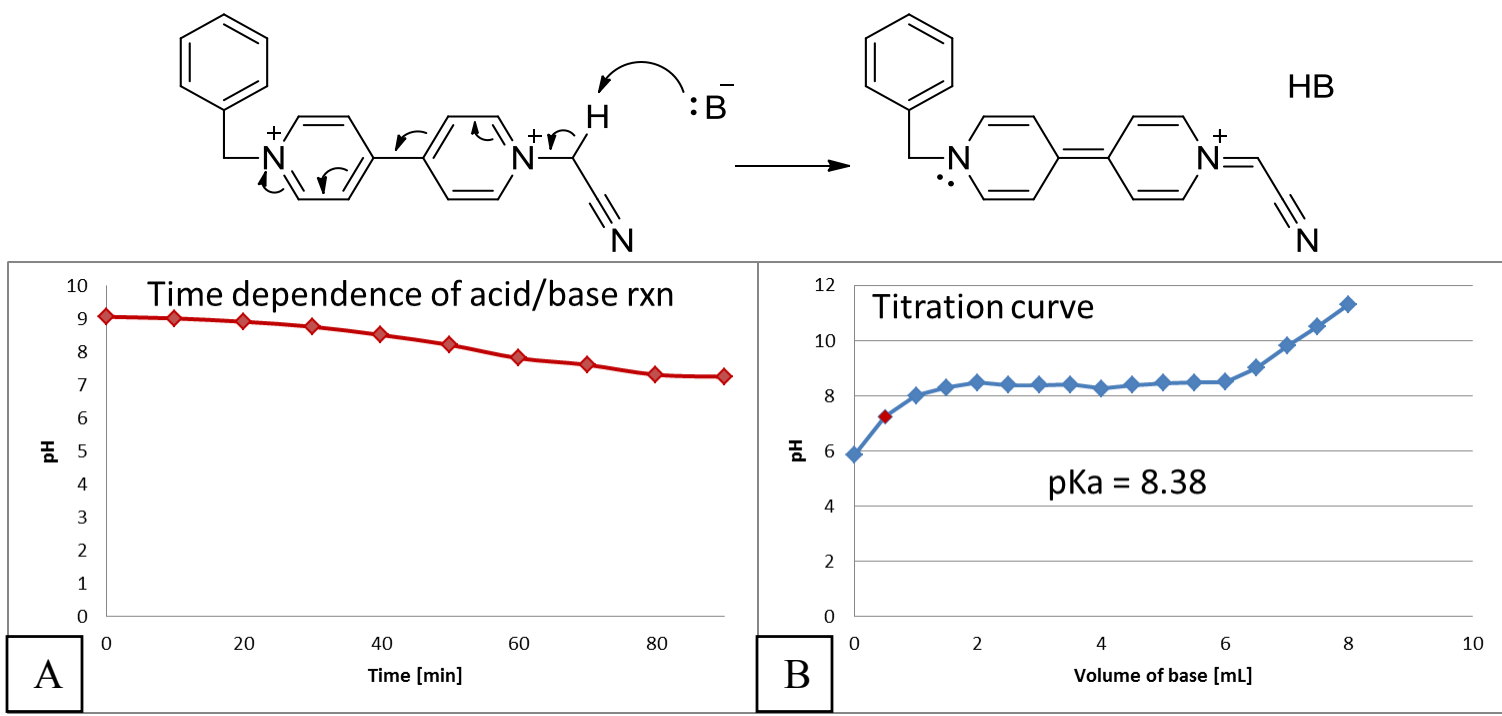

Figure 50. Determination of $\mathrm{BNV}_{\mathrm{pK}}$ by titration with $\mathrm{NaOH}$. (A) Upon the first aliquot of titrant, the $\mathrm{pH}$ spiked and began to drift towards a lower $\mathrm{pH}$, requiring $>1.5$ hours to reach equilibrium. Subsequent additions of titrant required moderately less time to equilibrate. (B) The buffer region indicated a $\mathrm{pK}_{\mathrm{a}}$ of 8.38 . 


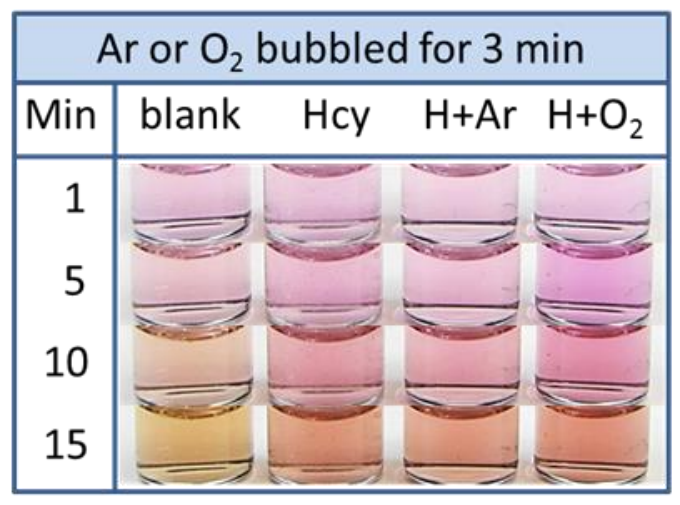

Figure 51. Dissolved oxygen increased the initial rate of absorbance at $540 \mathrm{~nm}$. Reaction conditions: $2.00 \mathrm{mM}$ pCN probe in $80.0 \mathrm{mM}$ phosphate buffer $\mathrm{pH} 8.0$ with 15.0 $\mu \mathrm{M}$ of Hcy in vials labeled 'Hcy,' ' $\mathrm{H}+\mathrm{Ar}$,' and ' $\mathrm{H}+\mathrm{O}_{2}$.'

Figure 51 shows the pCN probe response in relation to dissolved oxygen concentration. Vials labeled 'blank' and 'Hcy' were not gassed before the addition of probe. Argon or oxygen was bubbled through the bulk buffer solutions in the vials labeled ' $\mathrm{H}+\mathrm{Ar}$ ' or ' $\mathrm{H}+\mathrm{O}_{2}$ ' respectively for $3 \mathrm{~min}$ before the addition of probe. Gassing with inert argon decreases the relative concentration of dissolved oxygen by displacement. Likewise, gassing with oxygen enriches the oxygen content of solutions. At time points 5 and $10 \mathrm{~min}, \lambda_{\mathrm{abs}}=540 \mathrm{~nm}$ was the most intense for the vial corresponding to the highest oxygen concentration. The 'H+Ar' vial, corresponding to the lowest oxygen content, had an attenuated response at $540 \mathrm{~nm}$ compared to the nongassed 'Hcy' vial. 


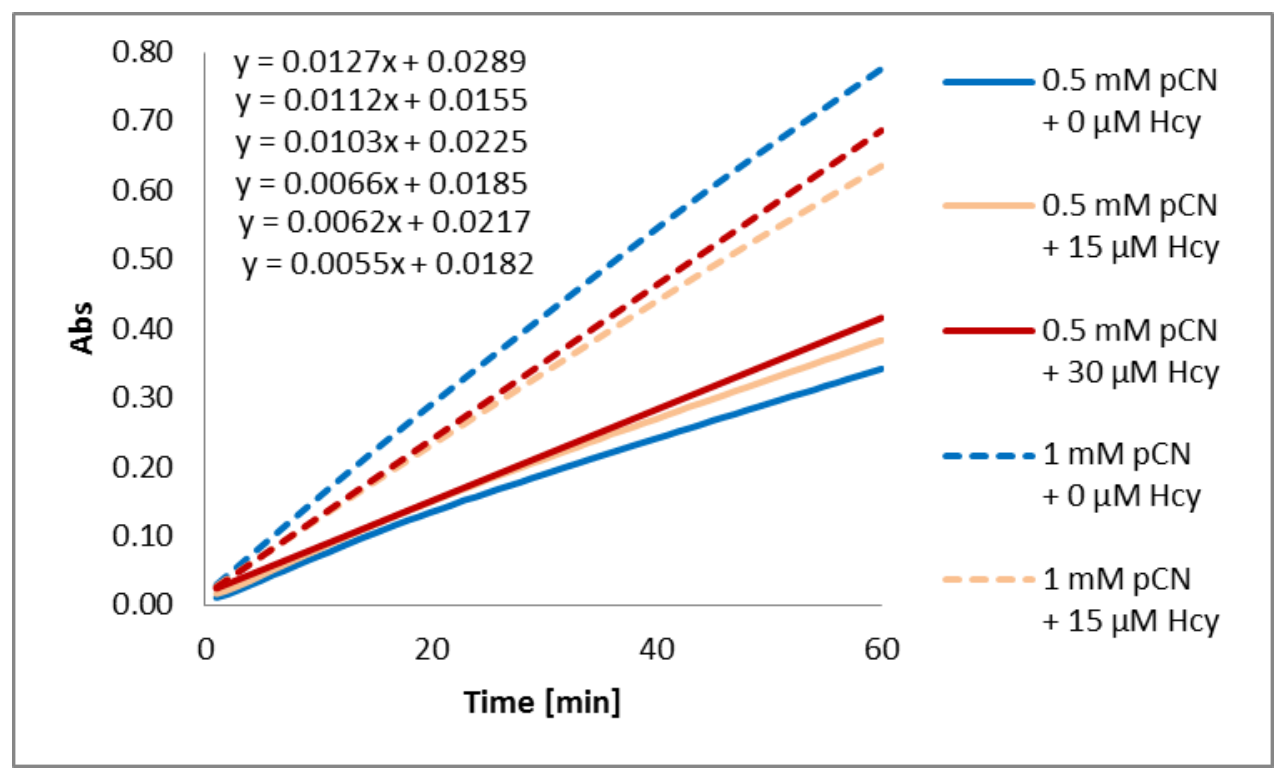

Figure 52. Slopes of $\lambda_{\mathrm{abs}}=413 \mathrm{~nm}$ used to estimate rates of formation for non-radical pCN probe product. Measurements performed in $80.0 \mathrm{mM}$ phosphate buffer $\mathrm{pH} 8.0$ with $15 \% \mathrm{v} / \mathrm{v}$ IPA.

Although the evolution of reaction products is a dynamic process with competitive consecutive and parallel reactions, the essentially $1^{\text {st }}$ order rate of increase at $\lambda_{\mathrm{abs}}=413 \mathrm{~nm}$ with respect to $\mathrm{pCN}$ suggests a unimolecular transition state where the labile hydrogen of the probe dissociates before pCN interacts with Hcy (Table 2).

Table 2. Reaction orders for non-radical $\mathrm{pCN}$ probe product with respect to $\mathrm{pCN}$ probe and Hcy analyte. Rates obtained from Figure 52.

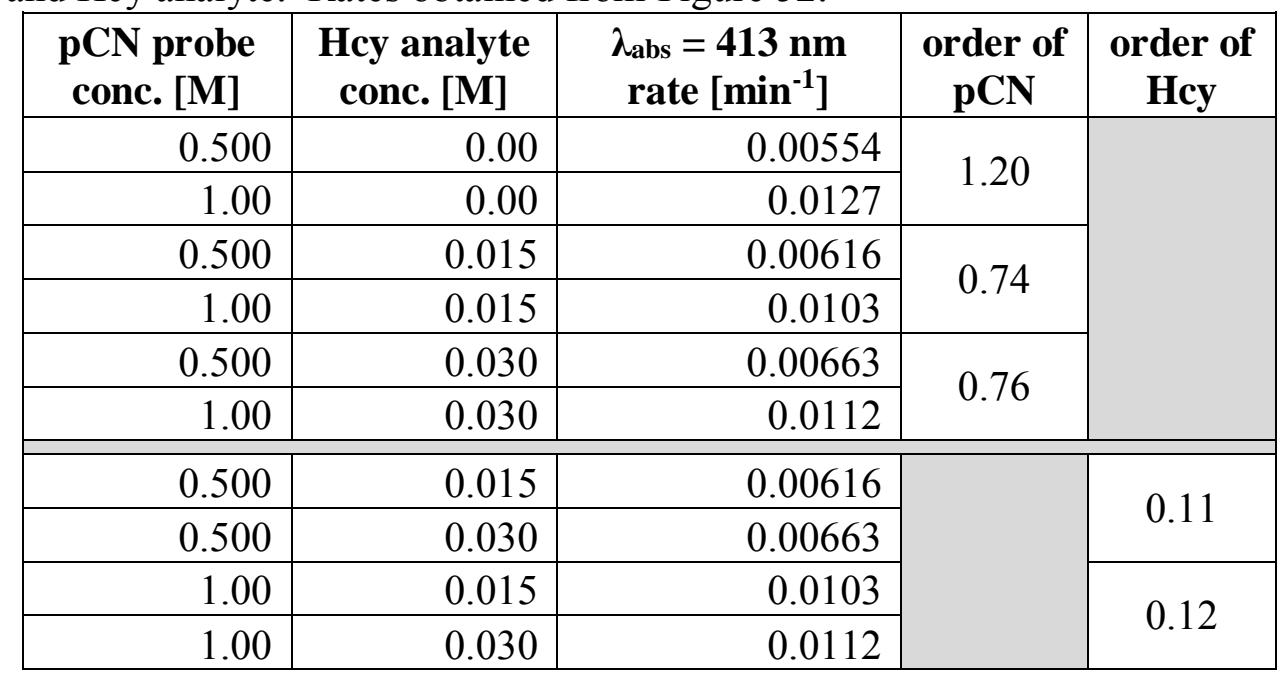



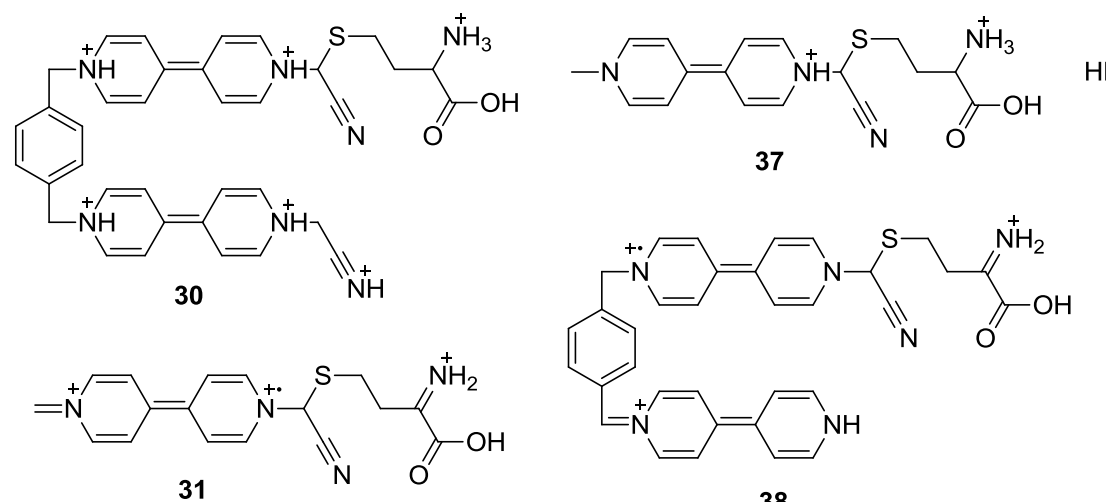

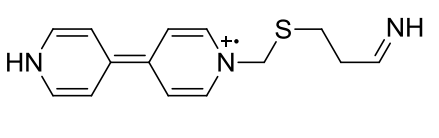

38

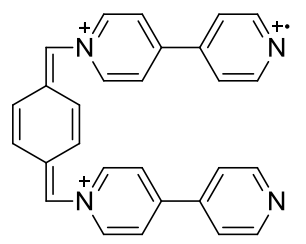

32
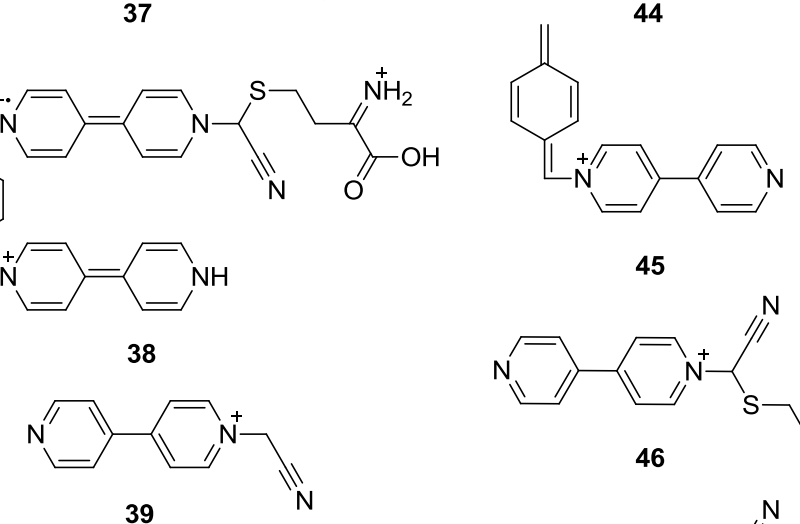

45

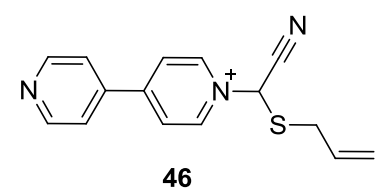

46
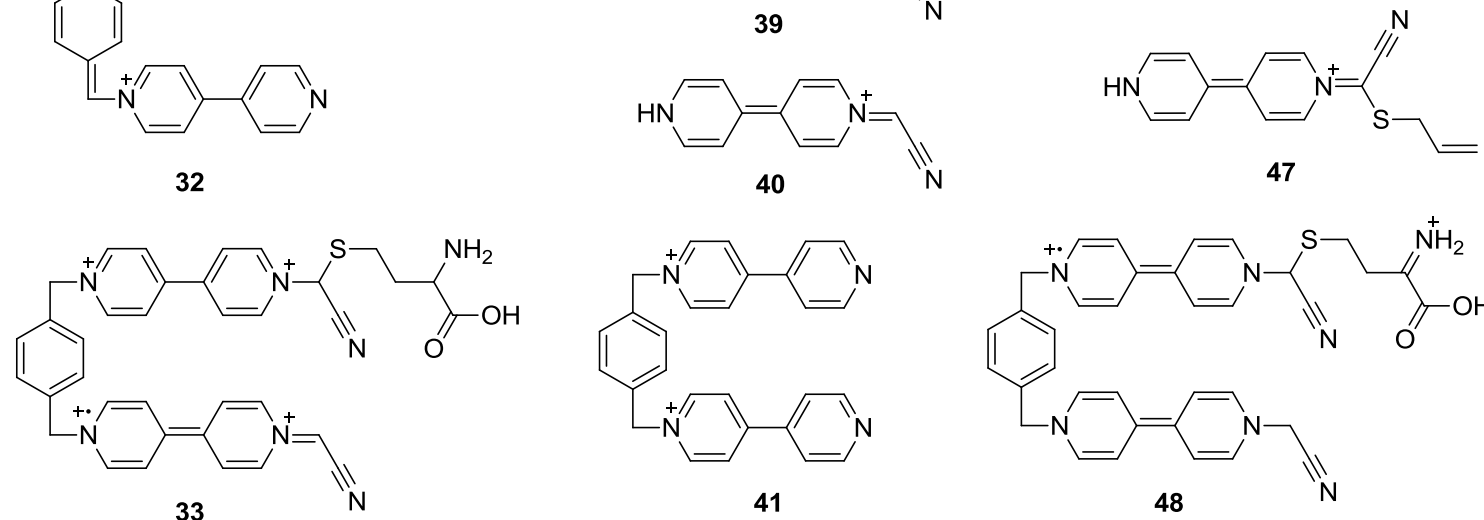

41
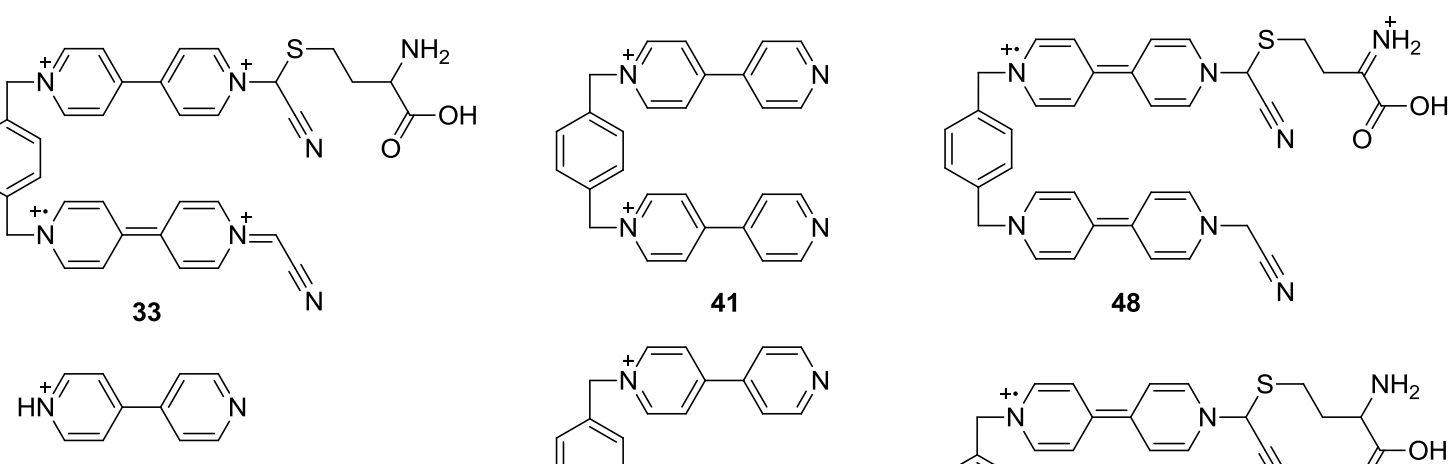

34
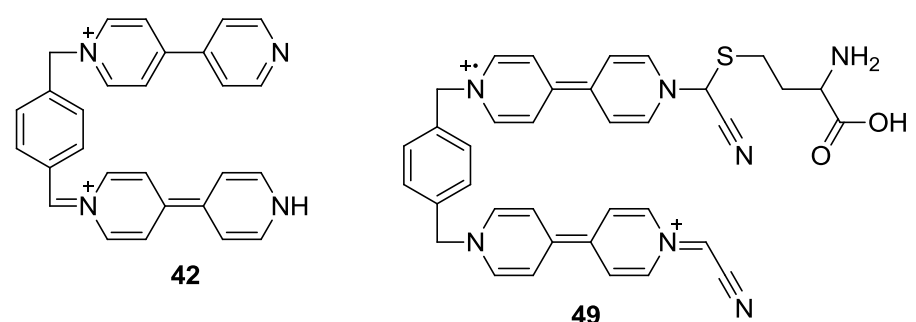

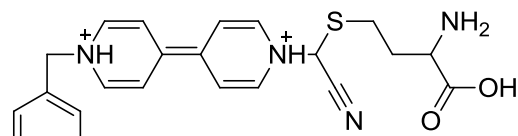
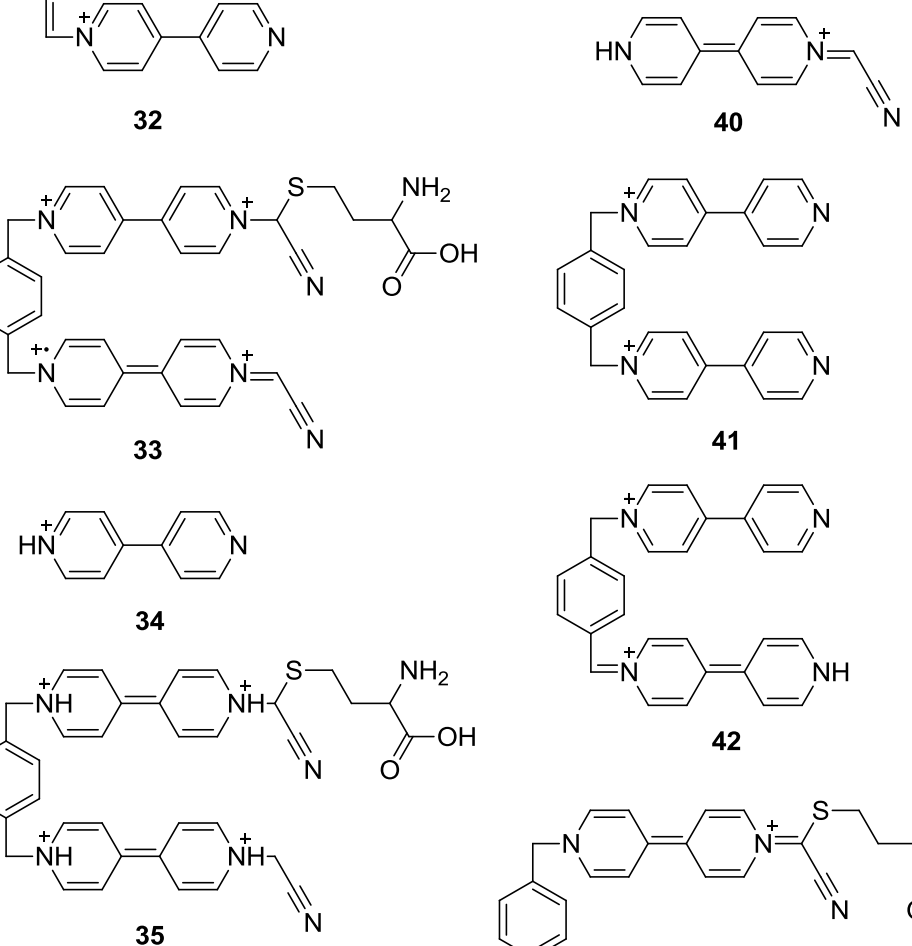

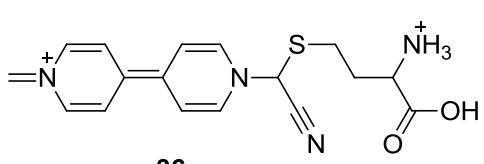

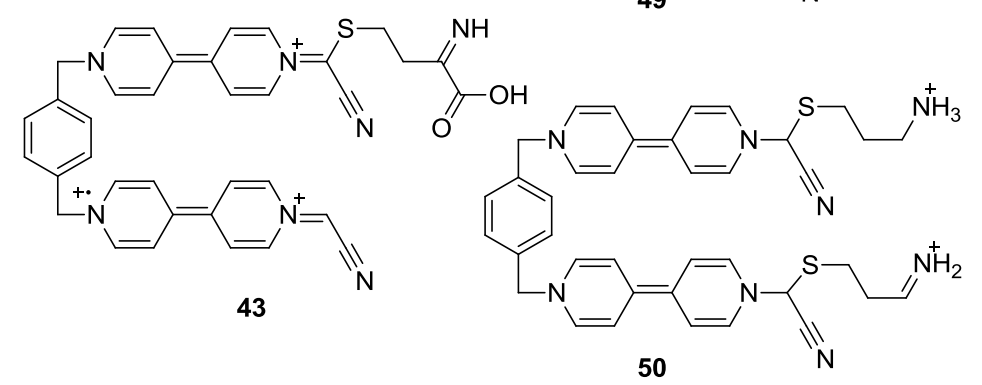

Figure 53. Structures of ions $\mathbf{3 0}-\mathbf{5 0}$ identified in the mass spectra of the pCN and Hcy reaction mixture. 


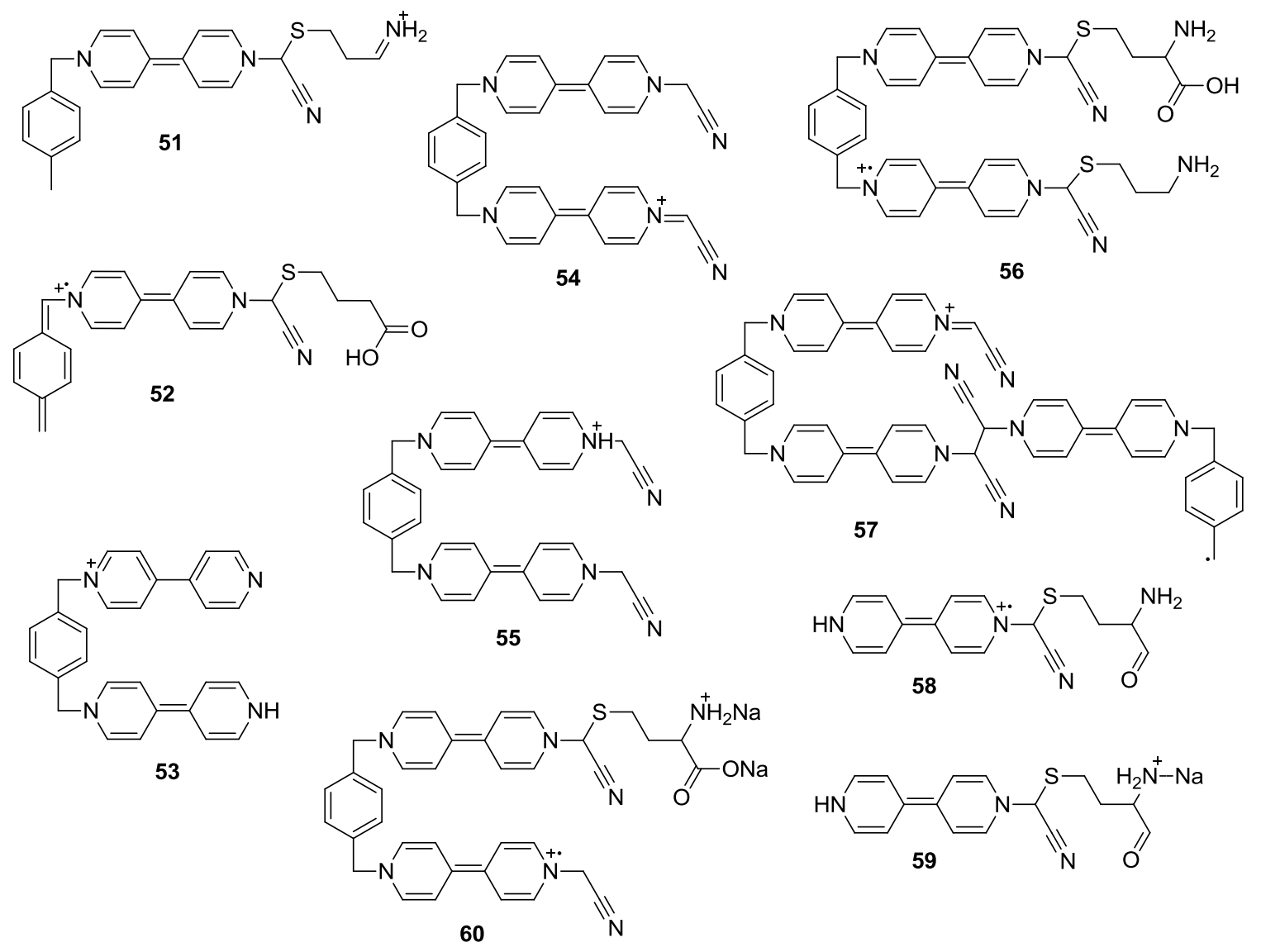

Figure 54. Structures of ions $\mathbf{5 1}-\mathbf{6 0}$ identified in the mass spectra of the $\mathrm{pCN}$ and Hcy reaction mixture.

Table 3. Masses of ions identified in the mass spectra of the $\mathrm{pCN}$ and Hcy reaction mixture. $\mathrm{NF}=$ not found. Full specta can be found in Appendix C.

\begin{tabular}{|c|c|c|c|}
\hline Ion $\#$ & Calculated $\mathrm{m} / \mathrm{z}$ & Found $\mathrm{m} / \mathrm{z}$ MALDI & Found $\mathrm{m} / \mathrm{z}$ ESI \\
\hline $\mathbf{3 0}$ & $105.88,106.05$ & $105.80,106.09$ & $\mathrm{NF}$ \\
\hline $\mathbf{3 1}$ & 114.04 & $\mathrm{NF}$ & 14.03 \\
\hline $\mathbf{3 2}$ & 138.06 & $\mathrm{NF}$ & 138.08 \\
\hline $\mathbf{3 3}$ & 157.06 & $\mathrm{NF}$ & 157.06 \\
\hline $\mathbf{3 4}$ & 157.08 & $\mathrm{NF}$ & 157.06 \\
\hline $\mathbf{3 5}$ & 158.32 & 158.34 & $\mathrm{NF}$ \\
\hline $\mathbf{3 6}$ & 172.06 & 172.07 & $\mathrm{NF}$ \\
\hline $\mathbf{3 7}$ & 173.07 & $172.93,173.20$ & $\mathrm{NF}$ \\
\hline $\mathbf{3 8}$ & 196.08 & $\mathrm{NF}$ & 196.08 \\
\hline $\mathbf{3 9}$ & 196.09 & $\mathrm{NF}$ & 196.08 \\
\hline $\mathbf{4 0}$ & 196.09 & $\mathrm{NF}$ & 196.08 \\
\hline $\mathbf{4 1}$ & $208.10,208.60$ & 208.63 & $208.10,208.57$ \\
\hline $\mathbf{4 2}$ & $208.10,208.60$ & 208.63 & $208.10,208.57$ \\
\hline
\end{tabular}




\begin{tabular}{|c|c|c|c|}
\hline $\mathbf{4 3}$ & 208.41 & $\mathrm{NF}$ & 208.57 \\
\hline $\mathbf{4 4}$ & 259.11 & 259.14 & 259.12 \\
\hline $\mathbf{4 5}$ & 259.12 & 259.14 & 259.10 \\
\hline $\mathbf{4 6}$ & 268.09 & 268.11 & 268.09 \\
\hline $\mathbf{4 7}$ & 268.09 & 268.11 & 268.09 \\
\hline $\mathbf{4 8}$ & 314.12 & 314.12 & 314.09 \\
\hline $\mathbf{4 9}$ & 314.12 & 314.12 & 314.09 \\
\hline $\mathbf{5 0}$ & 337.15 & 337.17 & $\mathrm{NF}$ \\
\hline $\mathbf{5 1}$ & 389.18 & 389.19 & $\mathrm{NF}$ \\
\hline $\mathbf{5 2}$ & 417.15 & 417.19 & 417.16 \\
\hline $\mathbf{5 3}$ & 417.21 & 417.19 & 417.16 \\
\hline $\mathbf{5 4}$ & 495.23 & $\mathrm{NF}$ & 495.13 \\
\hline $\mathbf{5 5}$ & 497.24 & $\mathrm{NF}$ & 497.13 \\
\hline $\mathbf{5 6}$ & 718.29 & 718.31 & $\mathrm{NF}$ \\
\hline $\mathbf{5 7}$ & 793.36 & 793.35 & $\mathrm{NF}$ \\
\hline $\mathbf{5 8}$ & 314.12 & 314.12 & 314.09 \\
\hline $\mathbf{5 9}$ & 337.11 & 337.17 & $\mathrm{NF}$ \\
\hline $\mathbf{6 0}$ & 337.11 & 337.17 & $\mathrm{NF}$ \\
\hline
\end{tabular}

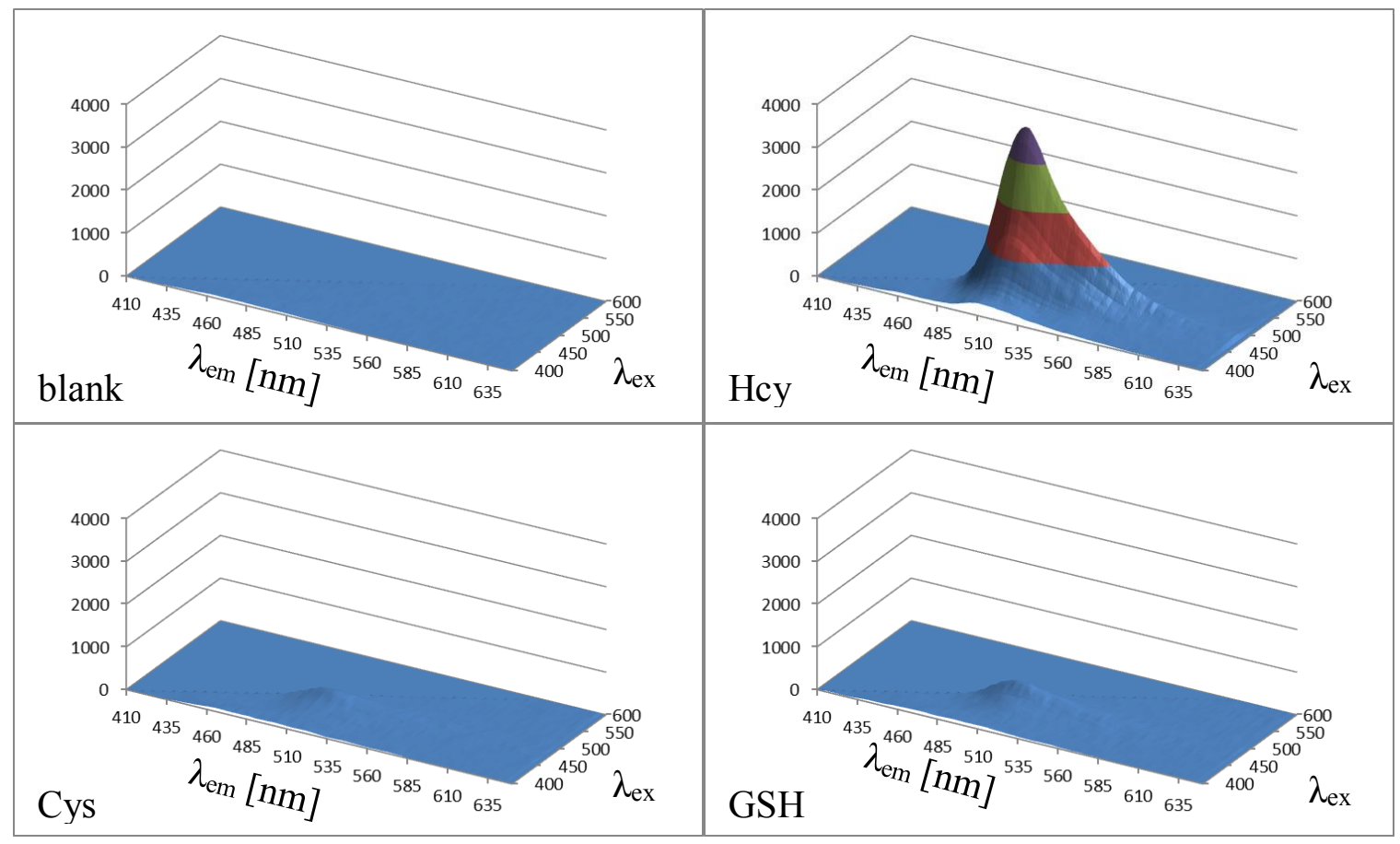

Figure 55. Fluorescence selectivity for Hcy with $50.0 \mu \mathrm{M} \mathrm{mAC}$ in $80.0 \mathrm{mM}$ phosphate buffer $\mathrm{pH} 6.0$ with $200 \mu \mathrm{M}$ of the indicated thiol. $\lambda_{\mathrm{ex}} / \lambda_{\mathrm{em}}=485 / 510 \mathrm{~nm}$. After $12 \mathrm{hr}$. 


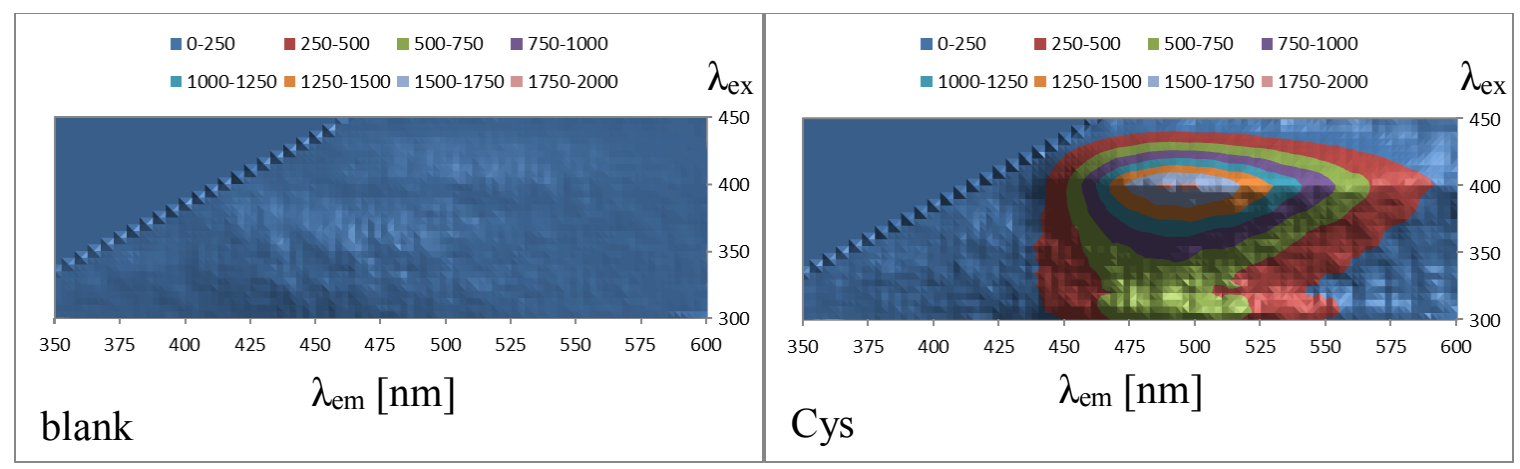

Figure 56. Comparison of oCN blank and $200 \mu \mathrm{M}$ of Cys in $80.0 \mathrm{mM}$ phosphate buffer at pH 6.0 after $1 \mathrm{hr}$. Max $\lambda_{\mathrm{ex}} / \lambda_{\mathrm{em}}=405 / 500 \mathrm{~nm}$. oCN response was selective for Cys at pH 8.0 (not shown).

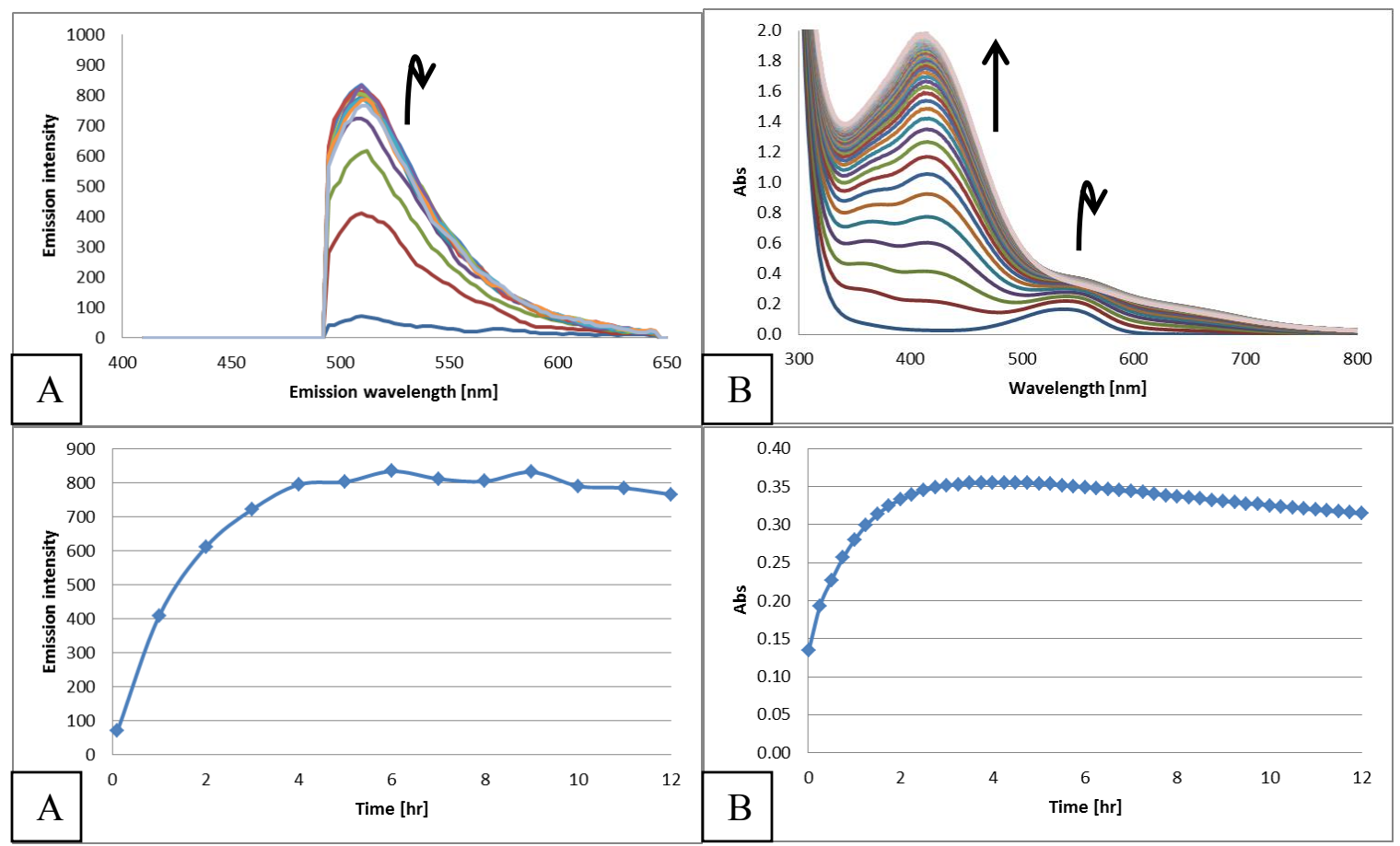

Figure 57. Rate of change in viologen $\lambda_{\text {em }}$ mirrored $\lambda_{\text {abs }}$ in $80.0 \mathrm{mM}$ phosphate buffer at pH 8.0 without analyte. (A) Fluorescence of $50.0 \mu \mathrm{M}$ pCN, top: $\lambda_{\text {ex }}=480 \mathrm{~nm}$ with a scan every hour for $12 \mathrm{hrs}$, bottom: $\lambda_{\mathrm{ex}} / \lambda_{\mathrm{em}}=480 / 510 \mathrm{~nm}$. (B) Absorbance of $1.00 \mathrm{mM}$ pCN with $15 \% \mathrm{v} / \mathrm{v}$ IPA, top: spectrum scanned every $15 \mathrm{~min}$ for $12 \mathrm{hrs}$, bottom: plot of $\lambda_{\mathrm{abs}}=540 \mathrm{~nm}$. 
Appendix B: NMR Spectra

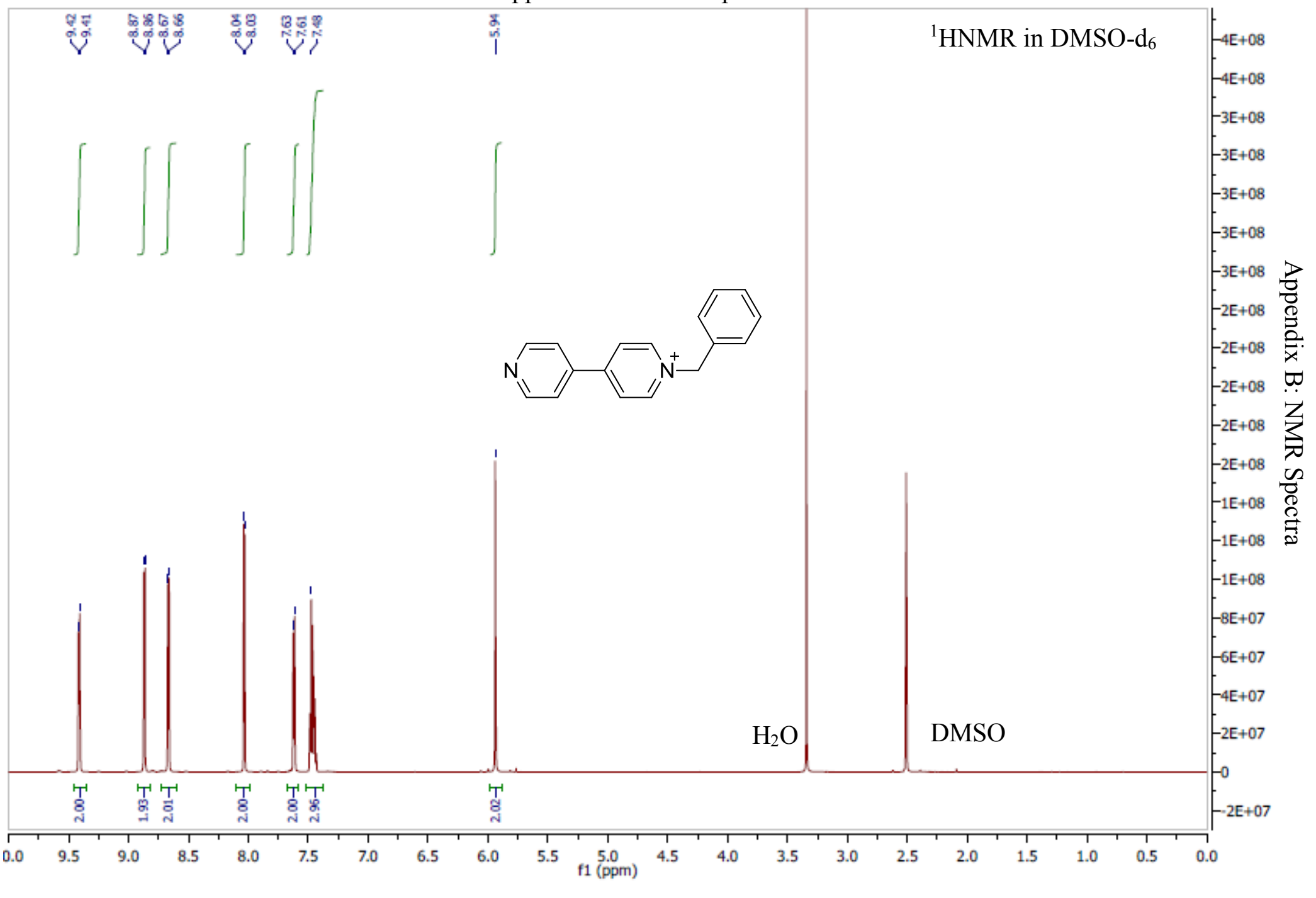




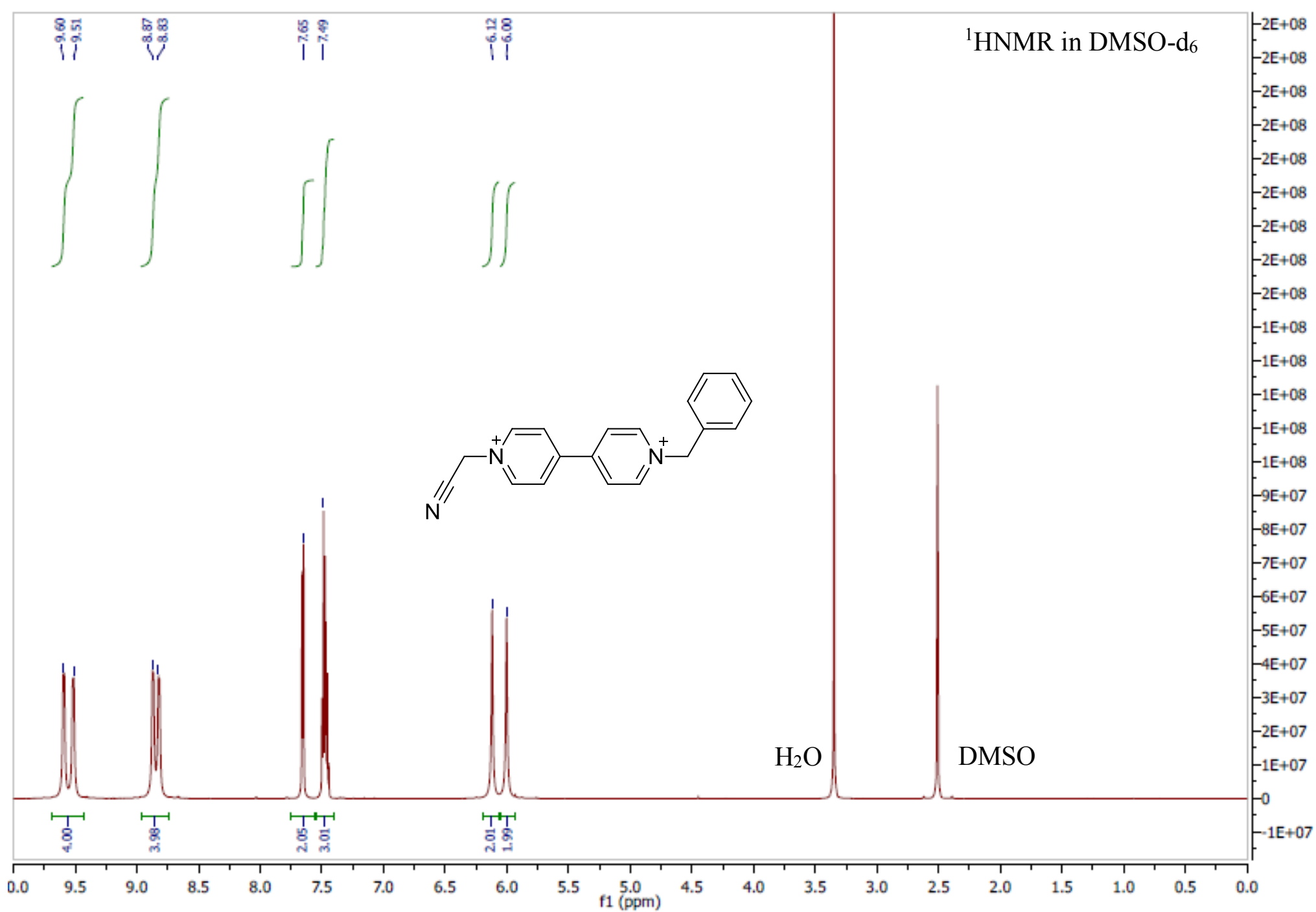




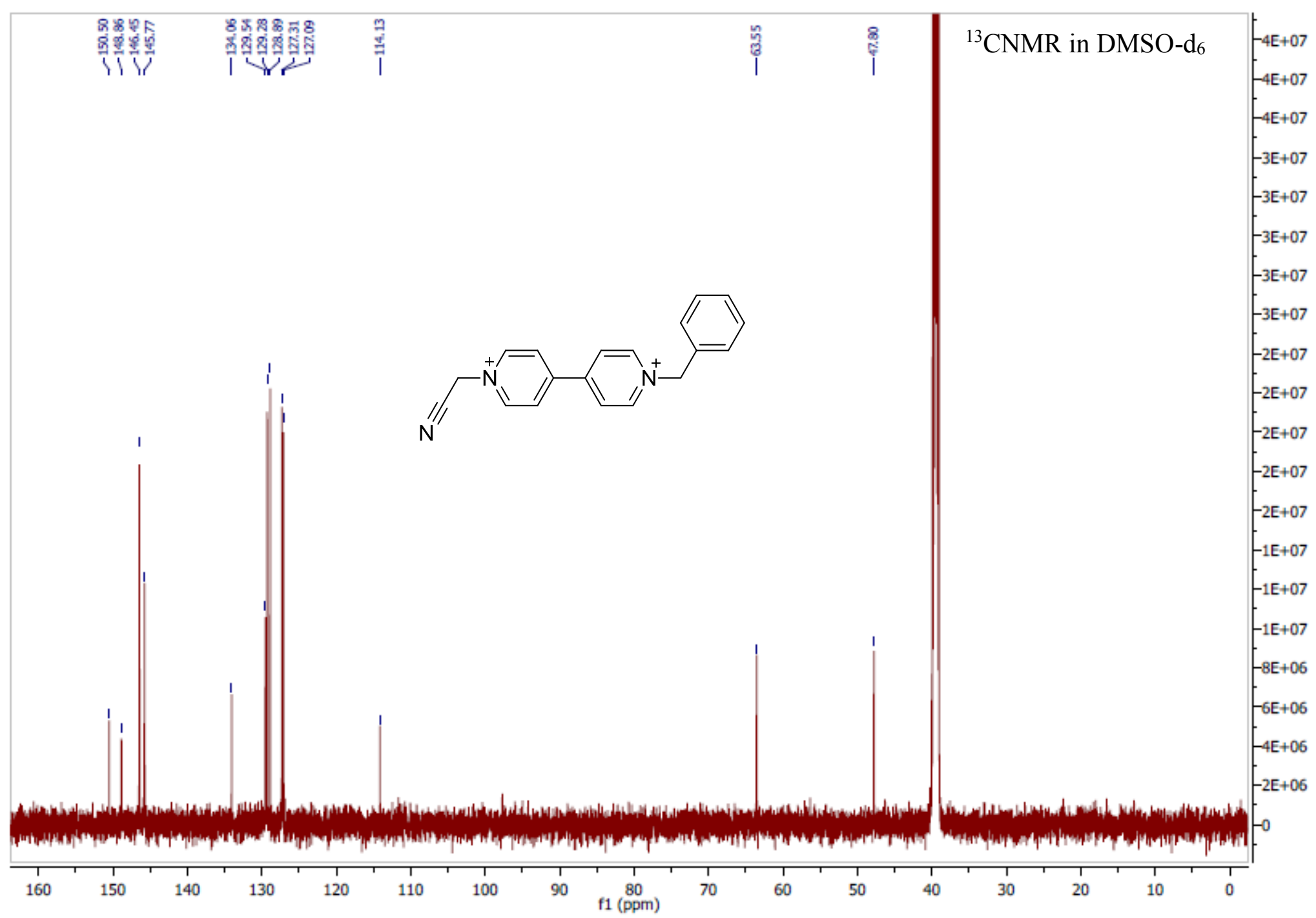




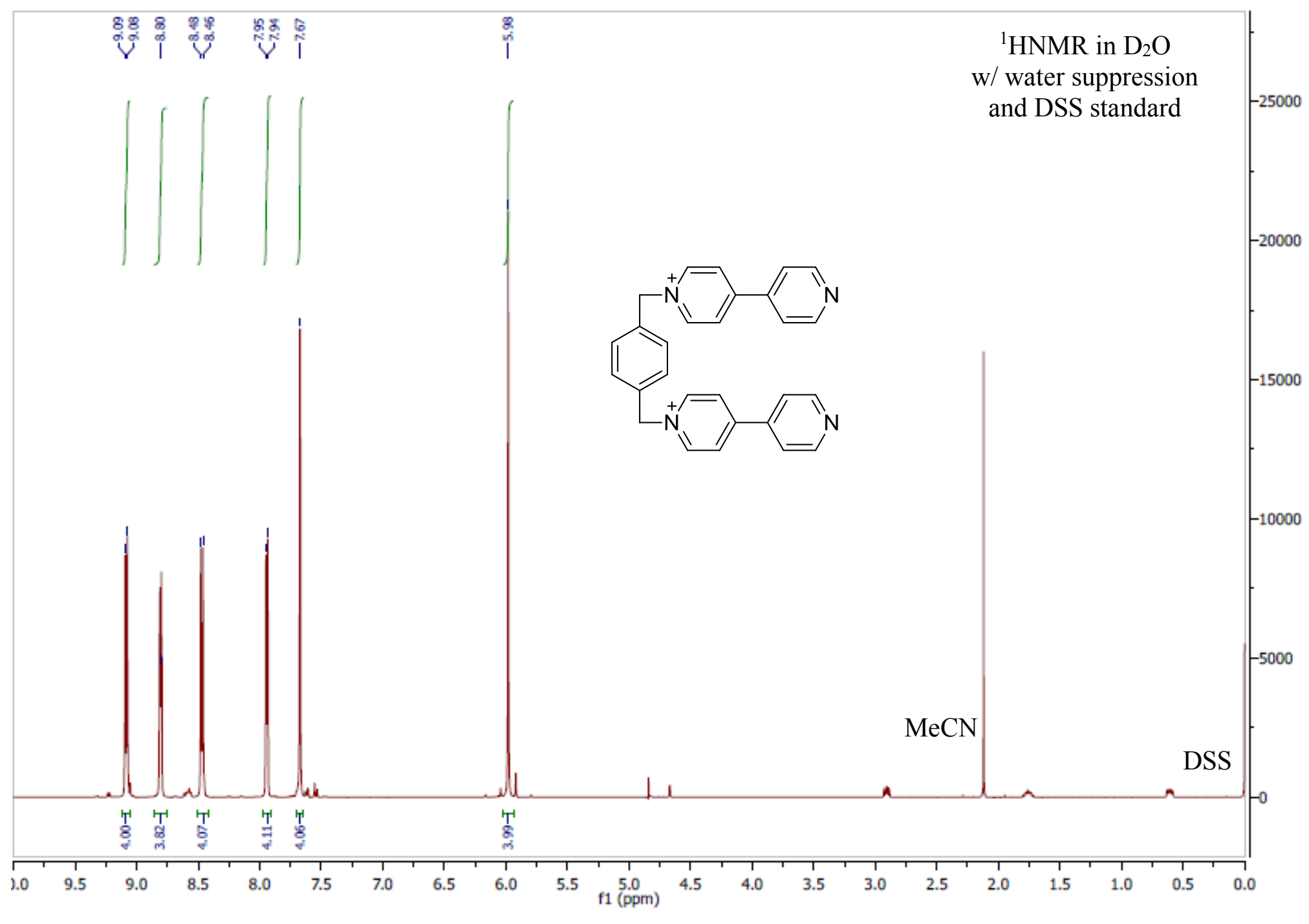




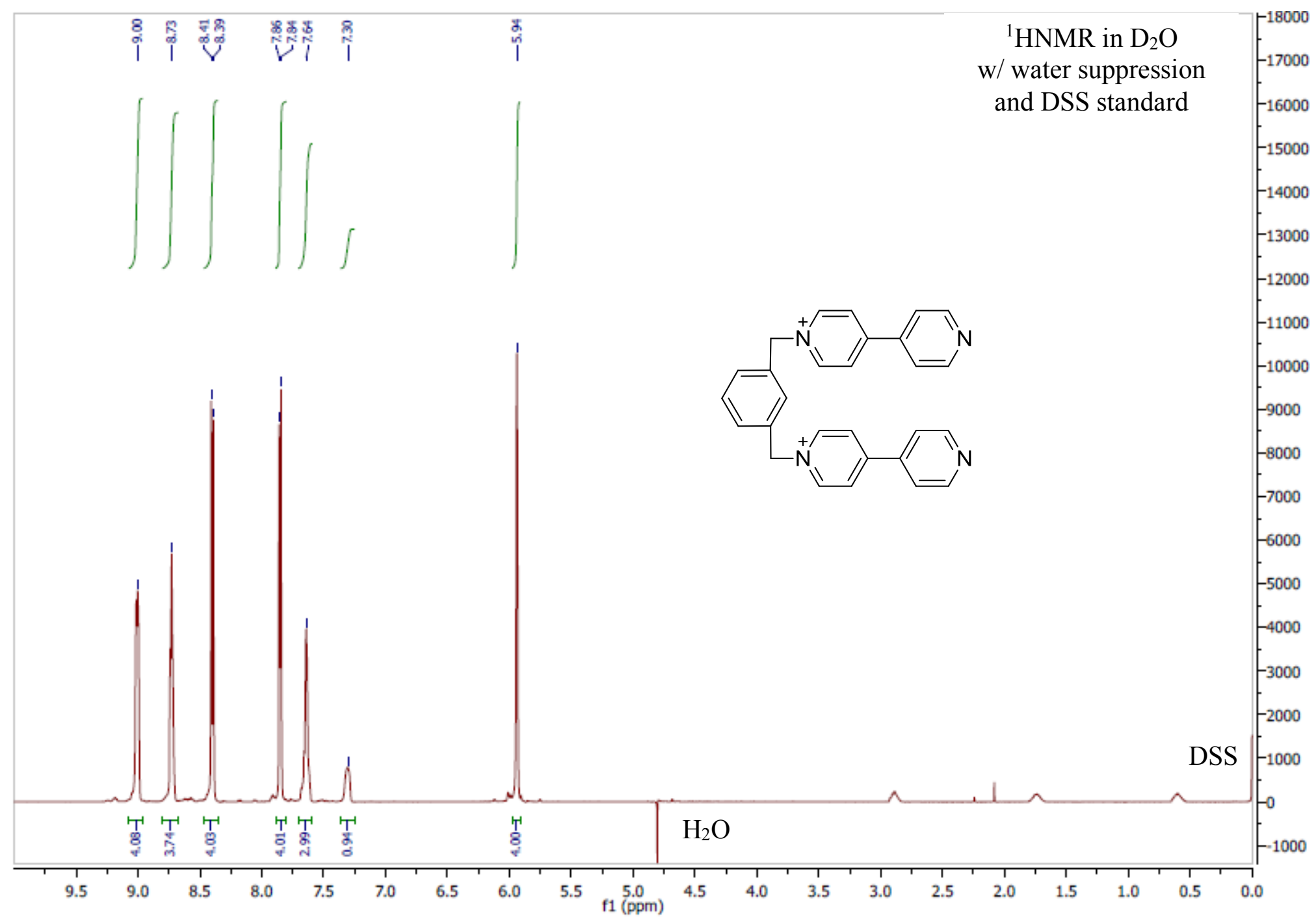




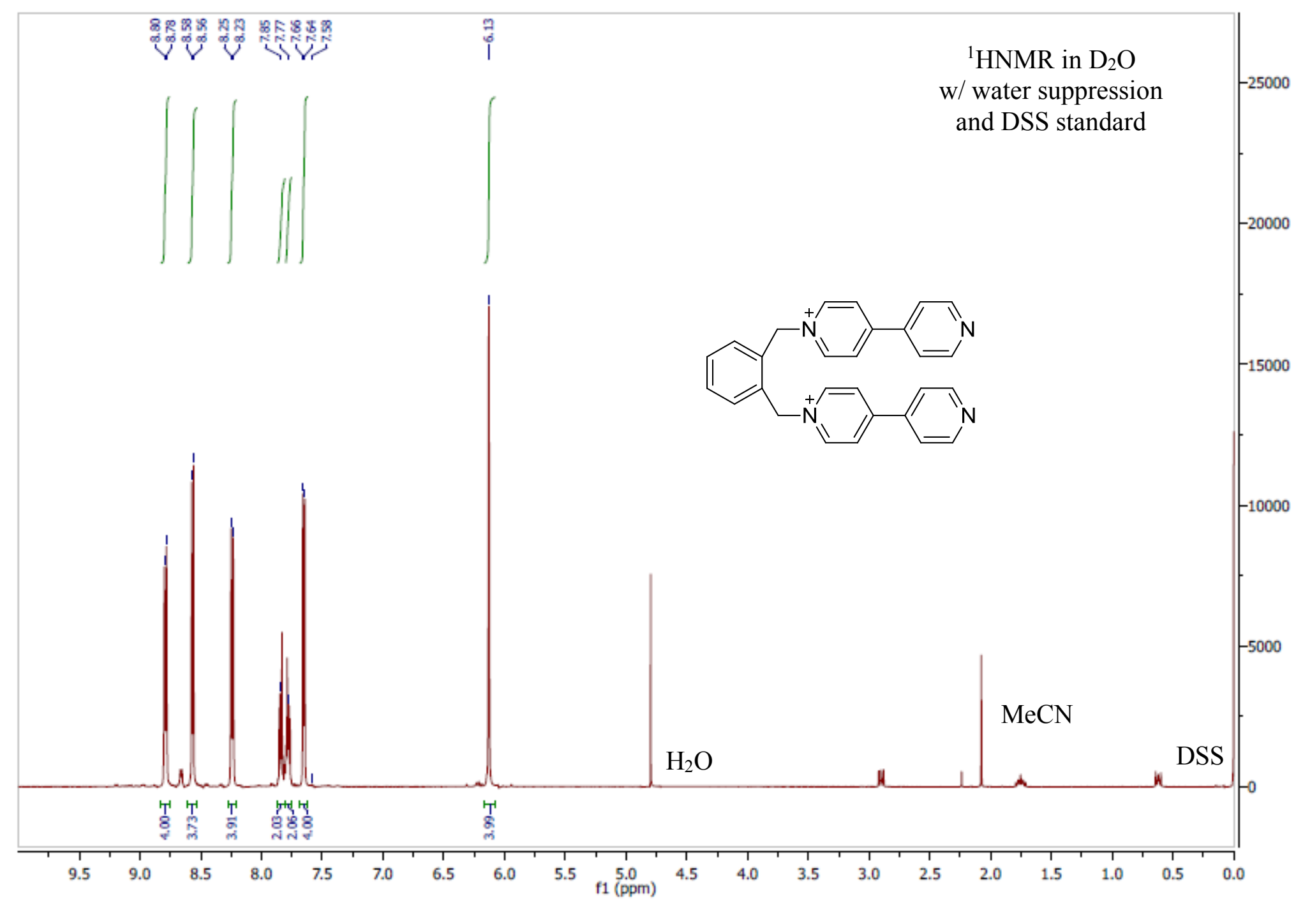

$\overline{8}$ 


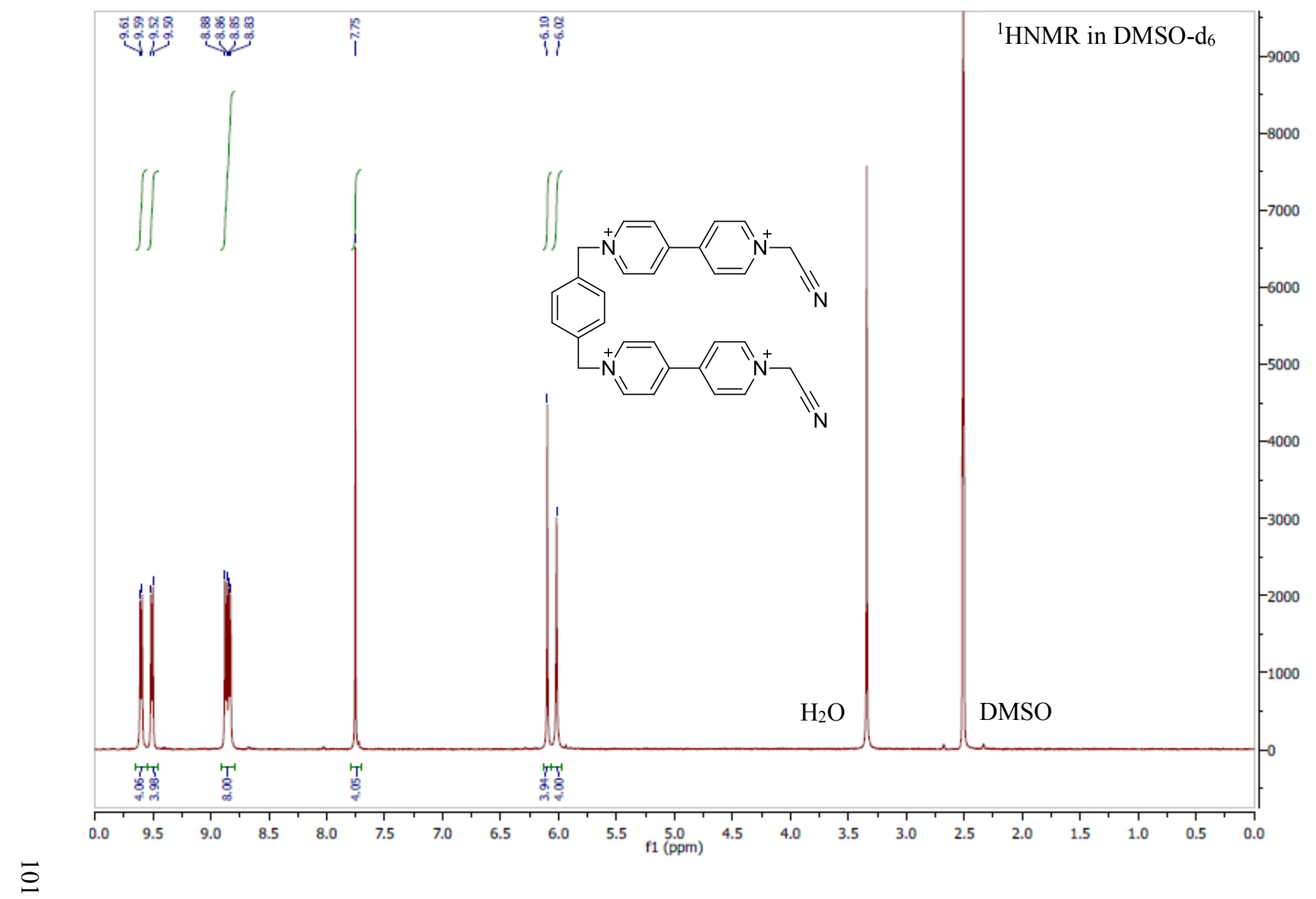




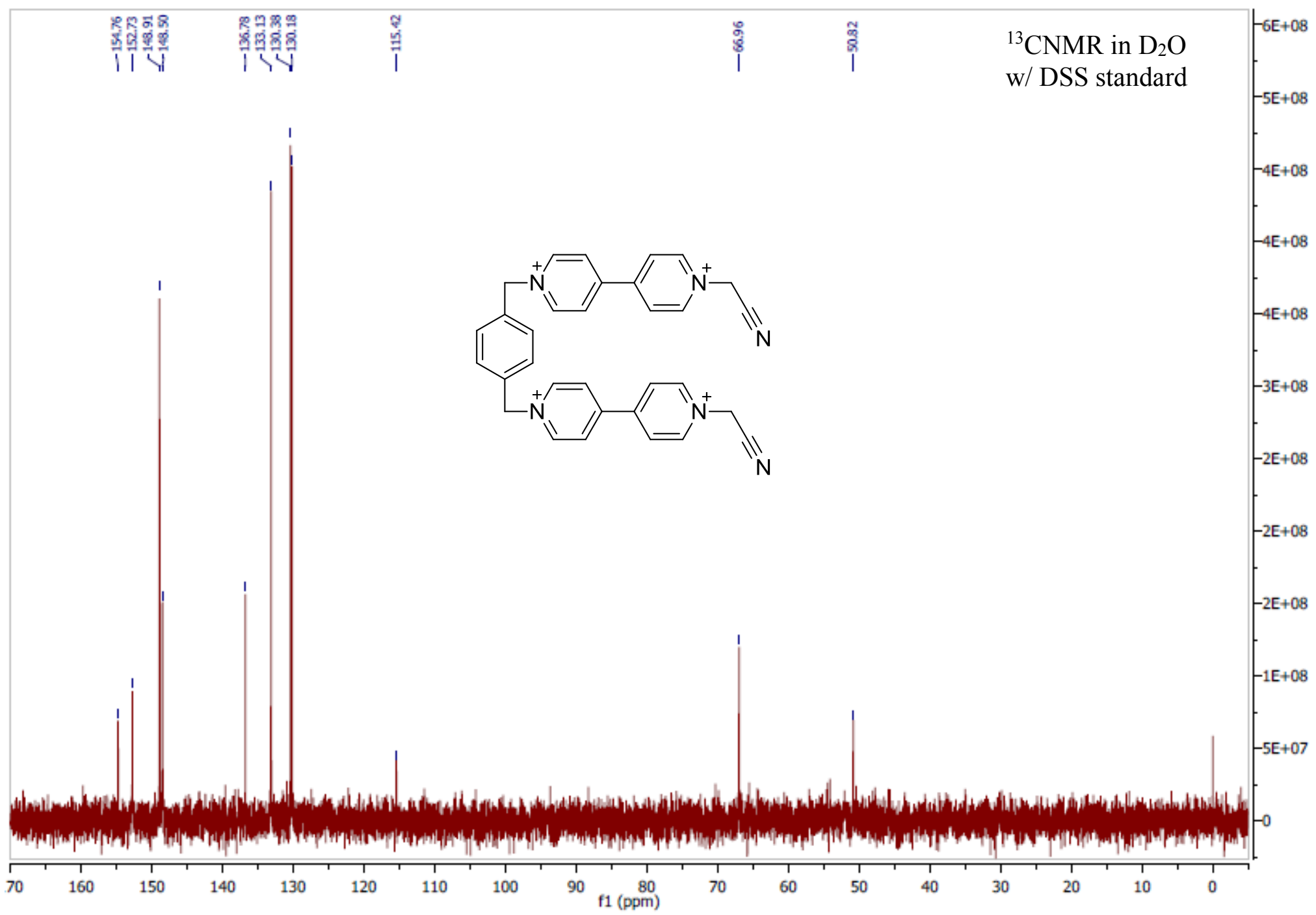




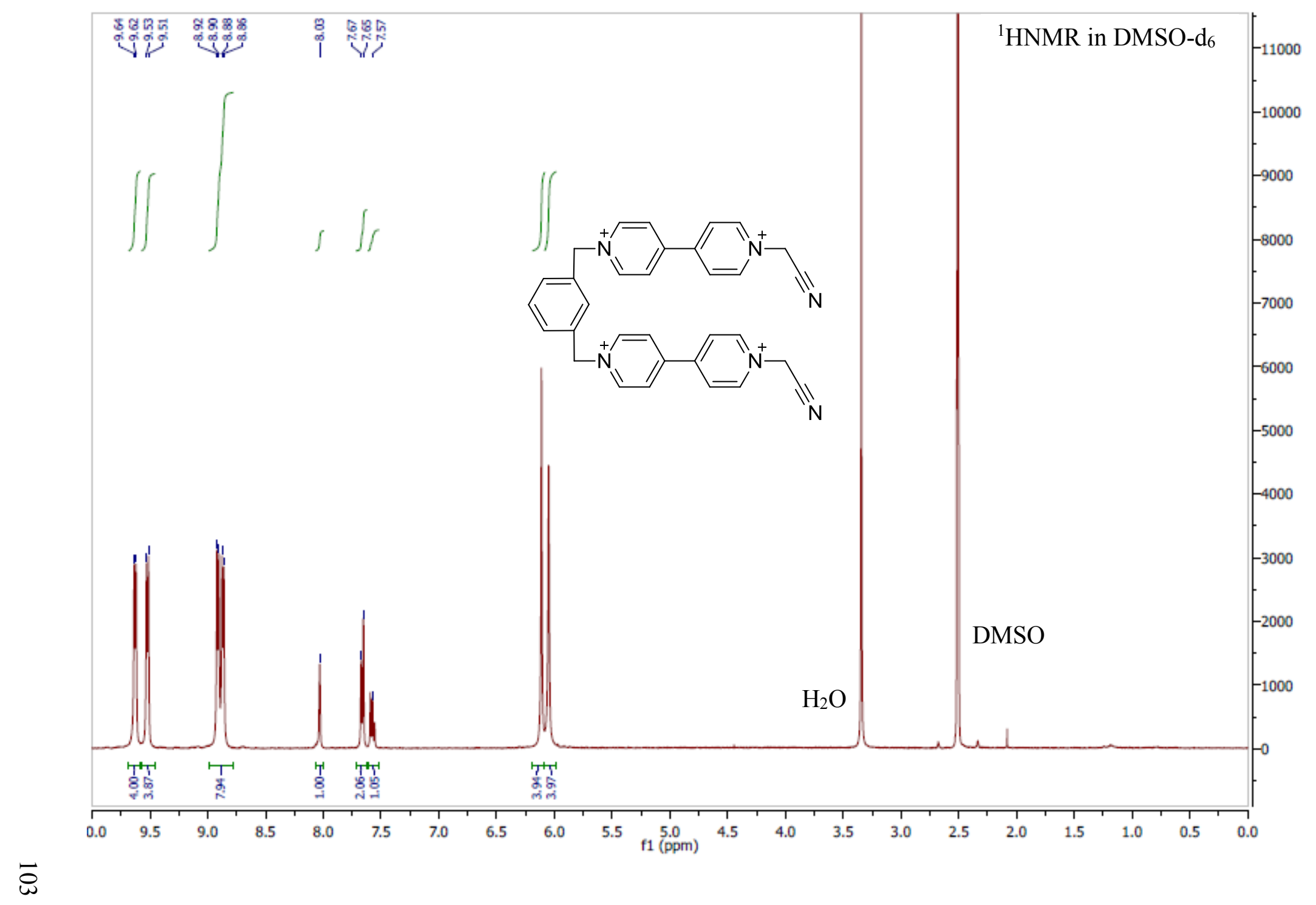




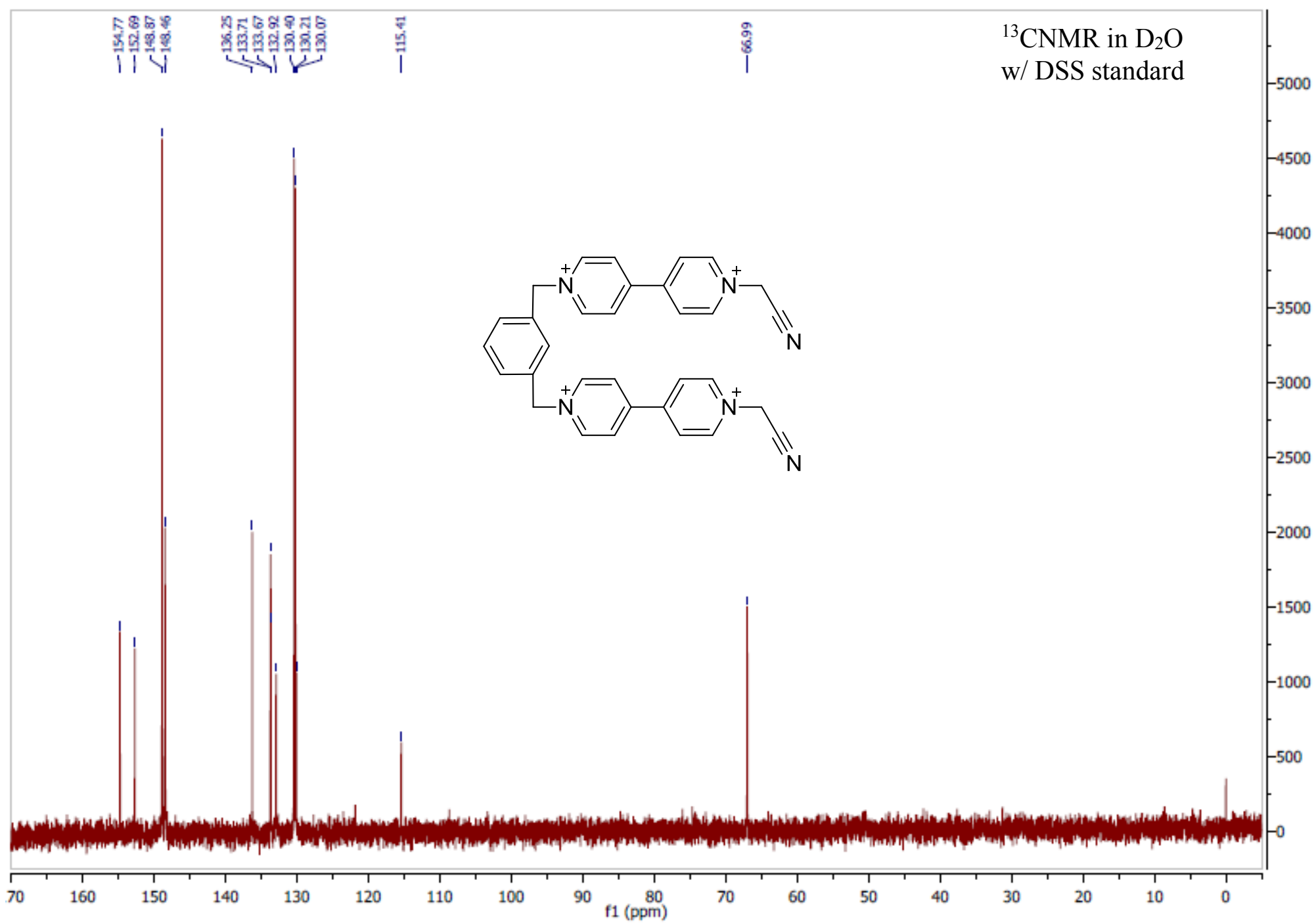

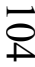




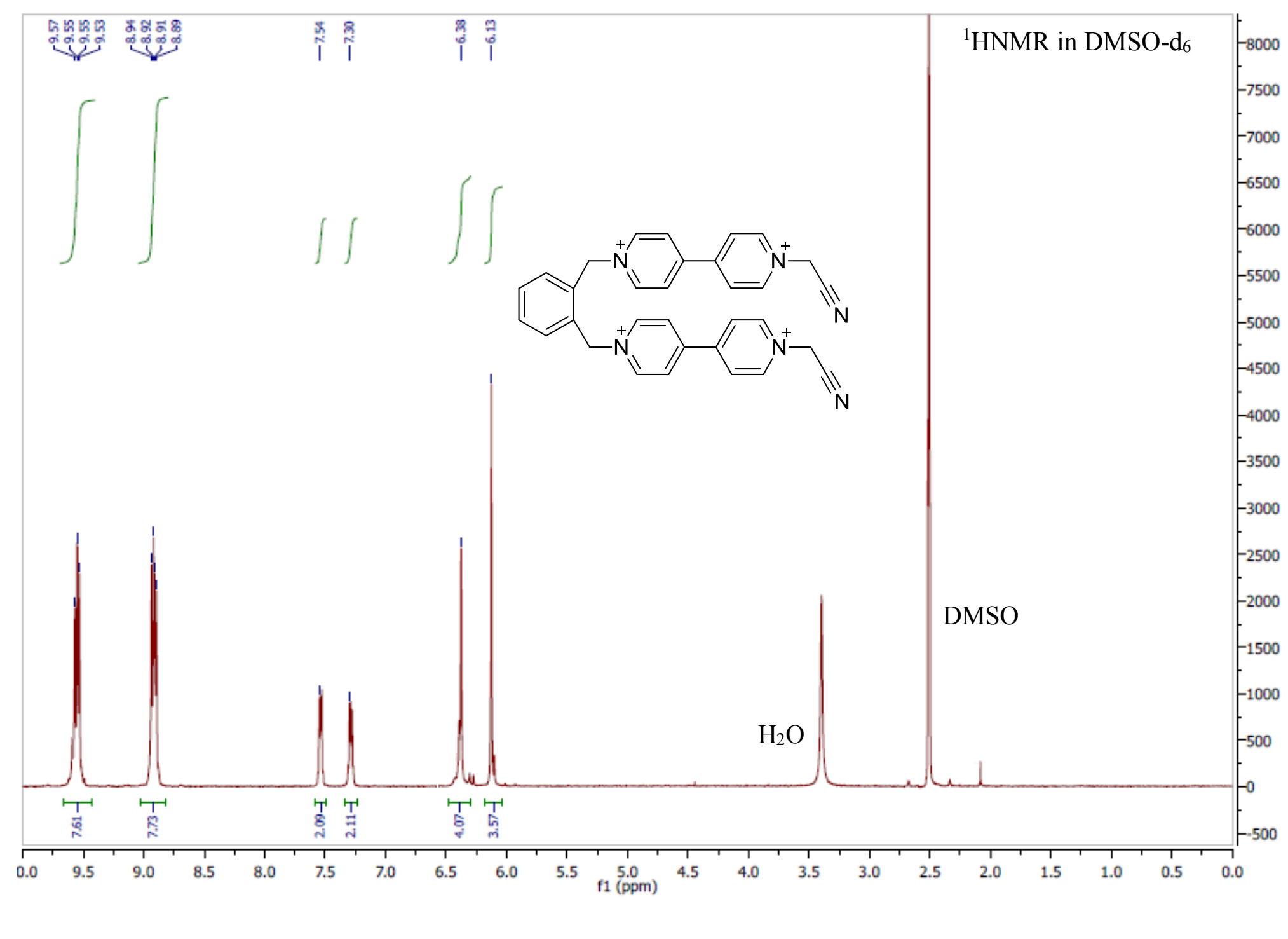




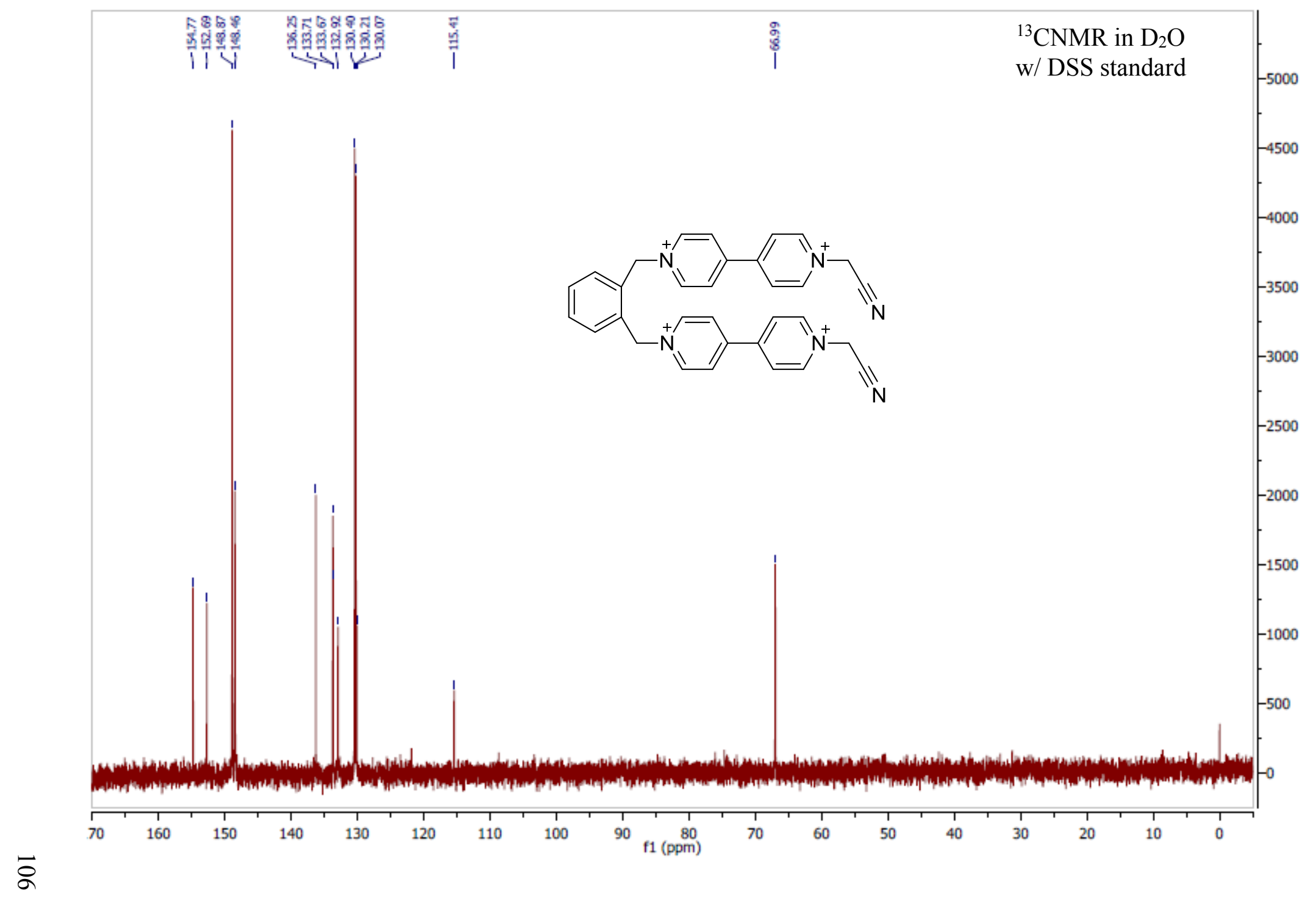




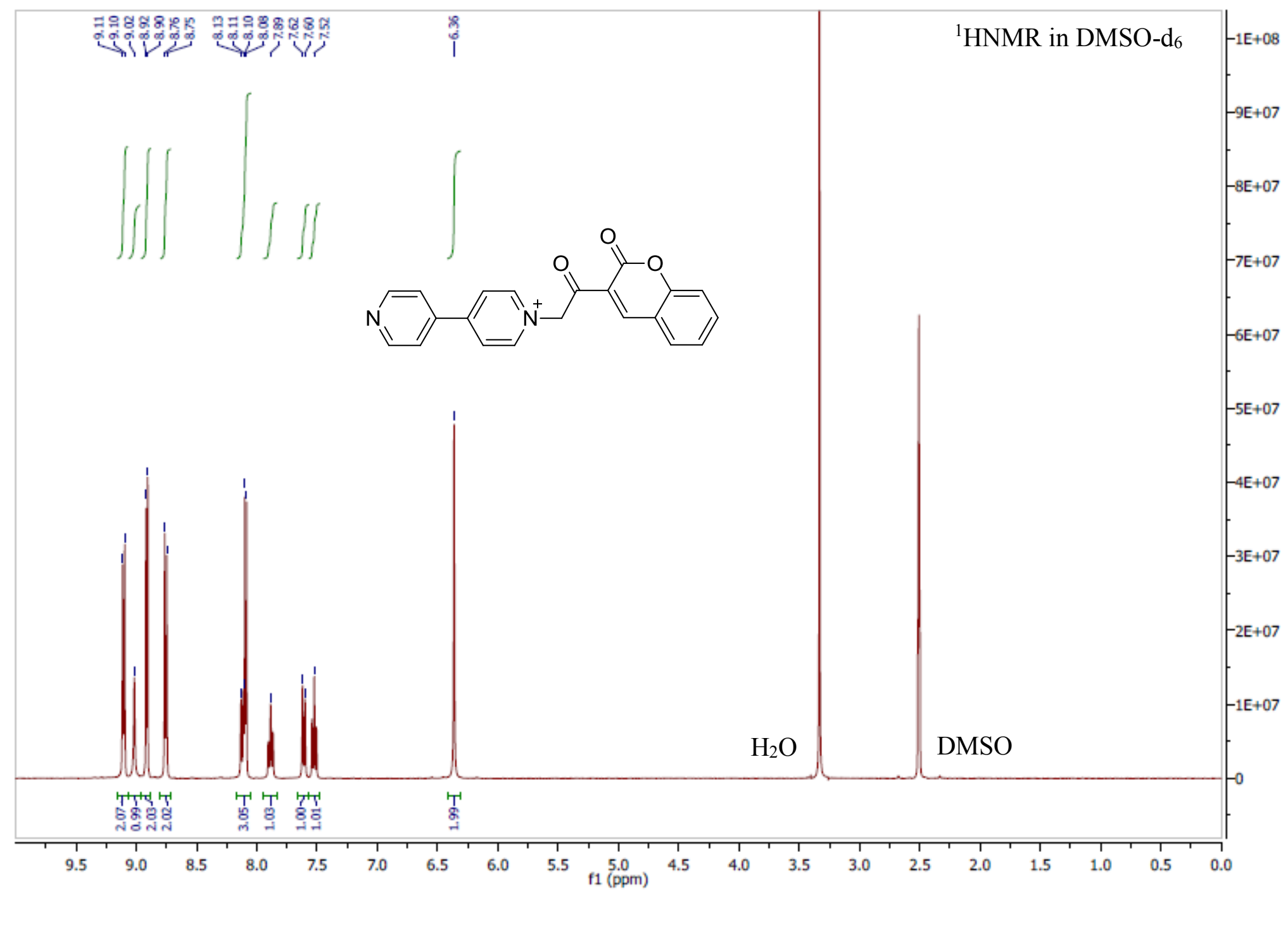

s 


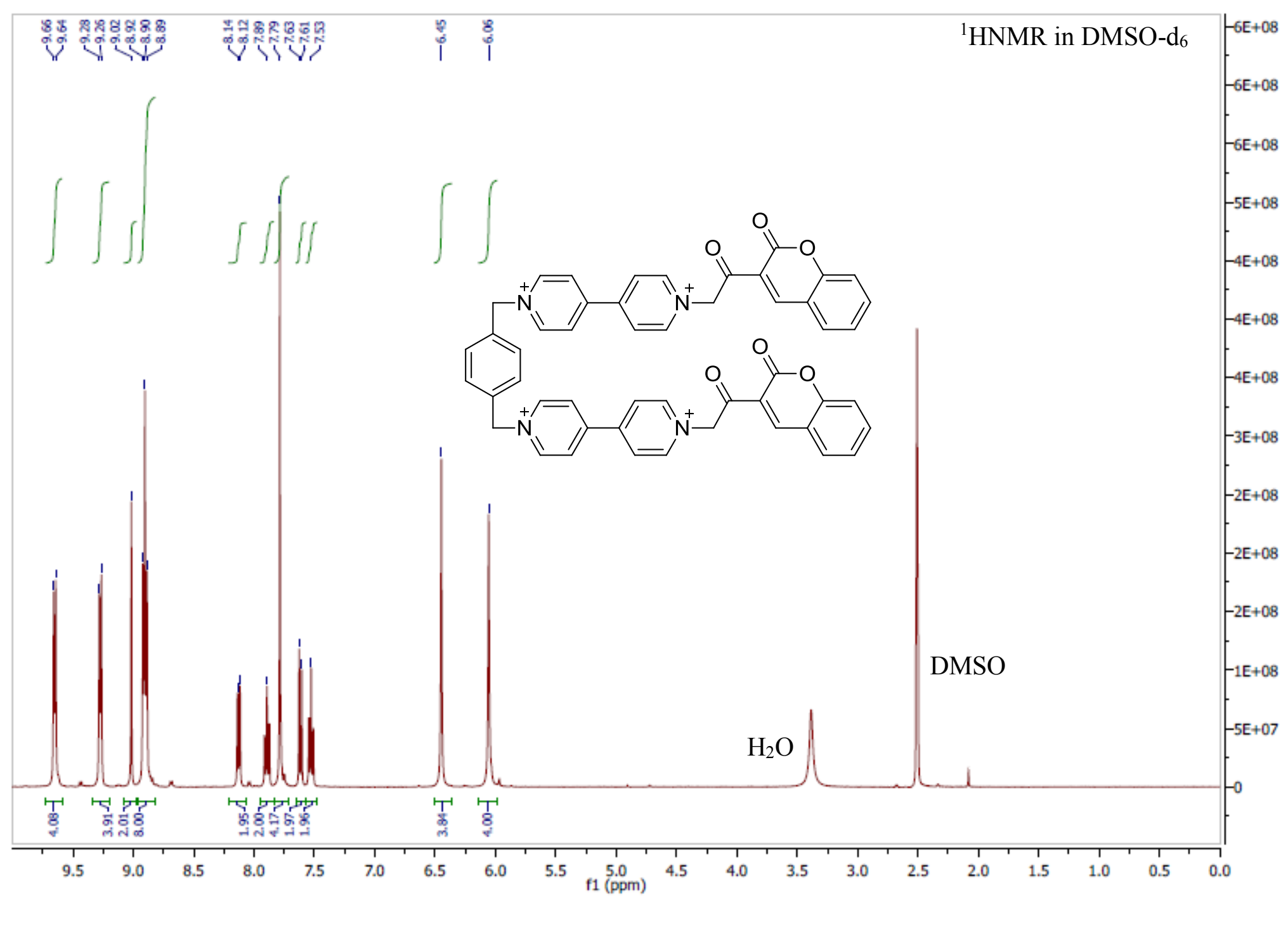




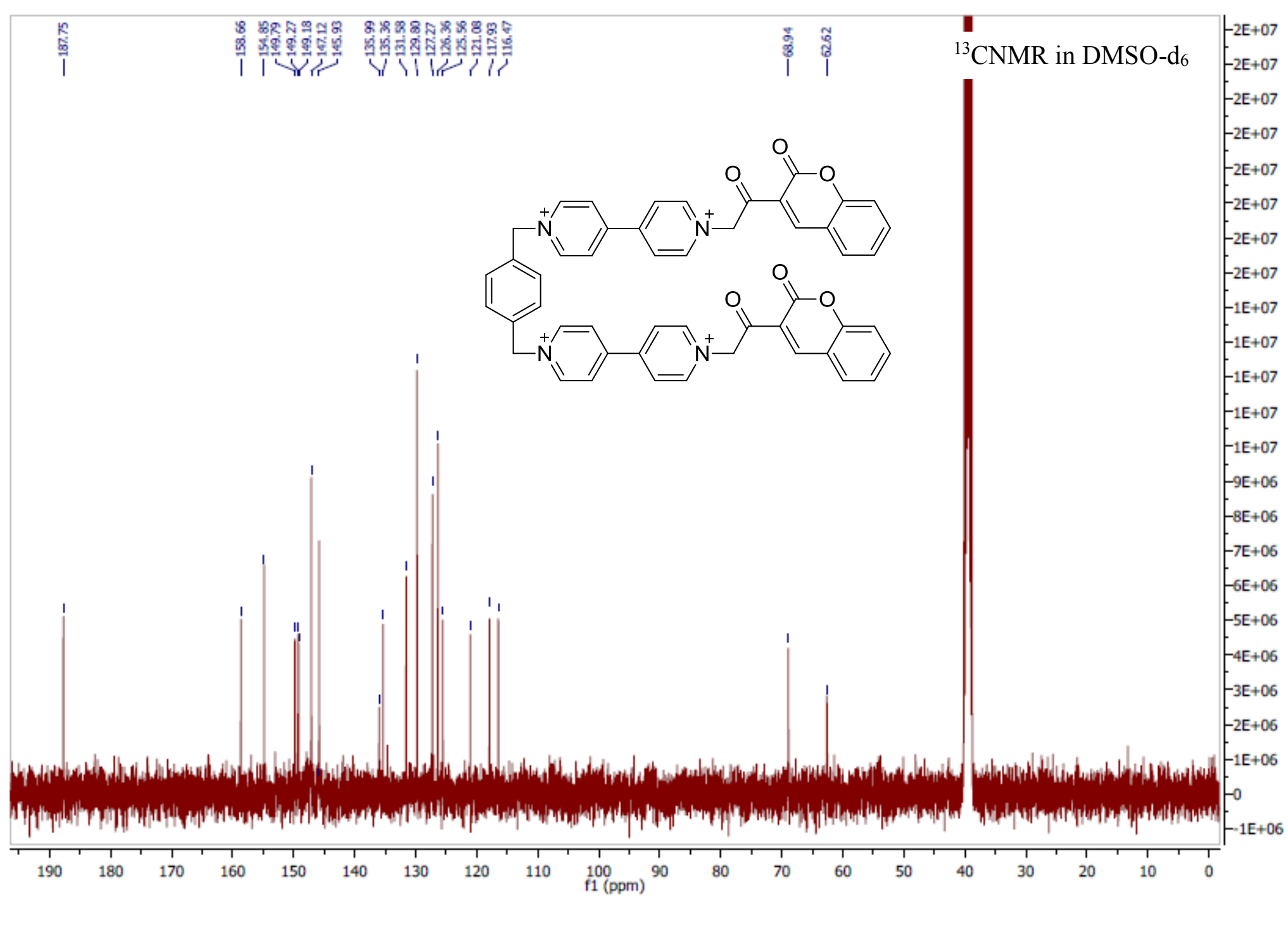




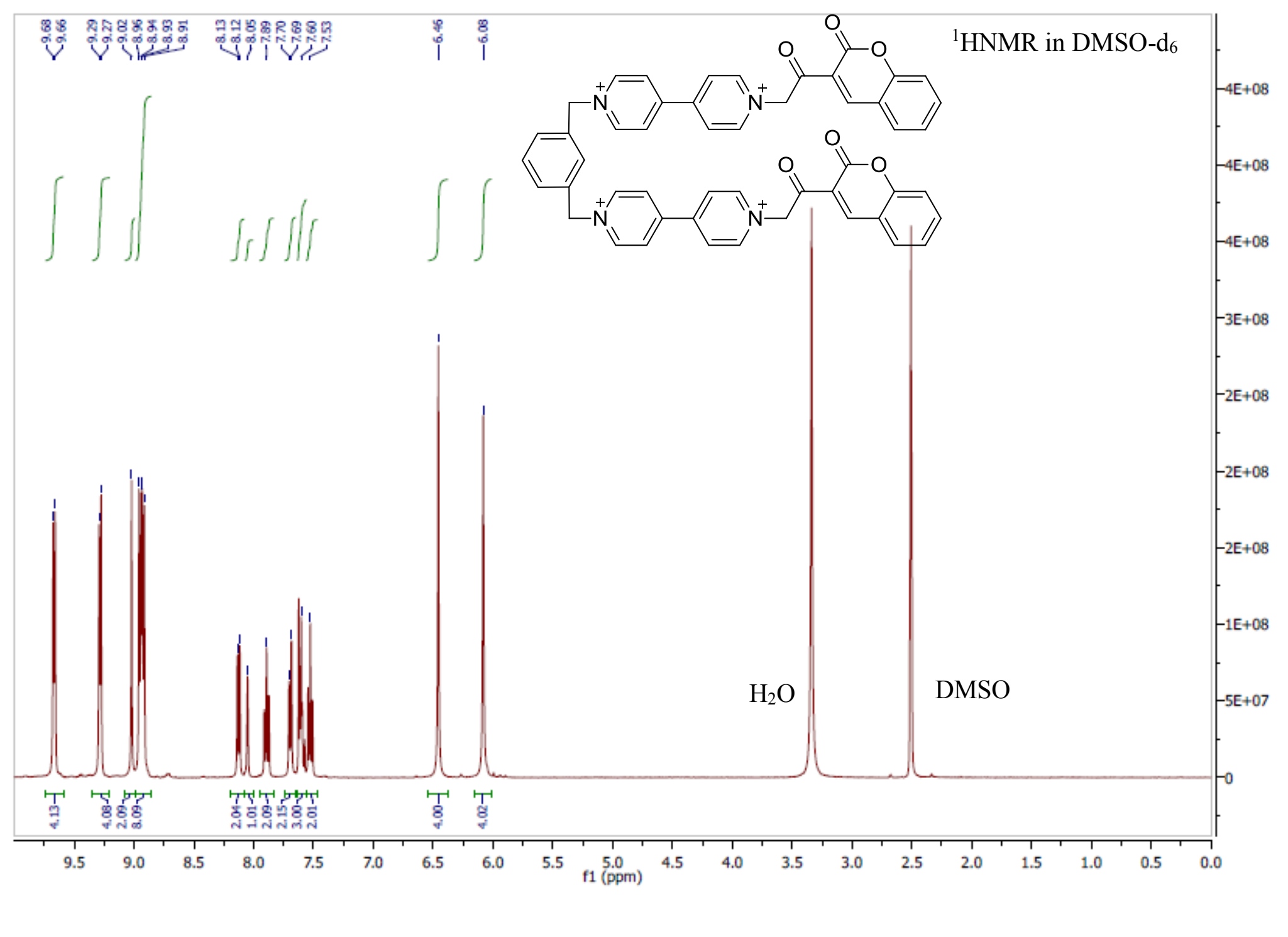




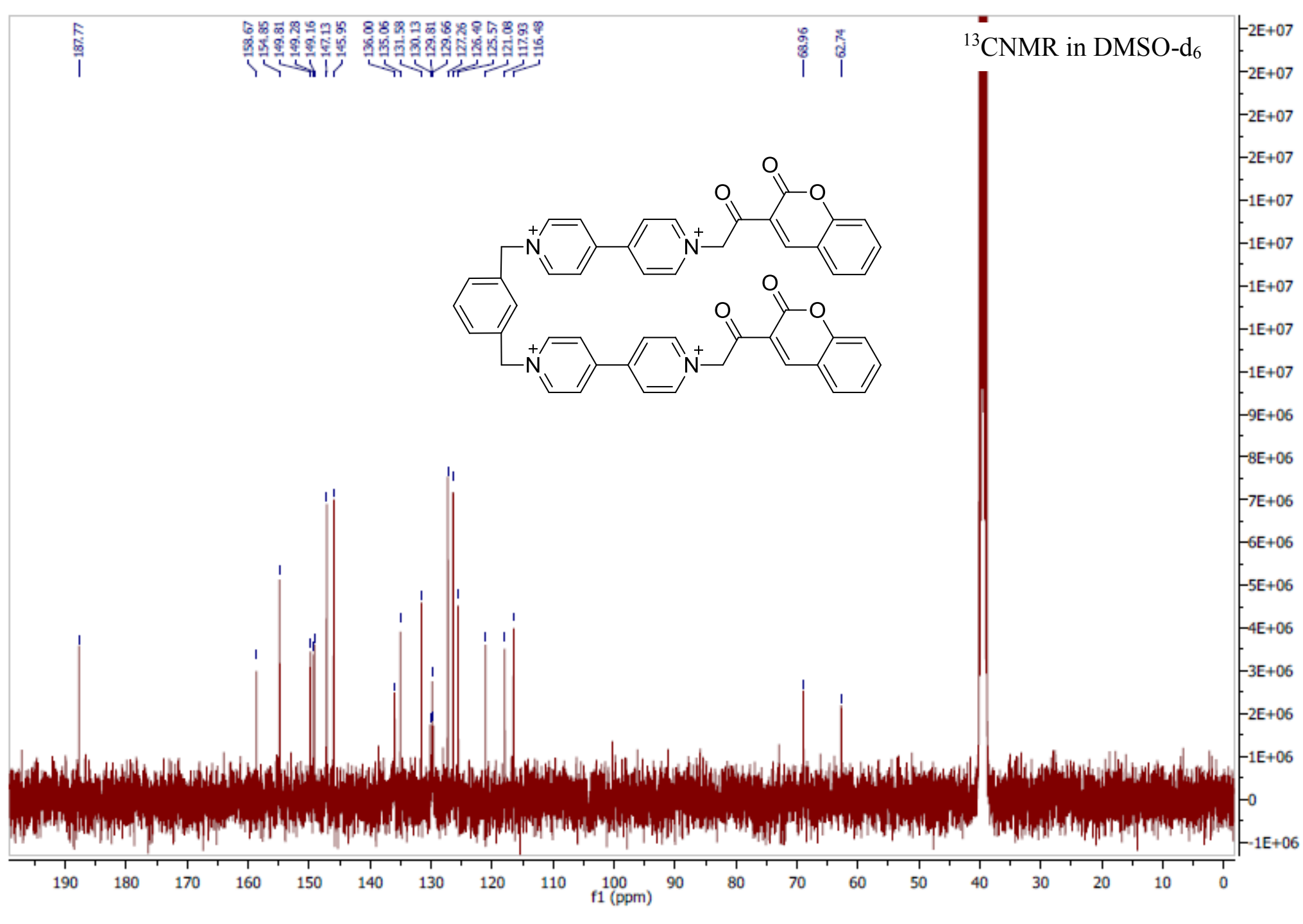




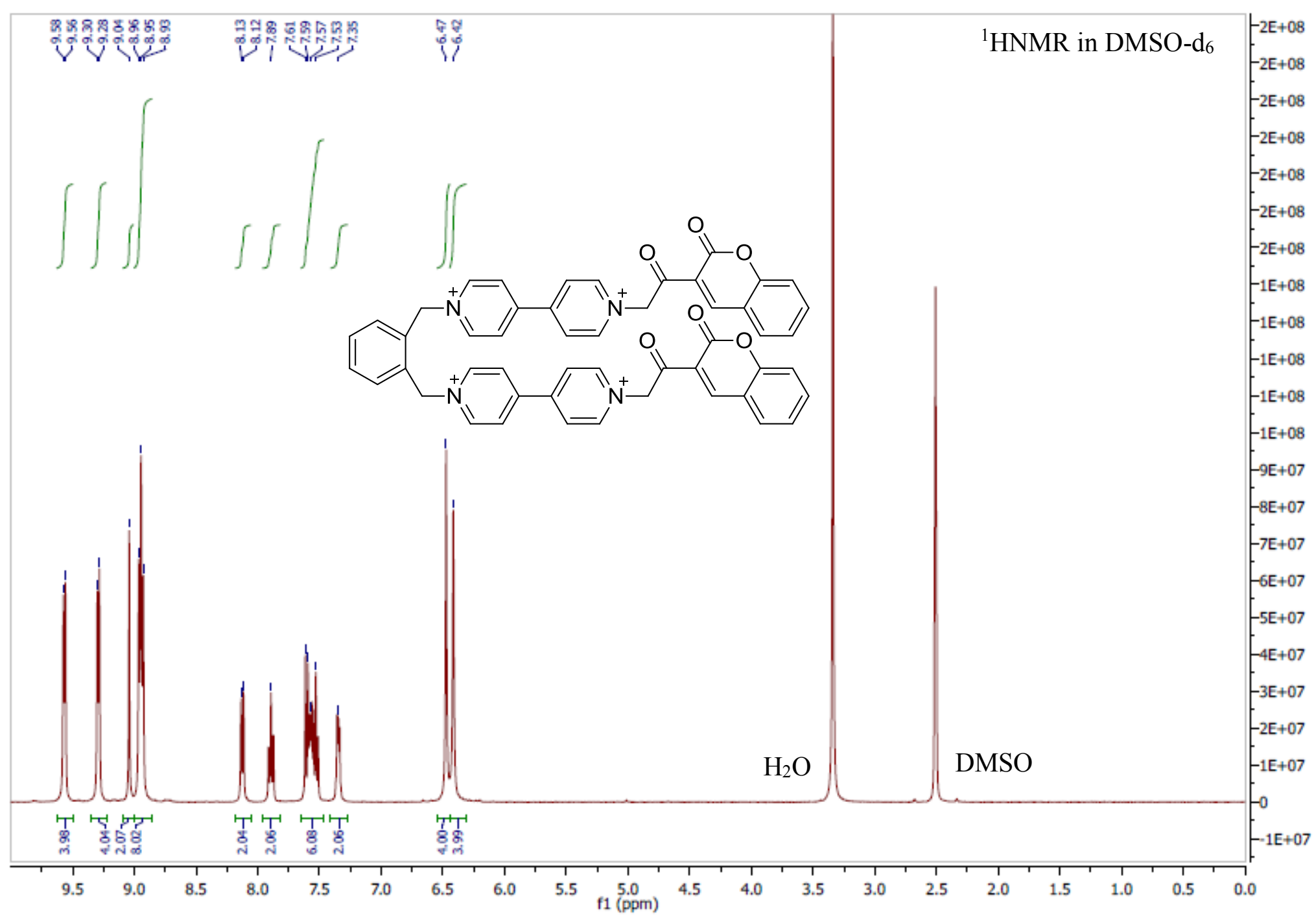




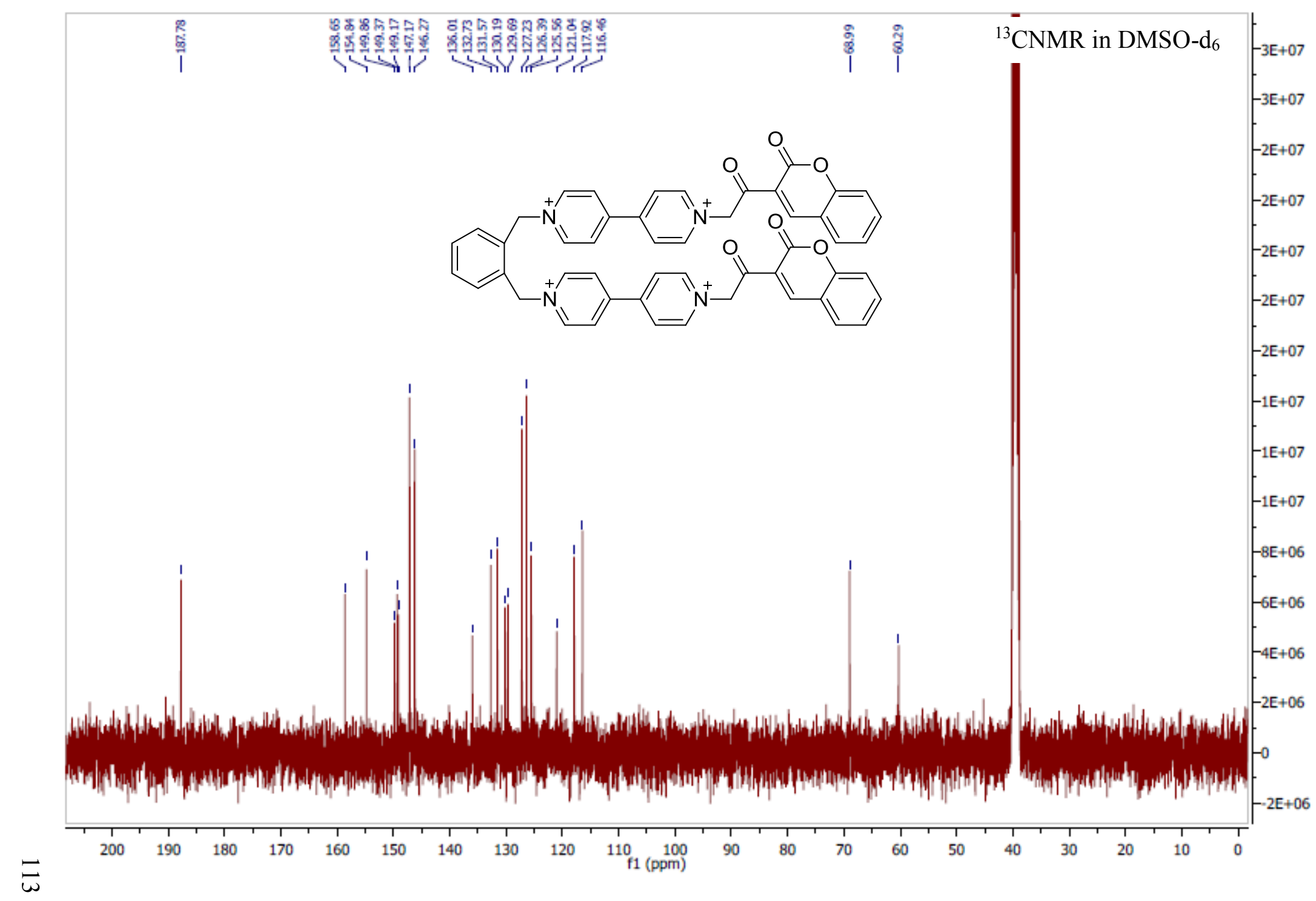


Appendix C: Mass Spectra

oBN \#6-17 RT: 0.12-0.24 AV: 12 NL: 1.49E5

oBN \#6-17 RT: $0.12-0.24$ AV: 12 NL:
T: FTMS + p ESI Full ms [50.00-1005.98]

$105 \exists$

100

95

90

85

80

75

$\bar{\nabla}$

oCN $10[\mathrm{M}-2 \mathrm{H}+\mathrm{MeO}]^{2+}$

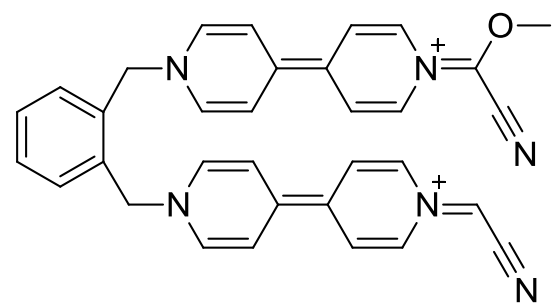

Chemical Formula: $\mathrm{C}_{33} \mathrm{H}_{28} \mathrm{~N}_{6} \mathrm{O}^{2+}$

m/z: 262.1157 (100.0\%), 262.6174 (35.7\%),

263.1191 (6.2\%), $262.6142(2.2 \%)$

P
0
0
0
0
0
$\Omega$
3
3
0
0
0
0
0
0
0
0
0

263.6070

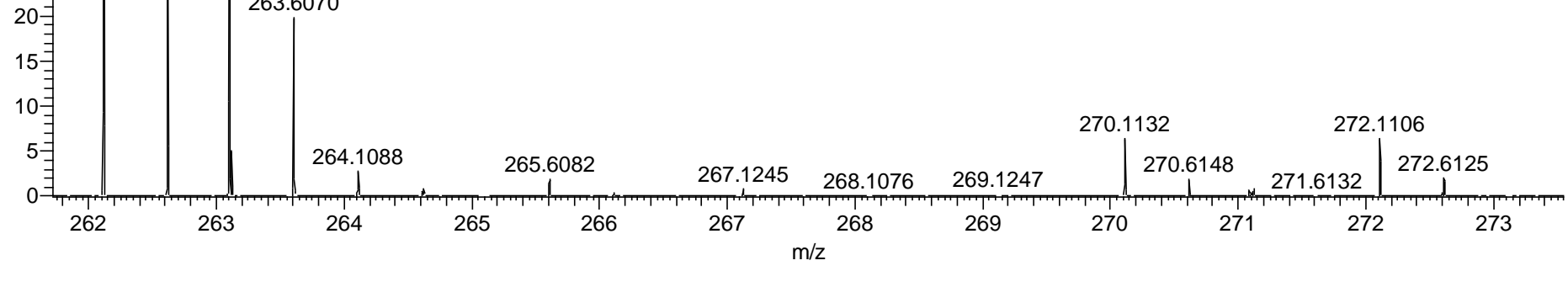


mBN\#15-17 RT: 0.21-0.24 AV: 3 NL: 2.44E5

T: FTMS + p ESI Full ms [50.00-1005.98]

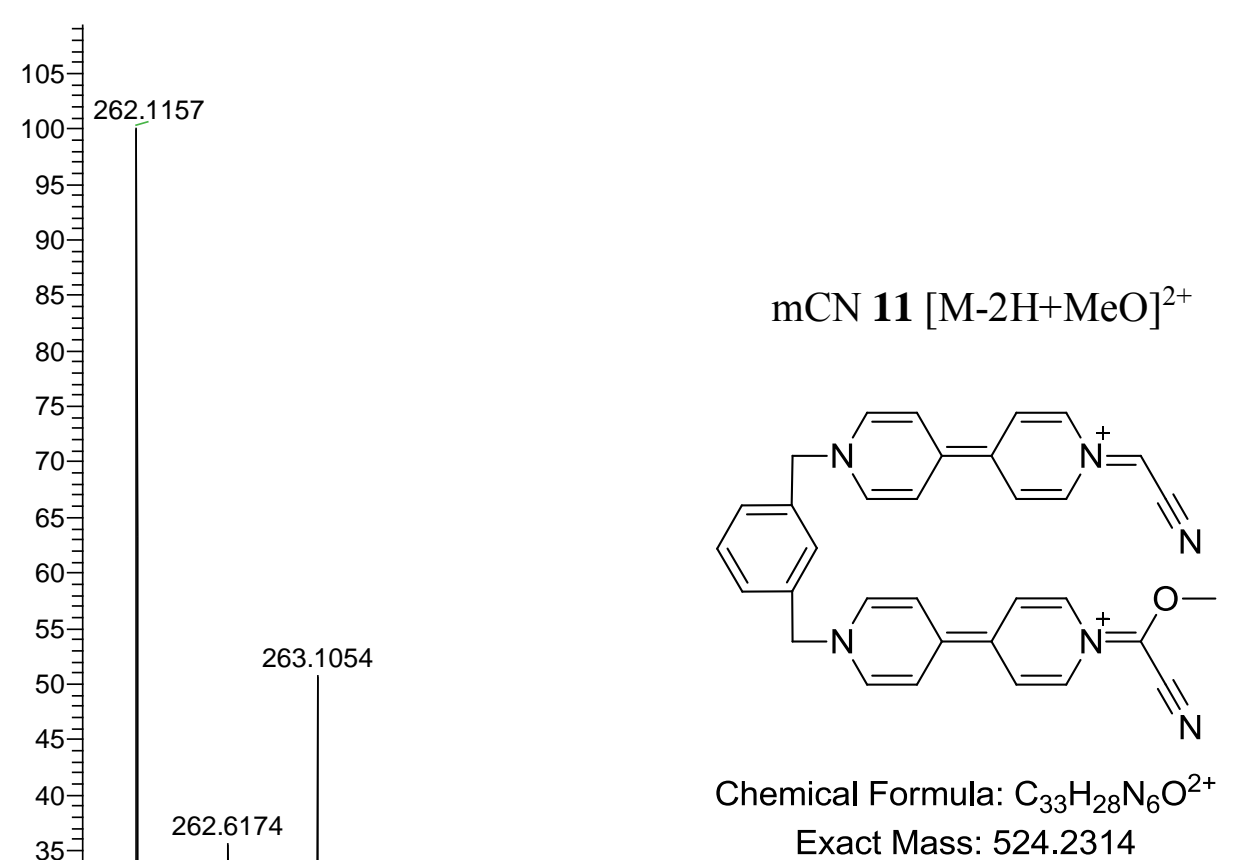

m/z: 262.1157 (100.0\%), 262.6174 (35.7\%), $263.1191(6.2 \%), 262.6142(2.2 \%)$ 
pBN\#6 RT: $0.12 \quad$ AV: 1 NL: $1.57 E 4$

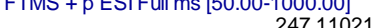

100

95

$90=$

85

80

75

(1)

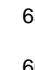

55

50

s.t.

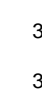

s.

20-

$$
\text { I }
$$

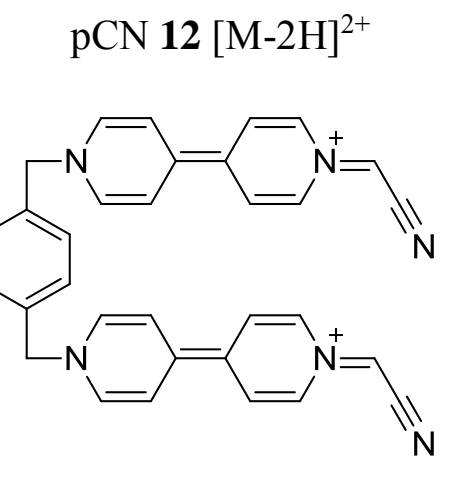

Chemical Formula: $\mathrm{C}_{32} \mathrm{H}_{26} \mathrm{~N}_{6}{ }^{2+}$ m/z: 247.11040 (100.0\%), 247.61208 (34.6\%), 248.11375 (5.8\%), $247.60892(2.2 \%)$

248.96506

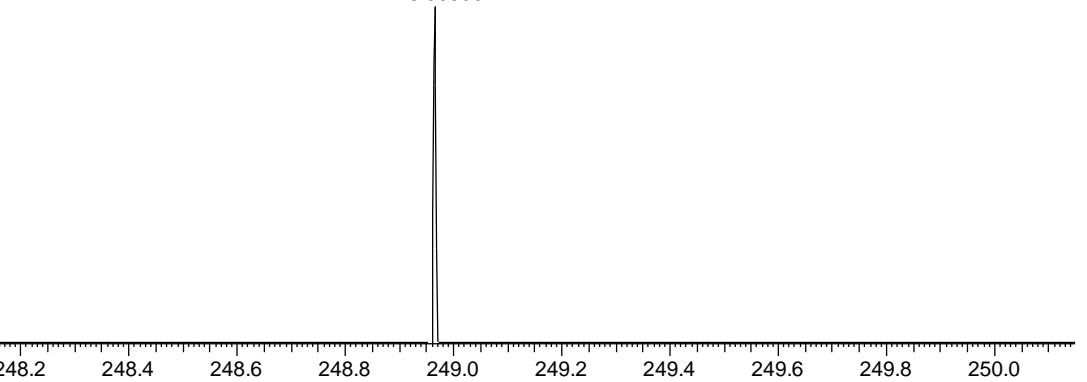




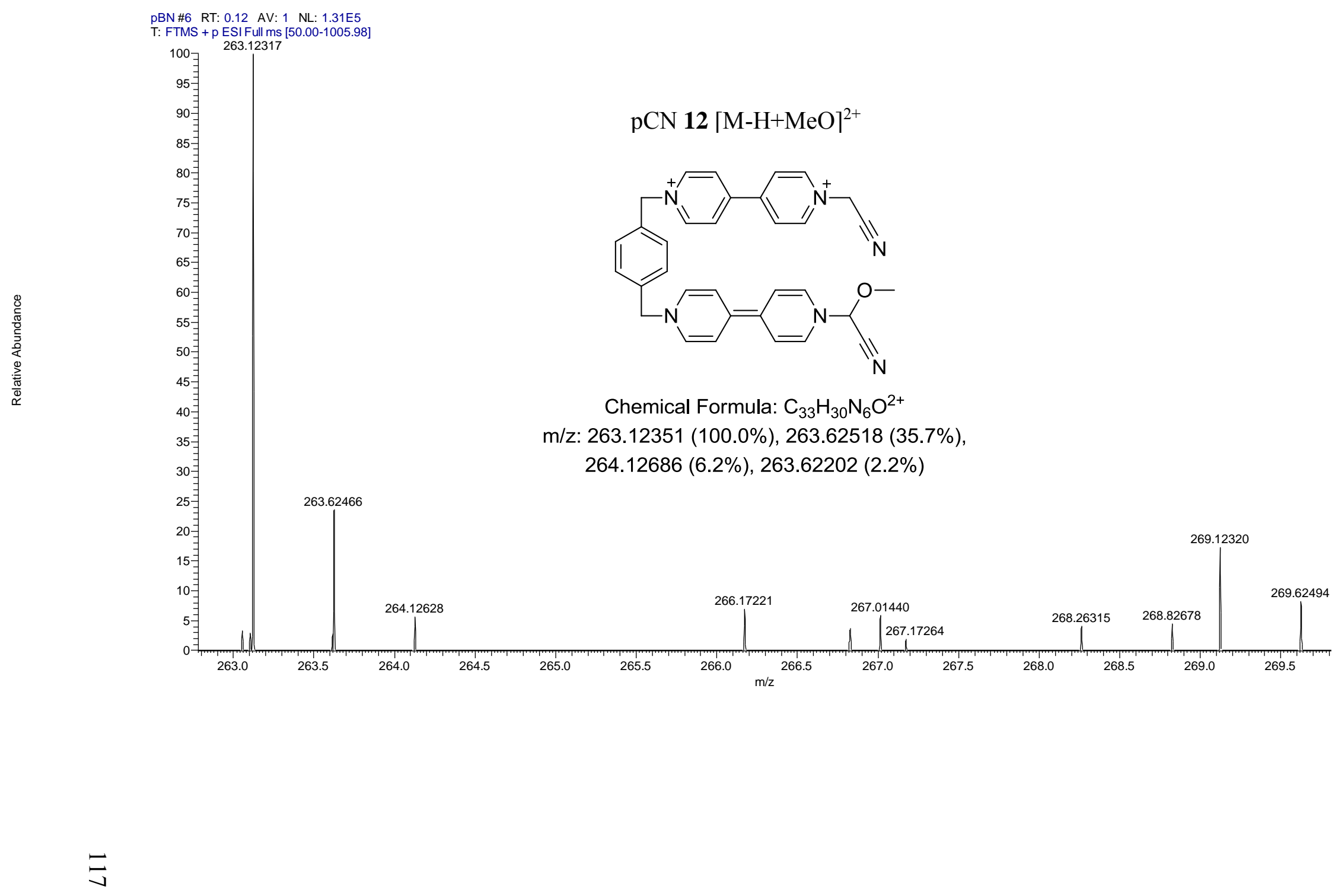




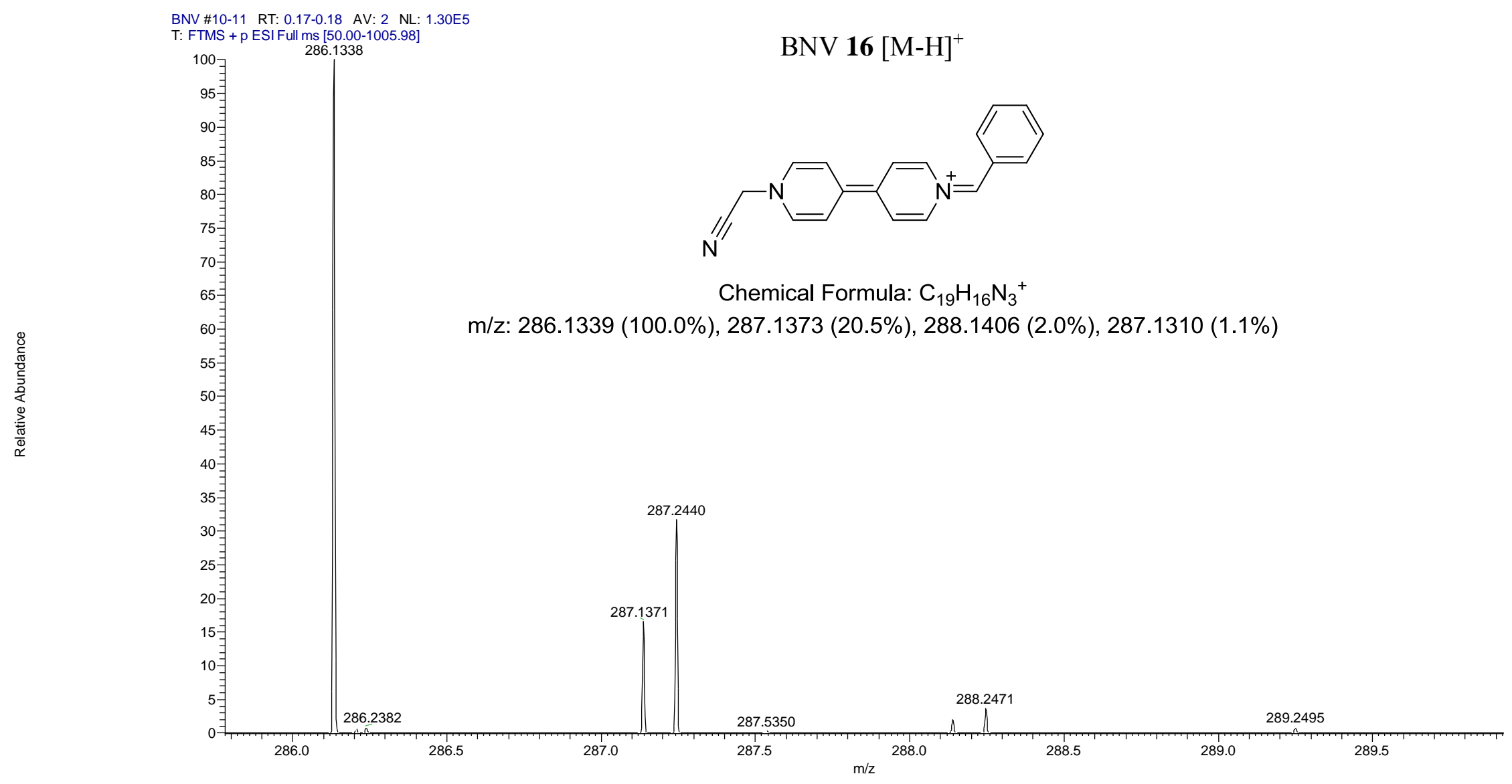

$\vec{\infty}$ 


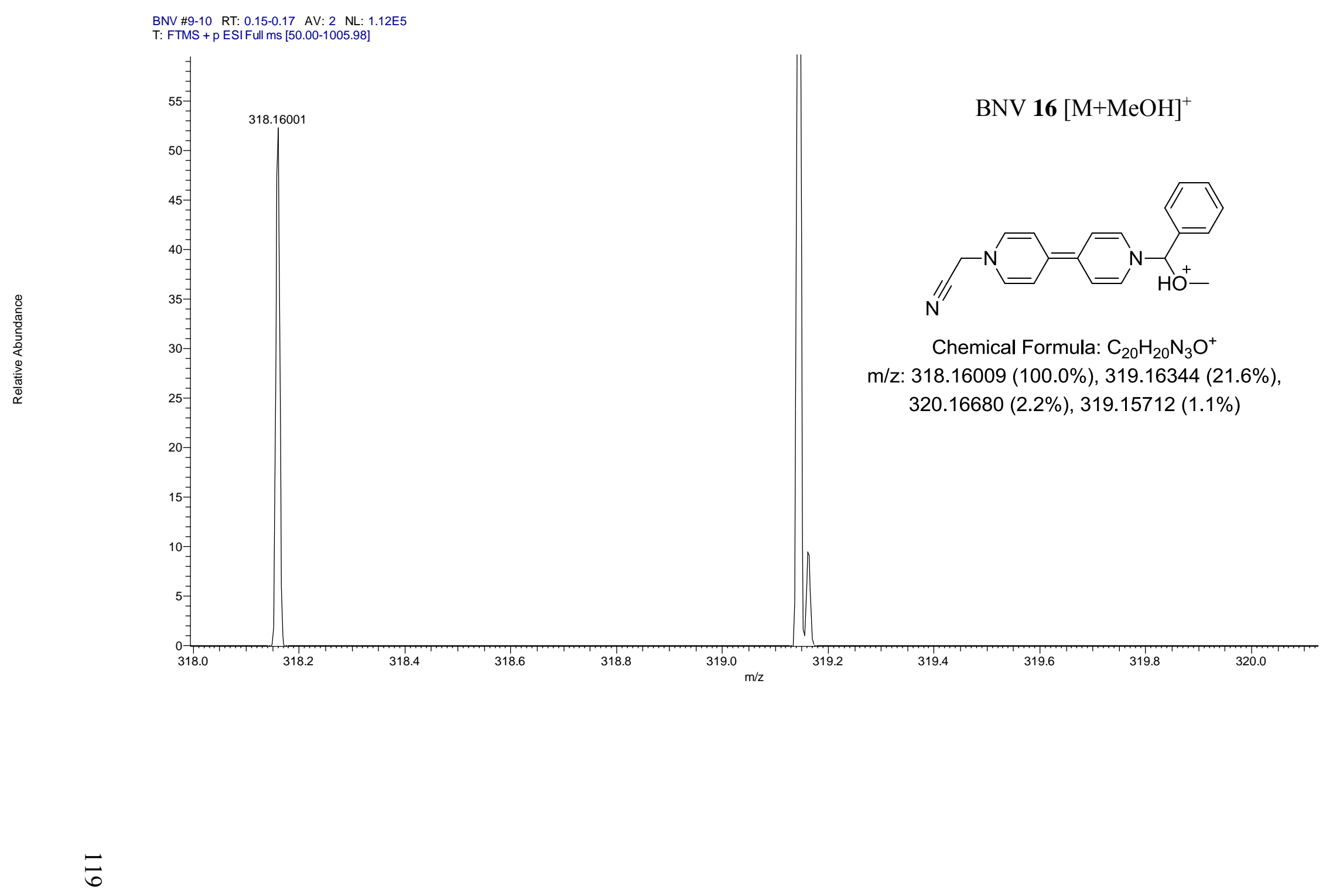




\section{diluted $1000 \mathrm{x}$ in $\mathrm{MeOH}+\mathbf{0 . 1} \% \mathrm{HCOOH}$}

DAVIN_RMS020613DR_STRONGIN_02-13-2013_ESI-POS01 87 (1.736) Cm (81:108)

$100 \quad 314 . \overline{09}$

9.12

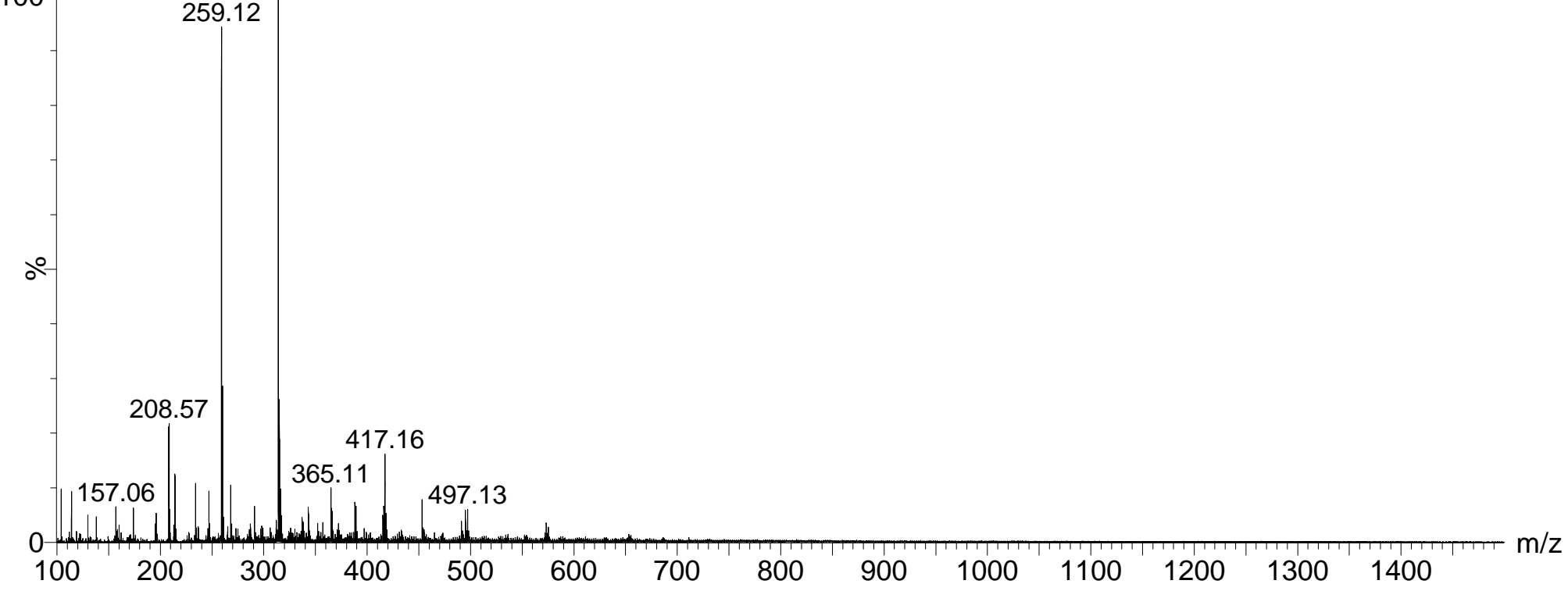

Full mass spectrum

Reaction between $20.0 \mathrm{mM} \mathrm{pCN}$ and $20.0 \mathrm{mM}$ Hcy in $100 \mathrm{mM}$ phosphate buffer $\mathrm{pH} 8.0$ collected by positive mode ESI-TOF-MS in $\mathrm{MeOH}$ with $0.1 \%$ formic acid.
15:01:07 13-Feb-2013

TOF MS ES+

$1.33 \mathrm{e} 4$

్ㅗ 


\section{diluted $1000 \mathrm{x}$ in $\mathrm{MeOH}+\mathbf{0 . 1} \% \mathrm{HCOOH}$}

DAVIN_RMS020613DR_STRONGIN_02-13-2013_ESI-POS01 87 (1.736) Cm (81:108)

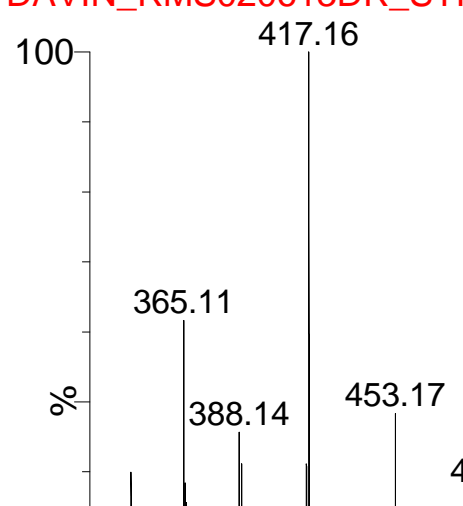

100

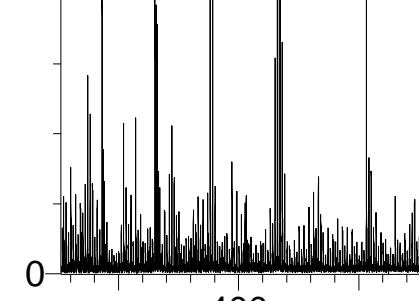

400

500

497.13

573.16

$536.10 \quad 653.16$

$711.26 \quad 777.38$

$600 \quad 700$

800

900

1000

300-1000 Da range mass spectrum

Reaction between $20.0 \mathrm{mM}$ pCN and $20.0 \mathrm{mM}$ Hcy in $100 \mathrm{mM}$ phosphate buffer $\mathrm{pH} 8.0$ collected by positive mode ESI-TOF-MS in $\mathrm{MeOH}$ with $0.1 \%$ formic acid. 


\section{diluted $1000 \mathrm{x}$ in $\mathrm{MeOH}+\mathbf{0 . 1} \% \mathrm{HCOOH}$}

DAVIN_RMS020613DR_STRONGIN_02-13-2013_ESI-POS01 87 (1.736) Cm (81:108)

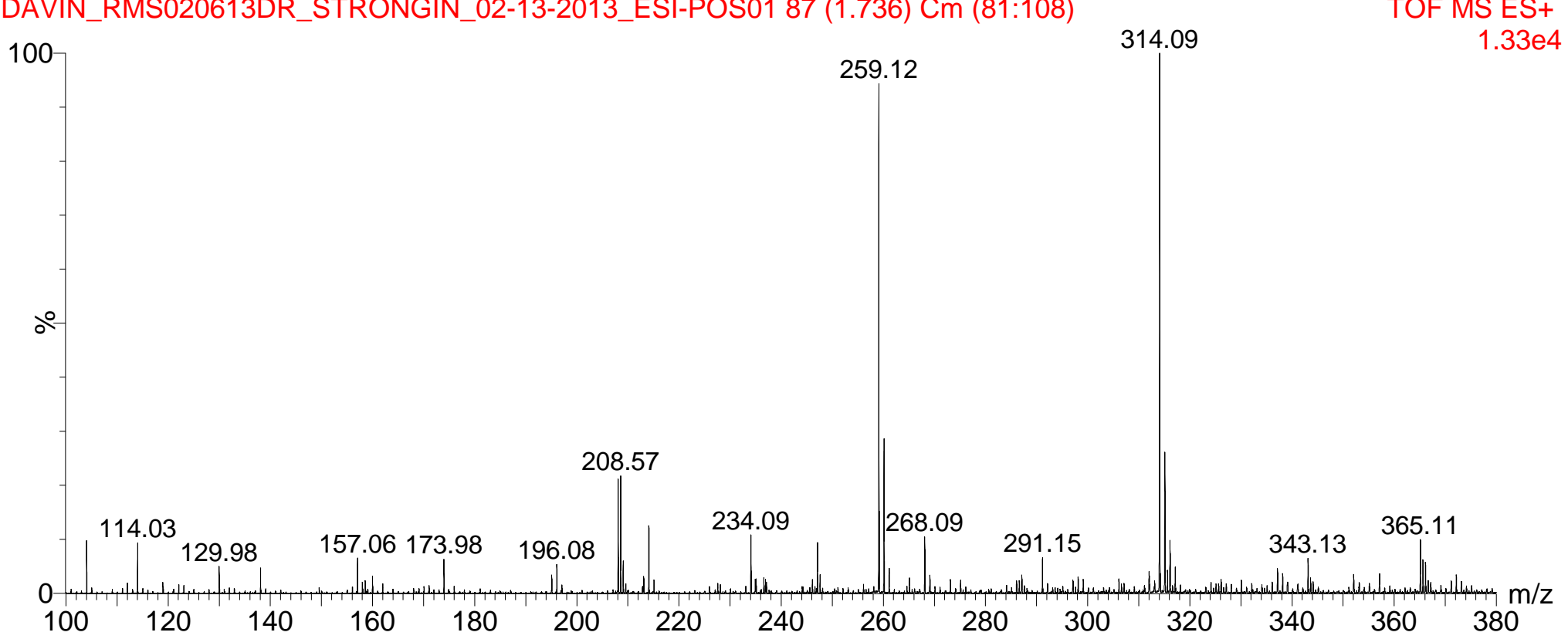

100-400 Da range mass spectrum

Reaction between $20.0 \mathrm{mM} \mathrm{pCN}$ and $20.0 \mathrm{mM}$ Hcy in $100 \mathrm{mM}$ phosphate buffer $\mathrm{pH} 8.0$ collected by positive mode ESI-TOF-MS in $\mathrm{MeOH}$ with $0.1 \%$ formic acid. 


\section{diluted $1000 \mathrm{x}$ in $\mathrm{MeOH}+\mathbf{0 . 1} \% \mathrm{HCOOH}$}

DAVIN_RMS020613DR_STRONGIN_02-13-2013_ESI-POS01 87 (1.736) Cm (81:108)

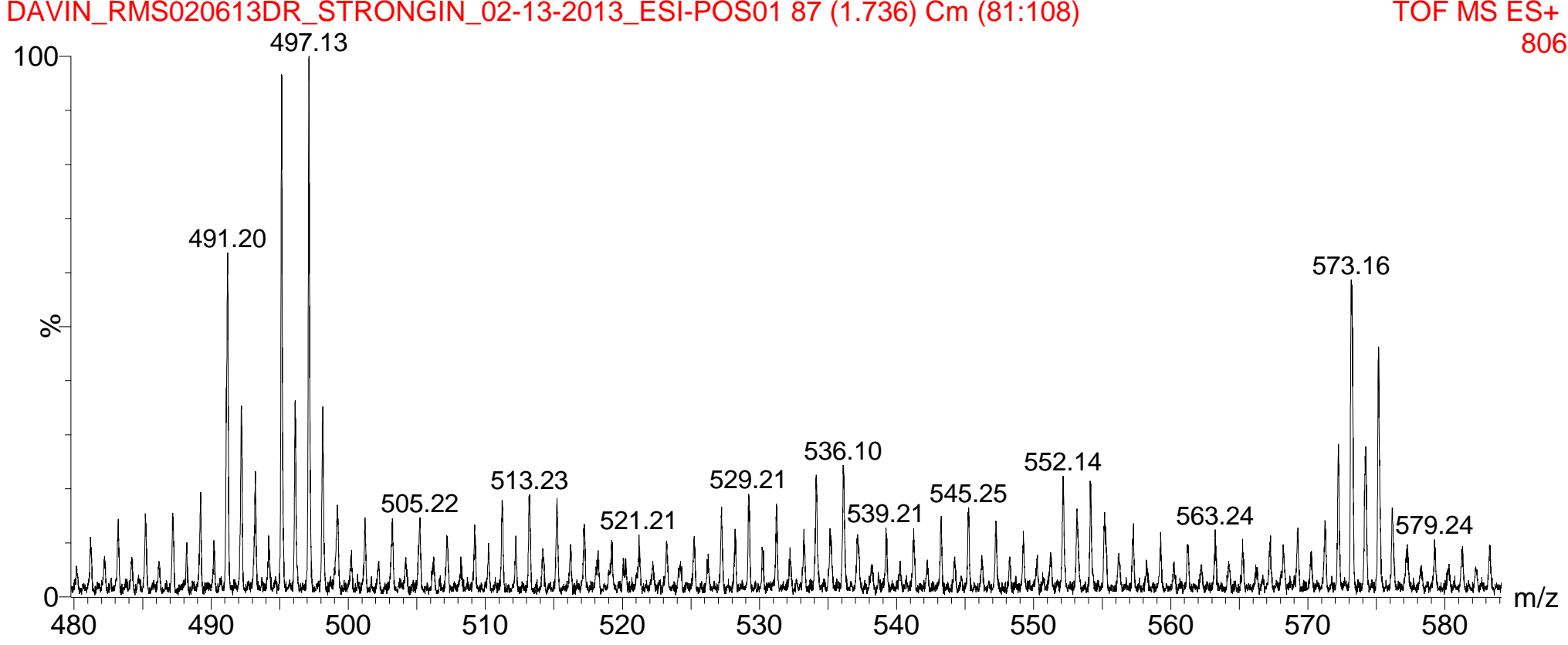

15:01:07 13-Feb-2013

TOF MS ES+

806

480-580 Da range mass spectrum

Reaction between $20.0 \mathrm{mM} \mathrm{pCN}$ and $20.0 \mathrm{mM}$ Hcy in $100 \mathrm{mM}$ phosphate buffer $\mathrm{pH} 8.0$ collected by positive mode ESI-TOF-MS in $\mathrm{MeOH}$ with $0.1 \%$ formic acid. 


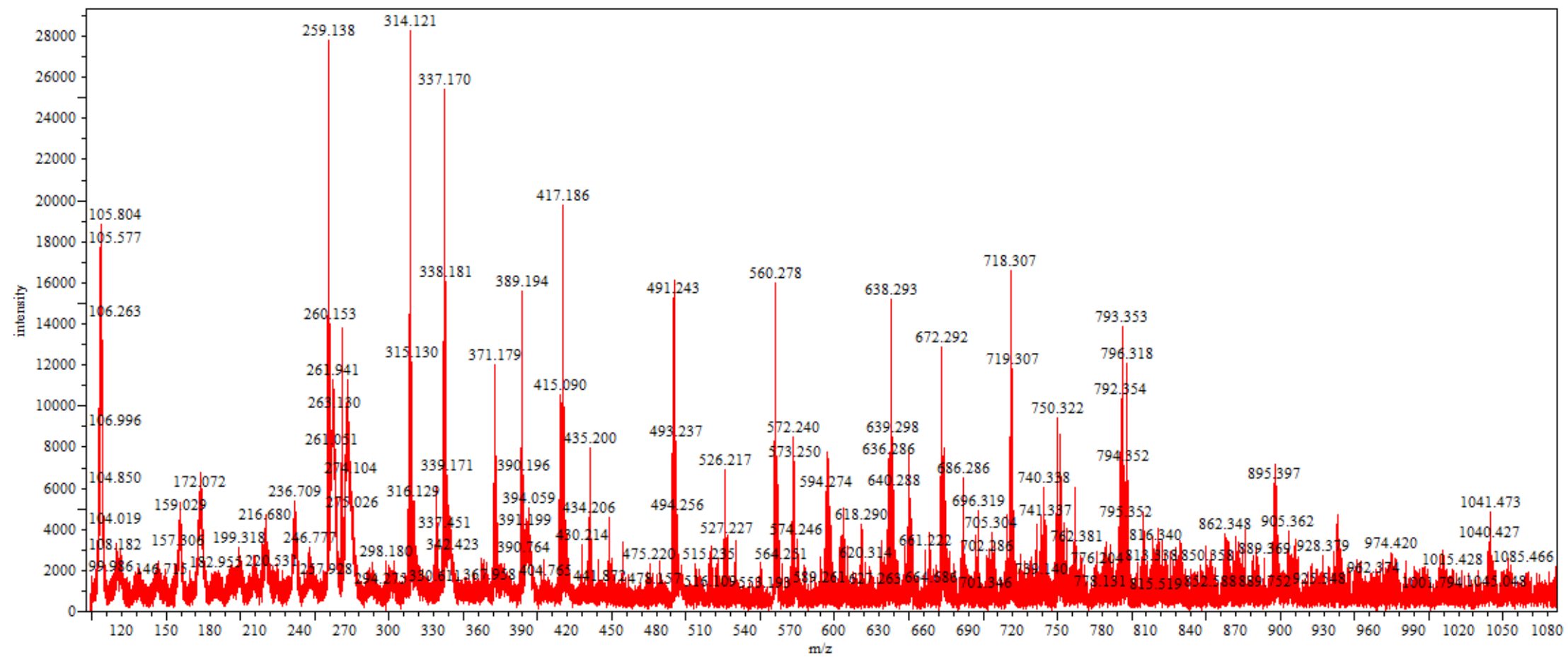

Full mass spectrum

Reaction between $20.0 \mathrm{mM} \mathrm{pCN}$ and $20.0 \mathrm{mM}$ Hcy in $100 \mathrm{mM}$ phosphate buffer $\mathrm{pH} 8.0$ collected by MALDITOF-MS in positive ion mode with $\alpha$-Cyano-4-hydroxycinnamic acid as the matrix. 


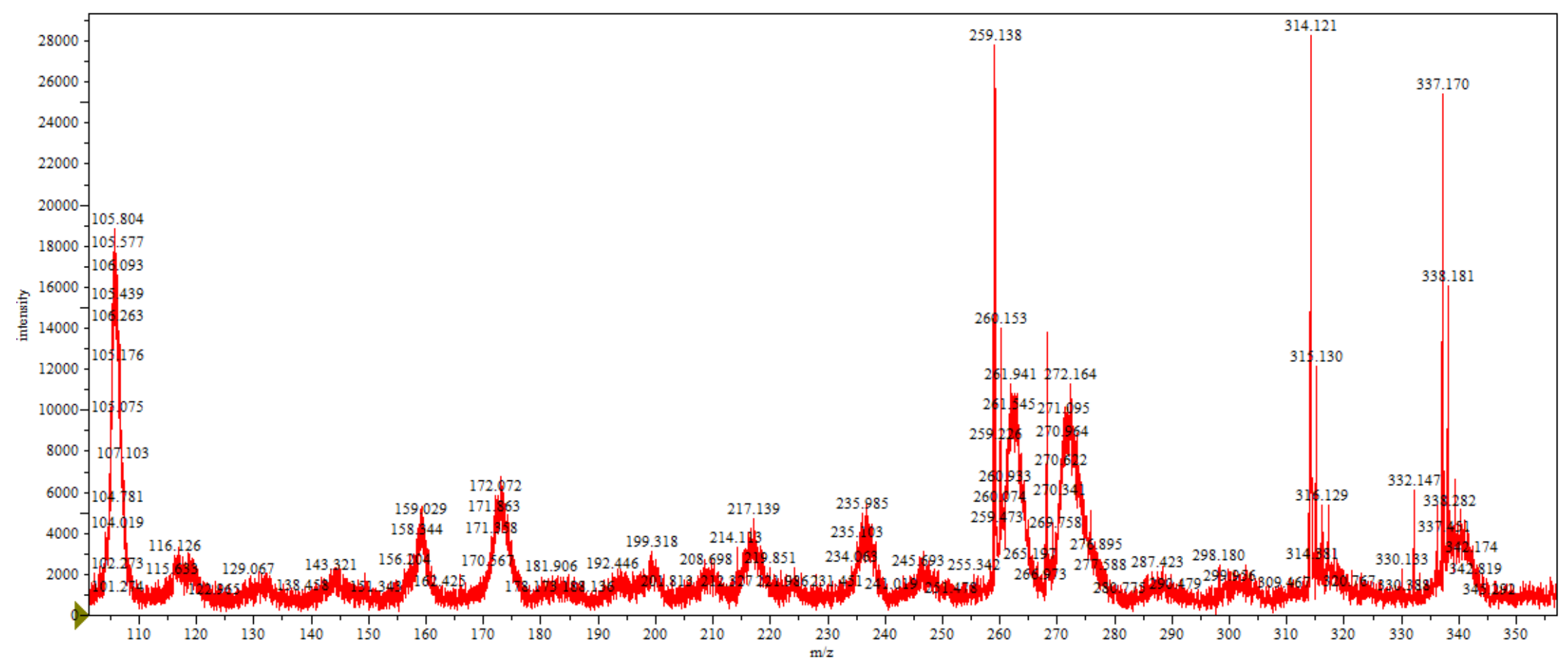

100-350 Da mass spectrum

Reaction between $20.0 \mathrm{mM}$ pCN and $20.0 \mathrm{mM}$ Hcy in $100 \mathrm{mM}$ phosphate buffer $\mathrm{pH} 8.0$ collected by MALDITOF-MS in positive ion mode with $\alpha$-Cyano-4-hydroxycinnamic acid as the matrix. 


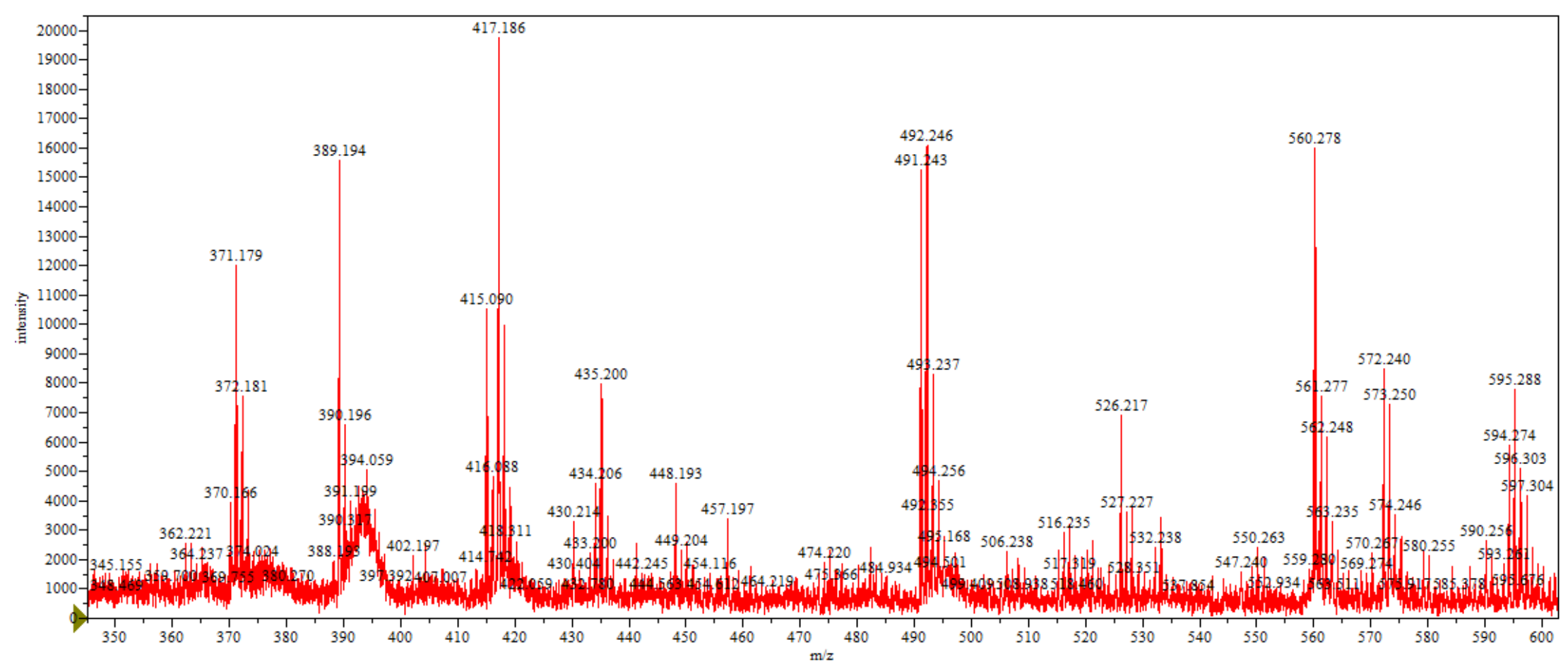

\section{0-600 Da mass spectrum}

Reaction between $20.0 \mathrm{mM} \mathrm{pCN}$ and $20.0 \mathrm{mM}$ Hcy in $100 \mathrm{mM}$ phosphate buffer $\mathrm{pH} 8.0$ collected by MALDITOF-MS in positive ion mode with $\alpha$-Cyano-4-hydroxycinnamic acid as the matrix. 


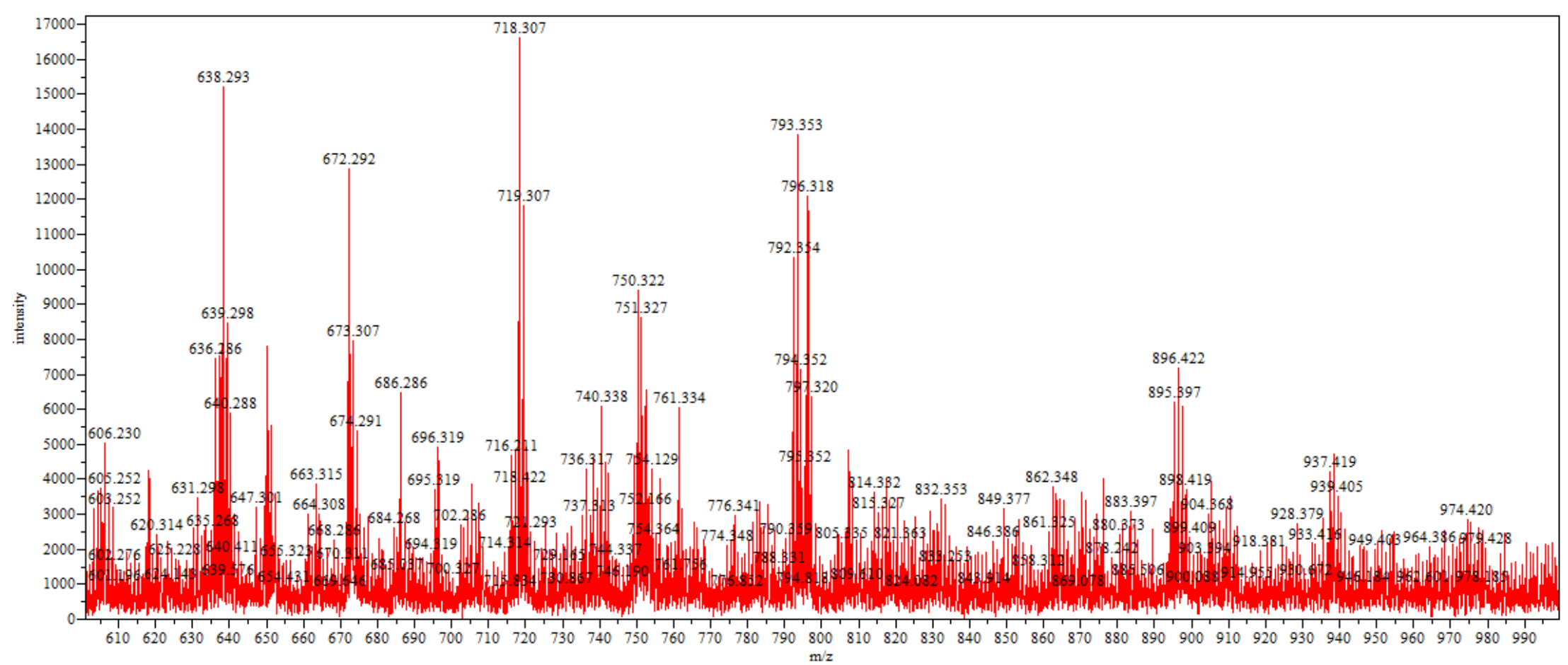

600-1000 Da mass spectrum

Reaction between $20.0 \mathrm{mM}$ pCN and $20.0 \mathrm{mM}$ Hcy in $100 \mathrm{mM}$ phosphate buffer pH 8.0 collected by MALDITOF-MS in positive ion mode with $\alpha$-Cyano-4-hydroxycinnamic acid as the matrix. 